\title{
POLYCARBOXYLIC ACIDS VIA CATALYTIC HYDROCARBOXYLATION OF POLYBUTADIENES
}

Narayanan Pondicherry

A Thesis Submitted for the Degree of PhD

at the

University of St Andrews

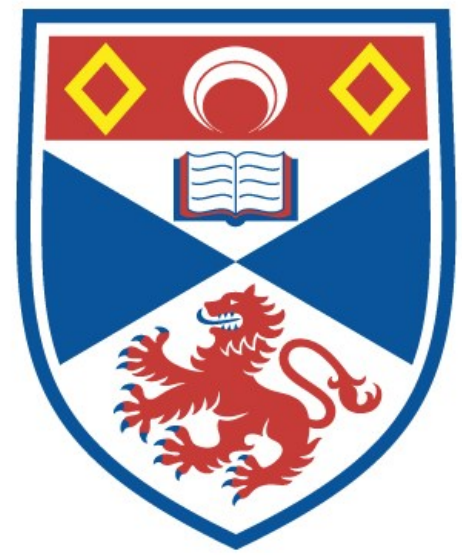

1992

Full metadata for this item is available in

St Andrews Research Repository

at:

http://research-repository.st-andrews.ac.uk/

Please use this identifier to cite or link to this item:

http://hdl.handle.net/10023/15259

This item is protected by original copyright 


\title{
POLYCARBOXYLIC ACIDS
}

$$
\text { via }
$$

\section{CATALYTIC HYDROCARBOXYLATION OF POLYBUTADIENES}

\author{
a thesis presented by
}

\section{NARAYANAN PONDICHERRY}

to the

\section{UNIVERSITY OF ST. ANDREWS}

\author{
in application for
}

\section{THE DEGREE OF DOCTOR OF PHILOSOPHY}

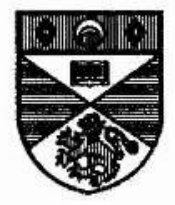

St. Andrews

September 1991

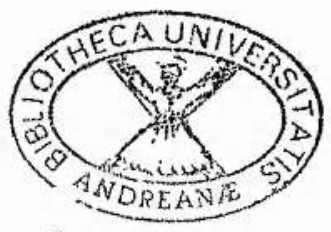


ProQuest Number: 10170828

All rights reserved

INFORMATION TO ALL USERS

The quality of this reproduction is dependent upon the quality of the copy submitted.

In the unlikely event that the author did not send a complete manuscript and there are missing pages, these will be noted. Also, if material had to be removed, a note will indicate the deletion.

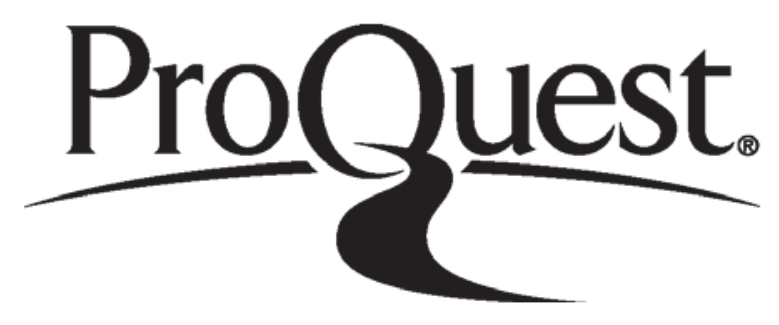

ProQuest 10170828

Published by ProQuest LLC (2017). Copyright of the Dissertation is held by the Author.

All rights reserved.

This work is protected against unauthorized copying under Title 17, United States Code Microform Edition (C) ProQuest LLC.

ProQuest LLC.

789 East Eisenhower Parkway

P.O. Box 1346

Ann Arbor, MI 48106 - 1346 
Th B B 


\section{DECLARATION}

I, Narayanan Pondicherry, hereby certify that this thesis has been composed by myself, that it is a record of my own work, and that it has not been accepted in partial or complete fulfilment of any other degree or professional qualification.

St. Andrews

Date 27.9 .1991

I was admitted to the Faculty of Science of the University of St.Andrews under Ordinance General No.12 on 1st October 1988 and as a candidate for the degree of Ph.D on 1st September 1989.

St. Andrews

Date 27.9 .1991

I hereby certify that the candidate has fulfilled the conditions of the Resolution and Regulations appropriate to the Degree of Ph.D.

Signature of Supervisor ${ }_{C}$

Date

$$
261 \text { tebtember (9)9) }
$$




\section{COPYRIGHT}

In submitting this thesis to the University of St.Andrews I understand that I am giving permission for it to be made available for use in accordance with the regulations of the University Library for the time being in force, subject to any copyright vested in the work not being affected thereby. I also understand that the tittle and abstract will be published, and that a copy of the work may be made and supplied to any bonafide library or research worker. 
Dedicated with gratitude to my grandparents, parents, sister and brother 


\section{ACKNOWLEDGEMENTS}

I would like to express my sincere thanks to Professor David Cole-Hamilton firstly for giving me an opportunity to do postgraduate research under his supervision and secondly for his endless patience, constant encouragement and guidance during the course of my postgraduate studies. I also wish to thank my industrial supervisors, Drs A.F.Gerrard, D.Randall and B.G.Clubley for their invaluable discussions and assistance.

Thanks also go to :

My coworkers Peter Pogorzelec, Douglas Foster, Ahmed Iraqi, Barry Kaye, Arumugam, Imelda Utuk, Jo MacDougall, Neil Fairfax, Russell Clarke, Ros Gash, Steve Lawson, John Stevenson and Simon Thompson.

The technical staff at St.Andrews for their help particularly, Jim Bews (computing), Jim Rennie, David Clarke, Bob Cathcart (workshop), Colin Smith (glass blower), John Smith (d.s.c.), Sylvia Smith (microanalysis), Marjory Parker (stores) and Melanja Smith (n.m.r.).

My special thanks to Miss Angela Teke for being a good friend of mine and also for her assistance in German translations.

To my friends and colleagues from St.Andrews University a hearty thanks for making the last three years so enjoyable and so memorable, particulary Joseph Rasquinha, Gopal S. Iyengar, Michael Page and Maggie Davies. 
Finally, I wish to thank my parents, sister and brother for their encouragement, help, love and untiring support right from the day I started my postgraduate research. I hope I have fulfilled their long cherished desires.

I am indebted to Ciba-Geigy and the University of St.Andrews for providing a Research Studentship. 


\section{ABBREVIATIONS}

DIOP

DIPHOL

dppb

dppf

DMF

MIBK

$\mathrm{PPh}_{3}$

$\mathrm{PPh}_{3} \mathrm{O}$

rtm

THF
2,3-o-Isopropylidene-2,3-dihydroxy-1,4-bis(diphenyl phosphino)butane

(S,S)-trans-4,5-bis[(5H-dibenzophospholyl)methyl]-

2,2-dimethyl-1,3-dioxolan

1,4-bis(diphenylphosphino)butane

1,1'-bis(diphenylphosphino)butane

Dimethyformamide

Methyl isobutyl ketone

Triphenylphosphine

Triphenylphosphine oxide

Room temperature

Tetrahydrofuran 


\section{ABSTRACT}

Polybutadiene having varying degrees of 1,4 and1,2 units $(0$ $100 \%$ cis , $14-60 \%$ trans , 20-88 \% pendant carbon-carbon double bonds) have been reacted with carbon monoxide in the presence of water and palladium based catalysts to give new polymers in which the double bonds are hydrocarboxylated. When using $\left[\mathrm{PdCl}_{2}\left(\mathrm{PPh}_{3}\right)_{2}\right] / \mathrm{SnCl}_{2}$ as catalysts, very high regiospecificities can be obtained with only the double bonds pendant from the chain being hydrocarboxylated. When using $\mathrm{PdCl}_{2}$ as catalyst, in the presence of $\mathrm{CuCl}_{2}$ and $\mathrm{O}_{2}$, hydrocarboxylation takes place both at the pendant carbon-carbon double bonds and back bone carbon-carbon double bonds. Complete hydrocarboxylation of all the carbon-carbon double bonds in polybutadiene can be carried out by sequential catalytic reaction i.e., catalysis by $\left[\mathrm{PdCl}_{2}\left(\mathrm{PPh}_{3}\right)_{2}\right] / \mathrm{SnCl}_{2}$ followed by (recatalysis) $\left[\mathrm{PdCl}_{2}\left(\mathrm{PPh}_{3}\right)_{2}\right] / \mathrm{PPh}_{3}$. A new method based on ${ }^{1} \mathrm{H}$ and ${ }^{13} \mathrm{C}$ n.m.r. has been developed to characterise polybutadienes and their hydrocarboxylated products.

The hydrocarboxylation reaction catalysed by $\left[\mathrm{PdCl}_{2}\left(\mathrm{PPh}_{3}\right)_{2}\right] / \mathrm{SnCl}_{2}$ is truly homogeneous although catalytic decomposition is a problem because their exists a small temperature window between the onset of catalysis and the onset of catalytic decomposition. Unlike the starting materials the products, which are solids with melting points well above the room temperature are soluble in organic solvents or dilute base and have been shown to have corrosion inhibition and wood preservation properties. 


\section{CONTENTS}

page

Acknowledgements

Abbreviations

Abstract

Chapter 1 Hydrocarboxylation of alkenes and polybutadienes Background and literature review

1.1 Introduction

1.2. Hydrocarboxylation of 1-alkenes

1.2.1 Nickel catalysed reactions 10

1.2.2 Cobalt catalysed reactions 14

1.2.3 Palladium catalysed reactions 16

1.2.4 Rhodium catalysed reactions 23

1.2.5 Reactions catalysed by other metal complexes 25

1.2.5.1 Platinum catalysed reactions 25

1.2.5.2 Iridium catalysed reactions 25

1.2.5.3 Copper catalysed reactions 26

1.3. Hydrocarboxylation of dienes/trienes 28

Non-Conjugated dienes $\quad 28$

1.3.1 Cobalt catalysed reactions 28

1.3.2 Nickel catalysed reactions 29

1.3.3 Palladium catalysed reactions 29

Conjugated dienes 31

1.3.4 Cobalt catalysed reactions 32

1.3.5 Palladium catalysed reactions 33 
1.4 Hydrocarboxylation of functionalised alkenes

1.4.1 Cobalt catalysed reactions

1.4.2 Palladium catalysed reactions

1.4.3 Reactions catalysed by other metal complexes

2.2.2 ${ }^{1} \mathrm{H}$ and ${ }^{13} \mathrm{C}$ n.m.r. analysis 56

2.2.2.1 ${ }^{13} \mathrm{C}$ n.m.r. analysis $\quad 56$

2.2.2.2 1 H n.m.r. analysis $\quad 59$

2.2.2.2.1 Analysis of starting materials 59

2.2.2.2.2 Method One 65

2.2.2.2.3 Method Two 69

2.2.2.2.4 Method Three 69

2.2.3 Infrared analysis $\quad 88$

2.2.4. Microanalysis 95 
Chapter 3 Hydrocarboxylation of polybutadienes catalysed by palladium complex system $\left[\mathbf{P d C l}_{2}\left(\mathbf{P P h}_{3}\right)_{2}\right] / \mathbf{S n C l}_{2} 98$

3.1 Introduction 98

$\begin{array}{ll}3.1 .1 \text { Hydrosilylation } & 98\end{array}$

3.1.2 Hydrogenation 103

3.1.3 Hydroformylation 105

$\begin{array}{ll}3.1 .4 & \text { Epoxidation } \\ & 113\end{array}$

3.2 Results and Discussion 117

$\begin{array}{lll}3.2 .1 & \text { Effect of pressure } & 119\end{array}$

3.2.2 Effect of temperature 119

$\begin{array}{ll}3.2 .3 \text { Reaction period } & 119\end{array}$

$\begin{array}{ll}3.2 .4 \text { Amount of solvent } & 120\end{array}$

3.2.4.1 Amount of polybutadiene 120

3.2.5. Analysis of hydrocarboxylated polybutadienes 121

3.2.5.1 Infrared analysis 121

3.2.5.2 $1 \mathrm{H}$ and ${ }^{13} \mathrm{C}$ n.m.r. analysis 124

3.2.5.2.1 $1 \mathrm{H}$ n.m.r. analysis 124

3.2.5.2.2 ${ }^{13} \mathrm{C}$ n.m.r. analysis 124

3.2.5.3 Determination of molecular weights $\quad 129$

3.2.5.4 Differential Scanning Calorimetry 132

$\begin{array}{ll}3.2 .6 \text { Catalyst stability } & 135\end{array}$

3.2.7 Effect of co-catalysts 137

3.2.8. Effect of adding excess triphenylphosphine 138

$\begin{array}{ll}3.2 .9 \text { Effect of water } & 138\end{array}$ 
3.2.11 Studies on the relationship between catalyst stability and activity of the catalyst

3.2.11.1 Tests on homogeneity of the reaction

3.2.11.2 Effect of triphenylphosphine oxide

3.2.11.3 Possible physical effects on catalyst stability

3.2.12 Effect of heater design

3.2.13 Recatalysis

3.2.14 Scale up.

Chapter 4 Hydrocarboxylation of polybutadienes catalysed by $\mathbf{P d C l}_{2}$ in the presence of air and $\mathrm{CuCl}_{2} \quad 161$

4.1 Introduction

4.2 Results and Discussion

4.2.1 Methods of analysis

4.2.1.1 Infrared analysis

4.2.1.2 $1 \mathrm{H}$ and ${ }^{13} \mathrm{C}$ n.m.r. analysis

4.2.1.2.1 ${ }^{1} \mathrm{H}$ n.m.r. analysis

4.2.1.2.2 ${ }^{13} \mathrm{C}$ n.m.r. analysis 
5.1.1 Wood preservation

5.1.2 Corrosion inhibition 185

5.1.3. Introduction of other functional groups

Chapter 6 Experimental Methods and Starting Materials 189

References 


\section{Chapter 1}

Hydrocarboxylation of alkenes and polybutadienes

(background and literature review)

\section{$\underline{1.1 \quad \text { Introduction }}$}

This chapter reviews hydrocarboxylation reactions on alkenes in general and hydrocarboxylation modification reactions on polymers.

Water-soluble synthetic polymers are a family of materials that have been developed commercially and studied scientifically at an accelerating pace in recent years. Partly this is a reflection of the increasing diversity in the application of water-soluble polymers as a group in mineral processing, oil-recovery, etc.

Certain water-soluble synthetic polymers containing carboxylic acid groups have been found to exhibit antitumour and anti-viral effects ${ }^{1}$. They are also used in the water treatment industries to prevent the deposition of inorganic salts on metal surfaces and to reduce metallic corrosion. These products have found major outlets in industrial cooling systems and desalination plants. Presently they are being widely used as surface coating materials ${ }^{2}$.

The chemical modification of polymers is a post polymerisation process which is used in certain situations:

(i) to improve and optimise the chemical and mechanical properties of existing polymers, or

(ii) to introduce desirable functional groups in to the polymer.

Many chemical reactions with polymers are possible, as reflected in the breadth and depth of the associated literature. The chemical 
modification of unsaturated polymers via homogeneous catalysis offers a potentially useful method for the introduction of desirable functional groups to the polymer chains. The functionalisation involves hydroxylation, hydroformylation, hydrosilyation, hydrogenation, epoxidation, and various other chemical reactions involving synthetic and natural polymers.

The application of homogeneous catalysis can thus become a powerful tool in the synthesis of a wide range of polymeric compounds of industrial interest. One advantage of homogeneous catalysis over heterogeneous catalysis is its greater ability effectively to catalyse reactions on the polymeric substrates. The slow rates and low yields observed when heterogeneous catalysts are used in such reactions are generally ascribed to the difficulty of orientating a long polymer chain on the immobile active site. In contrast, a homogeneous catalyst offers catalytic mobility and circumvents such orientation problems, thus increasing their potential for diffusion on the polymer. (Homogeneous catalysis as used here implies that the catalytically active species is molecularly dispersed (solvated) in the polymer or a cosolvent. Heterogeneous catalysis implies that the catalytically active species and the substrates are in two different phases, e.g., solid catalyst, liquid substrates).

One of the ways to synthesise speciality polymers with certain desirable functional groups is by the polymerisation of monomers with the desirable functional groups. These polymers all have their functional groups directly attached to the main chain in the polymers. 
However there are often a number of difficulties associated with polymerisation of the monomers ${ }^{3}$ such as

(i) difficulty in polymerisation

(ii) side reactions during polymerisation

(iii) difficulty in the preparation of desirable monomers

(iv) and, in the case of copolymerisation, unfavourable reactivity ratios.

Alternatively, catalytic chemical reactions on unsaturated polymers in which the desirable functional groups are introduced into available unsaturated sites in polymers, such as polybutadiene, can be employed to synthesise certain speciality polymers. Here, the functional group can be separated from the main chain by a flexible spacer group. Polybutadienes are of special interest in this context, since very regiospecific polybutadienes are available with desirable molecular weights and molecular weight distributions. The relative ratios of the three types of double bond (cis or trans in the backbone and pendant) can be controlled. The products thus obtained by the introduction of desirable functional groups have the same regiospecificity and chain length properties, provided that side reactions such as crosslinking and isomerisation, for example, are avoided.

Our interest in functionalised polymers is in the area of corrosion inhibition, calcium carbonate scale control, wood preservation etc., of which carboxylated polymers are finding most application. Thus, in this chapter we will review hydrocarboxylation reaction on alkenes in general and hydrocarboxylation modifications on polymers,particularly polybutadienes. Publications which are either important or relevant to our work have been discussed in detail. 
Hydrocarboxylation refers to the reaction of alkenes with carbon monoxide and water in the presence of catalysts to give mixtures of straight chain and branched chain carboxylic acids (Equation 1.1).

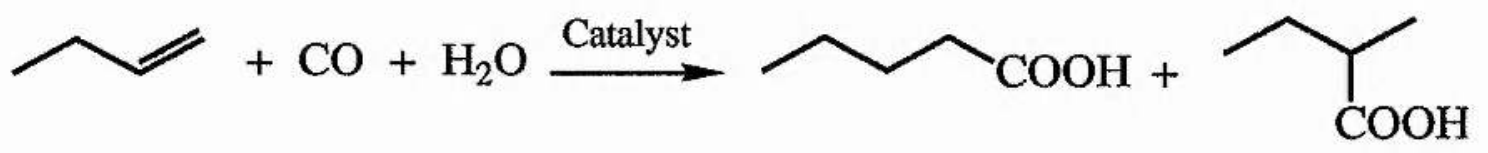

Equation 1.1

If alcohols are used in place of water, then esters are produced. These hydrocarboxylation reactions are also known as Reppe reactions ${ }^{4}$ after the originator. In his original process Reppe used a nickel carbonyl catalyst for the synthesis of propanoic acid from ethene, at $270^{\circ} \mathrm{C}$ and carbon monoxide pressure of $200 \mathrm{~atm}$ (Equation 1.2).

$$
\mathrm{CH}_{2}=\mathrm{CH}_{2}+\mathrm{CO}+\mathrm{H}_{2} \mathrm{O} \quad \frac{\left[\mathrm{Ni}(\mathrm{CO})_{4}\right]}{270^{\circ} \mathrm{C}, 200 \mathrm{~atm}} \quad \mathrm{CH}_{3} \mathrm{CH}_{2} \mathrm{COOH}
$$

Equation 1.2

The reactions of alkenes with carbon monoxide and water (or alcohols) to form acids (or esters) was already known before Reppe's work. The earlier process proceeded only at high pressure (700-900 atm CO) and at high temperature (about $300^{\circ} \mathrm{C}$ ) in the presence of catalysts such as phosphoric acid, heteropolyacids, boron trifluoride, and metal halides. Operation at such high temperature i.e., $250-300^{\circ} \mathrm{C}$ had certain inherent disadvantages. Carbonylation of alkenes, particularly above $c a 150^{\circ} \mathrm{C}$ is always accompanied by side reactions such as the water-gas shift reaction (Equation 1.3). 


$$
\mathrm{CO}+\mathrm{H}_{2} \mathrm{O} \longrightarrow \mathrm{CO}_{2}+\mathrm{H}_{2}
$$

Equation 1.3

The hydrogen that is formed hydrogenates unreacted alkene and reacts with carbon monoxide and the alkene to form aldehydes, alcohols, and other products. Isomerisation, polymerisation, resinification and cleavage of the alkene also proceed readily at higher temperature. Hardy 5 described experiments in which a mixture of ethene, carbon monoxide and steam were passed through $\mathrm{H}_{3} \mathrm{PO}_{4}$ at $290-300{ }^{\circ} \mathrm{C}$ and 450 atmospheres, where, for every molecule of ethene converted into acid, approximately three were hydrated, and two were polymerised. Finally, the severe conditions required lead to the danger of corrosion of the walls of the reactor. This situation has led to a search for newer catalysts that would act at lower temperature than the conventional catalyst and would at the same time be relatively cheap, readily accessible, and offer the possibility of higher selectivity.

The development of homogeneous catalysis began over fifty years ago with the pioneering work of Reppe. Reppe and coworkers hypothesised ${ }^{4}$ that hydrocarboxylation of alkenes occurs as shown in Scheme 1.1. In this an alkene, $\mathrm{RCH}=\mathrm{CH}_{2}$, reacts with carbon monoxide to form intermediate [1]. This may be attacked either at (a) or (b), to yeild straight chain and/or branched chain carboxylic acids respectively. 


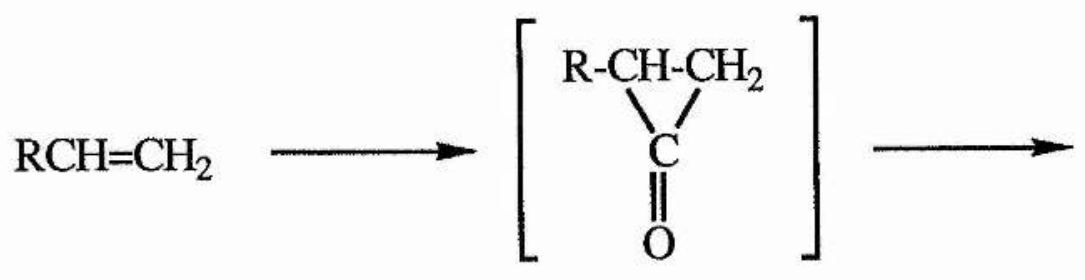

[1]

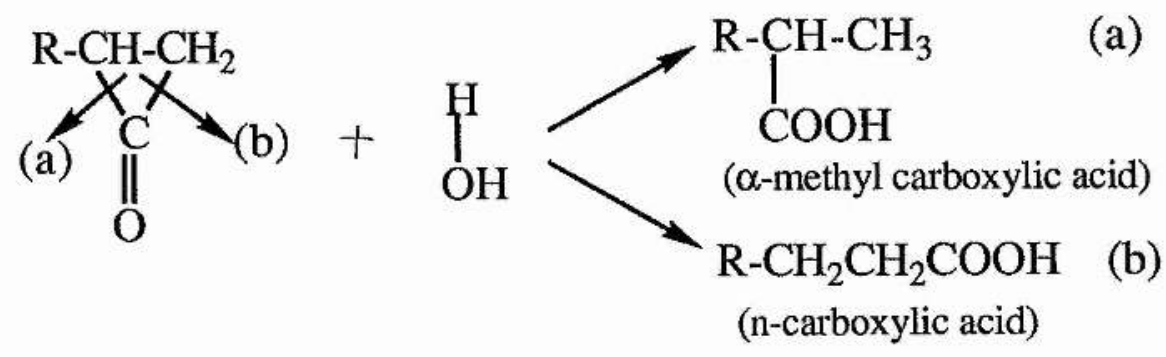

Scheme 1.1

Depending on the amount of catalyst used (Reppe normally used the nickel complex $\left.\left[\mathrm{Ni}(\mathrm{CO})_{4}\right]\right)$, distinctions were made between a stoichiometric (Equation 1.4), and a catalytic conversion (Equation 1.5).

$\underline{\text { Stoichiometric }}$

$$
4 \mathrm{CH}_{2}=\mathrm{CH}_{2}+\mathrm{Ni}(\mathrm{CO})_{4}+4 \mathrm{C}_{2} \mathrm{H}_{5} \mathrm{OH}+2 \mathrm{HCl}
$$$$
4 \mathrm{CH}_{2}\left(\mathrm{COOC}_{2} \mathrm{H}_{5}\right) \mathrm{CH}_{3}+\mathrm{NiCl}_{2}+\mathrm{H}_{2}
$$

Equation 1.4

Catalytic

$$
\mathrm{CH}_{2}=\mathrm{CH}_{2}+\mathrm{CO}+\mathrm{C}_{2} \mathrm{H}_{5} \mathrm{OH} \stackrel{\text { Ni salt }}{\longrightarrow} \mathrm{CH}_{2}\left(\mathrm{COOC}_{2} \mathrm{H}_{5}\right) \mathrm{CH}_{3}
$$

Equation 1.5 
In each case, a compound possesing an active hydrogen atom, e.g. water or alcohol, is also present.

The stoichiometric method is carried out with nickel carbonyl and an acid. Less stringent conditions are necessary compared with the catalytic process, temperatures $c a 160^{\circ} \mathrm{C}$ at pressures of about 50 atmospheres of carbon monoxide are normally employed.

The catalytic method involves the formation of nickel carbonyl in situ from carbon monoxide and a nickel salt such as $\mathrm{NiCl}_{2}, \mathrm{NiI}_{2}$, $\left[\mathrm{Ni}(\mathrm{CO})_{4}\right],\left[\left(\mathrm{C}_{2} \mathrm{H}_{5} \mathrm{CO}\right)_{2} \mathrm{Ni}\right]$, etc. The reaction temperatures are around $250^{\circ} \mathrm{C}$, with carbon monoxide pressures of 200 atmospheres.

Once a moderately satisfactory technique for affecting the reaction had been evolved, Reppe applied the two methods to a variety of compounds with little variation in conditions. Over the years, Reppe and co-workers studied hydrocarboxylation reactions on unsaturated substrates quite extensively and published a number of papers and patents ${ }^{4}$. Since this discovery, the area of hydrocarboxylation has been one of frantic activity to become one of the most exciting and controversial new areas of chemistry. Many synthetically useful applications have been reported 2 .

Various classifications for the hydrocarboxylation reactions reviewed below are feasible. No method is pre-eminent as any single catalytic reaction can be accomplished by more than one transition metal complex and, not infrequently, a reaction may give rise to a multitude of products. For the purpose of this review, a classification in terms of the type of substrate, i.e., monoalkenes, di- and tri-alkenes, and functionalised alkenes has been adopted.

Most of the elements that have proved valuable in forming complexes suitable for catalytic homogeneous carbonylation appear in group VIII (now groups 8-10) of the periodic table. Salts and complexes 
of $\mathrm{Pd}, \mathrm{Pt}, \mathrm{Ru}, \mathrm{Rh}, \mathrm{Ir}, \mathrm{Fe}, \mathrm{Ni}$, and Co have been used as catalysts. For hydrocarboxylation reactions, complexes of $\mathrm{Co}, \mathrm{Ni}$ and $\mathrm{Pd}$ have been most extensively studied, although strenuous efforts are being made to find catalysts from among the less expensive metals.

The catalytic activity of the transition metal salts and complexes is the result of a delicate balance of valence states and strengths of chemical bonds. Too strong a bond between alkene and the transition metal catalyst results in a stable compound showing no catalytic activity. Similarly, there is no catalytic activity if the reaction between alkene and the transition metal cannot occur. Not only must the alkene be accommodated by the transition metal, but also the carbon monoxide must be able to bind if transfer of carbon monoxide to the substrate is to occur. However, it must be noted that the products of catalytic hydrocarboxylation may themselves inhibit or show no catalytic activity. For example, $\left[\mathrm{Pd}(\mathrm{CO})\left(\mathrm{PPh}_{3}\right)_{3}\right]^{6}$, isolated from the reaction mixture during hydrocarboxylation of cyclohexene with carbon monoxide and ethanol, in the presence of $\left[\mathrm{PdCl}_{2}\left(\mathrm{PPh}_{3}\right)_{2}\right]$ and a two molar excess of triphenylphosphine as the catalyst, showed no catalytic activity at all in the hydrocarboxylation of alkenes. Thus the catalytic activity depends on a delicate balance of energies with regard to the binding of the substrates.

The efficiency and the product distribution of the hydrocarboxylation reactions depends markedly on a number of factors: The nature of the nucleophile i.e., water or alcohol, the structure of the alkene, the catalyst, the solvent, and the physical parameters of the reaction such as variation of temperature and carbon monoxide pressure.

In the following section we will discuss the role of these various parameters and their importance in homogeneous hydrocarboxylation 
reactions with respect to various substrates (i.e.,monoalkenes, dialkenes, functionalised alkenes, etc.).

\subsection{Hydrocarboxylation of 1-alkenes}

Generally, 1-alkenes on hydrocarboxylation give rise to an isomeric mixture of carboxylic acids or their esters. As mentioned earlier the most active catalysts for hydrocarboxylation are found in the salts and complexes of $\mathrm{Ni}, \mathrm{Co}, \mathrm{Pd}, \mathrm{Pt}$ and $\mathrm{Rh}$ complexes. A general observation on the characteristics of these metal catalysed hydrocarboxylation reactions of 1- alkenes is presented in Table 1.1.

In general, it has been found that nickel catalysed reactions with 1-alkenes give branched acids. Cobalt catalysts tend to cause more side reactions i.e. there is a greater tendency to form ketones. However, the presence of pyridine type bases markedly improves the selectivity to straight chain acids. In the case of palladium catalysts, regioselectivity very much depends on a number of factors such as ligands, the nature of $\mathrm{R}$ in $\mathrm{R}-\mathrm{CH}=\mathrm{CH}_{2}$, solvent, hydrogen donor and physical parameters. When using rhodium catalysts, regioselectivity can be increased by using a promoter. Iridium catalysed reactions always tends to form terminal acids with 1-alkenes. 


\begin{tabular}{|c|c|c|c|c|}
\hline Catalyst & Promoter & Conditions & $\begin{array}{c}\text { Yield } \\
\text { (linear) }\end{array}$ & References \\
\hline $\mathrm{Ni}$ & $\mathrm{X}_{2}$ or $\mathrm{HX}$ & $250-300^{\circ} \mathrm{C}$ & $80-90 \%$ & 7,8 \\
& & $200-400 \mathrm{~atm}$ & $(50 \%)$ & \\
$\mathrm{Co}$ & $\mathrm{HI}, \mathrm{Py}$ & $180-220^{\circ} \mathrm{C}$ & $70-95 \%$ & $9,10,11$ \\
& & $200 \mathrm{~atm}$ & $(70 \%)$ & \\
$\mathrm{Pd}$ & $\mathrm{R}_{3} \mathrm{P}$ and $\mathrm{HCl}$ & $80-100^{\circ} \mathrm{C}$ & $95 \%$ & $12,13,14,15$ \\
& & $30-700 \mathrm{~atm}$ & $(70-90 \%)$ & \\
$\mathrm{Rh}$ & $\mathrm{HX}$ & $150-220^{\circ} \mathrm{C}$ & $95 \%$ & 16 \\
& & $30 \mathrm{~atm}$ & $(50-60 \%)$ & \\
$\mathrm{Ir}$ & $\mathrm{HX}$ & $150-220^{\circ} \mathrm{C}$ & $95 \%$ & 17 \\
& & & $(70 \%)$ & \\
\hline
\end{tabular}

Table 1.1

\subsubsection{Nickel catalysed reactions.}

The hydrocarboxylation of 1-alkenes usually proceeds under aqueous acidic conditions in the presence of tetracarbonyl nickel or of a nickel salt such as nickel(II) iodide. Hydrocarboxylation of ethene using a three component catalytic system, namely $\left[\mathrm{Ni}\left(\mathrm{NH}_{3}\right)_{6} \mathrm{Cl}_{2}\right], \mathrm{NaI}$, and Raney nickel yielded, upon distillation, propanoic acid and tetracarbonyl nickel18(Equation 1.6).

$\left[\mathrm{Ni}\left(\mathrm{NH}_{3}\right)_{6} \mathrm{Cl}_{2}\right], \mathrm{NaI}$, Raney $\mathrm{Ni}$

$$
\mathrm{CH}_{2}=\mathrm{CH}_{2}+\mathrm{CO}+\mathrm{H}_{2} \mathrm{O}-280^{\circ} \mathrm{C}, 250 \mathrm{~atm}
$$

Equation 1.6 
The presence of $\left[\mathrm{Ni}(\mathrm{CO})_{4}\right]$ proves that this species is formed under the reaction conditions. It has been suggested that the catalytic species in all the reactions catalysed by $\left[\mathrm{Ni}(\mathrm{CO})_{4}\right]$ is the hydrido nickel carbonyl complex (Equation 1.7). Nickel compounds must be used in the presence of promoters like hydrogen halides 8,19 .

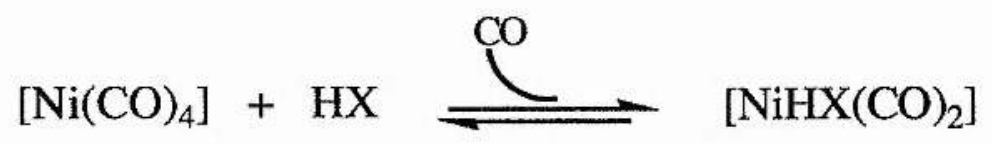

Equation 1.7

The hydrocarboxylation reaction mechanism ${ }^{20}$ is represented in Scheme 1.2.
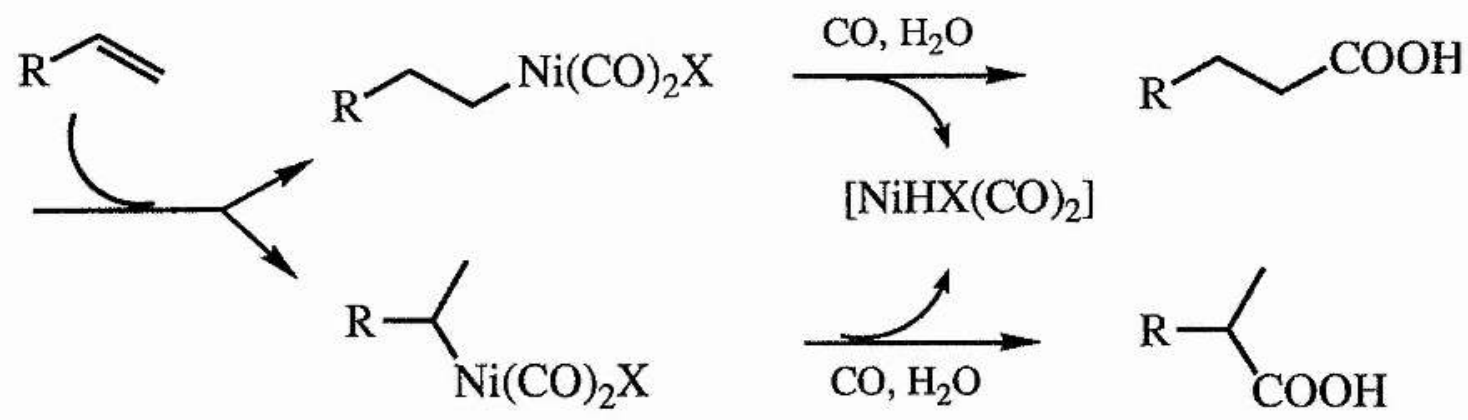

Scheme 1.2

The reaction catalysed by $\left[\mathrm{Ni}(\mathrm{CO})_{4}\right]$ is thought to be analogous to that catalysed by $\left[\mathrm{HCo}(\mathrm{CO})_{4}\right]$.

An alternative mechanism involving the formation of a nickel cyclobutanone intermediate (2) that reacts first with hydrogen halides has been proposed 21 and is represented in Scheme 1.3. 

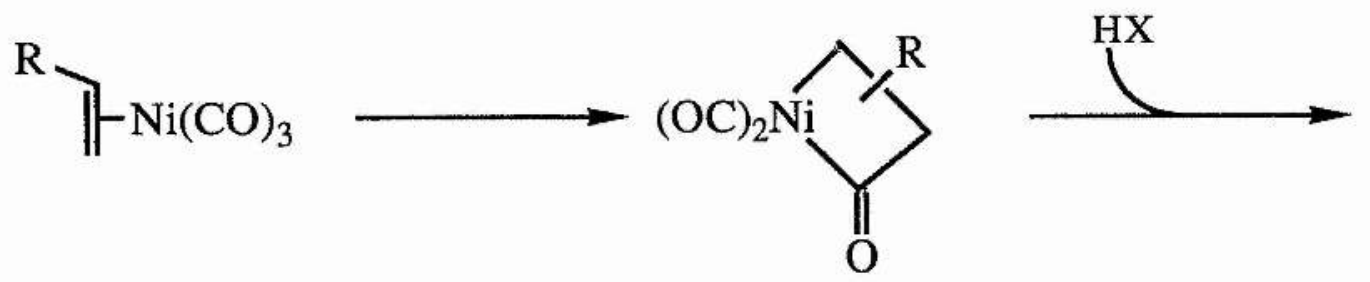

( 2 )
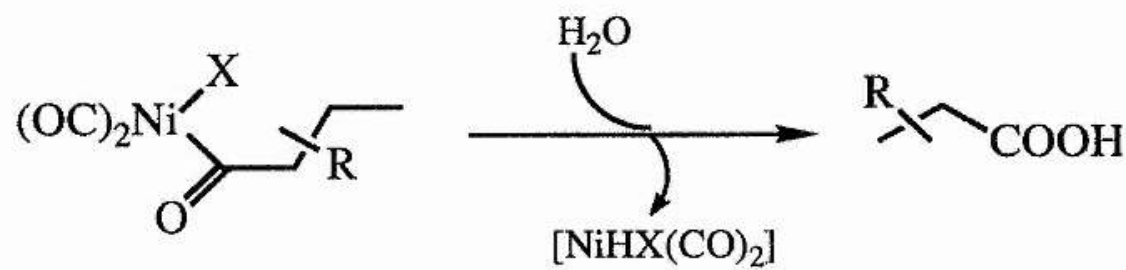

Scheme 1.3

Intermediate (2) is related to a ruthenium complex which has been formed by reaction of complexed carbon monoxide and alkyne, but (2) does not have the endocyclic double bond (Equation 1.8). No direct evidence for these proposed mechanisms has been established.

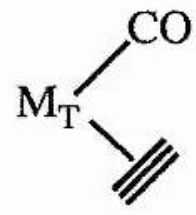

$$
\mathrm{M}_{\mathrm{T}}=\mathrm{Rh}
$$

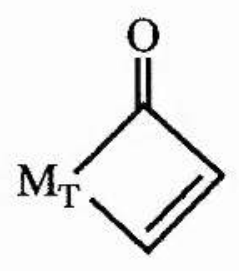

Equation 1.8

In nickel catalysed hydrocarboxylation reactions, ketone formation is sometimes observed. Ethene yields appreciable amounts of diethyl ketone in addition to propanoic acid22 (Equation 1.9). 
$\mathrm{CH}_{2}=\mathrm{CH}_{2}+\mathrm{CO}+\mathrm{H}_{2} \mathrm{O} \frac{\left[\mathrm{Ni}(\mathrm{CO})_{4}\right]}{300^{\circ} \mathrm{C}, 450 \mathrm{~atm}} \quad \mathrm{CH}_{2}(\mathrm{COOH}) \mathrm{CH}_{3}+\mathrm{C}_{2} \mathrm{H}_{5} \mathrm{COC}_{2} \mathrm{H}_{5}$

Equation 1.9

This is in accord with competition between water and alkene for reaction with an acyl-nickel intermediate (Scheme 1.4).

When $\left[\mathrm{Ni}(\mathrm{CO})_{4}\right]$ is used as the catalyst the reaction rate is dependent upon the pressure of carbon monoxide. An increase in carbon monoxide pressure increases the reaction rate; decrease in carbon monoxide pressure decreases the reaction rate.

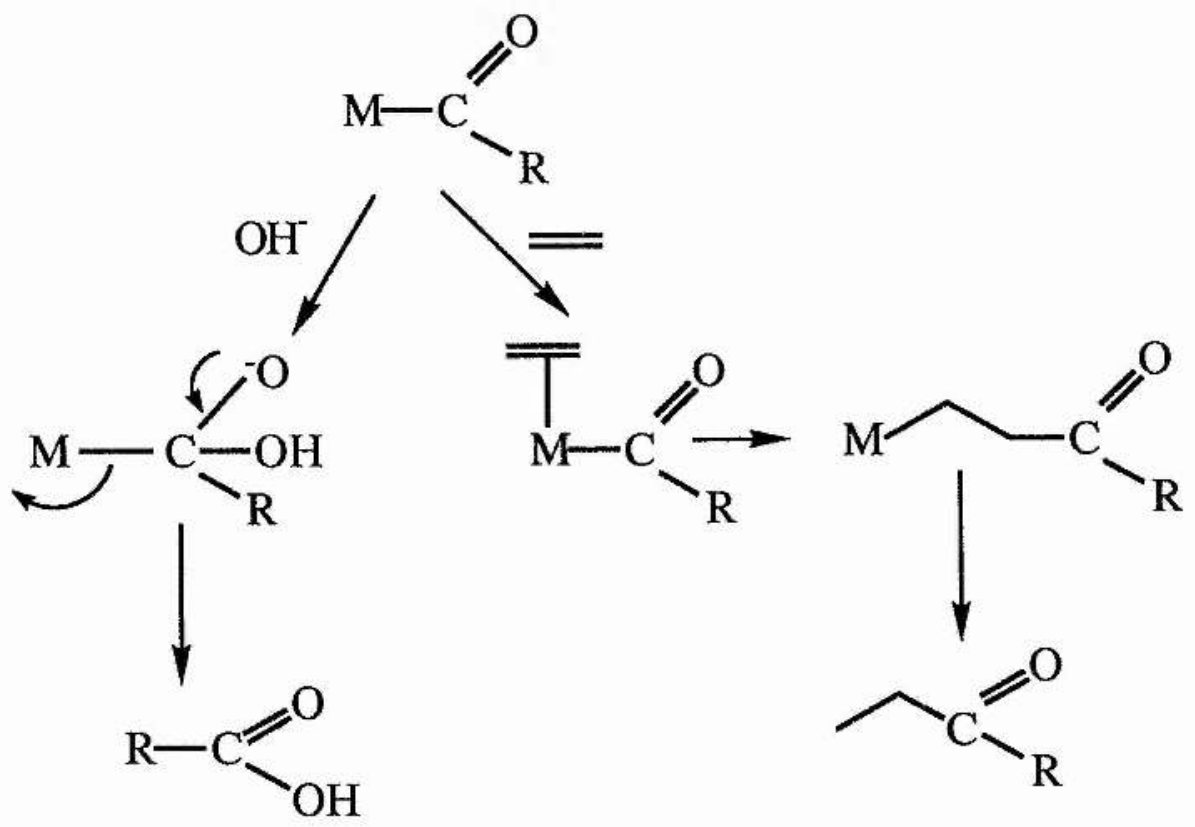

Scheme 1.4 


\subsubsection{Cobalt catalysed reactions}

Being good hydroformylation catalysts, cobalt complexes, in general, tend to cause more side reactions than nickel catalysts i.e., ketones are formed (Equation 1.10).

$$
\begin{aligned}
& \mathrm{CH}_{2}=\mathrm{CH}_{2}+\mathrm{CO}+\mathrm{H}_{2} \mathrm{O} \stackrel{\text { Co propionate }}{\longrightarrow} \mathrm{C}_{2} \mathrm{H}_{5} \mathrm{COOH}+\mathrm{C}_{2} \mathrm{H}_{5} \stackrel{\text { 을 }}{\mathrm{O}} \mathrm{C}_{2} \mathrm{H}_{5} \\
& 234^{\circ} \mathrm{C}, 660 \mathrm{~atm} \text { ( } 45 \% \text { yield) }
\end{aligned}
$$

\section{Equation 1.10}

With increasing temperature, the yields of acids decreases, and yields of ketone derivatives increases. With increase in carbon monoxide pressure the reaction rate is accelerated and the amounts of ketone derivatives decreases. The rate and selectivity to straight chain carboxylic acid derivatives is markedly improved by the presence of pyridine type bases. Thus hydrocarboxylation of 1-alkenes produces $80 \%$ of the linear acid 10,11 .

The basicity and structure of the promoter are important. The effects 17 are summarised in Table 1.2.

\begin{tabular}{|c|c|}
\hline Promoter & Relative rate of catalysis \\
\hline pyridine & 10 \\
$\alpha$-picoline & 1 \\
$\beta$-picoline & 10 \\
2,6-Lutidine & 0 \\
Triethylamine & 0 \\
\hline
\end{tabular}

Table 1.2 
It can be seen that a strong base which is sterically hindered completely stops the catalytic reaction. The most reasonable interpretation of the pyridine type bases is that they attack the intermediate acyl cobalt species, cleaving the cobalt-carbon bond, and giving rise to a pyridinium cation which is solvated to carboxylic acid or ester and the pyridinium cation.

Foster, Hershman and Morris 17 suggested that pyridine acts as both an inhibitor and a promoter in the reaction. The Heck and Breslow 23 mechanism (Scheme 1.5) agrees with the former if one postulates that the concentration of the acyl cobalt carbonyl intermediate is extremely small.

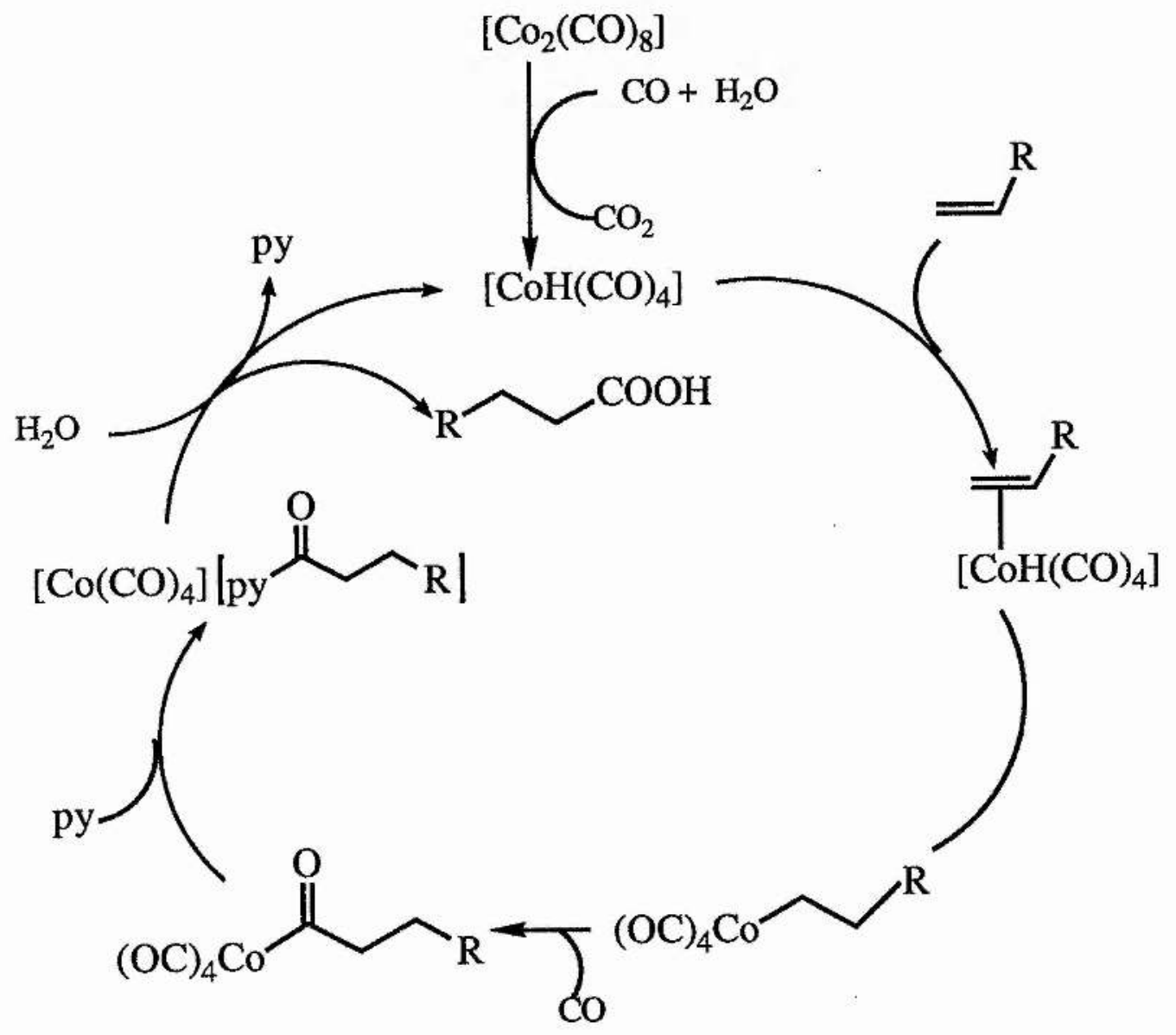

Scheme 1.5 
X-ray 17 structural investigations carried out on a solid complex crystallised from a hydroesterification reaction mixture showed the compound to be $\left[\right.$ pyridine $\left.{ }_{2} \mathrm{H}\right]+\left[\mathrm{Co}(\mathrm{CO})_{4}\right]^{-}$. The cation consists of a proton bonded to the nitrogen of the pyridines (Figure 1.1).

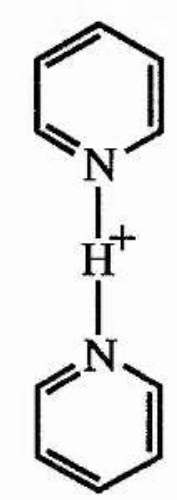

Figure 1.1

It appears that the majority of the cobalt is in this catalytically inactive form (Equation 1.11).

$$
\left[\mathrm{Py}_{2} \mathrm{H}\right]^{+}\left[\mathrm{Co}(\mathrm{CO})_{4}\right]^{-} \underset{\text { pyridine }}{\rightleftharpoons}\left[\mathrm{HCo}(\mathrm{CO})_{4}\right]
$$

Equation 1.11

\subsubsection{Palladium catalysed reactions}

After the epoch making introduction in 1960 of the Wacker process 24 by which acetaldehyde is produced from ethene using $\mathrm{PdCl}_{2}$ as a catalyst (Equation 1.12), palladium complexes were recognised as 
versatile catalysts for hydrocarboxylation reactions.

$$
\mathrm{CH}_{2}=\mathrm{CH}_{2}+1 / 2 \mathrm{O}_{2} \stackrel{\mathrm{PdCl}_{2} / \mathrm{CuCl}_{2}}{\longrightarrow} \mathrm{CH}_{3} \mathrm{CHO}
$$

Equation 1.12

Alper and coworkers 25 reported a modified $\mathrm{PdCl}_{2}-\mathrm{CuCl}_{2}$ catalytic system that operated under mild conditions (room temperature and pressure), as an effective catalyst for hydrocarboxylating 1-alkenes with great regioselectivity to branched acids. Alper and coworkers in a patent 26 extended this method for hydrocarboxylating polymers, Further detailed discussion is carried out in Chapter 4. A U.S. patent 27 similarly reports hydrocarboxylation of cis - and trans polybutadiene in the presence of $\mathrm{PdCl}_{2}$ as catalyst. However no details were given about the methods, or yields when using $\mathrm{PdCl}_{2}$ as catalyst.

The greatest advantage in using complex palladium catalysts is that they are very active even at low concentration and low temperatures. The activity of palladium catalysts are highly sensitive to the various factors governing the reaction. The efficiency and product distribution of the reaction depends markedly on the nature of the nucleophile i.e., water or alcohol, the structure of the alkene and the phosphine ligand, and other reaction variables such as solvent, temperature and carbon monoxide pressure.

For 1- octene hydrocarboxylation, $n$ to iso ratios from 3.0 to 0.5 are observed depending on temperature, carbon monoxide pressure, nature and amount of added phosphines and additional reagents 13 . Consiglio and Marchelli reported 28 that when triphenylphosphine was used as ligand attached to the palladium species, the branched chain carboxylic acid was obtained on hydrocarboxylation of styrene, Whilst 
with DIOP as ligand the straight chain carboxylic acid was the major product (Figure 1.2).

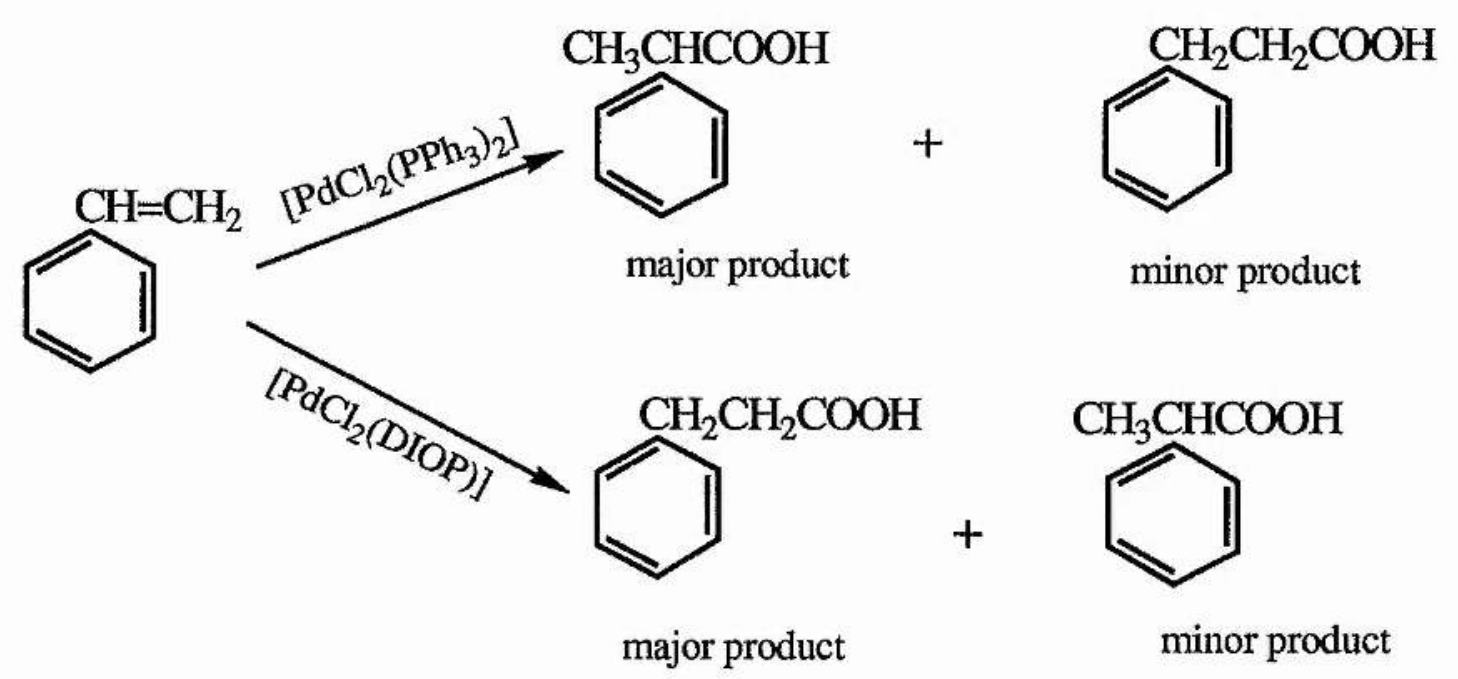

Figure 1.2

Fuchikami and coworkers 29 studied hydrocarboxylation and hydroesterification of trifluoropropene (TFP) and pentafluorostyrene (PFS) in the presence of palladium complexes and report that hydroesterification of TFP in the presence of $\left[\mathrm{PdCl}_{2}\left(\mathrm{PPh}_{3}\right)_{2}\right]$ as the catalyst gave different ratios of branched to straight chain in different solvents under the same reaction conditions of temperature and pressure $\left(100^{\circ} \mathrm{C}, 110 \mathrm{~atm}\right)$ (Table 1.3).

\begin{tabular}{|c|c|c|}
\hline Solvent & Yield & Branched/Unbranched \\
\hline $\mathrm{C}_{2} \mathrm{H}_{5} \mathrm{OH}$ & $74 \%$ & $49 / 51$ \\
$\mathrm{THF}$ & $93 \%$ & $71 / 29$ \\
$\mathrm{C}_{6} \mathrm{H}_{6}$ & $95 \%$ & $79 / 21$ \\
\hline
\end{tabular}

Table 1.3 
By using the same solvent, acetone, for hydroesterification of TFP with ethanol as the hydrogen donor, different catalysts gave different yields and selectivity (Table 1.4).

\begin{tabular}{|c|c|c|c|}
\hline Catalyst & Conditions & Yield & $\begin{array}{l}\text { Branched/Unbr- } \\
\text { anched }\end{array}$ \\
\hline $\mathrm{PdCl}_{2}\left(\mathrm{PPh}_{3}\right)_{2}$ & $100^{\circ} \mathrm{C}, 110 \mathrm{~atm}$ & $82 \%$ & $52 / 48$ \\
$\mathrm{PdCl}_{2}(\mathrm{dppb})$ & $120^{\circ} \mathrm{C}, 110 \mathrm{~atm}$ & $12 \%$ & $<1 / 99$ \\
$\mathrm{PdCl}_{2}(\mathrm{dppf})$ & $120^{\circ} \mathrm{C}, 110 \mathrm{~atm}$ & $16 \%$ & $11 / 89$ \\
\hline
\end{tabular}

Table 1.4

They observed that during the hydrocarboxylation of PFS, when the source of hydrogen was changed from methanol to water, the selectivity of the catalyst $\left[\mathrm{PdCl}_{2}\left(\mathrm{PPh}_{3}\right)_{2}\right]$ changed considerably from branched to unbranched product (Table 1.5).

\begin{tabular}{|c|c|c|c|c|}
\hline $\begin{array}{c}\text { Source of } \\
\text { hydrogen }\end{array}$ & Conditions & Conversion & Yield & $\begin{array}{c}\text { Branched } \\
\text { unbranched }\end{array}$ \\
\hline $\mathrm{CH}_{3} \mathrm{OH}$ & $\begin{array}{c}100^{\circ} \mathrm{C}, \\
70 \mathrm{~atm}\end{array}$ & $88 \%$ & $71 \%$ & $93 / 7$ \\
$\mathrm{H}_{2} \mathrm{O}$ & $\begin{array}{c}125^{\circ} \mathrm{C} \\
110 \mathrm{~atm}\end{array}$ & $100 \%$ & $90 \%$ & $27 / 73$ \\
\hline
\end{tabular}

Table 1.5

Knifton 30 reported hydrocarboxylation of 1 -alkenes to give exclusively linear carboxylic esters in the presence of a variety of 
palladium complexes such as $\left[\mathrm{PdCl}_{2}\left(\mathrm{PPh}_{3}\right)_{2}\right]-\mathrm{SnCl}_{2},\left[\mathrm{PdCl}_{2}\right.$ (p$\left.\left.\left.\mathrm{CH}_{3} \mathrm{C}_{6} \mathrm{H}_{4}\right)_{3} \mathrm{P}\right)_{2}\right]-\mathrm{SnCl}_{2}$, $\left.\left[\mathrm{PdCl}_{2}\left(\mathrm{p}-\mathrm{CH}_{3} \mathrm{OC}_{6} \mathrm{H}_{4}\right)_{3} \mathrm{P}\right)_{2}\right]-\mathrm{SnCl}_{2}$, and $\left[\mathrm{PdCl}_{2}\left(\mathrm{PPh}_{3}\right)_{2}\right]-\mathrm{GeCl}_{2}$. For example, in the hydroesterification of

1-heptene the highest selectivity to methyl octanoate was obtained using $\left.\left[\mathrm{PdCl}_{2}\left(\mathrm{p}-\mathrm{ClC}_{6} \mathrm{H}_{5}\right)_{3} \mathrm{P}\right)_{2}\right]-\mathrm{SnCl}_{2}$, and the highest yield of methyloctanoate (78\%) was obtained using $\left.\left[\mathrm{PdCl}_{2}\left(\mathrm{p}-\mathrm{CH}_{3} \mathrm{C}_{6} \mathrm{H}_{4}\right)_{3} \mathrm{P}\right)_{2}\right]-\mathrm{SnCl}_{2}$. Correlation between the catalytic performance and either the size or electronic character of the coordinated ligands was not proposed.

Knifton found that $\left[\mathrm{PdCl}_{2}\left(\mathrm{PPh}_{3}\right)_{2}\right]-\mathrm{SnCl}_{2}$ was the best catalytic system. This gave a yield of $76 \%$, and selectivity of $87 \%$ to methyl octanoate on hydroesterification of 1-heptene, as shown in equation 1.13 .

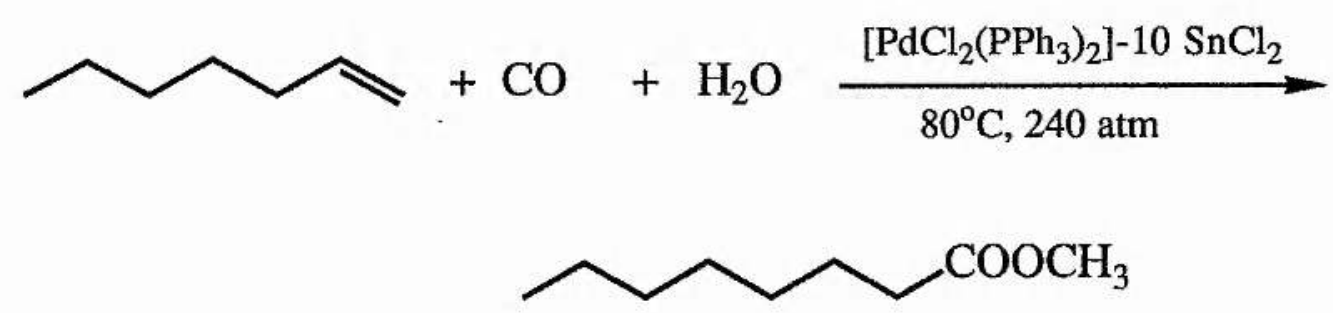

Equation 1.13

The high regioselectivity is observed to be relatively insensitive to parameters such as carbon monoxide pressure, solvent, and the nature of the coreactant, but is significantly influenced by the structure of the alkenes and the composition of the active catalyst. Thus in the absence of cocatalyst $\mathrm{SnCl}_{2}$, no regioselectivity was observed, i.e., equal amounts of linear and branched ester were obtained. Knifton observed that the catalyst $\left[\mathrm{PdCl}_{2}\left(\mathrm{PPh}_{3}\right)_{2}\right]-\mathrm{SnCl}_{2}$ also carbonylates linear and branched 1-alkenes, internal alkenes, and cyclic alkenes. Sterically hindered branched 1-alkenes in which the alkyl substituent is on the $\beta$ or $\gamma$ carbon atoms also undergo regioselective hydroesterification, with selectivity 
greater than $95 \%$.

Internal, disubstituted alkenes undergo hydroesterification more slowly than 1-alkenes. With these compounds the catalyst is no longer selective and gives both straight and branched chain products.

Knifton also observed that under identical reaction conditions used for hydroesterification of 1-heptene, when methanol was replaced by water as the nucleophile coreactant 1-heptene, conversion was greater than $95 \%$ and selectivity to octanoic acid was $86 \%$.

The mechanism of the $\mathrm{Pd}(\mathrm{II})$-catalysed hydroesterification of 1-alkenes as proposed by Knifton (Scheme 1.6), is based on both electronic and steric factors. According to the author the high $\pi$ acceptor strength of the phosphorus and of $\mathrm{SnCl}_{3}$ lowers the electron density of the palladium metal. This favours the formation of a palladium hydride species, as well as coordination of nucleophiles such as carbon monoxide and the alkene. To explain the observed selectivity in his studies Knifton proposed that bulky ligands like $\mathrm{PPh}_{3}$ and $\mathrm{SnCl}_{3}$ give rise to the sterically hindered palladium complex (A) which favours both anti-Markownikov $\mathrm{Pd}-\mathrm{H}$ addition (step 3) and high equilibrium concentrations of the less sterically hindered straight-chain $\sigma$-alkyl and $\sigma$-acyl platinum complexes such as D and F. Other evidence for the Pd-H mechanism was given by performing blank experiments i.e., in the absence of the substrate alkene, Knifton isolated the intermediate $\left[\mathrm{PdH}\left(\mathrm{SnCl}_{3}\right)\left(\mathrm{P}_{(}\left(\mathrm{C}_{6} \mathrm{H}_{5}\right)_{3}\right)_{2}\right]$ responsible for hydroesterification. Kingston and Scollary 31 have similarly reported the isolation of the palladium hydride complex. 


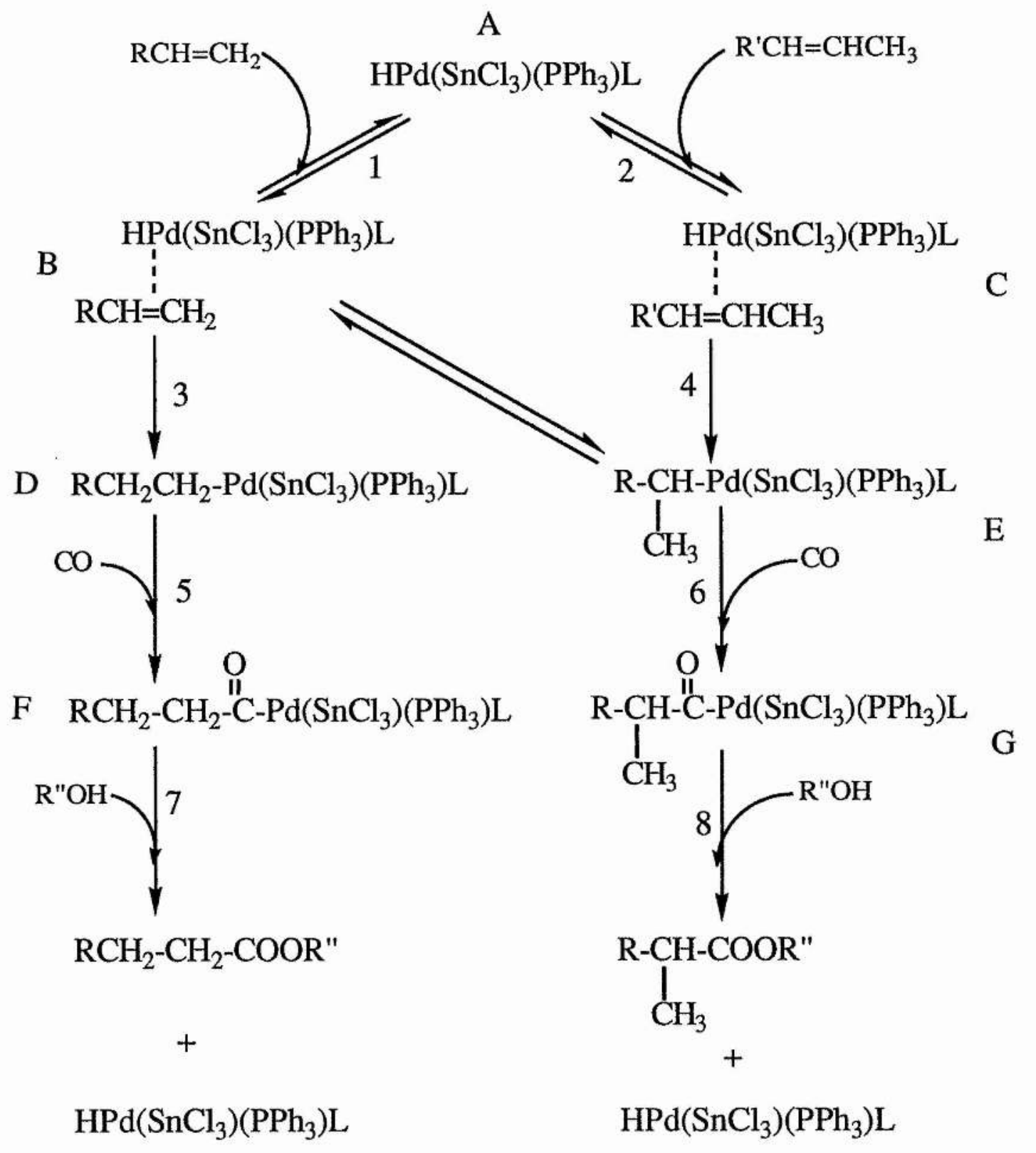

Scheme 1.6

Similarly, Terekhora and coworkers 32 reported high yield and high regioselectivity for linear acids upon hydrocarboxylation of alkenes in the presence of $\left[\mathrm{PdCl}_{2}\left(\mathrm{PPh}_{3}\right)_{2}\right]$. Addition of excess triphenyl phosphine improved further the yield and selectivity to straight chain acids ${ }^{14}$. Increase in selectivity, in some cases $>99 \%$, and yield was also 
observed upon addition of a cocatalyst for example, $\mathrm{SnCl}_{2}$ to the catalytic system 15 . With the same catalytic system it was observed 33 that hydrocarboxylation of internal alkenes for example, 2-pentene and cyclic alkenes for example, cyclohexene is slower than for 1-alkenes. For straight chain alkenes, replacing carbon monoxide with synthesis gas resulted in higher yield and regioselectivity 34 . However in the case of styrene this finding is reversed 35 . Lapidus and coworkers 36 reported that hydrocarboxylation of polybutadiene in the presence of $\left[\mathrm{PdCl}_{2}\left(\mathrm{PPh}_{3}\right)_{2}\right]$ and excess triphenylphosphine occured mainly at the pendant carbon-carbon double bond position. Further discussion about this work is carried out along with our work in Chapter 3.

\subsubsection{Rhodium catalysed reactions}

Hydrocarboxylation of alkenes in the presence of a rhodium catalyst and a halogen promoter also gives rise to both straight chain and branched chain carboxylic acids as do the other metals. Compared to other metals such as cobalt or nickel, rhodium catalysts operate at much lower pressures i.e., below 100 atmospheres. Reactions selective for linear carboxylic acids can be obtained under certain conditions. For example, Burke 37 reported that 1-hexene on hydrocarboxylation in the presence of $\left[\mathrm{RhCl}_{3}\right] .3 \mathrm{H}_{2} \mathrm{O}$, and the halide promoter $\mathrm{CH}_{3} \mathrm{I}$ gave $68 \%$ straight chain carboxylic acid; 1-heptanoic acid and 9.5\% 2-methylhexanoic acid (Equation 1.14).

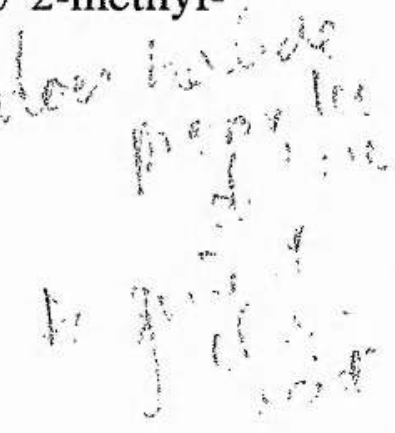




$$
\mathrm{CH}_{3}\left(\mathrm{CH}_{2}\right) \mathrm{CH}=\mathrm{CH}_{2}+\mathrm{CO}+\mathrm{H}_{2} \mathrm{O} \quad \stackrel{\left[\mathrm{RhCl}_{3}\right] \cdot 3 \mathrm{H}_{2} \mathrm{O}, \mathrm{CH}_{3} \mathrm{I}}{170^{\circ} \mathrm{C}, 20 \mathrm{~atm}}
$$

$\mathrm{CH}_{3}\left(\mathrm{CH}_{2}\right)_{3} \mathrm{CH}_{2} \mathrm{CH}_{2} \mathrm{COOH}+\mathrm{CH}_{3}\left(\mathrm{CH}_{2}\right)_{3} \mathrm{CH}(\mathrm{COOH}) \mathrm{CH}_{3}$

Equation 1.14

However the selectivity is not very high compared to palladium catalysts. The rate of hydrocarboxylation of terminal or internal alkenes can be increased by adding minor amounts of compounds of iron, cobalt or manganese ${ }^{38}$.

A British patent ${ }^{39}$ describes hydrocarboxylation of 1-Hexene in high conversion (80\%) and selectivity $(99 \%)$ to $C_{7}$ carboxylic acid using the rhodium complex $\mathrm{RhCl}_{3} \cdot 3 \mathrm{H}_{2} \mathrm{O}$ as catalyst in the presence of a halide promoter in acetic acid solvent. The selectivity to straight chain heptanoic acid was less than 25\% (Equation 1.15). In the absence of halide promoter no reaction occurred.

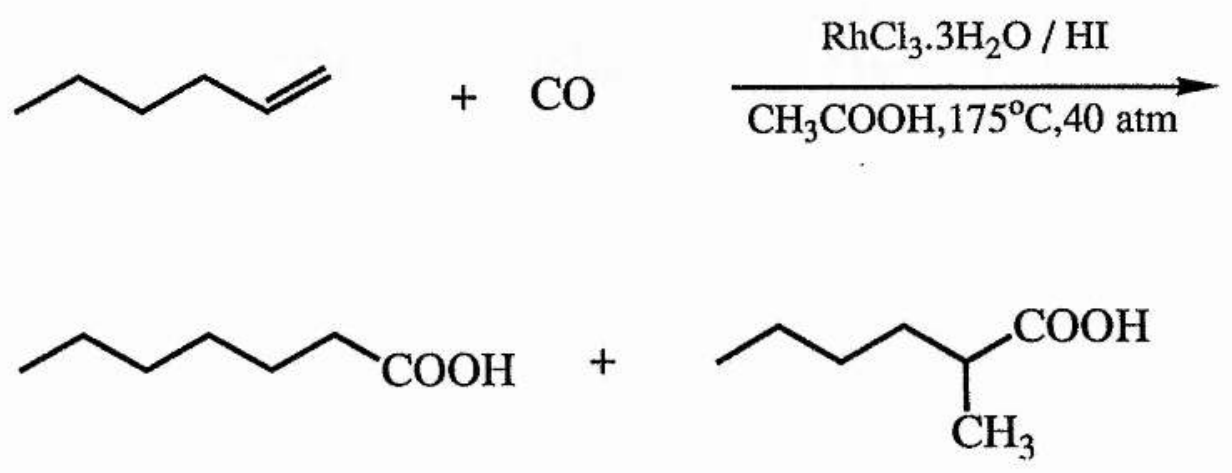

Equation 1.15 


\subsubsection{Reactions catalysed by other metal complexes}

\subsubsection{Platinum catalysed reactions}

Platinum compounds, e.g. $\mathrm{H}_{2}\left[\mathrm{PtCl}_{6}\right]$ in the presence of $\mathrm{SnCl}_{2}$, only catalyse the hydrocarboxylation of 1-alkenes, internal alkenes being relatively inert to hydrocarboxylation. Under drastic conditions 40 they gave low conversions and mixtures of products. Alkene isomerisation becomes the almost exclusive reaction.

Ligand stabilised platinum (II) along with group 14 metal halide complexes have been reported 41 to catalyse the homogeneous carbonylation of 1-alkenes to carboxylic acids or esters. For example, 1-heptene on hydroesterification in the presence of $\left[\mathrm{PtCl}_{2}\left(\mathrm{PPh}_{3} \mathrm{O}\right)\right]_{2}$ $\mathrm{SnCl}_{2}$ gave $86 \%$ yield and $98 \%$ selectivity to methyl octanoate (Equation 1.16). In the absence of cocatalyst no reaction took place.

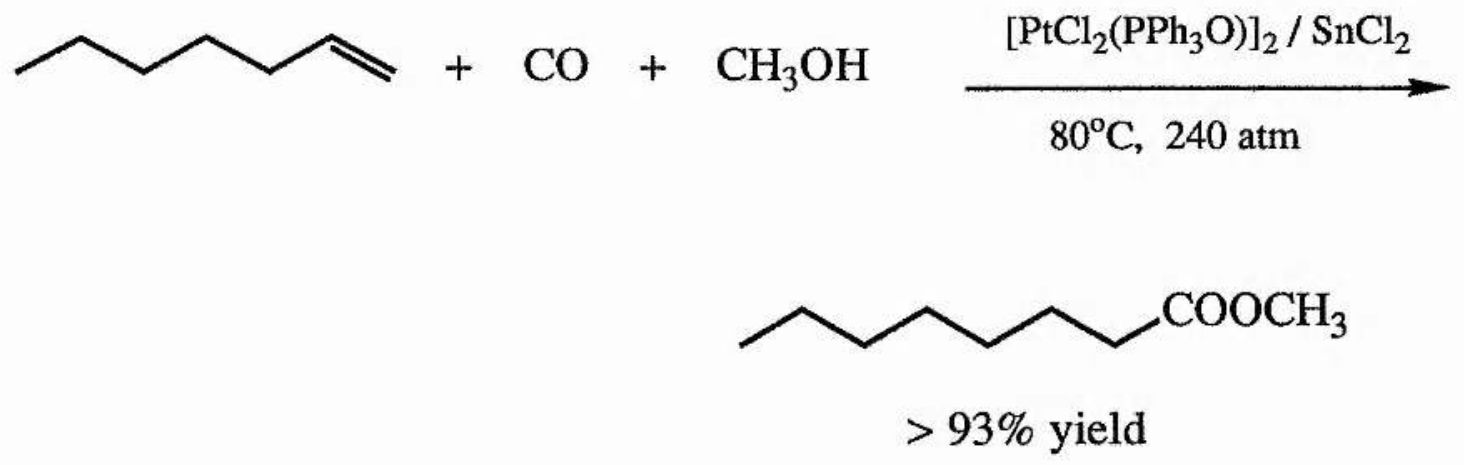

Equation 1.16

\subsubsection{Iridium catalysed reactions}

Iridium complexes function as catalysts for hydrocarboxylation of alkenes under reaction conditions very similar to those employed 
with rhodium complexes. The alkenes can be either terminal or internal and even with linear internal alkenes, a high proportion of terminal carboxylic acids are obtained. The iridium is most conveniently used in the form of an iridium trihalide. The iodide promoter can be used either as aqueous hydrogen iodide or as an alkyl iodide. Foster ${ }^{17}$ and coworkers obtained saturated acids on hydrocarboxylation of alkenes in the presence of the iridium complex catalyst $\left[\mathrm{HIr}(\mathrm{CO})_{2} \mathrm{I}_{2}\left(\mathrm{H}_{2} \mathrm{O}\right)\right]$. Studies on the progress of the reaction showed that the catalyst composition changed, with conversion of part of it to the less reactive species $\left[\operatorname{Ir}(\mathrm{CO})_{3} \mathrm{I}\right],\left[\operatorname{Ir}(\mathrm{CO})_{3} \mathrm{I}_{3}\right],\left[\operatorname{Ir}(\mathrm{CO})_{2} \mathrm{I}_{4}\right]^{-}$etc., species which lowered the reaction rate significantly.

\subsubsection{Copper catalysed reations}

In concentrated sulphuric acid, salts of copper(I) are active catalysts for the hydrocarboxylation of alkenes under very mild conditions $\left(50^{\circ} \mathrm{C}, 1 \mathrm{~atm}\right)$. The final products are tertiary carboxylic acids $^{42}$ (Equation 1.17).

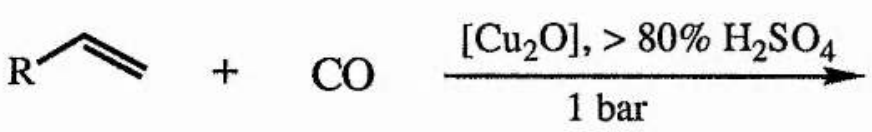<smiles>[R]C([R])(C)C(=O)O</smiles>

Where $\mathrm{R}^{1}$ and $\mathrm{R}^{2}=\mathrm{H}$, alkyl groups

\section{Equation 1.17}

It has also been observed that, in the presence of saturated hydrocarbons containing a tertiary hydrogen, e.g. methylcyclohexane, which was used 
as the solvent, the reaction occured both on this hydrocarbon and on the alkene (Equation 1.18).

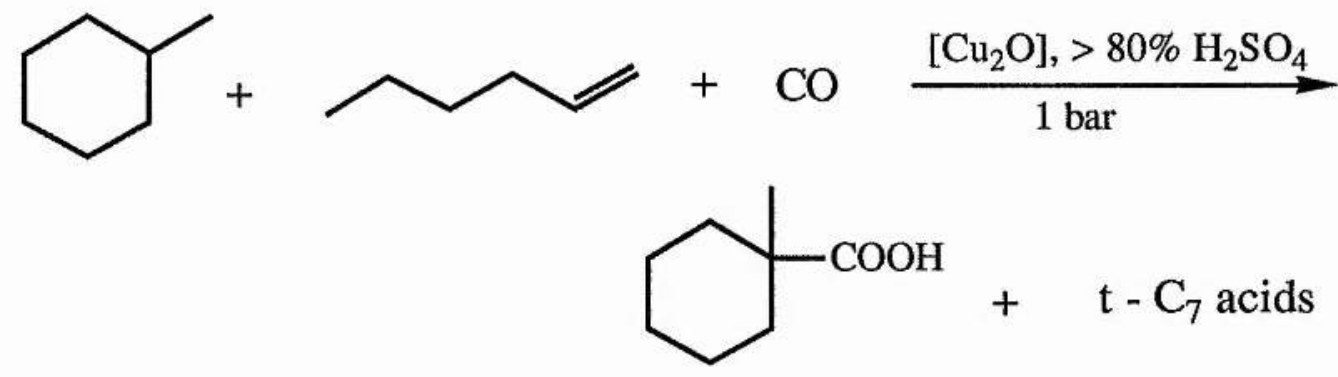

Equation 1.18

The copper-catalysed hydrocarboxylation of alkenes involves first the formation of a carbonium ion. This carbonium ion rapidly rearranges to more stable carbonium ions which are trapped by carbon monoxide.The role of the copper(I) compound, presumably $\left[\mathrm{Cu}(\mathrm{CO})_{3}\right]^{+}$, is to deliver carbon monoxide to the carbonium ion (Scheme 1.7). This species only exists at sulphuric acid concentrations greater than $80 \%$.

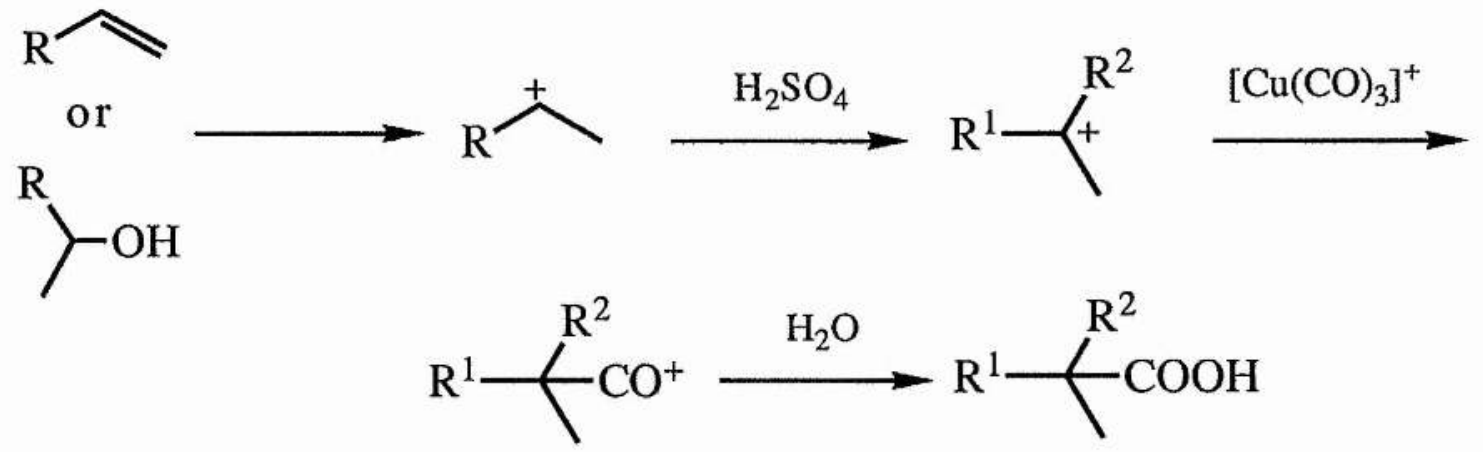

Scheme 1.7

Souma and Sano 43 obtained similar results on hydrocarboxylation 
Souma and Sano 43 obtained similar results on hydrocarboxylation of alkenes using copper carbonyl $\left[\mathrm{Cu}(\mathrm{CO})_{\mathrm{n}}{ }^{+}\right]$and silver carbonyl $\left[\mathrm{Ag}(\mathrm{CO})_{2}{ }^{+}\right]$catalysts at room temperature and at atmospheric carbon monoxide presssure in $\mathrm{BF}_{3}-\mathrm{H}_{2} \mathrm{O}$ solutions. For example, 1-hexene gave a mixture of 2,2-dimethylpentanoic acid and 2-methyl-2-ethylbutanoic acid. Dienes also reacted with carbon monoxide to give mixtures of monocarboxylic acids, and dicarboxylic acids. The yield of terminal carboxylic acid and the reaction rate decrease with a decrease in $\mathrm{BF}_{3}$ concentration. Saturated hydrocarbons also react with carbon monoxide in the presence of alkenes. In this case the hydride ion is abstracted from the saturated hydrocarbon by the carbonium ion formed from the alkene. Then the carbonium ion forms the tertiary carboxylic acid. Saturated hydrocarbons which have no tertiary hydrogens do not react with carbon monoxide. Hydride transfer takes place only in concentrated $\mathrm{BF}_{3}-\mathrm{H}_{2} \mathrm{O}$ solutions.

\subsection{Hydrocarboxylation of dienes}

\section{$\underline{\text { Non -conjugated dienes }}$}

Non conjugated dienes exhibit a similar behaviour to that of 1-alkenes. Depending upon the catalyst, non conjugated dienes can give rise to dicarboxylic acids and/or unsaturated monocarboxylic acids. The catalysts most employed for hydrocarboxylation of non conjugated dienes contain cobalt. However nickel and palladium also show some catalytic activity. 


\subsubsection{Cobalt catalysed reactions.}

With the cobalt catalyst, $\left[\mathrm{Co}_{2}(\mathrm{CO})_{8}\right]$ non conjugated dienes give dicarboxylic and saturated monocarboxylic acids 44 on hydrocarboxylation (see Table 1.6).

\subsubsection{Nickel catalysed reactions}

Non conjugated dienes react with stoichiometric amounts of the nickel complex $\left[\mathrm{Ni}(\mathrm{CO})_{4}\right]$ to give mono carboxylic acids. However the yields are not very high 45 (Table 1.6).

\begin{tabular}{|c|c|c|c|c|}
\hline Diene & Catalyst & Conditions & Product & Yield \\
\hline $\begin{array}{c}\text { 1,5-Hexa- } \\
\text { diene }\end{array}$ & $\mathrm{Co}_{2}(\mathrm{CO})_{8}$ & $\begin{array}{l}210^{\circ} \mathrm{C} \\
250 \mathrm{~atm}\end{array}$ & $\begin{array}{l}\text { Octanedioic } \\
\text { acid } \\
\text { Saturated } \\
\mathrm{C}_{7^{-}} \\
\text {monocarbo- } \\
\text { xylic acids }\end{array}$ & $34 \%$ \\
\hline $\begin{array}{c}\text { 1,5-Hexa } \\
\text { diene }\end{array}$ & $\mathrm{Ni}(\mathrm{CO})_{4}$ & $180^{\circ} \mathrm{C}$ & $\begin{array}{l}\text { 2-methyhex- } \\
\text { 5-enoic acid }\end{array}$ & $20 \%$ \\
\hline
\end{tabular}

Table 1.6 


\subsubsection{Palladium catalysed reactions}

If the double bonds are suitably juxtaposed intramolecular reactions are observed. For example, in the presence of the palladium complex, $\left[\mathrm{PdI}_{2}\left(\mathrm{PBu}_{3}\right)_{2}\right]$, a formal hydrocarboxylation followed by an intramolecular cyclisation takes place (Equation 1.19).

$\int_{\mathrm{CH}_{2} \mathrm{CH}=\mathrm{CH}_{2}}^{\mathrm{CH}_{2} \mathrm{CH}=\mathrm{CH}_{2}}+\mathrm{CO}+\mathrm{CH}_{3} \mathrm{OH}$
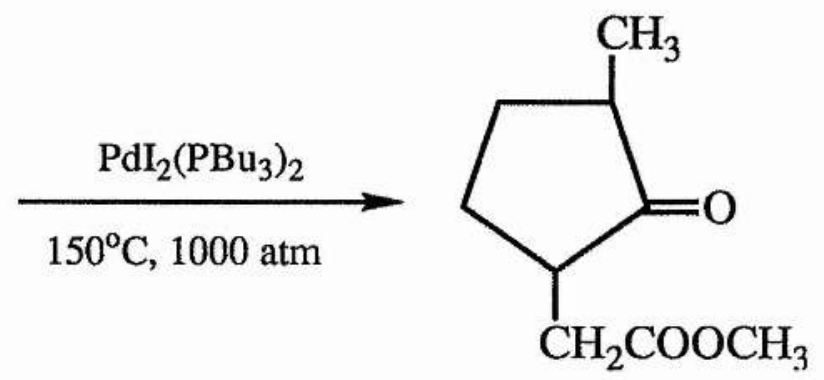

Equation 1.19

1,5-Cyclooctadiene gave methyl cyclo-oct-4-ene-1-carboxylate in $45 \%$ yield and the dicarboxylic esters in $30 \%$ yield 46 (Equation 1.20 ). It was observed that, as the reaction proceeded, the concentration of the unsaturated monoester increased rapidly to a maximum and then gradually decreased as the concentration of diesters increased.

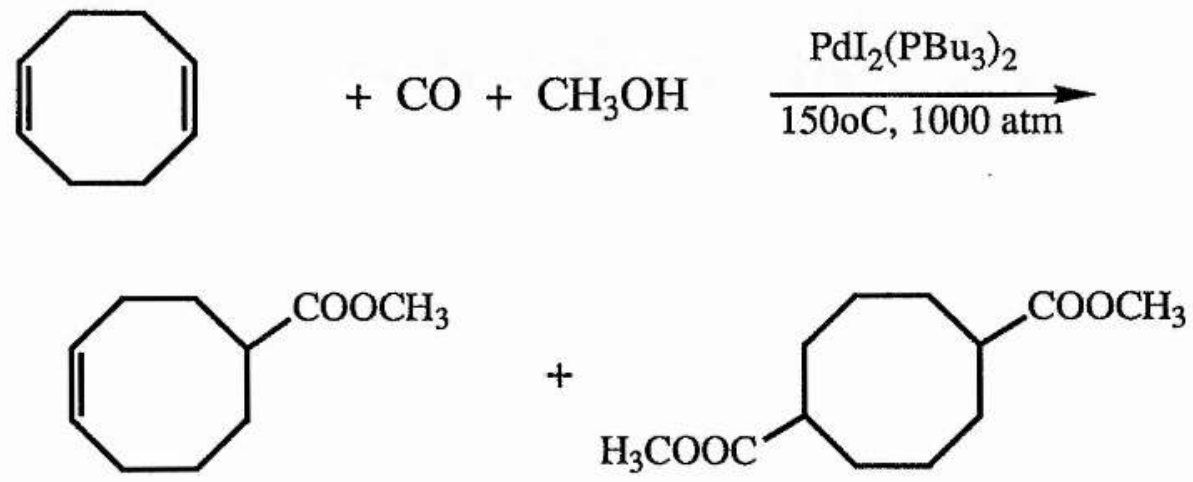

Equation 1.20 
With tri-alkenes as substrates it is possible to target hydrocarboxylation at the required double bond position. For example, it was not previously possible to convert 1,5,9-cyclododecatriene into 4,8-cyclododecadiene1-carboxylic acid, or its esters, or to the corresponding polycarboxylated compounds, since acenapthene derivatives and polymerisation products were formed instead. Bittler and coworkers 47 reported that in the presence of $\left[\mathrm{PdCl}_{2}\left(\mathrm{PPh}_{3}\right)_{2}\right]$ as catalyst, it was possible to cause one, two or all three double bonds in cyclododecatriene to react depending on the reaction conditions to give mainly the mono, di-, and triester; the monoester could be obtained without any byproducts (Equation 1.21 ) at low temperatures $\left(60^{\circ} \mathrm{C}\right)$.

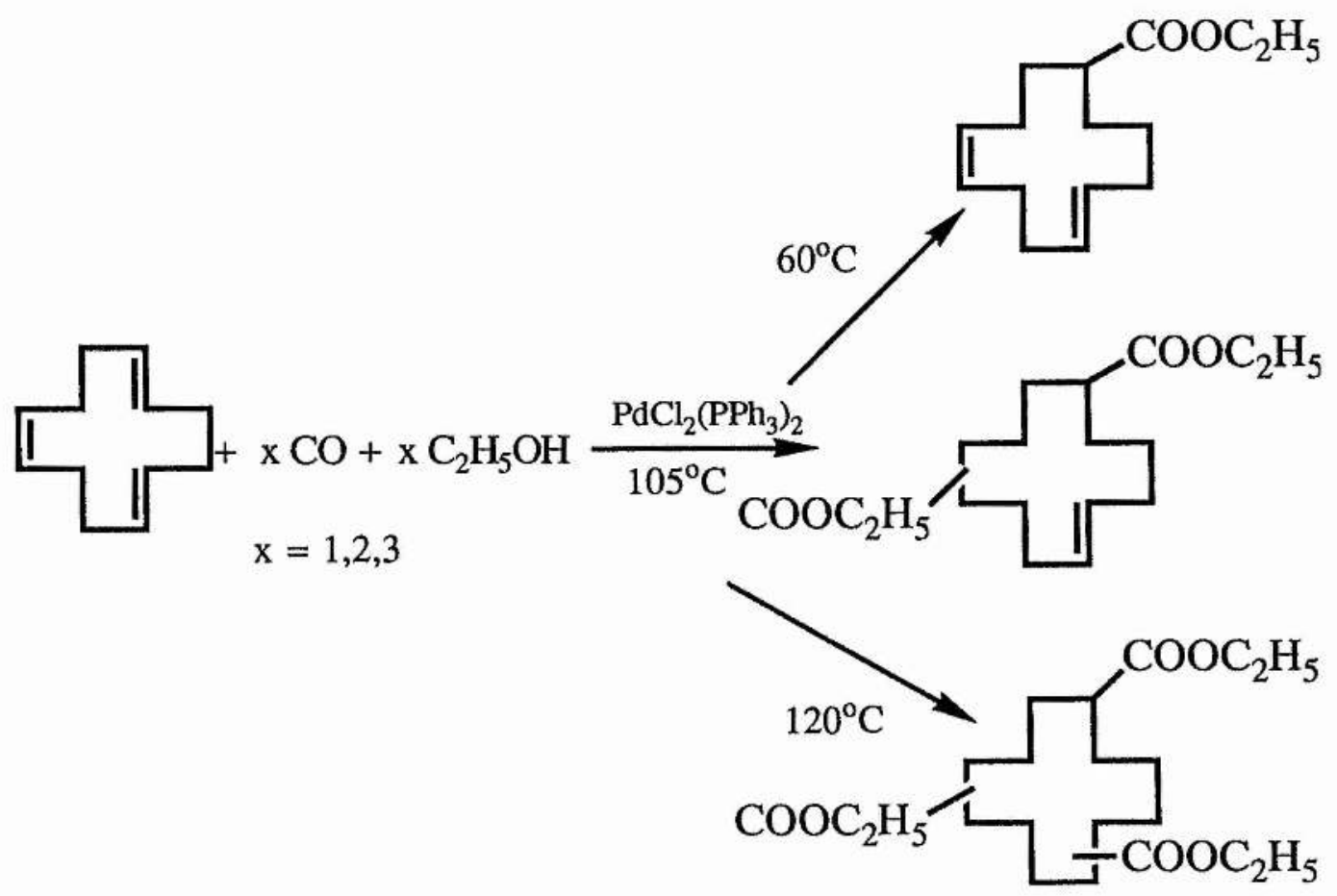

Equation 1.21 
$\underline{\text { Conjugated Dienes }}$

Under the usual high temperature conditions in the presence of nickel and cobalt catalysts, conjugated dienes fail to produce the expected hydrocarboxylation products. For example, conjugated 1,3dienes undergo a formal 1,4-addition of the elements of formic acid to give $\beta, \gamma$-unsaturated acids. The most used catalysts for hydrocarboxylation of conjugated dienes are the cobalt complex, $\left[\mathrm{Co}_{2}(\mathrm{CO})_{8}\right]$, and complexes of palladium.

\subsubsection{Cobalt catalysed reactions}

Butadiene reacted in the presence of $\left[\mathrm{Co}_{2}(\mathrm{CO})_{8}\right]$ to give the rearranged unsaturated acid in high yield (Equation 1.22). By increasing the temperature to $210^{\circ} \mathrm{C}$, reasonable yields of diacids, essentially adipic acid are obtained.

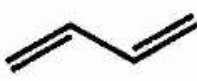

$$
\begin{aligned}
& \mathrm{CO}+\mathrm{H}_{2} \mathrm{O} \underset{160^{\circ} \mathrm{C}, 250 \mathrm{~atm}}{\stackrel{\left[\mathrm{Co}_{2}(\mathrm{CO})_{8}\right] / \mathrm{py}}{\longrightarrow}} \mathrm{COOH} \\
& \stackrel{210^{\circ} \mathrm{C}}{\mathrm{HOOC}} \sim \sim_{\mathrm{COOH}}
\end{aligned}
$$

Equation 1.22

Under hydrocarboxylation conditions, butadiene may also dimerise to vinyl cyclohexene 48 . The solvent used has a great effect on the proportion of dicarboxylic derivatives formed. Pyridine seems to determine the preferential formation of these compounds $49,50,51$, 
whereas with other solvents like dioxane, acetone, or isoquinoline, the main product is 3-pentenoic acid.

\subsubsection{Palladium catalysed reactions}

Palladium has been used as catalyst in the presence of methanol or ethanol at relatively low temperature $\left(56-150^{\circ} \mathrm{C}\right)$ and very high carbon monoxide pressures (1000 atm). Unsaturated monocarboxylic esters were obtained.

\begin{tabular}{|c|c|c|c|}
\hline Diene & Catalyst & Conditions & Product (Yield) \\
\hline Butadiene ${ }^{52}$ & $\mathrm{PdCl}_{2}\left(\mathrm{PPh}_{3}\right)_{2}$ & $\begin{array}{c}120-140^{\circ} \mathrm{C} \\
700 \mathrm{~atm}\end{array}$ & $\begin{array}{c}\text { 3-pentenoic acid } \\
(70 \%)\end{array}$ \\
\hline Butadiene $^{53}$ & $\mathrm{Pd}\left(\mathrm{PBu}_{3}\right)_{2}$ & $\begin{array}{c}150^{\circ} \mathrm{C}, \\
1000 \mathrm{~atm}, \\
\mathrm{CH}_{3} \mathrm{OH}\end{array}$ & $\begin{array}{c}\text { Methyl 3-pento- } \\
\text { noate ( } 73 \%) \\
\text { Methyl 4-pento- } \\
\text { noate (1\%) } \\
\text { 4-Vinylcyclo- } \\
\text { hexene(1-2\%) }\end{array}$ \\
\hline $\begin{array}{c}\text { 1,3-Cyclohexa- } \\
\text { diene } 54\end{array}$ & $\mathrm{PdCl}_{2}$ & $\begin{array}{c}100^{\circ} \mathrm{C} \\
1000 \mathrm{~atm} \\
\mathrm{C}_{2} \mathrm{H}_{5} \mathrm{OH}\end{array}$ & $\begin{array}{c}\text { Ethyl 2-cyclo- } \\
\text { hexene carboxy- } \\
\text { late }(80 \%)\end{array}$ \\
\hline $\begin{array}{c}\text { 1,3-Penta- } \\
\text { diene } 52\end{array}$ & $\mathrm{Na}_{2} \mathrm{PdI}_{4}$ & $\begin{array}{c}70^{\circ} \mathrm{C}, \\
1000 \mathrm{~atm}, \\
\mathrm{CH}_{3} \mathrm{OH} \\
\end{array}$ & $\begin{array}{c}\text { Methyl-2- } \\
\text { methylpenteno- } \\
\text { ate }(34 \%)\end{array}$ \\
\hline
\end{tabular}

Table 1.7

With palladium catalysts, even small changes in the type of ligand bound 
to the palladium markedly influenced the composition of the reaction products (Table 1.7).

\subsubsection{Nickel catalysed reactions}

Stoichiometric hydrocarboxylation of butadiene ${ }^{4}$ first formed a vinyl cyclohexene which then gave complex mixtures of mono and dicarboxylic acids (Equation 1.23).

$$
\begin{aligned}
& +\mathrm{CH}_{3} \mathrm{COOH}+\mathrm{H}_{2} \mathrm{O}+\left[\mathrm{Ni}(\mathrm{CO})_{4}\right] \underset{165^{\circ} \mathrm{C}}{\longrightarrow} \longrightarrow \\
& \left\{\begin{array}{l}
\text { Complex mixtures of mono } \\
\text { and dicarboxylic acids }
\end{array}\right\} \stackrel{\mathrm{CH}_{3} \mathrm{OH}}{\longrightarrow} \mathrm{C}_{8} \mathrm{H}_{13} \mathrm{COOCH}_{3}+\mathrm{C}_{12} \mathrm{H}_{20} \mathrm{O}_{4}
\end{aligned}
$$

Equation 1.23

The monocarboxylic acids on esterification with methanol yielded $\mathrm{C}_{8} \mathrm{H}_{13} \mathrm{COOCH}_{3}$, while a higher boiling fraction containing dicarboxylic acids gave on esterification the methyl ester of $\mathrm{C}_{12} \mathrm{H}_{20} \mathrm{O}_{4}$.

Catalytic hydrocarboxylation of butadiene 55 in the presence of $\left[\mathrm{Ni}(\mathrm{CO})_{4}\right]$ and a small amount of hydroquinone gave a mixture of 2-(3-cyclohexen-1-yl)propanoic acid and 2-(carboxycyclohexyl) propanoic acid (Equation 1.24). 

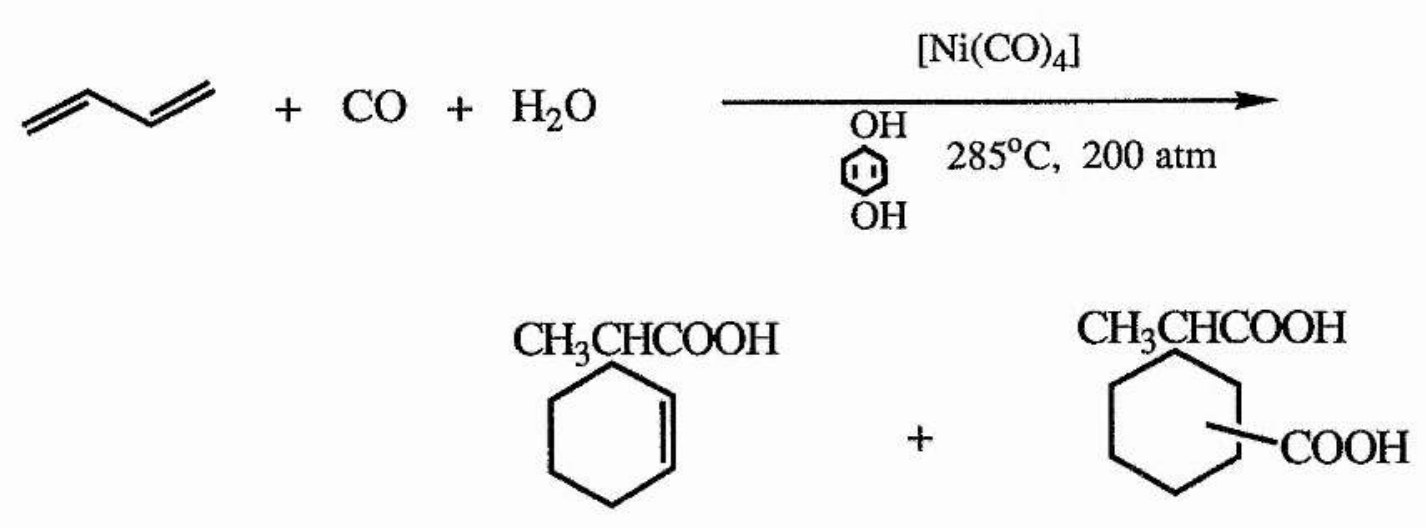

Equation 1.24

\subsubsection{Rhodium catalysed reactions}

Garlaschelli and coworkers 56 reported that by varying both the ligand attached to the catalyst and the physical parameters the yield and selectivity of isoprene hydrocarboxylation to give 4-methyl-3-pentenoic acid (pyroterebic acid) or its lactone derivative $\gamma, \gamma$-di-methyl- $\gamma$ butyrolactone can be altered (Equation 1.25).

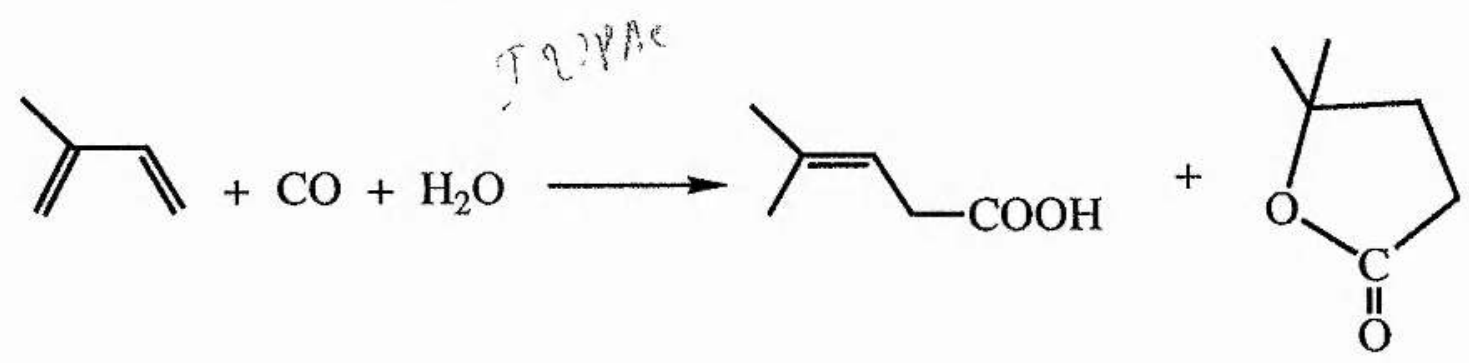

Equation 1.25

When hydrocarboxylation of isoprene was carried out with $[\mathrm{PPN}]\left[\mathrm{Rh}\left(\mathrm{CO}_{2}\right) \mathrm{X}_{2}\right]$ [ $\mathrm{PPN}=$ bis (triphenylphosphine iminium; $\left.\mathrm{X}=\mathrm{Cl}, \mathrm{I}\right]$ in the presence of aqueous $\mathrm{HI}$ as cocatalyst and tetrahydrofuran as the solvent, the products markedly depended on the HI/Rh ratio and 
temperature. Thus the use of low $\mathrm{HI} / \mathrm{Rh}$ ratio and lower temperature greatly depressed the formation of the lactone, and the pyroterebic acid could be obtained with an overall selectivity of $c a 85 \%$. Conversely high $\mathrm{HI} / \mathrm{Rh}$ ratio and higher temperature greatly favoured the formation of the $\gamma, \gamma$-di-methyl- $\gamma$-butyrolactone. Increase of either one or both of these parameters markedly lowered the selectivity towards oxygenated products owing to a steeper increase in the rate of the hydrogenation of isoprene to give an isomeric mixture of methyl butenes.

On the other hand with the $\left[\mathrm{Rh}_{4}(\mathrm{CO})_{12}\right] / \mathrm{HI}$ catalytic system, lactone was always obtained as the major product with little pyroterebic acid. An increase in temperature and/or $\mathrm{HI} / \mathrm{Rh}$ ratio lowered the selectivity. With a sub-stoichiometric isoprene/water ratio the system essentially catalysed the complete conversion of isoprene into $\gamma, \gamma$ dimethyl- $\gamma$-butyrolactone. When the isoprene/water molar ratio was increased so that water became the sub-stoichiometric reagent, the relative amount of pyroterebic acid present progressively increased at the expense of the lactones.

\subsection{Hydrocarboxylation of functionalised alkenes}

A fairly large number of unsaturated substrates containing various functional groups can be hydrocarboxylated in the presence of nickel, cobalt, and palladium catalysts. The functional groups in the unsaturated molecules are mainly halogens, carboxyl, carboalkoxy, and cyano groups. The products formed in these reactions are mixtures of isomeric esters or acids. Usually the reaction proceeds with the retention of the functional group, but in some cases, for example, when 
the functional group in the unsaturated molecule is a hydroxyl group, hydrocarboxylation in the presence of cobalt catalysts $\left[\mathrm{Co}_{2}(\mathrm{CO})_{8}\right]$ does not give the expected products but gives lactones due to intramolecular cyclisation.

\subsubsection{Cobalt catalysed reactions}

Using $\left[\mathrm{Co}_{2}(\mathrm{CO})_{8}\right]$ in the presence of $\left(\mathrm{C}_{6} \mathrm{H}_{5}\right)_{2} \mathrm{PCH}_{2} \mathrm{CH}_{2} \mathrm{P}\left(\mathrm{C}_{6} \mathrm{H}_{5}\right)_{2}$ as catalyst, acrylic acid upon hydrocarboxylation in ethanol gave $48 \%$ of $\left(\mathrm{CH}_{2} \mathrm{COOC}_{2} \mathrm{H}_{5}\right)_{2}$ and $43 \%$ of $\mathrm{HOOCCH}_{2} \mathrm{CH}_{2} \mathrm{COOC}_{2} \mathrm{H}_{5}$. Without $\left(\mathrm{C}_{6} \mathrm{H}_{5}\right)_{2} \mathrm{PCH}_{2} \mathrm{CH}_{2} \mathrm{P}\left(\mathrm{C}_{6} \mathrm{H}_{5}\right)_{2}$ the highest yields were $25.5 \%$ and $73 \%$ respectively 57 (Equation 1.26).

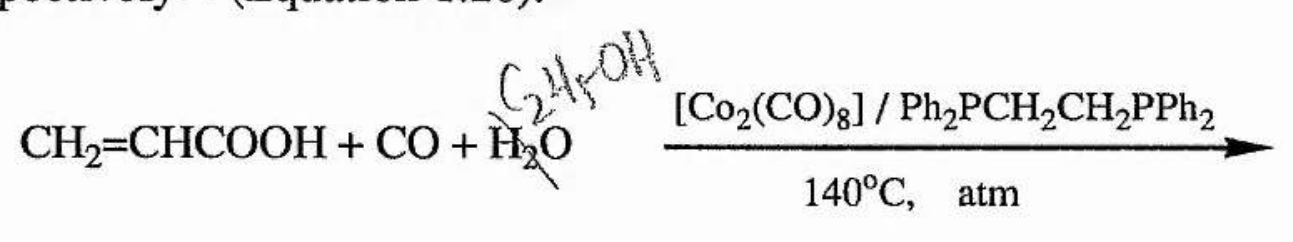

$\left(\mathrm{CH}_{2} \mathrm{COOC}_{2} \mathrm{H}_{5}\right)_{2}+\mathrm{HOOCCH}_{2} \mathrm{CH}_{2} \mathrm{COOC}_{2} \mathrm{H}_{5}$

di.....

Equation 1.26

In the presence of a $\left[\mathrm{Co}_{2}(\mathrm{CO})_{8}\right] /$ pyridine complex, isomeric hexenoic acids gave mixtures of $\mathrm{C}_{7}$-dicarboxylic acid with an isomeric distribution of the hydrocarboxylation product. Only in the case of 5 -hexenoic acid, was the unbranched $\mathrm{C}_{7}$-dicarboxylic acid the main product. With other isomeric hexenoic acids, for example 2-hexenoic acid, propyl succinic acid was the main isomer in the resulting mixture of dicarboxylic acids. It was proposed ${ }^{58}$ that cobalt carbonyl forms a five membered ring complex with the unsaturated carboxylic acid 
especially in the case of the pyridinium or alkali salt of the unsaturated acid. This stabilised isomeric cobalt intermediate would lead to the alkyl succinic acid or ester as the main isomeric product.

Pyridine and hydrogen gas improve conversions in the hydrocarboxylation of substrates like acrylonitrile 59 and methyl acrylate 60 in the presence of $\left[\mathrm{Co}_{2}(\mathrm{CO})_{8}\right]$.

\subsubsection{Palladium catalysed reactions}

Particularly good yields of esters are obtained by reacting vinyl chloride in the presence of $\left[\mathrm{PdCl}_{2}\left(\mathrm{PPh}_{3}\right)_{2}\right]$ and $\mathrm{HCl}^{47}$ in ethanol (Equation 1.27).

$$
\begin{aligned}
& \mathrm{Cl}+\mathrm{CO}+\mathrm{C}_{2} \mathrm{H}_{5} \mathrm{OH} \underset{90-120^{\circ} \mathrm{C}, 700 \mathrm{~atm}}{\stackrel{\mathrm{PdCl}_{2}\left(\mathrm{PPh}_{3}\right)_{2} / \mathrm{HCl}}{\longrightarrow}} \stackrel{\substack{\mathrm{COOC}_{2} \mathrm{H}_{5} \\
(80 \%)}}{\stackrel{\mathrm{Cl}}{\longrightarrow}} \\
& \mathrm{Cl} \mathrm{COOC}_{2} \mathrm{H}_{5}
\end{aligned}
$$

\section{Equation 1.27}

Frankel and Thomas 61 obtained 9(10) carboxystearic acids in high yields in the presence of a catalytic mixture of palladium (II) chloride and triphenylphosphine (Equation 1.28). 


$$
\begin{array}{r}
\mathrm{CH}_{3}\left(\mathrm{CH}_{2}\right)_{7} \mathrm{CH}=\mathrm{CH}\left(\mathrm{CH}_{2}\right)_{7} \mathrm{COOH} \underset{150^{\circ} \mathrm{C}, 272 \mathrm{~atm}}{\stackrel{\mathrm{PdCl}_{2} / \mathrm{PPh}_{3}}{\longrightarrow}} \\
\underset{\mathrm{CH}_{3}\left(\mathrm{CH}_{2}\right)_{7} \mathrm{CH}-\mathrm{Y}}{\mathrm{CH}\left(\mathrm{CH}_{2}\right)_{7} \mathrm{COOH}}
\end{array}
$$

$$
\text { When } \begin{aligned}
X & =\mathrm{H}, \mathrm{Y}=\mathrm{COOH} \\
X & =\mathrm{COOH}, \mathrm{Y}=\mathrm{H}
\end{aligned}
$$

\section{Equation 1.28}

Diels-Alder adducts such as the cyclohexene derivatives (Equation 1.29)

$$
\mathrm{CO}+\mathrm{C}_{2} \mathrm{H}_{5} \mathrm{OH} \underset{\operatorname{CoOC}_{2} \mathrm{H}_{5}}{\stackrel{\mathrm{PdCl}_{2}\left(\mathrm{PPh}_{3}\right)_{2}}{\longrightarrow}}
$$

\section{Equation 1.29}

and the corresponding norbornene derivative, which readily dissociate into their components at high temperatures, were effectively hydrocarboxylated with $\left[\mathrm{PdCl}_{2}\left(\mathrm{PPh}_{3}\right)_{2}\right]$ (Equation 1.30). 


$$
\mathrm{CO}+\mathrm{C}_{2} \mathrm{H}_{5} \mathrm{OH} \underset{0^{\circ} \mathrm{C}, 700 \mathrm{~atm}}{\stackrel{\mathrm{PdCl}_{2}\left(\mathrm{PPh}_{3}\right)_{2}}{\longrightarrow}} \stackrel{\mathrm{H}_{5} \mathrm{C}_{2} \mathrm{OOC}}{\mathrm{COOC}_{2} \mathrm{H}_{5}}
$$

Equation 1.30

They report that a mixture of $\mathrm{PdCl}_{2}$ and triphenylphosphine proved to be a more active and efficient catalytic system than preformed $\left[\mathrm{PdCl}_{2}\left(\mathrm{PPh}_{3}\right)_{2}\right]$ in increasing the yield and reducing the time of the reaction.

\subsubsection{Reactions catalysed by other metal complexes.}

\subsubsection{Iron catalysed reactions}

Recently, a fully catalytic regioselective hydrocarboxylation of acrylic acid to methyl malonic acid in the presence of $\left[\mathrm{Fe}(\mathrm{CO})_{5}\right]$ has been reported by Brunet and Passedargue 62 (Equation 1.31). This is the first reported use of iron in regioselective hydrocarboxylation.

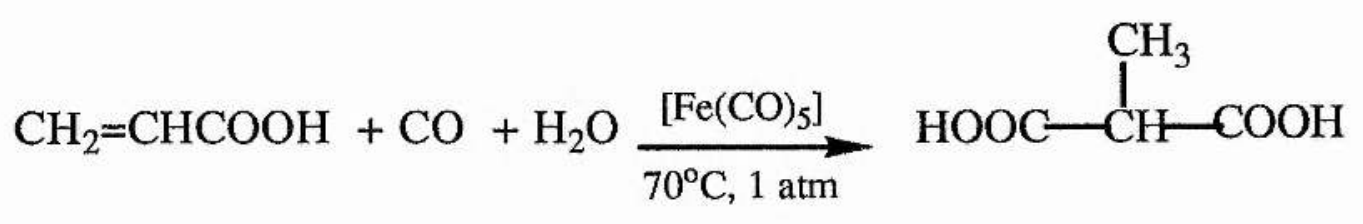

Equation 1.31 
This reaction by $\left[\mathrm{Fe}(\mathrm{CO})_{5}\right]$ was carried out in the presence of a base $\mathrm{Ca}(\mathrm{OH})_{2}$ in a $\mathrm{H}_{2} \mathrm{O}$-iPrOH mixture as solvent at $70^{\circ} \mathrm{C}$ under one atmosphere of carbon monoxide. Increase in carbon monoxide pressure inhibited the reaction suggesting that carbon monoxide dissociation did not take place at higher carbon monoxide pressure (Equation 1.32).

$\left[\mathrm{HFe}(\mathrm{CO})_{4}\right]^{-} \longrightarrow\left[\mathrm{HFe}(\mathrm{CO})_{3}\right]^{-}+\mathrm{CO}$

Equation 1.32

The proposed mechanism is shown in Scheme 1.8.

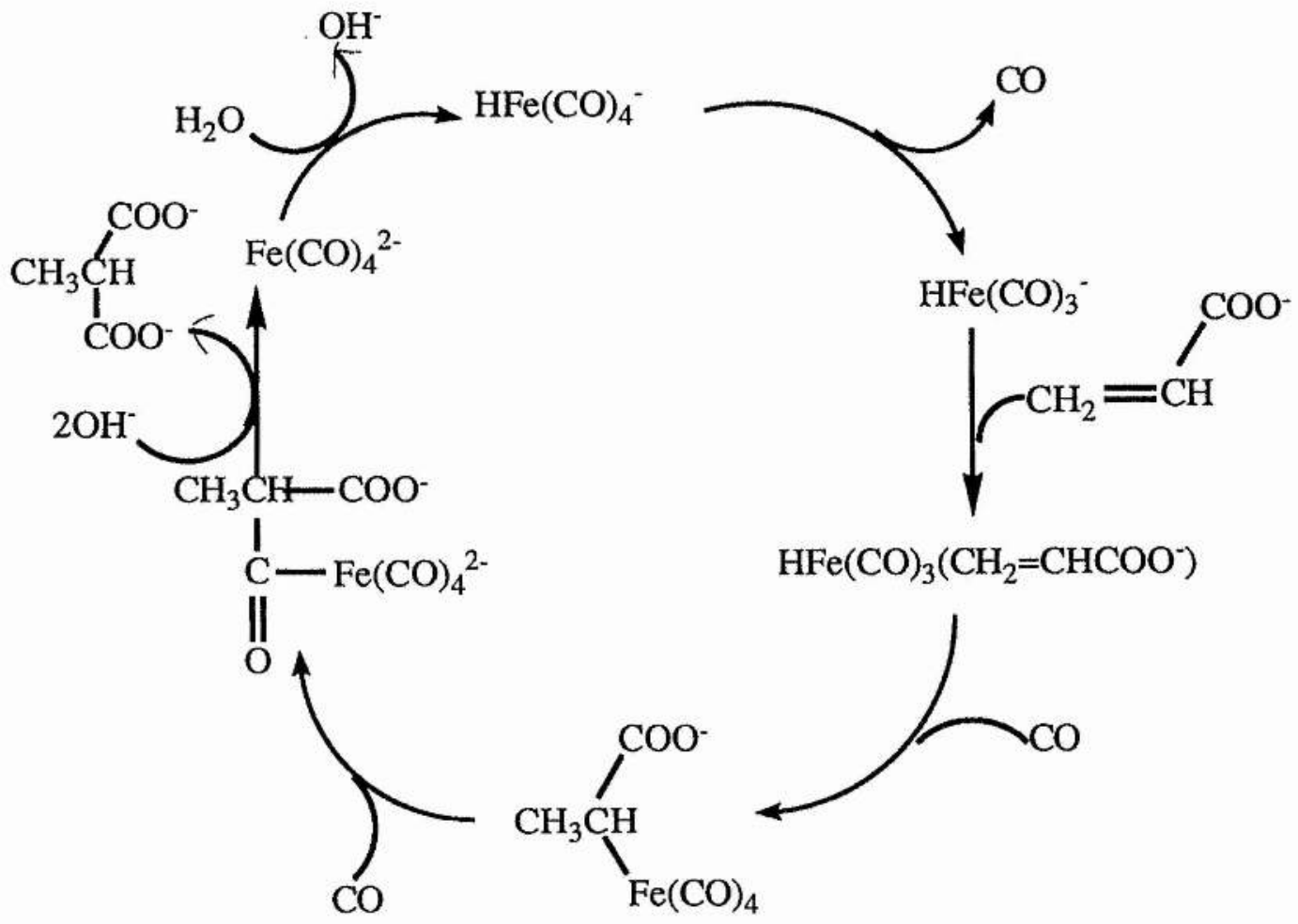

Scheme 1.8 


\subsection{Asymmetric hydrocarboxylation}

Asymmetric hydrocarboxylation, in principle, could have enormous importance for synthesising important chemicals, as by making chiral catalysts through the use of chiral ligands, stereoselectivity can be obtained. There are certain problems associated 63 with the synthesis however, due to the mechanistic complexity of the reactions, as itemised below:

1. the catalytic cycles of the reaction involve many steps.

2. the structures of the active catalyst species are strongly effected by reaction conditions, ratio of carbon monoxide to hydrogen, alcohol or water, and ratios of central transition metals to chiral ligands.

3. the regioselectivites of the reactions producing the desired optically active compounds (e.g., branched acids from 1-alkenes) are not always high.

4. very high carbon monoxide pressures ( 300- 700atm) are usually necessary to obtain high optical yields.

For asymmetric hydrocarboxylation, palladium has been exclusively employed as the metal and DIOP (Figure 1.3) type chiral diphosphines the most common ligands.

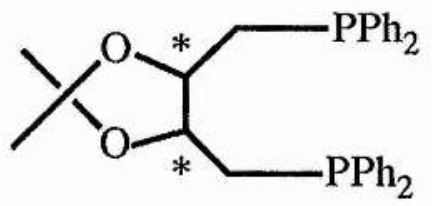

DIOP

Figure 1.3

Consiglio ${ }^{64}$ reported asymmetric hydrocarboxylation of alkenes 
to give high optical yields of branched esters in the presence of a $\left[\mathrm{PdCl}_{2} /(-) \mathrm{DIOP}\right]$ and $\mathrm{PPh}_{3}$ catalytic system. The reaction took place at a temperature of $100^{\circ} \mathrm{C}$, but required 400 atmospheres of carbon monoxide pressure. For example, $\alpha$-methyl styrene catalysed by $\left[\mathrm{PdCl}_{2} /(-)\right.$-DIOP] gave the ester of 3-phenylbutanoic acid with an optical purity of $\sim 60 \%$. Some ethyl-2-methyl-2-phenylpropanoate was also obtained. The ratio of (-)DIOP to palladium exerted a considerable influence on stereoselectivity for example, a ratio of 0.5 gave a better result than a ratio of 1 . Also monophosphines lead to predominant formation of the internal ester, while (-)-DIOP gave mainly the terminal ester.

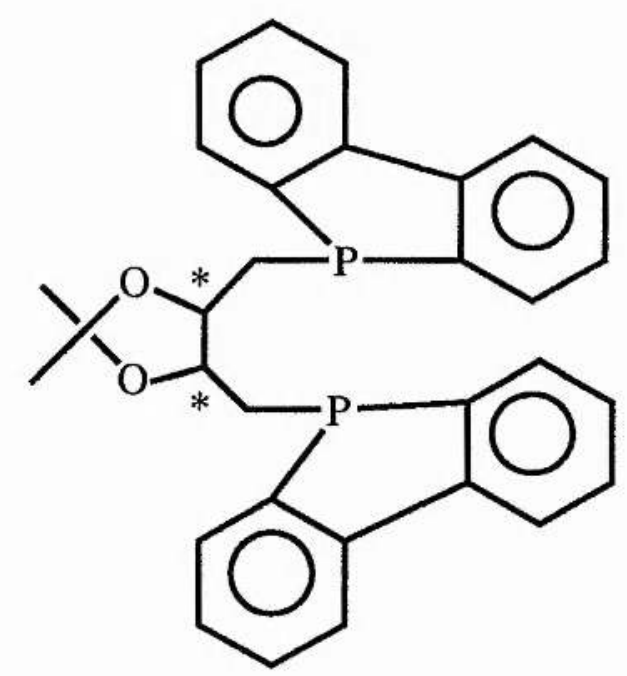

DIPHOL

Figure 1.4

When DIPHOL (Figure 1.4) was used in place of DIOP and the pressure lowered, the maximum yield observed was $\sim 47 \%$ e.e.

Alper and Hamel65 have reported the first asymmetric 
carbonylation of allyl alcohols to yield optically active lactones using poly $\alpha$ - amino acids as added chiral ligands. Thus treatment of but-2-en1-ol (Equation 1.33) under extremely mild conditions with carbon monoxide, oxygen, copper(II) chloride, and hydrochloric acid in tetrahydrofuran in the presence of palladium chloride and poly-Lleucine afforded (R)- $\alpha$-methyl- $\chi$-butyrolactone in $61 \%$ enantiomeric excess.

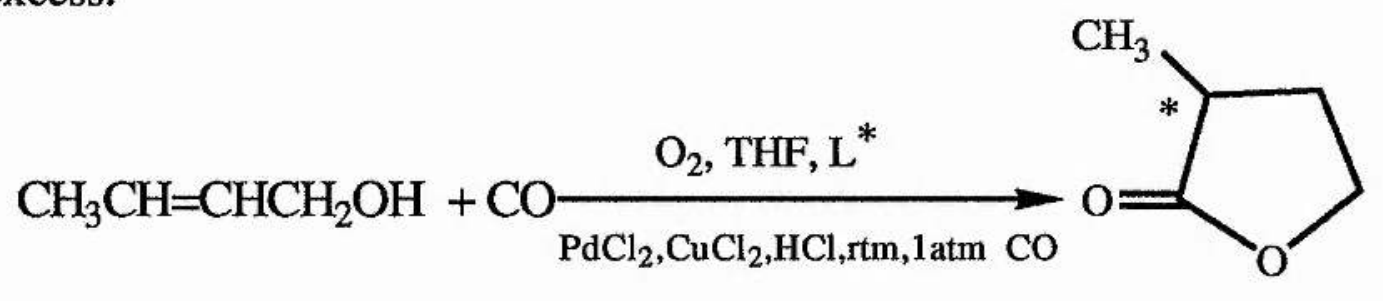

Equation 1.33

The chiral discrimination step in the asymmetric process with poly-L-leucine was the intramolecular addition of palladium hydride to the co-ordinated double bond of the five co-ordinate palladium (II) complex (Figure 1.5), to give a metallocyclo pentane [carbonyl insertion followed by reductive elimination to give the products].

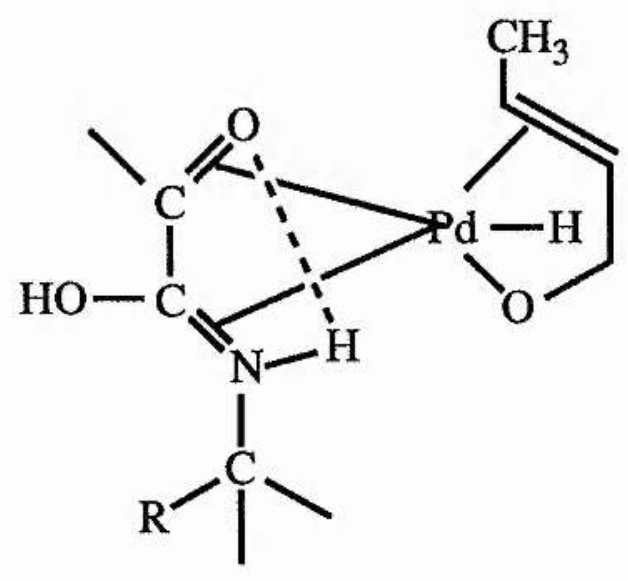

Figure 1.5

(L)-diethyl tartrate and (R)-and (S)-2,2'-bis (diphenylphosphino)-1,1'- 
binapthyl (BINAP) also produced optically active lactones, but in lower optical purity.

Ibuprofen [2-(p-iso-butylphenyl)propanoic acid](Figure1.7) and naproxen [2-(6-methoxy-2-napthyl)propanoic acid] (Figure 1.6) are two commercially important non-steroidal anti inflammatory agents.

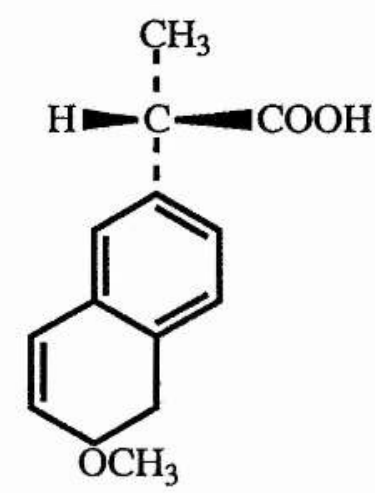

Naproxen

Figure 1.6

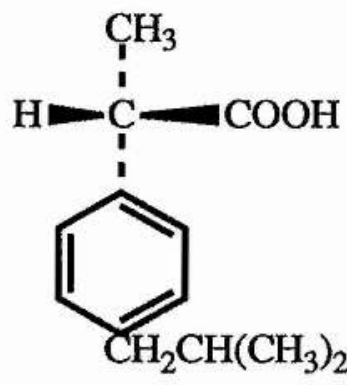

Ibuprofen

Metal-catalysed approaches to obtain optically active ibuprofen or naproxen have been in vogue recently. Ohata and coworkers 66 obtained a high degree of optical purity by using BINAP ruthenium(II)-catalysed hydrogenation of 2-(6-methoxynapthyl)-2-propenoic acid. A high pressure of hydrogen (135 atm) was required, and the acrylic acid derivative had to be synthesised via several steps. In 1987, Parrinello and Stille67 obtained naproxen from p-isobutylstyrene by hydroformylation in the presence of a $\mathrm{Pt}$ (II) complex of (2S,4S)-N-(tert-butoxycarbonyl)-4-diphenylphophino)-2-[(diphenylphosphino(methyl] prolidine[(-)-BPPM], with $\mathrm{SnCl}_{2}$. The hydroformylation reaction required drastic conditions (165 atm) and a subsequent step to 
produce acids. It was observed that while the enantiomeric excess of the formed aldehyde approached $80 \%$, the regioselectivity broke down with an unfavourable branched/linear ratio $(\sim 0.5)$.

Alper and Hame168 report the preparation of these two commecially important drugs under very mild conditions by carrying out hydrocarboxylation reactions (Equation 1.34) of p-isobutylstyrene and 2-vinyl-6-methoxynapthalene in the presence of $\mathrm{PdCl}_{2}$ and (R)-(-)-or(S)-(+)-1,1'-binapthyl-2,2'-diyl hydrogen phosphate (BNPPA)

$\mathrm{RCH}=\mathrm{CH}_{2}+\mathrm{CO}+\mathrm{H}_{2} \mathrm{O} \underset{\mathrm{PdCl}_{2}, \mathrm{CuCl}_{2}, \mathrm{HCl}, \mathrm{rtm}, 1 \text { atm } \mathrm{CO}}{\longrightarrow} \mathrm{RCH}\left(\mathrm{CH}_{3}\right) \mathrm{COOH}$

Equation 1.34

as the chiral ligand to yield (S)-(+)-and(R)-(-)-ibuprofen in $83-84 \%$ optical yield. Similarly, naproxen was obtained in good yield and in upto $91 \%$ optical yield. When other chiral ligands like L-menthol, Dmenthol, (R)-1,1'-bi-2-naphthol, D-diethyl tartrate (DET), and (S)-2,2'bis(diphenyl phosphino)-1,1'-binapthyl (BINAP) were used, only poor optical yields $(<10 \%)$ were obtained. 


\section{Chapter 2}

Analysis of Polybutadiene

\subsection{Introduction}

Since the bulk of this thesis is concerned with the synthesis of new polymers via hydrocarboxylation of polybutadiene it is important to be able to analyse the microstructure of the product and starting polymers. In this chapter, we discuss the various analytical methods that we have adopted.

A number of methods have been proposed for the analysis of polybutadienes or substituted polybutadienes. In this chapter a critical appraisal of the various methods of analysis, (i) Conductometric titration, (ii) ${ }^{1} \mathrm{H}$ and ${ }^{13} \mathrm{C}$ N.M.R., and (iii) Infrared spectroscopy, for analysing polybutadiene and its hydrocarboxylated products is provided, using samples of hydrocarboxylated polybutadiene obtained from (a) regiospecific hydrocarboxylation of pendant carbon-carbon double bonds, and (b) hydrocarboxylation of both internal and pendant carboncarbon double bonds, so that direct comparison can be made between the various methods.

\subsection{Method of analysis}

\subsubsection{Conductometric titration}

The electrical conductivity of a solution depends upon the number and mobility of any ions it contains. This principle is used to find the end points of acid-base and other titrations in a conductometric titration. 
Conductometric titration can offer several advantages over the use of indicators. For example, coloured solutions which cannot be titrated by ordinary volumetric methods with the help of indicators can be successfully titrated conductometrically. This method can also be employed in the case of very dilute solutions and also for weak acids and bases. Furthermore, no special care is necessary near the endpoint as it is determined graphically.

Four types of conductometric titrations are commonly known

1. titration of a strong acid, like hydrochloric acid, with a strong base, like sodium hydroxide.

2. titration of a weak acid, like acetic acid, with a strong base, like sodium hydroxide.

3. titration of a strong acid, like hydrochloric acid, with a weak base, like ammonium hydroxide.

4. titration of a mixture of a strong and a weak acid, such as hydrochloric acid and acetic acid, with a strong base, like sodium hydroxide.

For example, in the titration of hydrochloric acid with sodium hydroxide, the conductance of hydrochloric acid is due to the presence of hydrogen and chloride ions. As base is added gradually, the hydrogen ions are replaced by slow moving sodium ions, causing the conductivity of the solution to decrease (Equation 2.1).

$$
\mathrm{H}^{+}+\mathrm{Cl}^{-}+\left[\mathrm{Na}^{+}+\mathrm{OH}^{-}\right] \longrightarrow \mathrm{Na}^{+}+\mathrm{Cl}^{-}+\mathrm{H}_{2} \mathrm{O}
$$

Equation 2.1 
The conductivity continues to decrease until the acid has been completely neutralised. After this, the addition of base will result in an increase in the number of ions in the solution. The conductivity, therefore reaches a minimum value at the end point and then begins to increase. When conductivity is plotted against the volume of base added, two straight lines $\mathrm{AB}$ and $\mathrm{CD}$ are obtained (Figure 2.1). The point where $\mathrm{AB}$ and $\mathrm{CD}$ meet i.e., $\mathrm{X}$ gives the end point.

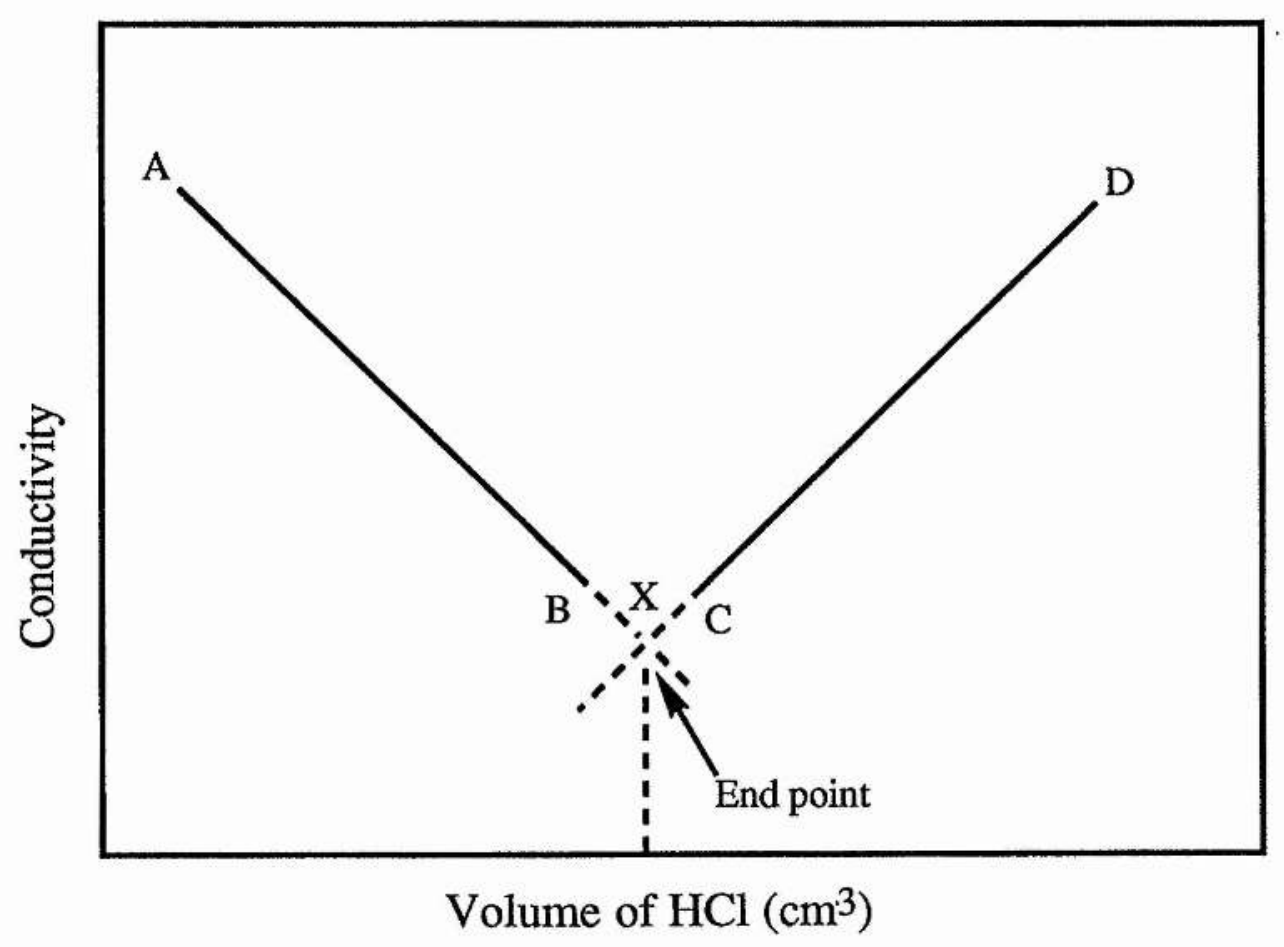

Figure 2.1. Titration of a strong acid against a strong base.

When a mixture of a strong and a weak base is to be titrated against a strong acid, a combination of curves is obtained as shown in Figure 2.2. Suppose a mixture of $\mathrm{NaOH}$ and $\mathrm{NH}_{3}(\mathrm{aq})$ is titrated against $\mathrm{HCl}, \mathrm{NaOH}$ being a much stronger base, will react first. The titration of $\mathrm{NH}_{3}$ (aq) will commence only after $\mathrm{NaOH}$ has been completely 


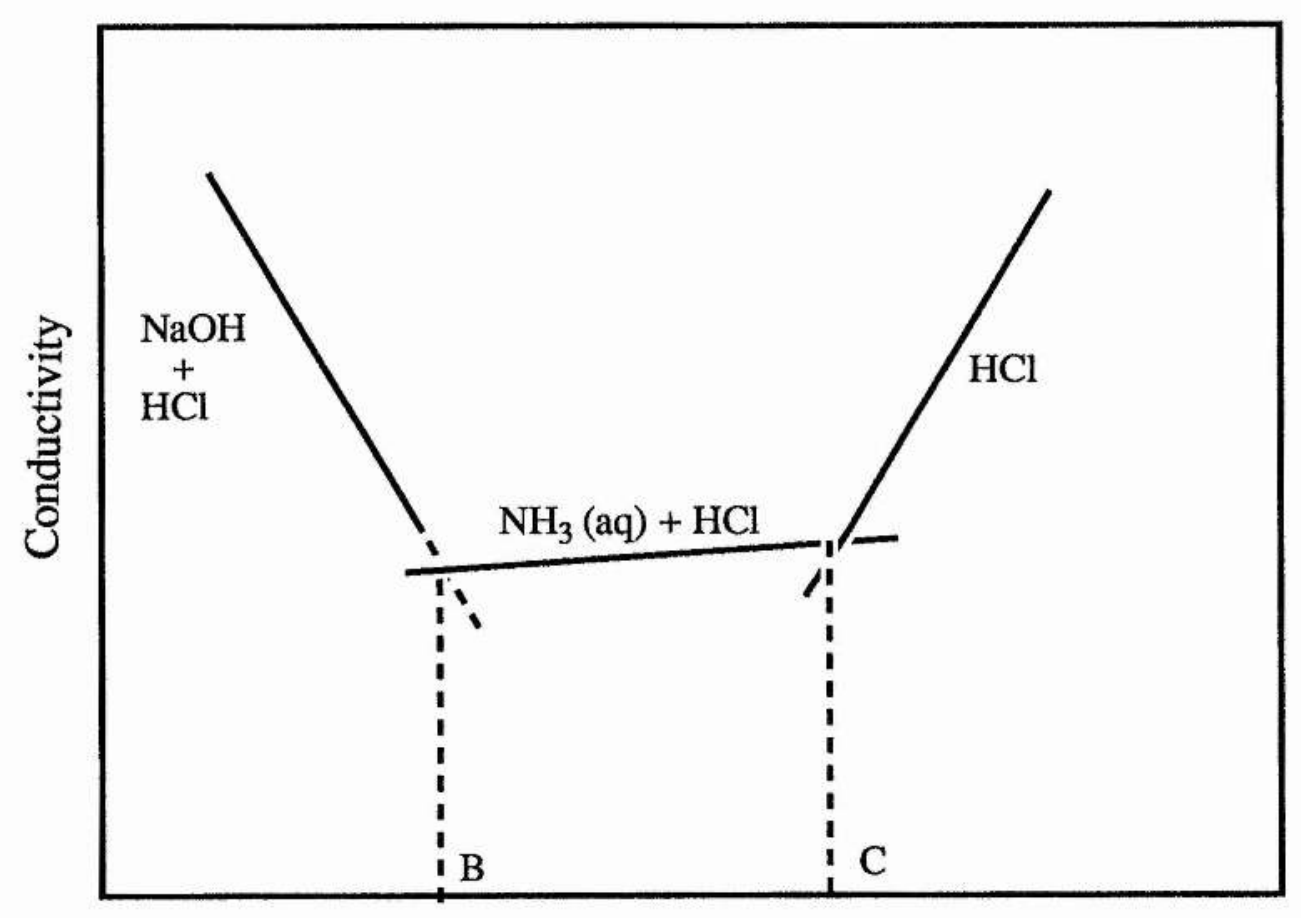

Volume of $\mathrm{HCl}\left(\mathrm{cm}^{3}\right)$

Figure 2.2. Titration of a mixture of a strong and a weak base against a strong acid

neutralised. Being a weak base, the number of ions increases slightly as more $\mathrm{HCl}$ is added so that a slight increase in conductivity is observed until all of the hydroxyl ions have been neutralised. The conductivity then rises sharply as more $\mathrm{HCl}$ is added on account of the presence of a larger number of ions, but also on account of the higher mobility of the $\mathrm{H}^{+}$ions. Hence, a combination of curves are obtained. In Figure 2.2 point $\mathrm{B}$ corresponds to the neutralisation of $\mathrm{NaOH}$ and point $\mathrm{C}$ corresponds to the neutralisation of $\mathrm{NH}_{3}(\mathrm{aq})$.

Our aim was to apply the above principle to find out the amount of $-\mathrm{COOH}$ groups in the polymer chain. For this the following procedure was adopted. 
The hydrocarboxylated polybutadiene was first converted to its corresponding sodium salt by dissolving the hydrocarboxylated polybutadiene (Figure 2.3) in excess of $\mathrm{NaOH}(0.01 \mathrm{M})$ and conductometric titration with $\mathrm{HCl}(0.01 \mathrm{M})$ was carried out.

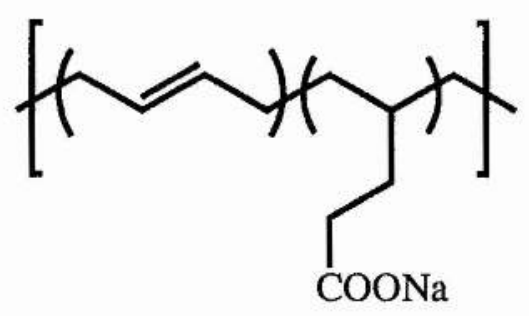

Figure 2.3

It was observed that initially all the excess $\mathrm{NaOH}$ was neutralised by $\mathrm{HCl}$ and the conductivity dropped because the mobile $\mathrm{OH}^{-}$ions were being replaced by the less mobile $\mathrm{Cl}^{-}$ions (Equation 2.2).

$$
\mathrm{HCl}+\mathrm{NaOH} \longrightarrow \mathrm{NaCl}+\mathrm{H}_{2} \mathrm{O}
$$

Equation 2.2

After all the $\mathrm{NaOH}$ had been neutralised, $\mathrm{HCl}$ started to react with m $\mathrm{COONa}$ ions (Equation 2.3).

$$
\sim \sim \mathrm{COO}^{-} \mathrm{Na}^{+}+\mathrm{HCl} \longrightarrow \mathrm{Na}^{+} \mathrm{Cl}^{-}+\sim \sim \mathrm{COOH}^{+}
$$

Equation 2.3 
Being a weak acid, the number of ions increases slightly as more $\mathrm{HCl}$ is added so that a slight increase in conductivity should be observed until all of the carboxylates have been neutralised. The conductivity then rose sharply as more $\mathrm{HCl}$ was added on account of the presence of the larger number of ions, but also on account of the higher mobility of the $\mathrm{H}^{+}$ ions. For polycarboxylic acids of the type under study, there is, however, a further complication. The protonated form of carboxylic acid is insoluble in water and hence precipitates during the titration.

In principle this is not a problem since it should just level the middle portion of the curve as is observed. However, one cannot be certain at what point a given polymer molecule precipitates i.e., how many of the carboxylic acid groups need to be protonated before precipitation occurs. If this is not $100 \%$ and if the ionic carboxylates that precipitated with the polymer molecule are not available for subsequent protonation (with release of $\mathrm{Na}^{+}$), the final end point will not be estimated correctly (For example, see Figure 2.14). Whether or not this is a genuine problem for the types of polymer we are analysing can be determined since the final end point should correspond to the end point obtained for titration of the same amount of $\mathrm{NaOH}$ as was used for the back titration. In general, this appears to be the case so that all of the carboxylic acid anions in the polymer are available for protonation. However elemental analysis (see section 2.2.4, Microanalysis) shows the presence of sodium ions in the hydrocarboxylated product. This means that some of the sodium ions are bound to the product polymer (as carboxylate) and not available for titration with $\mathrm{HCl}$. In certain cases, especially for polymers where there are $-\mathrm{COOH}$ groups on the backbone, there is considerable evidence that precipitation of partially neutralised polymers does occur (see section 2.2.2.2.3). 
For a specific example we select a polymer (initial composition $=$ $53 \%$ pendant, $31 \%$ internal $\mathrm{C}=\mathrm{C}$ and $16 \%$ saturation) prepared by hydrocarboxylation of polybutadiene where all the pendant carbon carbon-carbon double bonds have been selectively hydrocarboxylated. From ${ }^{1} \mathrm{H}$ n.m.r. calculations (see section 2.2.2. ${ }^{1} \mathrm{H}$ and ${ }^{13} \mathrm{C}$ n.m.r. for details) we have calculated that the overall conversion of the carboncarbon double bonds in the hydrocarboxylated product to be $43 \%$.

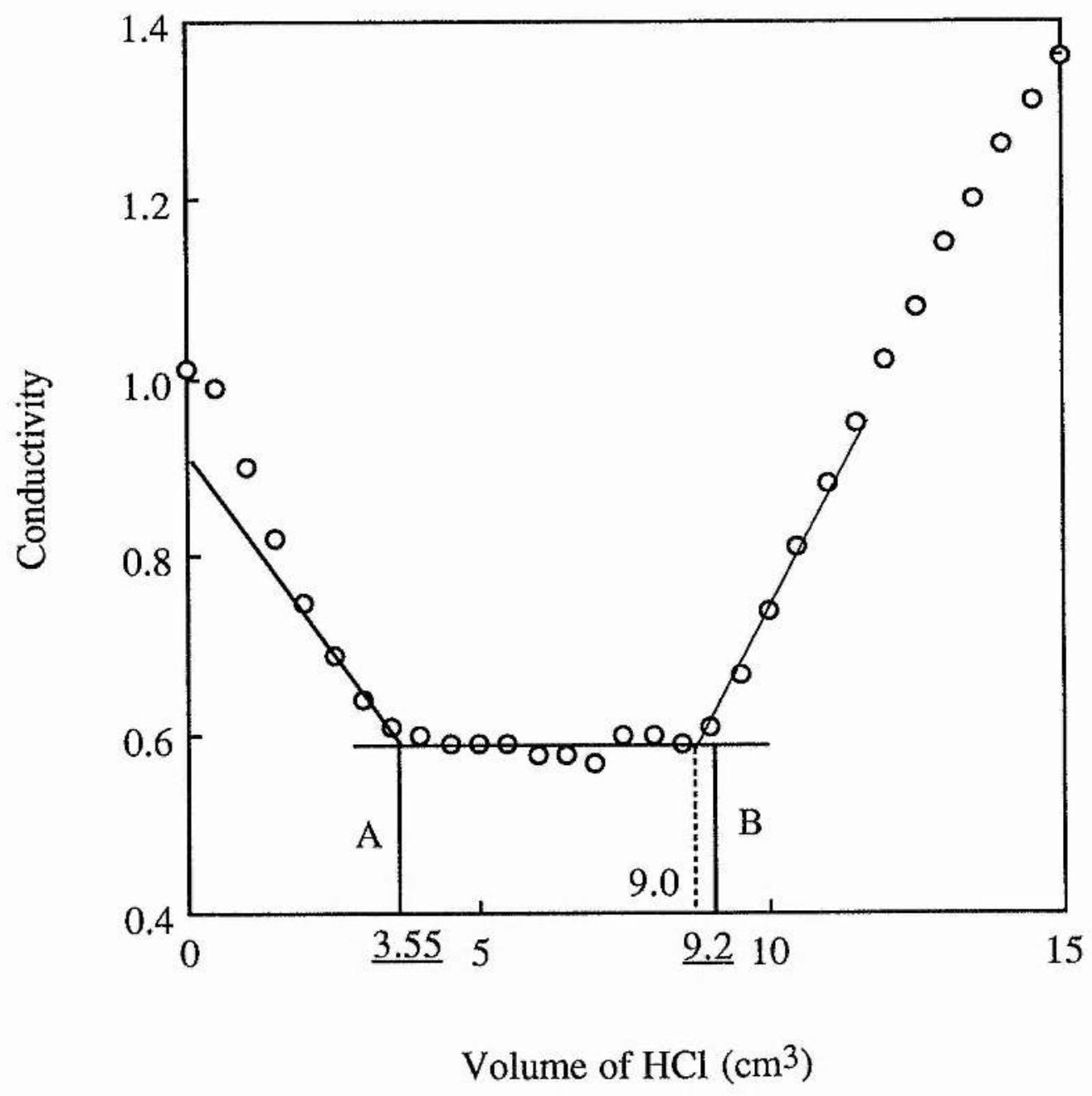

Figure 2.4 Conductometric titration between hydrocarboxylated polybutadiene (in $\mathrm{NaOH}$ ) and $\mathrm{HCl}$ 


\section{Calculation}

Figure 2.4 shows a graphic representation of the conductometric titration performed between hydrocarboxylated polybutadiene in $\mathrm{NaOH}$ versus $\mathrm{HCl}$.

$0.01 \mathrm{~g}$ of the hydrocarboxylated product under study was dissolved in 10 $\mathrm{cm}^{3}$ of $0.01 \mathrm{M} \mathrm{NaOH}$ and titrated with $0.01 \mathrm{M} \mathrm{HCl}$. Blank titration of $\mathrm{NaOH}$ with $\mathrm{HCl}$ gave $9.2 \mathrm{~cm}^{3}$ as the end point i.e., neutralisation point. First end point when all $\mathrm{NaOH}$ has reacted with $\mathrm{HCl}=3.55 \mathrm{~cm}^{3}$

As can be seen from the graph the final end point could not be determined precisely as precipitation of the polymer took place. The end point calculated based on titration comes to $9.0 \mathrm{~cm}^{3}$. This means that some of the $\mathrm{Na}^{+}$ions bound to the polymer chain are not available for titration with $\mathrm{HCl}$. However, since this is a back titration and that the final end point should correspond to the end point obtained for titration of the same amount of $\mathrm{NaOH}$ used. We, have, therefore, assumed that the final end point should be at $9.2 \mathrm{~cm}^{3}$.

Second end point when all COONa bound to the polymer has reactedwith $\mathrm{HCl}$ (based on back titration) $=9.2 \mathrm{~cm}^{3}$

Therefore $0.01 \mathrm{~g}$ of hydrocarboxylated product is equivalent to 5.65 $\mathrm{cm}^{3}$ of $0.01 \mathrm{M} \mathrm{HCl}$.

This in terms of moles will be

$0.01 \mathrm{~g}=\frac{5.65 \times 0.01}{1000}=5.65 \times 10^{-5}$ moles

Let ' $M$ ' be the mass in a.m.u. of the hydrocarboxylated product, which contains one proton,

then $\frac{0.01 \mathrm{~g}}{\mathrm{M}}=5.65 \times 10^{-5}$ moles 
Therefore, $\mathrm{M}=177$

The product butadiene will contain butadiene units of mass 54, carboxylic acid units of mass 100 , and hydrogenated butadiene units (saturated units) of mass 56, in this case the latter accounts for $16 \%$ of the initial butadiene units in the polymer.

The mass containing one proton will be

$$
\frac{a \times 100+b \times 54+c \times 56}{a},
$$

where a is the proportion of carboxylic acid units in the chain,

$\mathrm{b}$ is the proportion of unreacted units, and

$c$ is the proportion of saturation in the starting material $=0.16$

We then have

$$
\begin{aligned}
& \frac{\mathrm{a} \times 100+\mathrm{b} \times 54+0.16 \times 56}{\mathrm{a}}=177 \\
& \text { b } \times 54+0.16 \times 56=77 \mathrm{a}
\end{aligned}
$$

We know that $a+b=0.84$

Therefore $b=0.84-a$

$$
\begin{aligned}
& (0.84-a) \times 54+8.96=77 a \\
& 45.36-54 a+8.96=77 a \\
& 54.32=131 a \\
& a=\frac{54.32}{131}=0.4146=41 \%
\end{aligned}
$$


Therefore $b=0.84-0.41=0.43$

The final composition of the hydrocarboxylated product will be;

Remaining carbon-carbon double bond $=43 \%$

Overall conversion $($ Carboxylic acid $)=41 \%$

Saturated carbon-carbon units $=16 \%$

As can be seen the value obtained by using conductometric titration is in agreement with the values obtained from ${ }^{1} \mathrm{H}$ n.m.r. (43\%). However, information about the selectivity or the microstructure of the product cannot be obtained.

Conductometric titration can thus only be used to obtain information about the overall conversion of carboxylic acid units in the hydrocarboxylated product. However, a combination of a conductometric titration and $1 \mathrm{H}$ n.m.r. spectroscopy can give complete information on the microstructure of most of the polymers under study (see Chapter 4).

\section{$\underline{2.2 .2}{ }^{1} \underline{\mathrm{H}}$ and ${ }^{13} \underline{\mathrm{C} \text { n.m.r. spectroscopy }}$}

\section{$\underline{2.2 .2 .1}{ }^{13} \mathrm{C}$ n.m.r.}

The use of ${ }^{13} \mathrm{C}$ n.m.r. as a tool for investigating the microstructure of polybutadienes was first reported by Duch and Grant69 in 1970. Soon after quite a few papers were published using ${ }^{13} \mathrm{C}$ n.m.r techniques for determining the microstructure of polybutadienes 70,71 . Our assignment of the various peaks corresponding to $c i s$, trans and pendant carbon-carbon double bonds of polybutadiene were carried out according to Clague and coworkers 72 . 
A ${ }^{13} \mathrm{C}$ n.m.r. spectrum of polybutadiene is shown in Figure 2.5. The peaks at $115 \mathrm{ppm}$ and at $145 \mathrm{ppm}$ are assigned to the carbon atoms of the pendant carbon-carbon double bonds, while the peaks around 130 ppm are assigned to carbon atoms of the back bone carbon-carbon double bonds i.e., cis and trans.

${ }^{13} \mathrm{C}$ n.m.r studies of the hydrocarboxylated product firstly give an insight as to whether the hydrocarboxylation reaction has taken place or not, and secondly about the regioselectivity of the reaction. Based on the hydrocarboxylation reaction carried out using Alper's method (see chapter 4), on $100 \%$ cis polybutadiene (see Chapter 4, Table 4.2 polymer number 7 , page 169 ) we were able to assign the single peak at $176 \mathrm{ppm}$ to the carboxylic acid carbon attached directly to the back bone of the polymer. Based on this observation, assignments were then made for carboxylic acids peaks at $175 \mathrm{ppm}$ and $173 \mathrm{ppm}$ to the terminal carbon position and the penultimate carbon of the pendant group. It is worth mentioning here that when hydrocarboxylation is carried out based on Knifton's method (see chapter 3), only a single carboxylic acid peak at 175 ppm arises. Given that this method is known to be highly specific to hydrocarboxylation at the terminal carbon atom of terminal double bonds, we can assign the peak at $175 \mathrm{ppm}$ to such terminal carboxylic acid groups suggesting that the hydrocarboxylation reaction is very regiospecific. When using Alper's method for polybutadienes containing both back bone and pendant double bonds, three carboxylic acid peaks i.e., at $176 \mathrm{ppm}, 175 \mathrm{ppm}$ and $173 \mathrm{ppm}$ are observed, suggesting that the hydrocarboxylation reaction is nonselective, i.e., with the backbone (176 ppm), and terminal (175 ppm) and penultimate $(173 \mathrm{ppm})$ carbon atoms of pendant groups all being functionalised. 


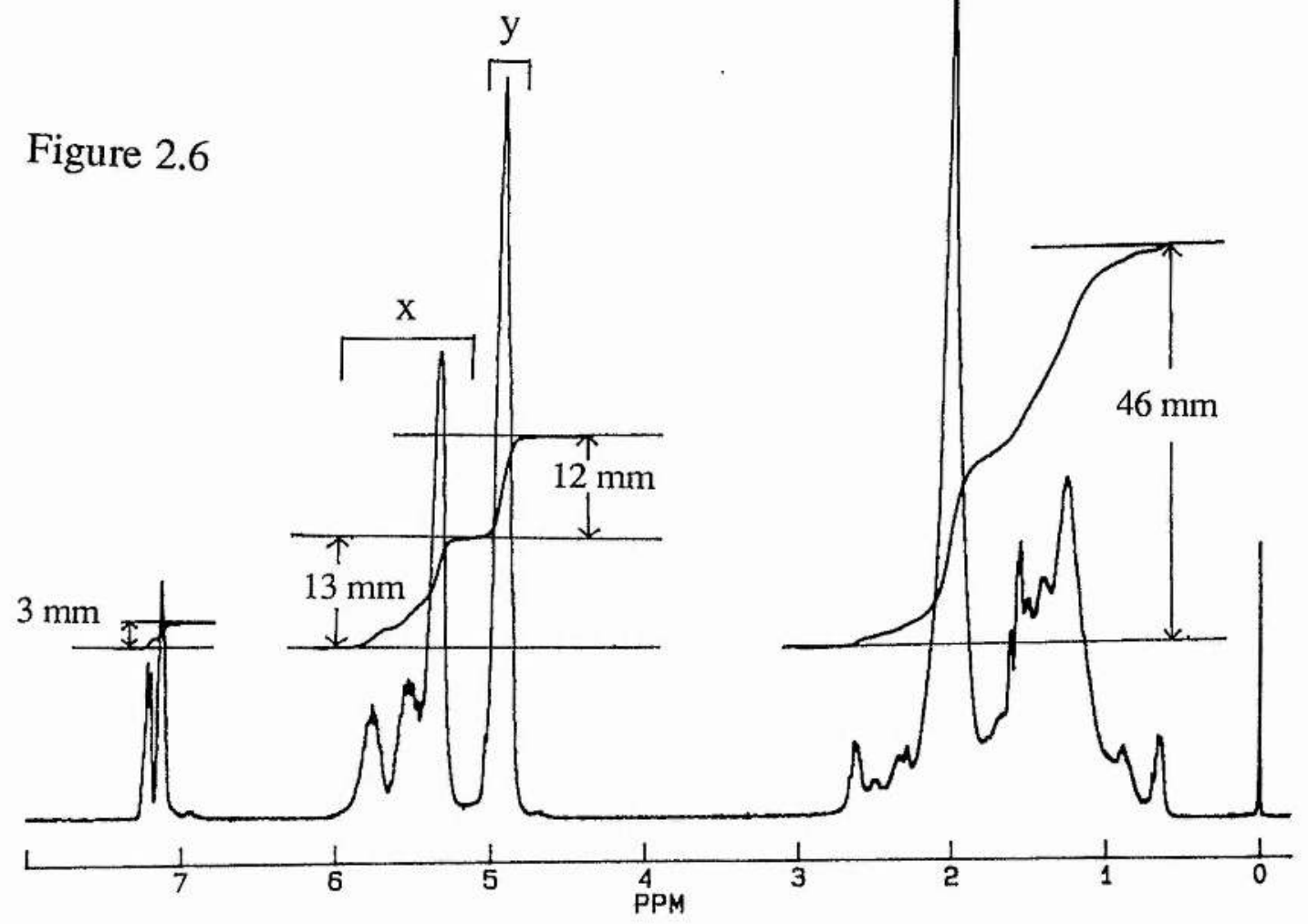

Figure 2.5

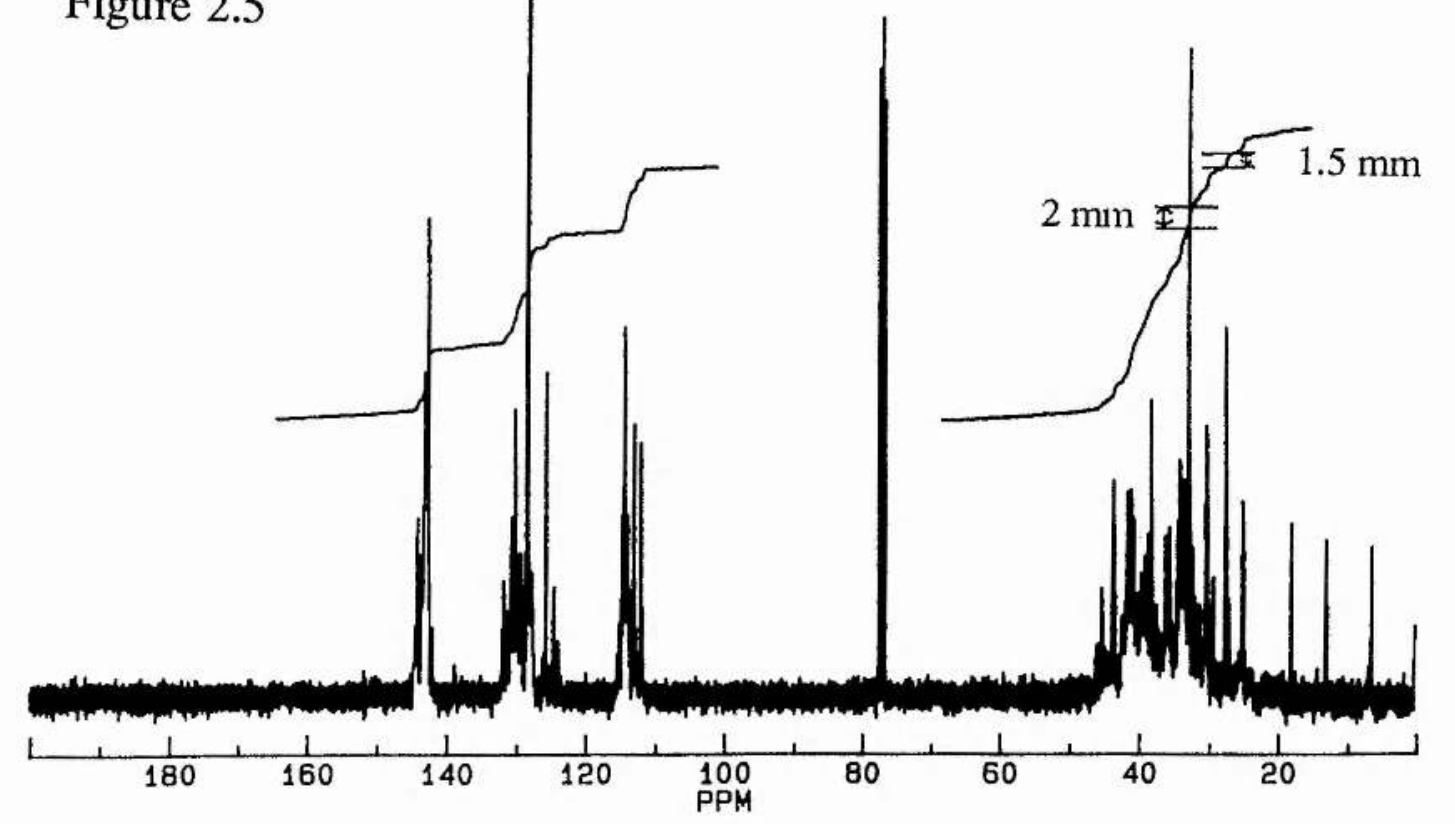

Figure $2.5{ }^{13} \mathrm{C}$ n.m.r spectrum of polybutadiene (phenyl terminated) Figure $2.6{ }^{1} \mathrm{H}$ n.m.r. spectrum of polybutadiene (phenyl terminated) 


\section{$\underline{2.2 .2 .2}{ }^{1} \underline{\mathrm{H} \text { n.m.r. spectroscopy }}$}

\subsection{Analysis of starting materials}

${ }^{1} \mathrm{H}$ n.m.r.spectroscopy is the precise tool used to calculate quantitatively the extent of hydrocarboxylation. Assignment of various peaks from the ${ }^{1} \mathrm{H}$ n.m.r. spectrum of polybutadiene were made according to Rempel and coworkers 73 and Zymonas and coworkers ${ }^{74}$. Our calculations are based on the calculations made by Rempel and coworkers 74 for hydrosilylation of polybutadienes. The ${ }^{1} \mathrm{H}$ n.m.r. spectrum of polybutadiene is shown in Figure 2.6.

The peaks in the range of $5.0-5.8 \mathrm{ppm}$ are characteristic of olefinic protons and in the range 1-2.3 ppm are due to aliphatic protons. The polybutadienes used in our study were either phenyl terminated or terminated with other groups like proton, hydroxyl, acid etc. In order to calculate the various constituents i.e., cis, trans , pendant units in the starting material polybutadiene, we first calculate the percentages of pendant carbon-carbon double bonds among overall double bonds present in the polymer as follows.

Calculation of percentage of terminal double bonds among double bonds

${ }^{1} \mathrm{H}$ n.m.r. spectroscopy is used to calculate the percentage of pendant carbon-carbon double bonds among double bonds present in the polymer. The ${ }^{1} \mathrm{H}$ n.m.r. spectrum is shown in Figure 2.6 and the assignment of the corresponding peaks is shown in Figure 2.7. 


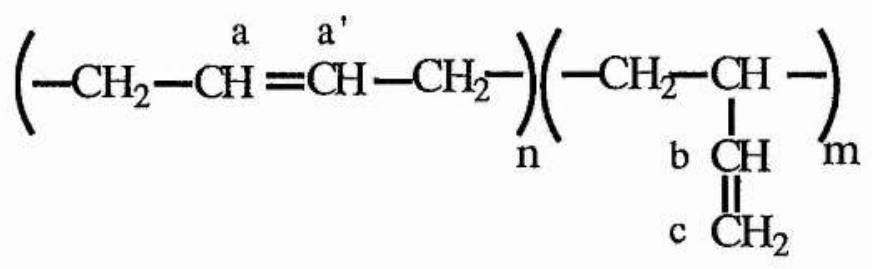

Figure 2.7

In the region ' $\mathrm{x}$ ' there are two protons ' $\mathrm{a}$ ' and ' $\mathrm{a} 1$ ' arising from the back bone double bonds and one proton ' $b$ ' from the penultimate carbon atom of the pendant double bonds. Two protons ' $c$ ' arising exclusively in the region ' $\mathrm{y}$ ' of the ${ }^{1} \mathrm{H}$ n.m.r. spectrum corresponds to the terminal proton of the pendant carbon-carbon double bonds. The proportion of pendant double bonds as a percentage of the total number of double bonds is given by :

1 proton from pendant position 1 proton from the pendant dbs +1 proton from $\mathrm{bb} \mathrm{dbs} \times 100 \%$

( where $b b=$ back bone and $\mathrm{dbs}=$ double bonds).

1 proton from pendant double bond $=\frac{y}{2}$

(as region ' $\mathrm{y}$ ' corresponds to 2 protons in the ${ }^{1} \mathrm{H}$ n.m.r. spectra)

1 proton from back bone double bonds $=\frac{x-y / 2}{2}$

Substituting equations (2) and (3) in equation (1) we get

$$
\begin{aligned}
& =\frac{y / 2}{\frac{y / 2+\frac{x-y / 2}{2}}{2}} \times 100 \\
& =\frac{y}{y+x-y / 2}
\end{aligned}
$$




$$
\begin{gathered}
=\frac{y}{x+y / 2} \\
\text { i.e., } \frac{m}{m+n}=\frac{2 y}{2 x+y} \times 100
\end{gathered}
$$

For calculation of the percentages of the various constituents i.e., cis, trans and pendant carbon-carbon double bonds present in the starting material we use both ${ }^{1} \mathrm{H}$ and ${ }^{13} \mathrm{C}$ n.m.r. and the calculation is done as follows:

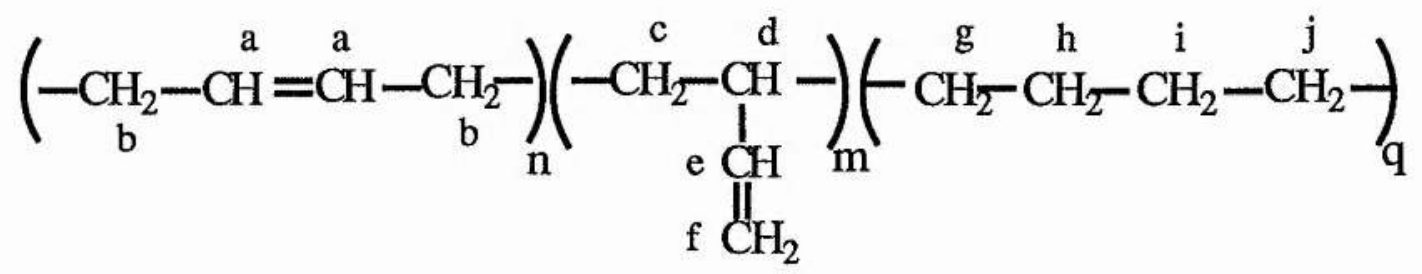

Figure 2.8

$a, b, c, d, e, f, g, h, i$,and $j$ are ten types of protons in different chemical environments. If $\mathrm{n}, \mathrm{m}$, and $\mathrm{q}$ are the fractions of butadiene units which are backbone, pendant and saturated respectively (see Figure 2.8), then

$$
\mathrm{n}+\mathrm{m}+\mathrm{q}=1
$$

Where $\mathrm{n}=$ fraction of back bone double bonds

$\mathrm{m}=$ fraction of terminal double bonds

$q=$ fraction of saturated units 
The percentage of terminal double bonds among overall double bonds has been shown previously to be given by (see equation 4 )

$$
\frac{m}{m+n}=\frac{2 y}{2 x+y}
$$

The degree of unsaturation for the starting material i.e., polybutadiene is calculated as follows.

$$
\frac{2 n+3 m}{4 n+3 m+8 q}=\frac{\text { integration of olefinic protons }}{\text { integration of aliphatic protons }}
$$

Substituting equations (5) and (6) in equation (7) will give the values of $\mathrm{m}, \mathrm{n}$, and $\mathrm{p}$. The percentages of $c i s$ and trans double bonds can be estimated from the integration of ${ }^{13} \mathrm{C}$ n.m.r. (cis peak at $32.7 \mathrm{ppm}$ and trans peak at $27 \mathrm{ppm}$ ) and from the value of $\mathrm{m}$.

In the following section an example of a polymer with a number average weight of 1000 is chosen and the calculation is shown below.

Figure 2.6 is the ${ }^{1} \mathrm{H}$ n.m.r. spectrum of polybutadiene phenyl terminated. Since there is a certain degree of saturation present in the polymer the value of $\mathrm{q}$ in these equations will be taken into account.

$$
\mathrm{n}+\mathrm{m}+\mathrm{q}=1
$$

From the ${ }^{1} \mathrm{H}$ n.m.r. the integral value of ' $\mathrm{y}$ ' $=12 \mathrm{~mm}$ and the integral value of ' $x$ ' $=13 \mathrm{~mm}$. Therefore,

$$
\frac{m}{m+n}=\frac{2 y}{2 x+y}=0.63
$$

$$
m(1-0.63)=0.63 n, \quad \text { Therefore, } \quad m=1.7 n
$$


Substituting the value of $\mathrm{m}$ from equation (9) in equation (8)

$$
\begin{gathered}
\mathrm{p}=1-2.7 \mathrm{n} \\
\frac{2 \mathrm{n}+3 \mathrm{~m}}{4 \mathrm{n}+3 \mathrm{~m}+8 \mathrm{p}}=\frac{25}{46}=0.54
\end{gathered}
$$

Substituting the values of $\mathrm{m}$ from equation (9) and $\mathrm{p}$ from equation (10) in equation (11), we get

$$
\begin{aligned}
& \frac{2 n+3 \times 1.7 n}{4 n+3 \times 1.7 n+8-8 \times 2.7 n}=0.54 \\
& \frac{7.1 n}{8-12.5 n}=0.54 \\
& n=0.31
\end{aligned}
$$

Substituting the value of $\mathrm{n}$ in equations (9) and (10) we get

$$
\mathrm{m}=0.53 \text {, and } \mathrm{q}=0.16
$$

It is possible to estimate the relative amounts of cis and trans double bonds from the ${ }^{1} \mathrm{H}$ n.m.r. spectrum. However this is obtained from the ${ }^{13} \mathrm{C}$ n.m.r. spectrum as follows.

Carbon atoms $\alpha$ to trans double bonds give rise to signal at 32.7 ppm, whilst carbon atoms $\alpha$ to cis double bonds give rise to a signal at $27 \mathrm{ppm}$. Being in similar environments, their Overhauser enhancement are likely to be similar to one another so that integration can be used to compare the relative amounts of these species. The ${ }^{13} \mathrm{C}$ n.m.r.spectrum of the same polymer as described above, is shown in Figure 2.5. 
Measuring the height of the integration peak at 32.7 ppm gives trans $=2$

Measuring the height of the integration peak at 27 ppm gives cis $=1.5$

Therefore proportion of trans $=\frac{2}{3.5}=0.57 \sim 0.6$

$$
\text { proportion of } \mathrm{cis}=\frac{1.5}{3.5}=0.42 \sim 0.4
$$

From the ${ }^{1} \mathrm{H}$ n.m.r. spectrum we know the percentage of back bone double bonds as $31 \%$

Therefore $31 \times 0.6=18.6 \sim 19 \%$ trans

$$
31 \times 0.4=12.4 \sim 12 \% \text { cis. }
$$

The composition of polybutadiene is $c i s=12 \%$

$$
\begin{aligned}
& \text { trans }=19 \% \\
& \text { pendant }=53 \% \\
& \text { saturation }=16 \%
\end{aligned}
$$

The reported value from Aldrich Chemical Company was 5\% cis, 10\% trans , $45 \%$ pendant, and $40 \%$ saturated units.

In principle, a very similar method can be used for determining the micro-structure of a functionalised polybutadiene provided either that the functional group introduced has resonances in the ${ }^{1} \mathrm{H}$ n.m.r. which are significantly shifted from the other polymer resonances (e.g., for introduced $-\mathrm{Si}\left(\mathrm{CH}_{3}\right)_{2} \mathrm{Cl}$ or $-\mathrm{CHO}$ groups) or that the protons originally on the double bonds of the polymer resonate in a different 
but distinctive region of the ${ }^{1} \mathrm{H}$ n.m.r. spectrum (epoxidised polymers are those containing added -OH groups). For hydrocarboxylated polymers, however, neither of these criteria holds so that direct analysis of the degree of hydrocarboxylation of the polymer is difficult. It should be noted that the position and intensity of the signal from the -OH protons vary considerably depending upon the presence of water in the polymer or the n.m.r. solvent (usually $\mathrm{d}^{6}$-acetone or $\mathrm{d}^{4}$ methanol) so this cannot be used for determining the degree of hydrocarboxylation of the polymer. Uncertainity about the position and intensity of the resonance from the $-\mathrm{OH}$ protons also causes difficulties in using the relative intensities of the aliphatic and olefinic regions of the spectrum for product analysis, these are further exacerbated by the presence of traces of other solvents (e.g. methyl isobutyl ketone) which are difficult to remove from the polymer in their entirely. We have, therefore, had to develop other methods for the analysis of the hydrocarboxylated polymers.

\subsection{Method 1}

This method is used when hydrocarboxylation takes place only at the pendant double bonds

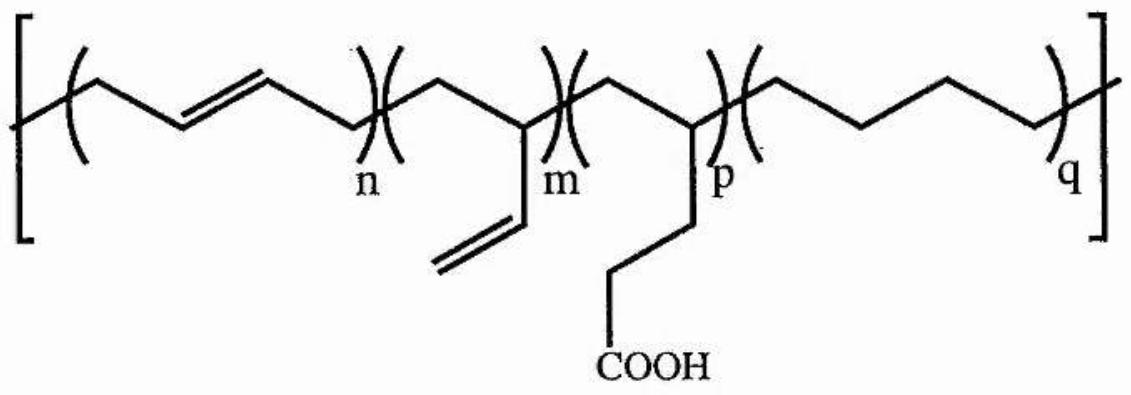

Figure 2.9

where $\quad n=$ fraction of back bone double bonds 


$$
\begin{aligned}
& \mathrm{m}=\text { fraction of terminal double bonds } \\
& \mathrm{p}=\text { fraction of hydrocarboxylation } \\
& \mathrm{q}=\text { fraction of saturated carbon-carbon bonds }
\end{aligned}
$$

Values of $n, m$. and $q$ (Figure 2.9) are know from the starting material. Since the hydrocarboxylation reaction is very regiospecific, we assume that after the reaction the percentage of the back bone double bonds remains unchanged i.e., the value of $\mathrm{n}$ remains the same. Therefore in the hydrocarboxylated product

$$
\text { Let, } \mathrm{n}=\mathrm{n}_{\mathrm{O}}
$$

(where $\mathrm{n}_{\mathrm{o}}$ is the back bone double bonds in the starting material).

$$
\frac{m}{m+n}=\frac{2 y}{2 x+y}=A
$$

where $\mathrm{A}$ is the ratio of pendant double bonds to all double bonds in the hydrocarboxylated polybutadiene.

On substituting equation (13) in equation (12) we get

$$
\begin{aligned}
& \mathrm{m}=\mathrm{n}_{\mathrm{o}} \mathrm{A}+\mathrm{mA} \\
& \mathrm{m}(1-\mathrm{A})=\mathrm{n}_{\mathrm{o}} \mathrm{A} \\
& \mathrm{m}=\frac{\mathrm{n}_{\mathrm{o}} \mathrm{A}}{1-\mathrm{A}} \\
& \mathrm{m}+\mathrm{p}=\mathrm{m}_{\mathrm{o}}
\end{aligned}
$$

(where $\mathrm{m}_{\mathrm{o}}$ is the percentage of pendant double bonds in the starting material). 


$$
\mathrm{p}=\mathrm{m}_{\mathrm{o}}-\frac{\mathrm{n}_{\mathrm{o}} \mathrm{A}}{1-\mathrm{A}}
$$

\section{Example}

Let us consider a specific example where hydrocarboxylation takes place only at the terminal position of the pendant group.

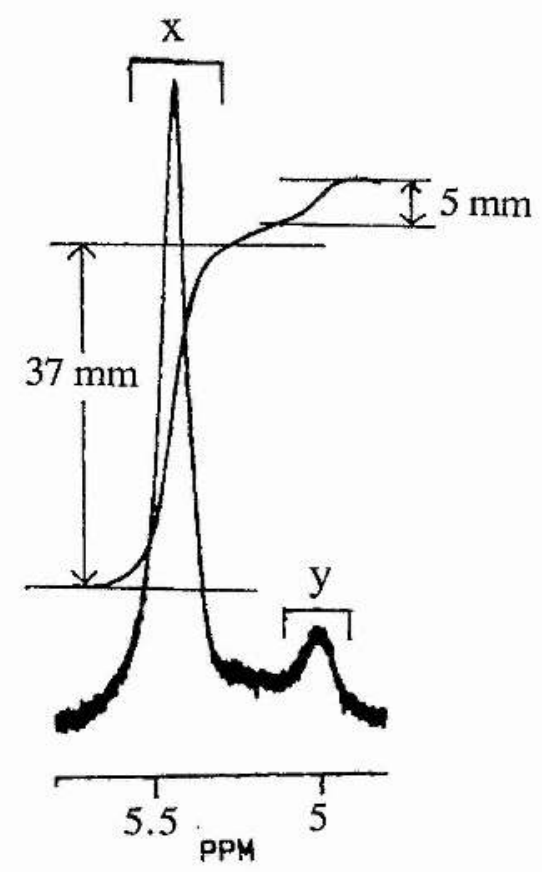

Figure $2.10{ }^{1} \mathrm{H}$ n.m.r. spectrum of hydrocarboxylated polybutadiene

The composition of the starting polybutadiene chosen as an example is

$$
\begin{aligned}
& \text { cis }=12 \% \\
& \text { trans }=19 \% \\
& \text { pendant }=53 \% \\
& \text { Saturation }=16 \%
\end{aligned}
$$

therefore, accordingly $\mathrm{n}_{\mathrm{o}}=31 \%, \mathrm{~m}_{\mathrm{o}}=53 \%$, and $\mathrm{q}_{\mathrm{o}}=16 \%$. 
Then $\mathrm{n}=\mathrm{n}_{\mathrm{o}}=31 \%$

Since hydrocarboxylation takes place only at the terminal carbon atom, the value of $n_{o}$ remains unchanged. The percentage of terminal double bonds among double bonds is calculated by measuring the heights of the integration of the regions ' $x$ ' and ' $y$ ' of the ${ }^{1} \mathrm{H}$ n.m.r. spectrum (see Figure 2.10).

$$
\frac{\mathrm{m}}{\mathrm{m}+\mathrm{n}}=\frac{2 \mathrm{y}}{2 \mathrm{x}+\mathrm{y}}=\frac{10}{79}=0.13
$$

On substituting the values of equation (15) in equation (14), we get

$$
\begin{aligned}
& \mathrm{m}=\mathrm{m} \times 0.13+0.31 \times 0.13 \\
& \mathrm{~m}(1-0.13)=0.31 \times 0.13 \\
& \mathrm{~m}=0.05
\end{aligned}
$$

Substituting the value of $\mathrm{m}$ in the equation

$$
\mathrm{m}+\mathrm{p}=\mathrm{m}_{\mathrm{o}}
$$

we get $p=0.53-0.05=0.48$

Hence the final composition of the hydrocarboxylated product is :

$$
\begin{aligned}
& \text { cis }=12 \% \\
& \text { trans }=19 \% \\
& \text { pendant }=5 \% \\
& \mathrm{COOH}=48 \% \\
& \text { saturation }=16 \%
\end{aligned}
$$


This would correspond to an "overall conversion" of butadiene unis to carboxylic acids of $48 \%$ and a conversion based on pendant carboncarbon double bonds of $91 \%$.

\subsection{Method 2}

This method is used when hydrocarboxylation takes place either at the back bone double bond or at the pendant double bond position or both. The polymers studied were phenyl terminated and hence intergrations relative to the phenyl region, which does not change after reaction is used as standard for calculating the degree of unsaturation in the hydrocarboxylated polybutadiene as shown below (Figure 2.11).

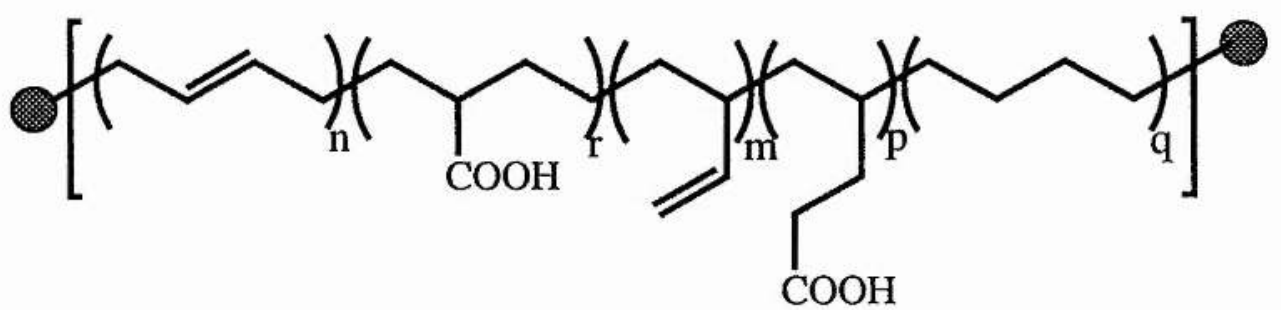

where, $\bigcirc=\mathrm{C}_{6} \mathrm{H}_{5}$

$\mathrm{n}=$ fraction of back bone double bonds

$\mathrm{r}=$ fraction of carboxylic acid at the back bone

$\mathrm{m}=$ fraction of terminal double bonds

$\mathrm{p}=$ fraction of carboxylic acid at the terminal carbon position

$q=$ fraction of saturated units

Figure 2.11 
The percentage of saturated carbon-carbon double bonds remains unaffected.

Firstly, we calculate the ratio of pendant double bonds to all double bonds in the hydrocarboxylated product from the ${ }^{1} \mathrm{H}$ n.m.r. spectra as before i.e.,

$$
\begin{aligned}
& \frac{m}{n+m}=A \\
& \text { (where } A=\frac{2 y}{2 x+y} \text { ) }
\end{aligned}
$$

Secondly,

$$
\frac{2 \mathrm{n}+3 \mathrm{~m}}{\phi} \quad=\quad \mathrm{B}_{1}
$$

(i.e., $=\frac{\text { integration of olefinic protons in the product polymer }}{\text { integration of phenyl protons in the product polymer }}$ )

$$
\frac{2 n_{0}+3 m_{0}}{\phi}=B_{2}
$$

(i.e., $=\frac{\text { integration of olefinic protons in the starting material }}{\text { integration of phenyl protons in the starting material }}$ )

(where $\mathrm{n}_{\mathrm{o}}$ and $\mathrm{m}_{\mathrm{o}}$ are percentages of back bone double bonds and terminal double bonds in the starting material repectively).

Dividing equation (17) by equation (18) we get

$$
\frac{2 n+3 m}{2 n_{o}+3 m_{o}}=\frac{B_{1}}{B_{2}}
$$


We know, $n+r=n_{0}$

Similarly $\mathrm{m}+\mathrm{p}=\mathrm{m}_{\mathrm{o}}$

Solving the four equations (16), (18), (19), and (20) simultaneously we get the composition of the hydrocarboxylated polymer.

$$
\begin{aligned}
& n=\frac{C-A C}{A+2} \\
& r=n_{0}-n \\
& m=\frac{A C}{2+A} \\
& p=m_{0}-m
\end{aligned}
$$

where, $C=\frac{B_{1}}{B_{2}}\left(2 n_{o}\right)+\frac{B 1}{B_{2}}\left(3 m_{o}\right)$

However before applying this method for calculating the percentage of conversion at the internal and pendant carbon-carbon double bond position, we can check this method by applying to the previous hydrocarboxylation reaction where conversion takes place only at the pendant position. In theory we should not get any conversion of the back bone double bonds at all in the hydrocarboxylated product.

Figure 2.12 (a) and (b) shows the ${ }^{1} \mathrm{H}$ n.m.r. spectra of the hydrocarboxylated product and the starting polybutadiene. Firstly, we calculate the ratio of pendant double bonds to all the double bonds in the hydrocarboxylated product as shown previously according to equation (4). 
Figure 2.12 (a)
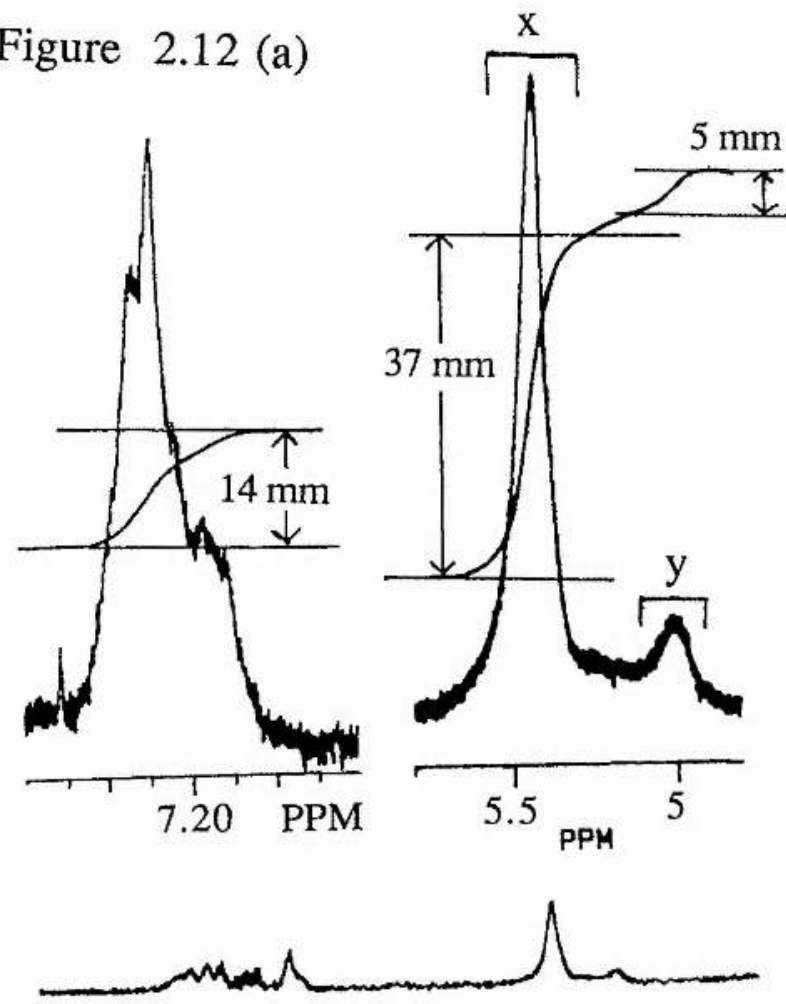

Figure $2.12(b)$

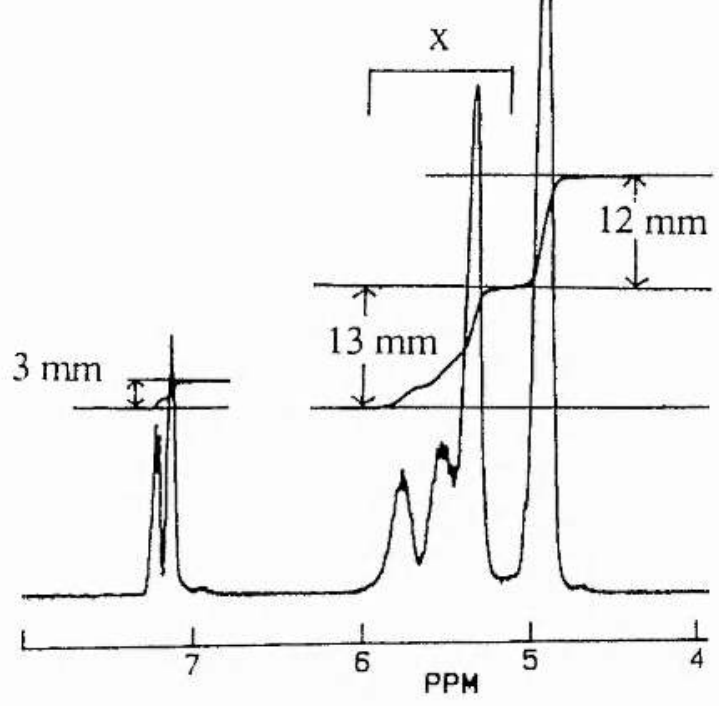

Figure 2.12 (a) ${ }^{1} \mathrm{H}$ n.m.r. spectrum of hydrocarboxylated polybutadiene (b) ${ }^{1} \mathrm{H}$ n.m.r. spectrum of polybutadiene(phenyl terminated) 


$$
\frac{\mathrm{m}}{\mathrm{m}+\mathrm{n}}=\mathrm{A}=0.13
$$

Secondly according to equation 17

$$
\frac{2 n+3 m}{\phi}=\frac{42}{14}=3=B_{1}
$$

Thirdly, according to equation 18

$$
\frac{2 \mathrm{n}_{\mathrm{o}}+3 \mathrm{~m}_{\mathrm{o}}}{\phi}=\frac{25}{3}=8.3=\mathrm{B}_{2}
$$

Therefore $\frac{\mathrm{B}_{1}}{\mathrm{~B}_{2}}=\frac{3}{8.3}=0.36$

Substituting the value obtained in equation 28 in the following equation will give the value of $\mathrm{C}$

$$
\begin{aligned}
& C=\frac{B_{1}}{B_{2}}\left(2 n_{o}\right)+\frac{B 1}{B_{2}}\left(3 p_{o}\right) \\
& C=0.8
\end{aligned}
$$

Substituting the values of $\mathrm{A}=0.13$ and $\mathrm{C}=0.8$ in equations $21,22,23$, and 24 will give the value of $\mathrm{n}, \mathrm{r}, \mathrm{m}$, and $\mathrm{p}$ as $\mathrm{n}=32.7 \%$, $\mathrm{r}=-1.7, \mathrm{~m}=5 \%$ and $\mathrm{p}=48 \%$.

The negative value obtained clearly shows that none of the back bone double bonds have reacted and it is close enough to give confidence in the method. Hence the final composition of the hydrocarboxylated product will be 
Back bone double bonds $=31 \%$

Remaining pendant double bonds $=5 \%$

Carboxylic acid at the pendant position $=48 \%$

(i.e.,Overall conversion)

This would correspond to an "overall conversion" of butadiene unis to carboxylic acids of $48 \%$ and a conversion based on pendant carboncarbon double bonds of $91 \%$.

The values obtained on applying this method is clearly in agreement to those of the values obtained using Method 1 (Overall conversion $=48 \%$ )

We will now apply this method to a specific example where hydrocarboxylation reaction occurs both at the back bone and at the pendant carbon-carbon double bond position. Figure 2.6 shows the $1 \mathrm{H}$ n.m.r.spectrum of the starting material and Figure 2.13 the ${ }^{1} \mathrm{H}$ n.m.r. spectrum of the hydrocarboxylated product.

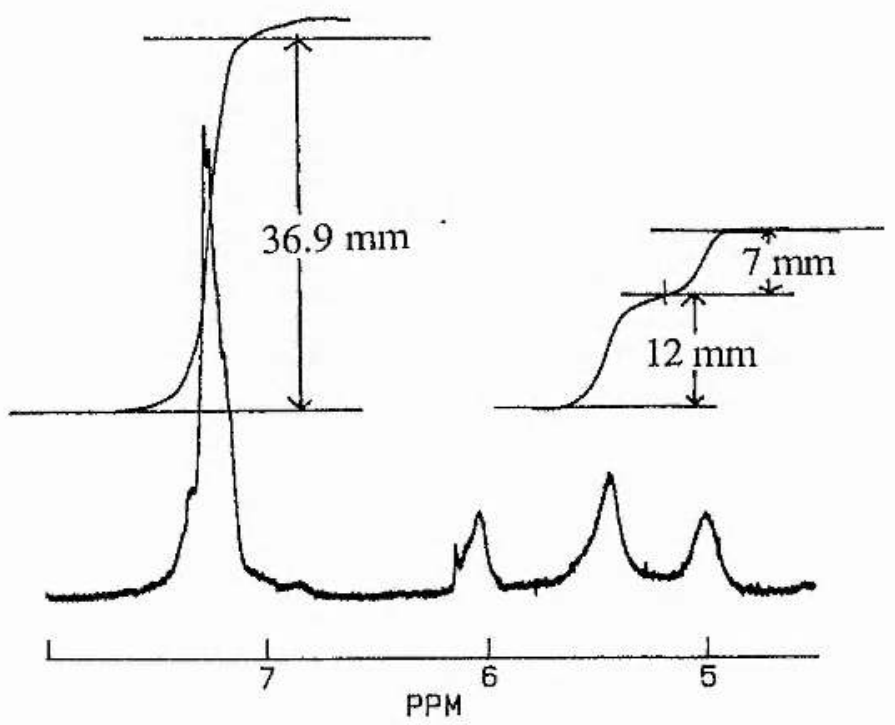

Figure $2.13{ }^{1} \mathrm{H}$ n.m.r. spectrum of hydrocarboxylated polybutadiene (phenyl terminated) 
Firstly, we calculate the ratio of the pendant double bonds to all double bonds using equation (4) as mentioned earlier.

i.e., $\quad \frac{m}{n+m}=\frac{2 y}{2 x+y}=\frac{14}{31}=0.45=A$

Secondly, according to equation 17 ;

$$
\frac{2 \mathrm{n}+3 \mathrm{~m}}{\phi}=\frac{19}{36.5}=0.51=\mathrm{B}_{1}
$$

Thirdly, according to equation 18;

$$
\frac{2 \mathrm{n}_{\mathrm{o}}+3 \mathrm{~m}_{\mathrm{O}}}{\phi}=\frac{25}{3}=8.33=\mathrm{B}_{2}
$$

Therefore $\frac{\mathrm{B}_{1}}{\mathrm{~B}_{2}}=0.062$

Substituting the value of $\frac{B_{1}}{B_{2}}$ obtained in equation 32 in the following equation will give the value of $\mathrm{C}$

$$
\begin{aligned}
& C=\frac{B_{1}}{B_{2}}\left(2 n_{o}\right)+\frac{B_{1}}{B_{2}}\left(3 m_{o}\right) \\
& C=0.14
\end{aligned}
$$

Substituting the values of $\mathrm{A}=0.45$ and $\mathrm{C}=0.14$ in equations $21,22,23$, and 24 will give the values of $\mathrm{n}, \mathrm{r}, \mathrm{m}$, and $\mathrm{p}$. as $\mathrm{n}=3 \%, \mathrm{r}=28 \%, \mathrm{~m}=$ $3 \%, \mathrm{p}=50 \%$. Thus the composition of the final hydrocarboxylated product is 
Remaining back bone double bonds $=3 \%$

Carboxylic acid at the back bone $\quad=28 \%$

Remaining pendant double bonds $\quad=3 \%$

Carboxylic acid at the pendant position $=50 \%$

Saturated carbon-carbon bonds $\quad=16 \%$

Total carboxylic acid $\quad=78 \%$

In order to check the accuracy of the method applied a conductometric titration was performed on the above hydrocarboxylated polymer. A graphical representation of the titration is shown in Figure 2.14. A few problems were encountered during the titration.

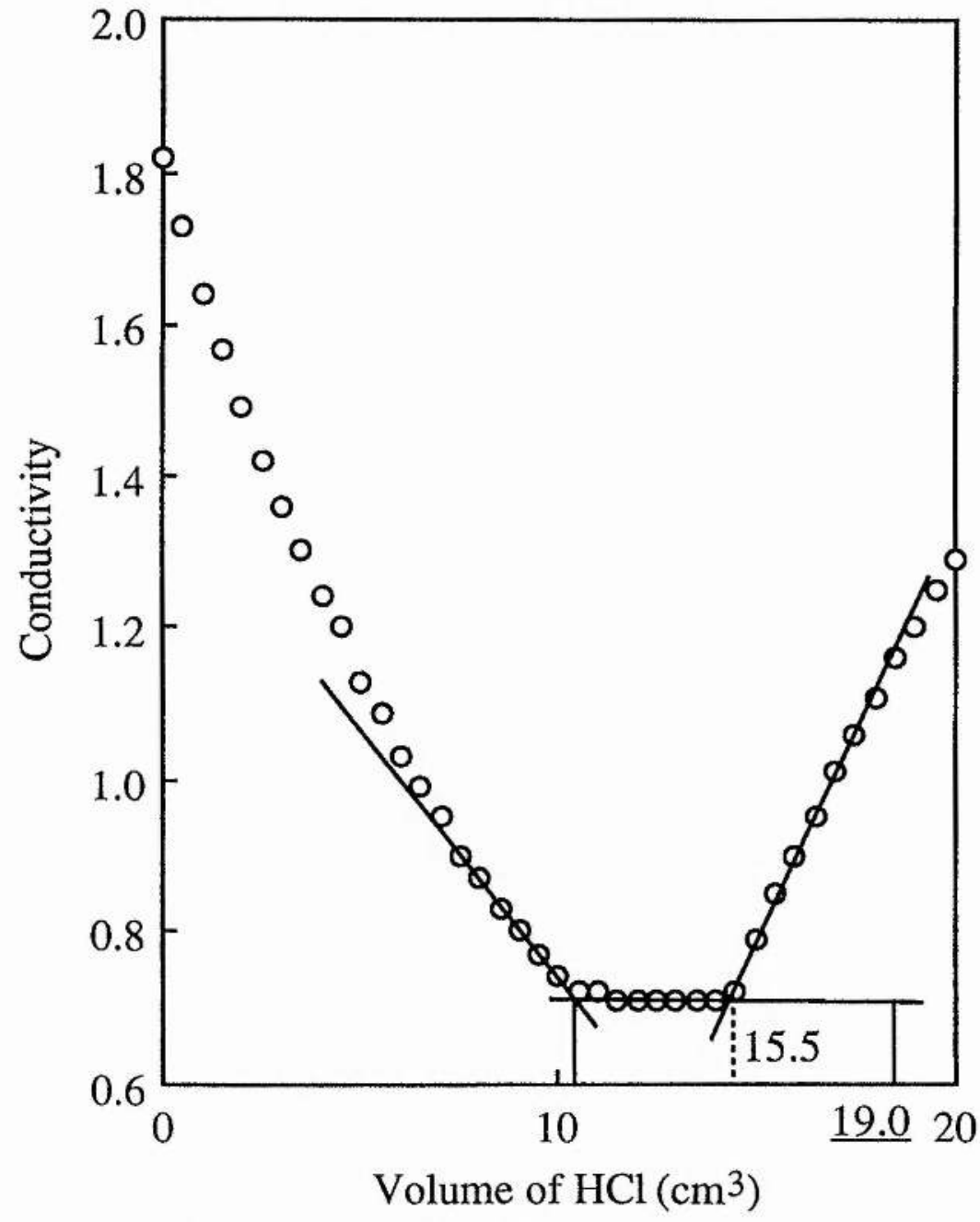

Figure 2.14. Conductometric titration between hydrocarboxylated polybutadiene (in $\mathrm{NaOH}$ ) and $\mathrm{HCl}$ 
In this polymer also the final end point (see Figure 2.14) could not be determined precisely as precipitation of the polymer took place. The end point based on titration was 15.5. This means that some of the $\mathrm{Na}^{+}$ ions bound to the polymer chain are not available for titration with $\mathrm{HCl}$. However, since this is a back titration, the final end point should correspond to the end point obtained for titration of the same amount of $\mathrm{NaOH}$ used. We, have, therefore, assumed that the final end point should be at $19 \mathrm{~cm}^{3}$.

\section{Calculation}

$0.01 \mathrm{gm}$ of the hydrocarboxylated polymer was dissolved in $20 \mathrm{~cm}^{3}$ of $0.01 \mathrm{M} \mathrm{NaOH}$ and titrated with $0.01 \mathrm{M}$ of $\mathrm{HCl}$. Blank titration of $\mathrm{NaOH}$ with $\mathrm{HCl}$ gave $19.0 \mathrm{~cm}^{3}$ as the end point i.e., neutralisation point. First end point when all the $\mathrm{NaOH}$ has reacted with $\mathrm{HCl}=10.5$

Second end point when COONa bound to the polymer has reacted with $\mathrm{HCl}$ (based on blank titration) $=19.0$

Therefore $0.01 \mathrm{gm}$ of hydrocarboxylated product is equivalent to 8.5 $\mathrm{cm}^{3}$ of $0.01 \mathrm{~cm}^{3} \mathrm{M} \mathrm{HCl}$.

This in terms of moles will be

$0.01 \mathrm{gm}=\frac{8.5 \times 0.01}{1000}=8.5 \times 10^{-5} \mathrm{moles}$

Let ' $\mathrm{M}$ ' be the mass in a.m.u. of the hydrocarboxylated product, which containes one proton, then

$$
\frac{0.01 \mathrm{gm}}{\mathrm{M}}=8.5 \times 10^{-5} \text { moles }
$$

Therefore $\mathrm{M}=118$ 
Substituting this value of $M$ in the equation

$$
\frac{\mathrm{a} \times 100+\mathrm{b} \times 54+\mathrm{c} \times 56}{\mathrm{a}}=\mathrm{M}
$$

where a is the proportion of carboxylic acid units in the chain,

$\mathrm{b}$ is the proportion of unreacted units

$\mathrm{c}$ is the proportion of saturation in the starting material $=0.16$

$\frac{\mathrm{a} \times 100+\mathrm{b} \times 54+0.16 \times 56}{\mathrm{a}}=118$

$\mathrm{b} \times 54+0.16 \times 56=18 \mathrm{a}$

We know $a+b=0.84$

Therefore $\mathrm{b}=0.84-\mathrm{a}$

$$
\begin{aligned}
& (0.84-a) 54+0.16 \times 56=18 a \\
& 45.36-54 a+8.96=18 a \\
& 54.32=72 a \\
& a=0.75
\end{aligned}
$$

Substituting the value of $a=0.75$ in the equation $a+b=0.84$ we can arrive at the final composition of the hydrocarboxylated product as

Overall carboxylic acid $=75 \%$

Remaining double bonds $=9 \%$

Saturated C-C bonds $=16 \%$

As can be seen the results obtained from conductometric titration is in reasonable agreement with those from the end group analysis method. 


\subsection{Method 3}

In some cases there are no suitable protons from end groups to use as a standard and where hydrocarboxylation occurs at both the pendant and backbone double bonds, it is necessary to use a combination of both ${ }^{1} \mathrm{H}$ and ${ }^{13} \mathrm{C}$ n.m.r. spectroscopy. Due to different relaxation times for the different carbon atoms and different nuclear Overhauser effects mean that integration of ${ }^{13} \mathrm{C}$ resonances cannot be used without some kind of calibration, it is necessary to obtain some indication of the relative sensitivities of the n.m.r. experiment to the ${ }^{13} \mathrm{C}$ resonances from the carboxylic acid carbon atoms and from the olefinic carbon atoms. For this method to be successful, it is necessary for all ${ }^{13} \mathrm{C}$ spectra of the product polymers to be run under identical conditions so that relative sensitivities obtained from one spectrum can be assumed to be the same as those existing in another spectrum.

We define a factor,' $f^{\prime}$, which, is the ratio between the receptivities of the olefinic and carboxylic carbon atom both terminal and internal. If ' $\mathrm{g}$ ' is the integral obtained from the carboxylic acid carbon atom and ' $h$ ' is the integral obtained from the resonance near $145 \mathrm{ppm}\left(\mathrm{CH}_{2}\right.$ of pendant double bond), then the factor $\mathrm{f}$ is then given by

$$
\frac{g f}{h}=\frac{p}{m}
$$

(where $\mathrm{p}$ corresponds to the fraction of carboxylic acid and $\mathrm{m}$ corresponds to the remaining pendant carbon-carbon double bonds (see Figure 2.11).

Calculating this from a series of different phenyl terminated polymers for which the end group analysis has been used to obtain $p$ 
and $\mathrm{m}$ gives values of $\mathrm{f}$ as shown in Table 2.1. An average value of $\mathrm{f}=4.4$ is obtained. (see Table 4.2 , page 169 for composition*)

\begin{tabular}{|c|c|}
\hline Polymer Number * & 'f' factor \\
\hline 2 & 4.2 \\
4 & 4.4 \\
5 & 4.6 \\
\hline
\end{tabular}

Table 2.1

Using this value of $\mathrm{f}=4.4$ we can calculate the $\mathrm{COOH}$ conversion at the back bone and at the terminal carbon position of the unknown hydrocarboxylated product as shown below.

The relative amounts of back bone and pendant double bonds remaining in the polymer are available from the ${ }^{1} \mathrm{H}$ n.m.r. as described previously according to equation 4 .

If the ratio of the integrals of the ${ }^{13} \mathrm{C}$ resonances from the terminal carbon atom of the remaining pendant double bonds to that from the carboxylic carbon atoms $\frac{h}{g}$ is given by $D$, then

$$
\frac{m}{p}=\frac{D}{f}
$$

remembering (from equation 4 and also see Figure 2.11)

$$
\begin{aligned}
& \frac{\mathrm{m}}{\mathrm{n}+\mathrm{m}}=\mathrm{A} \\
& \mathrm{n}+\mathrm{r}=\mathrm{n}_{\mathrm{o}} \text {, and } \mathrm{m}+\mathrm{p}=\mathrm{p}_{\mathrm{o}}, \\
& \text { Therefore, } \mathrm{p}=\frac{\mathrm{m}_{\mathrm{o}}}{1+\frac{\mathrm{D}}{\mathrm{f}}}
\end{aligned}
$$




$$
\begin{aligned}
& \mathrm{m}=\frac{\mathrm{m}_{\mathrm{o}}}{1+\frac{\mathrm{f}}{\mathrm{D}}} \text { or } \mathrm{m}=\mathrm{p}_{\mathrm{o}}-\mathrm{p} \\
& \text { and } \mathrm{n}=\frac{\mathrm{m}_{\mathrm{o}}}{\mathrm{A}\left(1+\frac{\mathrm{f}}{\mathrm{D}}\right)}(1-\mathrm{A}) \\
& \mathrm{r}=\mathrm{n}_{\mathrm{o}}-\mathrm{n}
\end{aligned}
$$

The values of $\mathrm{p}, \mathrm{m}, \mathrm{n}$ and $\mathrm{r}$ will give both the amount of unreacted double bonds and the amount of conversion (both at the back bone and at the pendant position).

However before applying this method for calculating the percentage conversion (at the internal and pendant carbon-carbon position) of a non-phenyl terminated product, we can check this method by applying to the previous hydrocarboxylation reaction (phenyl terminated polymer).

Example 1 (phenyl terminated polymer)

The ${ }^{1} \mathrm{H}$ n.m.r. spectrum is shown in Figure 2.13 and the ${ }^{13} \mathrm{C}$ spectrum is shown in Figure 2.15.

From ${ }^{13} \mathrm{C}$ n.m.r. spectrum we calulate the value of $\mathrm{D}=\frac{8}{27}=0.30$ We know the value of $f=4.4$ and $A=0.45 \quad$ (value of $A$ from eq 29)

Applying the values of $\mathrm{f}$ and $\mathrm{D}$ in equation 35 we get, 


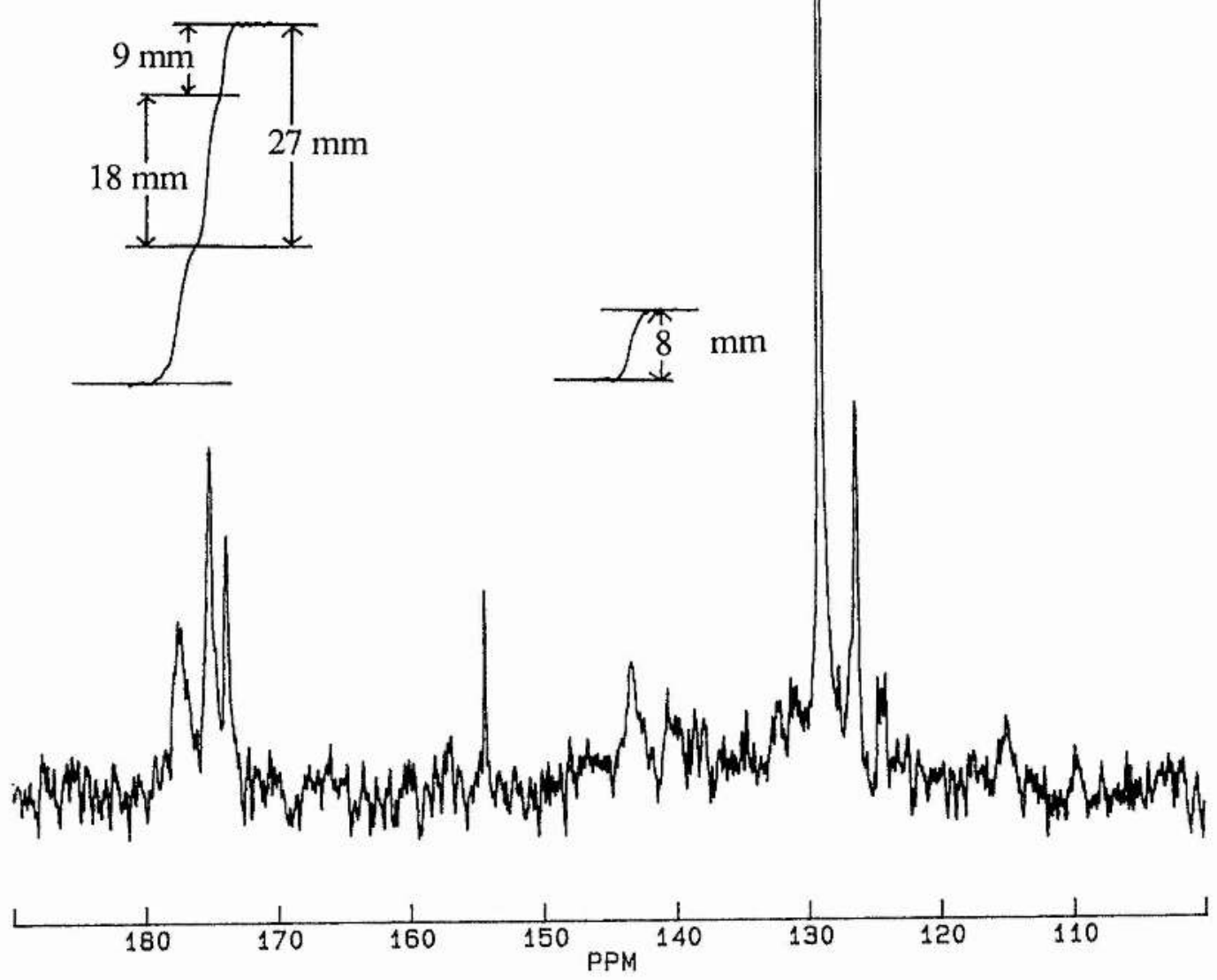

Figure $2.15{ }^{13} \mathrm{C}$ n.m.r spectrum of hydrocarboxylated polybutadiene (phenyl terminated) 


$$
\mathrm{p}=\frac{0.53}{1+\left(\frac{0.30}{4.4}\right)}=\quad \frac{0.53}{1.06}=0.50
$$

i.e., $50 \%$ pendant $\mathrm{COOH}$

Subtracting this value from $53 \%$ (initial starting pendant $\mathrm{C}=\mathrm{C} \%$ ) will give the remaining pendant carbon-carbon double bonds

i.e., $\mathrm{m}=53 \%-50 \%=3 \%$.

Once again applying the values of $\mathrm{f}=4.4$ and $\mathrm{A}=0.45$ and $\mathrm{D}=0.30$ in equation 37

$$
\mathrm{n}=\frac{0.53}{0.45\left(1+\frac{4.4}{0.30}\right)}(1-0.45)
$$

$\mathrm{n}=0.0412$ i.e, $4 \%$ back bone double bonds

$\mathrm{r}=31 \%-4 \%=27 \%$ back bone $\mathrm{COOH}$

The composition of the hydrocarboxylated product will be as shown in Table 2.2. Values obtained based on end group (phenyl) analysis for the same polymers are included for comparision. 


\begin{tabular}{|c|c|c|}
\hline $\begin{array}{c}\text { Various constituents } \\
\text { of hydrocarboxylated } \\
\text { polybutadiene }\end{array}$ & $\begin{array}{c}\text { Results obtained based } \\
\text { on 'f' factor (\%) }\end{array}$ & $\begin{array}{c}\text { Results obtained based } \\
\text { on end group analysis } \\
\text { method (\%) }\end{array}$ \\
\hline $\begin{array}{c}\text { Remaining bb dbs } \\
\text { COOH at bb position }\end{array}$ & 4 & 3 \\
Remaining pd dbs & 3 & 28 \\
COOH at pd position & 50 & 3 \\
Saturated C-C bonds & 16 & 50 \\
& 77 & 16 \\
\hline Total COOH (bb + pd)
\end{tabular}

Table 2.2

Calculation of percentage of carboxylic acid at the terminal carbon position and penultimate carbon position.

Once the amount of carboxylic acid at the pendant position is known it is possible to estimate from ${ }^{13} \mathrm{C}$ n.m.r. the relative amounts of carboxylic acid at the terminal and the penultimate carbon positions of the pendant carbon units. This is done by measuring the heights of the peaks corresponding to terminal carbon position (175 ppm) and penultimate carbon position (173 ppm). An example is given below ( see Figure 2.14)

We know from our calculations, (based on $f$ factor, see Table 2.2) that amount of carboxylic acid at the pendant position $=50 \%$

Height of the peak at $175 \mathrm{ppm}$ corresponding to terminal carbon position $=18 \mathrm{~mm}$

Height of the peak at $173 \mathrm{ppm}$ corresponding to penultimate carbon position $=9 \mathrm{~mm}$ 
Therefore $50 \% \mathrm{COOH}=27 \mathrm{~mm}$

Therefore $18 \mathrm{~mm}=$ ? $\mathrm{COOH}$

$$
=\frac{50}{27} \times 18=33 \%
$$

Hence the amount of carboxylic acid at the terminal carbon position is equal to $33 \%$. From this value obtained we can calculate the amount of carboxylic acid at the penultimate carbon position i.e.,

$$
50 \%-33 \%=17 \% \mathrm{COOH}
$$

Hence the final composition of the hydrocarboxylated product is shown below (Table 2.3)

\begin{tabular}{|ccc|crr|c|}
\hline \multicolumn{2}{|c|}{ Remaining db bonds\% } & \multicolumn{3}{|c|}{ Carboxylic acid(\%) } & Total carboxylic acid \\
Cis & Trans & Pendant & $\mathrm{Bb}$ & $\mathrm{Tr}$ & Int & $(\%)$ \\
\hline 4 & 3 & 27 & 33 & 17 & 77 \\
\hline
\end{tabular}

where $\mathrm{db}=$ double bonds, $\mathrm{Bb}=$ back bone, $\mathrm{Tr}=$ terminal and $\operatorname{Int}=$ Internal

Table 2.3

As can be seen from the table above the values obtained on using $f$ factor agree with those of the end group analysis and conductometric titration.

Example 2 (non-phenyl terminated polymer)

The composition of the initial starting material was $(37 \%$ trans, $23 \%$ cis and $40 \%$ pendant carbon-carbon double bonds). The ${ }^{1} \mathrm{H}$ n.m.r 
spectrum and ${ }^{13} \mathrm{C}$ n.m.r. spectrum of the hydrocarboxylated product is shown in Figure 2.16 (a) and (b).

From ${ }^{1} \mathrm{H}$ n.m.r. spectrum of the hydrocarboxylated product the value of $\mathrm{A}$ is calculated using equation 4 i.e.,

$$
\frac{\mathrm{m}}{\mathrm{m}+\mathrm{n}}=\frac{2 \times 13}{2 \times 19+13}=0.51=\mathrm{A}
$$

From $13 \mathrm{C}$ n.m.r. spectrum of the hydrocarboxylated product the value of

$$
\mathrm{D}=\frac{11}{7}=1.6
$$

On substituting the values of $A=0.51, D=1.6$ and $f=4.4$ in equations $35,36,37$ and 38 we arrive at the composition of the final hydrocarboxylated product as

Remaining back bone double bonds $=10 \%$

Carboxylic acid at the back bone $=50 \%$

Remaining pendant double bonds $=11 \%$

Carboxylic acid at the pendant position $=29 \%$

By measuring the heights of the peaks corresponding to terminal carbon position $(175 \mathrm{ppm})$ and penultimate carbon position $(173 \mathrm{ppm})$ of the ${ }^{13} \mathrm{C}$ n.m.r. spectrum we can calculate the amount of carboxylic acid at the terminal position and at the penultimate carbon position.

Height of the peak at $175 \mathrm{ppm}$ corresponding to terminal carbon position $=5.5 \mathrm{~mm}$

Height of the peak at $173 \mathrm{ppm}$ corresponding to penultimate carbon position $=1.5 \mathrm{~mm}$

We know $29 \% \mathrm{COOH}=7 \mathrm{~mm}$ 
Figure 2.16 (a)

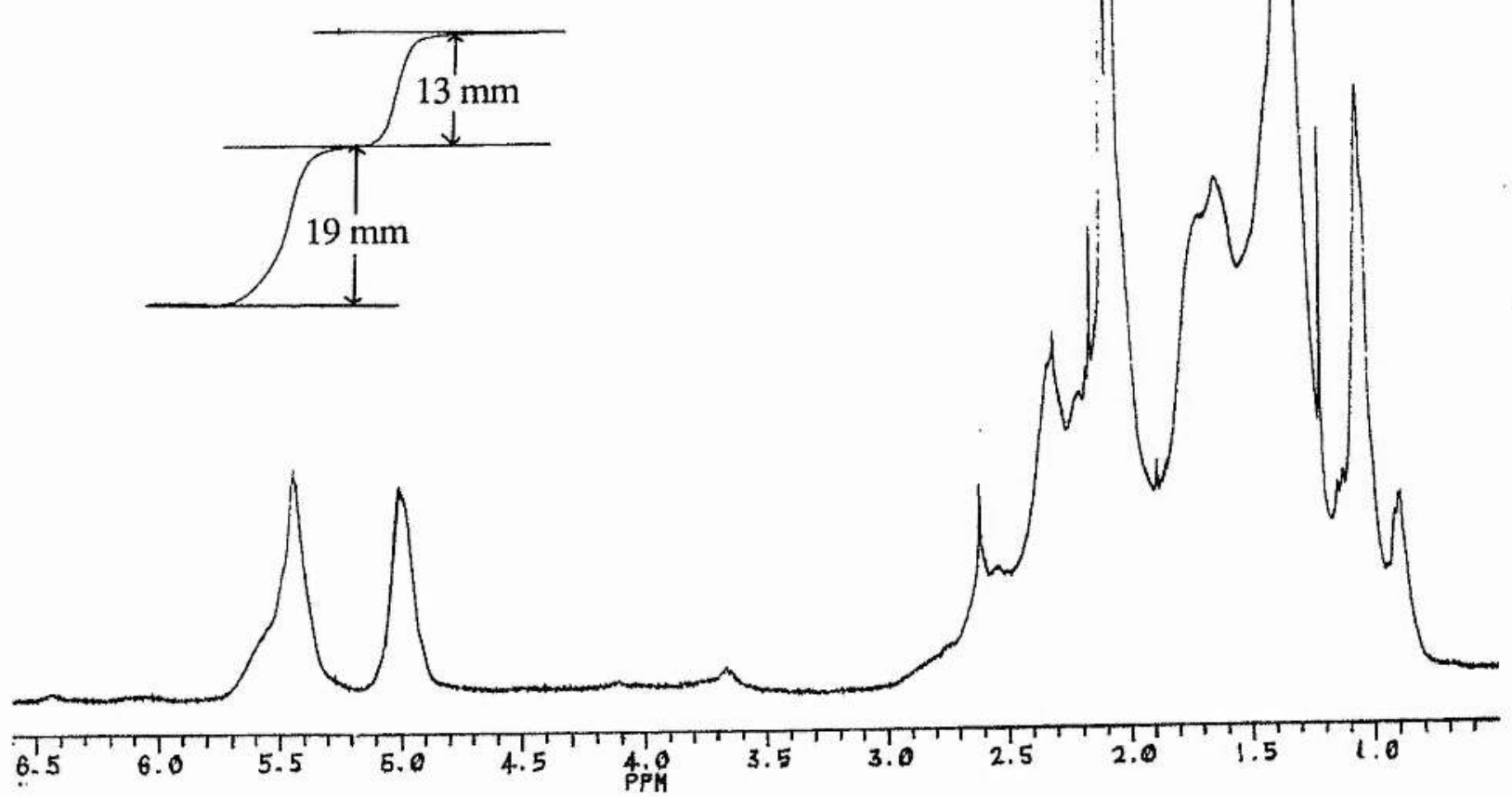

Figure $2.16(b)$

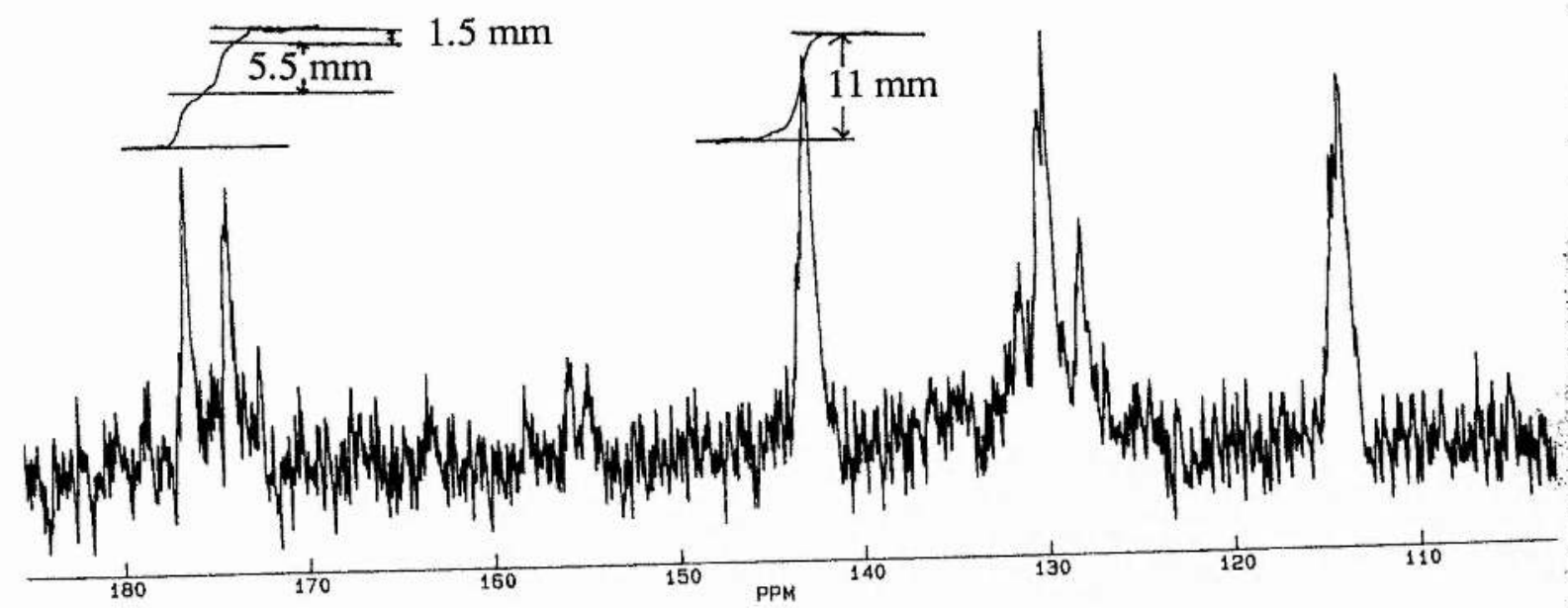

Figure 2.16 (a) ${ }^{1} \mathrm{H}$ n.m.r. spectrum of hydrocarboxylated polybutadiene (hydrogen terminated) (b) ${ }^{13} \mathrm{C}$ n.m.r spectrum of corresponding hydrocarboxylated polybutadiene 
Therefore $5.5 \mathrm{~mm}=? \mathrm{COOH}$

$$
=\frac{29}{7} \times 5.5=23 \%
$$

Hence the amount of carboxylic acid at the terminal carbon position is equal to $33 \%$. From this value obtained we can calculate the amount of carboxylic acid at the penultimate carbon position i.e.,

$$
29 \%-23 \%=6 \% \mathrm{COOH}
$$

The final composition of the hydrocarboxylated product is shown below

\begin{tabular}{|c|c|c|c|c|c|}
\hline \multicolumn{2}{|c|}{ Remaining db bonds } & \multicolumn{3}{|c|}{ Carboxylic acid } & \multirow[t]{2}{*}{ Total carboxylic acid } \\
\hline Cis Trans & Pendant & $\mathrm{Bb}$ & $\operatorname{Tr}$ & Int & \\
\hline 10 & 11 & 50 & 23 & 6 & 79 \\
\hline
\end{tabular}
(Table 2.4).

where $\mathrm{db}=$ double bonds, $\mathrm{Bb}=$ back bone, $\mathrm{Tr}=$ terminal and Int $=$ Internal

Table 2.4

\subsubsection{Infrared spectroscopy}

Various workers have developed IR methods for analysing polymers. However the earlier attempts were seriously handicapped by the lack of suitable reference compounds for selecting the analytical bands for calculating the absorption coefficients. 
By using the bands at $966,909,724 \mathrm{~cm}^{-1}$ obtained from the I.R. analysis of polybutadienes which were not rich in one particular kind of saturation, Hampton 75 tried to improve the absorption coefficients by a successive series of approximations. Binder 76 assigned the band at 680 $\mathrm{cm}^{-1}$ to $\mathrm{cis}$ units, by a modification of the method due to Hampton. Richardson 77 did not directly measure 1,4 cis units. Instead he used the typical wavelength at 966 , and $909 \mathrm{~cm}^{-1}$ for calculating percentages of trans and pendant units assuming the rest to be cis units.

Silas and coworkers 78 in 1959 published a method for determining 1, 4 cis units, using an empirical function for the area of the absorption bands between 833 and $634 \mathrm{~cm}^{-1}$. This was used for the calculation of the absorption coefficients of polybutadiene with quite high contents of 1,4 trans , 1,2 and 1,4 cis units. However this method did not take into account the region between 833 and $634 \mathrm{~cm}^{-1}$ where absorption bands can also occur due to non 1,4 cis units.

In the same year Morrero and coworkers 79 came up with formulae for calculating the various units of polybutadiene. They measured the bands at $967,913-910,740-732\left(\mathrm{~cm}^{-1}\right)$ generated by out of plane deformation of the $=\mathrm{C}-\mathrm{H}$ bond in 1,4 trans , 1,2 and 1,4 cis units respectively and proposed formulae based on measurement of absorption coefficients for calculating the different percentages of 1,4 and 1,2 units in polybutadiene.

$$
\begin{aligned}
& \mathrm{D}_{967}=\left(\mathrm{K}_{1,4 \text { trans }}^{967} \cdot \mathrm{P}_{1,4 \text { trans }}+\mathrm{K}_{1,2}^{967} \cdot \mathrm{P}_{1,2}+\mathrm{K}_{1,4 \text { cis }}^{967} \cdot \mathrm{P}_{1,4 \text { cis }}\right) \cdot \mathrm{S} \\
& \mathrm{D}_{913-910}=\left(\mathrm{K}_{1,2}^{910} \cdot \mathrm{P}_{1,2}+\mathrm{K}_{1,4 \text { cis }}^{910} \cdot \mathrm{P}_{1,4 \text { cis }}\right) \cdot \mathrm{S} \\
& \mathrm{D}_{740-732}=\left(\mathrm{K}_{1,2}^{740} \cdot \mathrm{P}_{1,2}+\mathrm{K}_{1,4 \text { cis }}^{740} \cdot \mathrm{P}_{1,4 \text { cis }}\right) \cdot \mathrm{S}
\end{aligned}
$$


Where $\quad D_{\lambda}$ is the optical density at wavelength $\lambda$

$\mathrm{K}_{\mathrm{x}} \lambda$ is the absorption coeffecient of the component $\mathrm{x}$ at the wavelength $\lambda$ expressed in $\mathrm{mg}^{-1} \mathrm{~cm}^{-1} .10 \mathrm{~cm}^{3}$

$P_{x}$ is the weight of the component $x$ in $10 \mathrm{~cm}^{3}$ of the solution

$\mathrm{S}$ is the thickness in $\mathrm{cm}$ of the cell used.

The relative percentage is given by

$$
\begin{array}{lll}
\mathrm{C}_{1,4 \text { trans } \%} & =P_{1,4 \text { trans }} \cdot \frac{100}{P} \\
C_{1,2} \% & =P_{1,2} \cdot \frac{100}{P} \\
C_{1,4 \text { cis } \%} & =P_{1,4 \text { trans }} \cdot \frac{100}{P}
\end{array}
$$

$\mathrm{P}$ being the weight in milligrams of polybutadiene dissolved in $10 \mathrm{~cm}^{3}$ $\mathrm{CS}_{2}$.

Nippon Soda Company 80 modified the above method by measuring the absorption of the trans double bonds at $967 \mathrm{~cm}^{-1}$ and 1,2 double bonds at $912 \mathrm{~cm}^{-1}$ in carbon disulphide solution using a liquid cell and arrived at the empirical formulae as shown below.

$$
\begin{aligned}
& \mathrm{V}(1,2-\mathrm{C}-\mathrm{H})=\mathrm{V}_{\mathrm{abs}} \times 0.03746 \\
& \mathrm{~T}(\text { trans } \mathrm{C}-\mathrm{H})+\mathrm{T}_{\mathrm{abs}} \times 0.04292-\mathrm{V}_{\mathrm{abs}} \times 0.00129 \\
& 1,2-\mathrm{C}-\mathrm{H}(\%)=\frac{\mathrm{V}}{\mathrm{V}+\mathrm{T}} \times 100 \\
& \text { Trans } \mathrm{C}-\mathrm{H}(\%)=\frac{\mathrm{T}}{\mathrm{V}+\mathrm{T}} \times 100
\end{aligned}
$$

(where $\mathrm{V}=$ pendant and $\mathrm{T}=$ trans units). 
However there are a few problems that we encountered in using the above mentioned methods of analysis. This is illustrated as follows.

Polybutadiene of the composition - $12 \%$ cis , $19 \%$ trans , 53\% pendant, and $16 \%$ saturation and its hydrocarboxylated product (selective hydrocarboxylation of the pendant carbon-carbon double bonds) of the composition $12 \%$ cis , 19\% trans, $10 \%$ pendant, $43 \%$ $\mathrm{COOH}$ (overall conversion) and $16 \%$ saturation previously determined by ${ }^{1} \mathrm{H}$ n.m.r. spectroscopy was chosen to illustrate the method of determining the composition of the hydrocarboxylated product by I.R. spectroscopy.

Figure 2.17 (a) and (b) shows the I.R. spectra of polybutadiene and its corresponding hydrocarboxylated product in the region 1200 $750 \mathrm{~cm}^{-1}$. The peaks at $912 \mathrm{~cm}^{-1}$ is associated with pendant double bonds, and the peak at $967 \mathrm{~cm}^{-1}$ is associated with trans double bonds. The heights of the peaks are measured from the base line as shown in Figure 2.17 (a) and (b).

\begin{tabular}{|c|c|c|}
\hline Polymer & Pendant $\left(912 \mathrm{~cm}^{-1}\right)$ & Trans $\left(967 \mathrm{~cm}^{-1}\right)$ \\
\hline Starting material & $78 \mathrm{~mm}$ & $33 \mathrm{~mm}$ \\
Product material & $55 \mathrm{~mm}$ & $40 \mathrm{~mm}$ \\
\hline
\end{tabular}

Therefore if the product had the same composition as the starting material, the height of the pendant peak at $912 \mathrm{~cm}^{-1}$ should be

$$
\frac{78 \times 40}{33}=95.54 \mathrm{~mm}
$$

But actually the height of pendant peak at $912 \mathrm{~cm}^{-1}=55 \mathrm{~mm}$ 

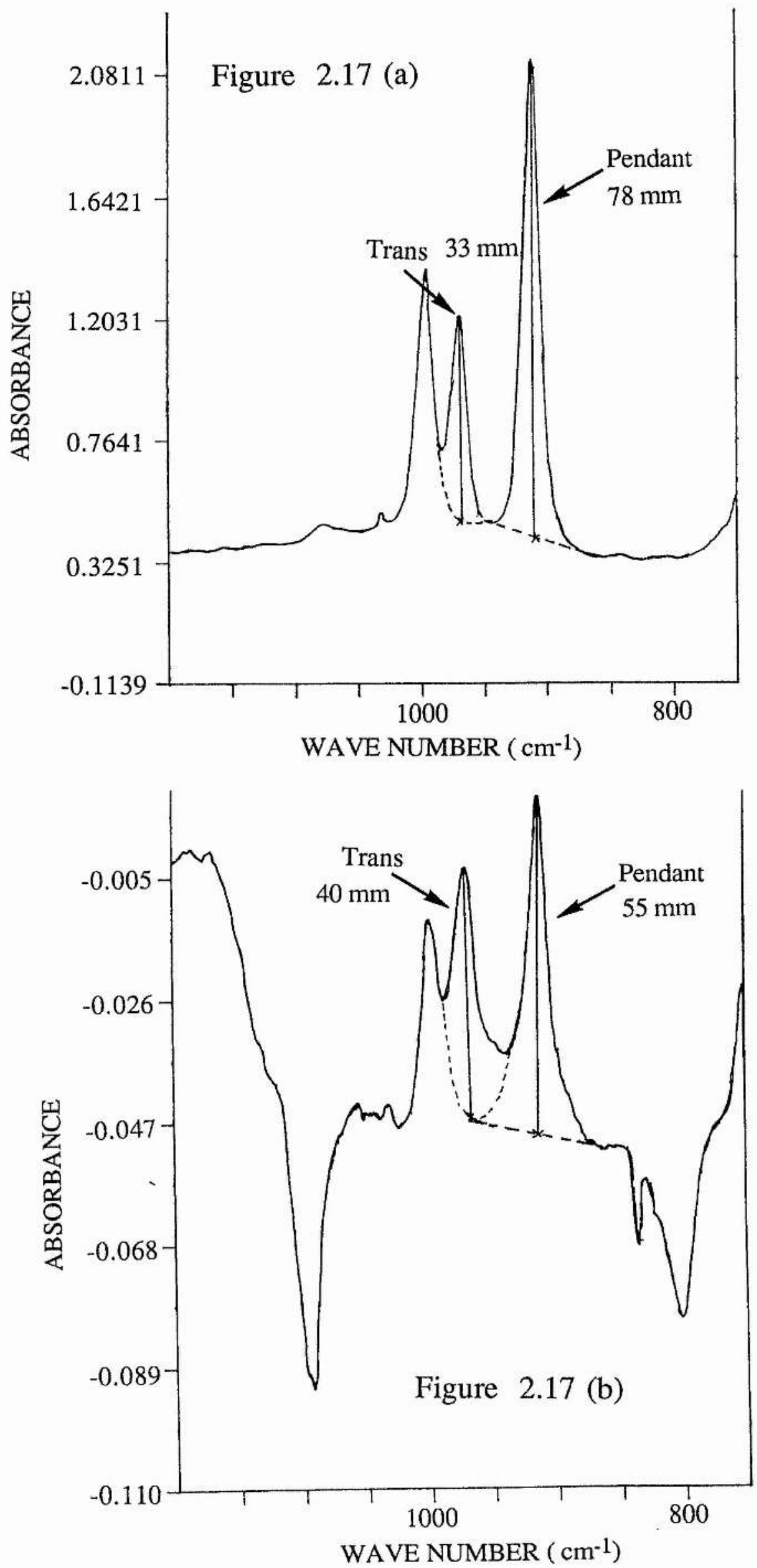

Figure 2.17 (a) I.R. spectrum of polybutadiene

(b) I.R. spectrum of corresponding hydrocarboxylated polybutadiene 
Therefore amount of double bonds remaining

$$
=\frac{55}{94.54}=0.58
$$

From this the percentage of polymer units remaining as pendant double bonds can be calculated i.e.,

$$
=0.58 \times 53=31 \%
$$

Percentage of carboxylic acid $=53-31=22 \%$

Hence the final composition of the hydrocarboxylated product as determined by I.R. is shown in Table 2.4. The results from ${ }^{1} \mathrm{H}$ n.m.r. analysis for the same polymer is shown for comparision.

\begin{tabular}{|c|c|c|}
\hline $\begin{array}{c}\text { Various constituents } \\
\text { of hydrocarboxylated } \\
\text { polybutadiene }\end{array}$ & $\begin{array}{c}\text { Results obtained from } \\
\text { Infrared Spectroscopy } \\
(\%)\end{array}$ & $\begin{array}{c}\text { Results obtained from } \\
\text { 1 H n.m.r.spectroscopy } \\
(\%)\end{array}$ \\
\hline Cis & 12 & 12 \\
Trans & 19 & 19 \\
Pendant & 31 & 10 \\
COOH (Over all) & 22 & 43 \\
Saturation & 16 & 16 \\
\hline
\end{tabular}

Table 2.4

From the table it can be seen that the results obtained from I.R. analysis is not in agreement with the ${ }^{1} \mathrm{H}$ n.m.r. results. This may be due to the following:

1. Extensive overlap of the relevant bands in the hydrocarboxylated 
Figure 2.18 (a)

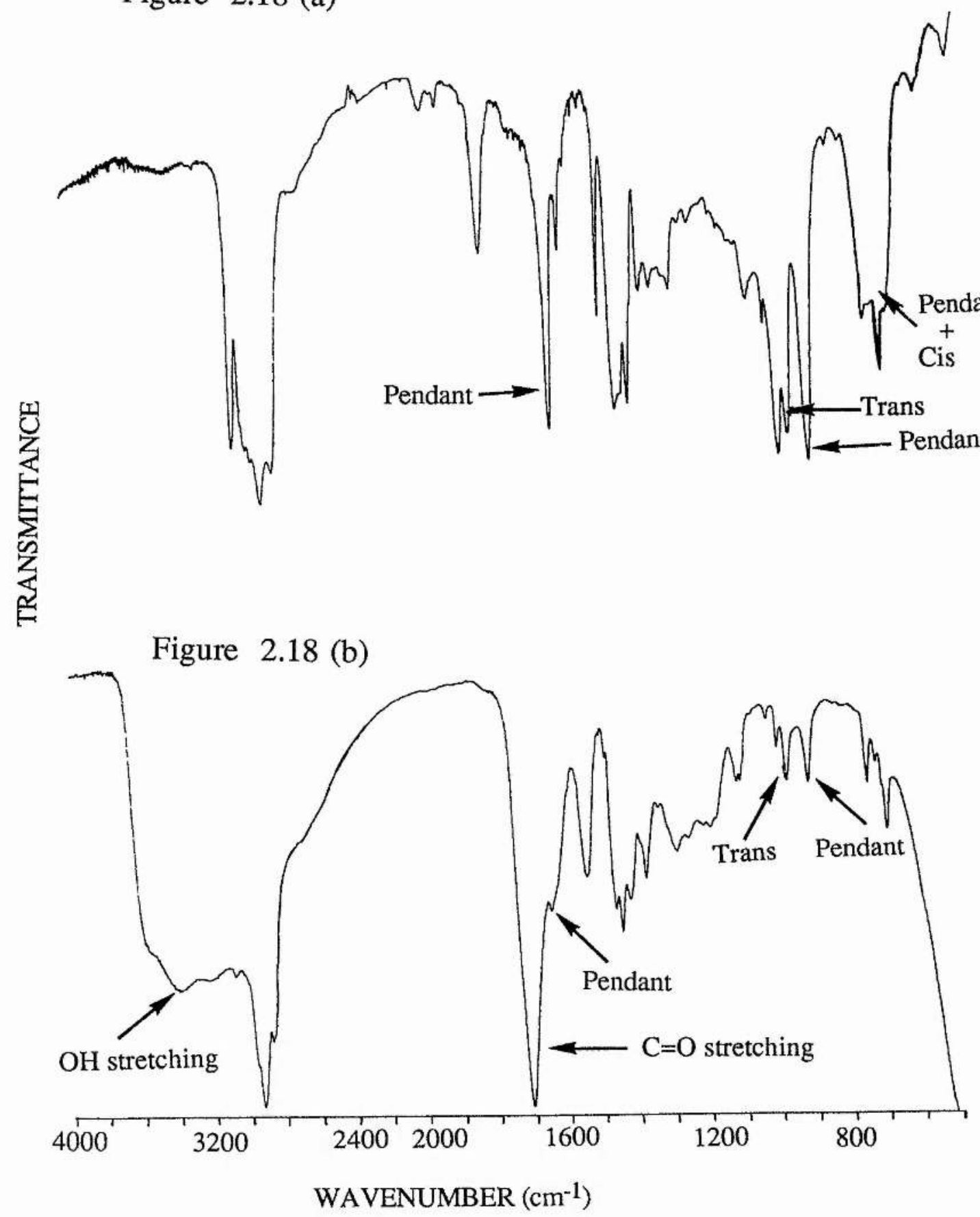

Figure 2.18 (a) I.R. spectrum of polybutadiene

(b) I.R. spectrum of corresponding hydrocarboxylated polybutadiene 
product make it difficult to obtain measurements, as an accurate assessment of the baseline could not be made (see Figure 2.17 (a) and (b)).

2. Furthermore, the products are only sparingly soluble in organic solvents and hence only give weak solutions.

Therefore it can be concluded from the above that only qualitative and not quantitative information could be obtained about the extent of the hydrocarboxylation reaction. The I.R. spectra of both the starting material i.e., polybutadiene showing the various peaks is shown in Figure 2.18 (a) and the hydrocarboxylated product is shown in Figure 2.18 (b). The disappearance of the characteristic peaks of unsaturation at $967,913-910$, and $740-732 \mathrm{~cm}^{-1}$ and the appearance of the characteristic peak for the acid group at $1727 \mathrm{~cm}^{-1}$ and a broad peak at $3310 \mathrm{~cm}^{-1}$, characteristic of the $\mathrm{OH}$ stretching vibration confirms a qualitative hydrocarboxylation reaction.

\subsubsection{Microanalysis}

Microanalysis of polybutadiene (intial composition of the starting material $2 \%$ saturated units, $14 \%$ trans, $84 \%$ pendant carbon-carbon double bonds) selectively hydrocarboxylated at terminal carbon position of the pendant group ( $>80 \%$ conversion) gave the following results on elemental analysis.

$\begin{array}{lccc} & \text { Carbon } & \text { Hydrogen } & \text { Sodium } \\ \text { Theoretical Composition } & 62.12 & 7.42 & 6.66 \\ \text { Result of Analysis } & 61.22 & 10.87 & 7.10\end{array}$


N.M.R. studies of the hydrocarboxylated product does show the presence of a trace of triphenylphosphine oxide. The discrepancy in the increase of the percentage of hydrogen observed is probably due to the presence of water in the product, hydrogen bonded to sodium ions or to the carboxylic acid group.

The amount of sodium in the hydrocarboxylated product is higher than expected from the titration results. A possible reason for this is that during titration, the sodium ions have enough time to leave the polymer and react with $\mathrm{HCl}$. In the preparations, however, the polymer is precipitated very quickly, by addition of a large number of excess of $7 \mathrm{M} \mathrm{HCl}$. Under these conditions, it is evident that some of the sodium ions are trapped within the bulk polymer (see Chapter 3, section 3.4 Experimental Section)

\section{$\underline{2.3 \text { Conclusion }}$}

We have examined four polymers using a variety of different methods. The results obtained by various methods are shown in Table 2.5. Examination of the table shows a good correlation between conductometric titration or methods using ${ }^{1} \mathrm{H}$ n.m.r. and ${ }^{13} \mathrm{C}$ n.m.r. for the selectively functionalised polymer, suggesting that these methods are relatively reliable, although ${ }^{1} \mathrm{H}$ and ${ }^{13} \mathrm{C}$ n.m.r. spectroscopy give more detailed information. For polymers which are phenyl terminated and in which hydrocarboxylation occurs at more than one site, methods based on end group analysis are applicable whilst for polymers that are not phenyl terminated a combination of ${ }^{1} \mathrm{H}$ and ${ }^{13} \mathrm{C}$ n.m.r data are required for analysis. The level of confidence of the results obtained for these polymers must be considered lower than that pertaining to the 
selectively hydrocarboxylated polymers. Finally, there appears to be serious problems for the analysis of hydrocarboxylated polybutadienes using I.R. spectrosocopy.

\begin{tabular}{|c|c|c|c|c|c|c|}
\hline Polymer & $\begin{array}{c}\text { Method } \\
\text { of } \\
\text { analysis }\end{array}$ & $\begin{array}{l}\text { bb dbs } \\
\text { (n) }(\%)\end{array}$ & $\begin{array}{c}\mathrm{bb} \\
\mathrm{COOH} \\
(\mathrm{r})(\%) \\
\end{array}$ & $\begin{array}{l}\text { pd dbs } \\
(\mathrm{m})(\%)\end{array}$ & $\begin{array}{c}\mathrm{pd} \\
\mathrm{COOH} \\
\text { (p) }(\%)\end{array}$ & $\begin{array}{l}\text { Saturat- } \\
\text { ed units } \\
\text { (q) }(\%) \\
\end{array}$ \\
\hline \multirow[t]{3}{*}{ A } & $\begin{array}{l}\text { (i) Titra } \\
\text { tion }\end{array}$ & 31 & - & 12 & 41 & 16 \\
\hline & $\begin{array}{l}\text { (ii) }{ }^{1} \mathrm{H} \\
\text { n.m.r. }\end{array}$ & 31 & - & 10 & 43 & 16 \\
\hline & (iii) I.R. & 31 & - & 31 & 22 & 16 \\
\hline \multirow[t]{2}{*}{ B } & $\begin{array}{l}\text { (i) }{ }^{1} \mathrm{H} \\
\text { n.m.r. }\end{array}$ & 31 & - & 5 & 48 & 16 \\
\hline & $\begin{array}{l}\text { (ii) End } \\
\text { group } \\
\text { analysis }\end{array}$ & 31 & - & 5 & 48 & 16 \\
\hline \multirow[t]{2}{*}{$\mathrm{C}$} & $\begin{array}{l}\text { (i) End } \\
\text { group } \\
\text { analysis }\end{array}$ & 3 & 28 & 3 & 50 & 16 \\
\hline & $\begin{array}{l}\text { (ii) }{ }^{1} \mathrm{H} \\
\text { and }{ }^{13} \mathrm{C} \\
\text { n.m.r. }{ }^{*}\end{array}$ & 4 & 27 & 3 & 50 & 16 \\
\hline
\end{tabular}

Table 2.5 


\section{Chapter 3}

Hydrocarboxylation of polybutadienes catalysed by the palladium complex $\left[\mathrm{PdCl}_{2}\left(\mathrm{PPh}_{3}\right)_{2}\right]-\mathrm{SnCl}_{2}$.

\subsection{Introduction}

In this chapter we will discuss our results on the hydrocarboxylation of polybutadienes catalysed by the palladium complex $\left[\mathrm{PdCl}_{2}\left(\mathrm{PPh}_{3}\right)_{2}\right]-\mathrm{SnCl}_{2}$. However, it is pertinent to first review the various post polymeric modifications such as, hydrosilylation, hydrogenation, hydroformylation and epoxidation. on preformed polymers, particularly polybutadienes.

\subsubsection{Hydrosilylation}

The first report on hydrosilylation of a polymer was reported by Barry and coworkers 81 . They used trichlorosilane to hydrosilylate natural hydrocarbons e.g. guttapercha and balata, as well as synthetic elastomeric butadiene-styrene copolymers (Equation 3.1). No catalyst was used in these reactions.

$$
\sim \mathrm{HSiCl}_{3} \stackrel{300^{\circ} \mathrm{C}}{\mathrm{C}_{6} \mathrm{H}_{6}} \rightarrow \underset{\mathrm{CH}}{\longrightarrow}=\mathrm{CH}_{2}+\underset{\mathrm{CH}}{\longrightarrow} \mathrm{CH}_{2} \stackrel{\mathrm{Si}}{\mathrm{S}}-
$$

where, $\mathrm{mm}=$ natural rubber or synthetic polymer

Equation 3.1. 
The first report of a catalytic, post hydrosilylation of polybutadiene using a transition metal catalyst complex appeared in a Japanese patent by Kunio and Kimitaka 82 . They were effective in hydrosilylating 1,2 polybutadiene with pentamethyldisiloxane to give hydrosilylated polybutadiene (Equation 3.2).

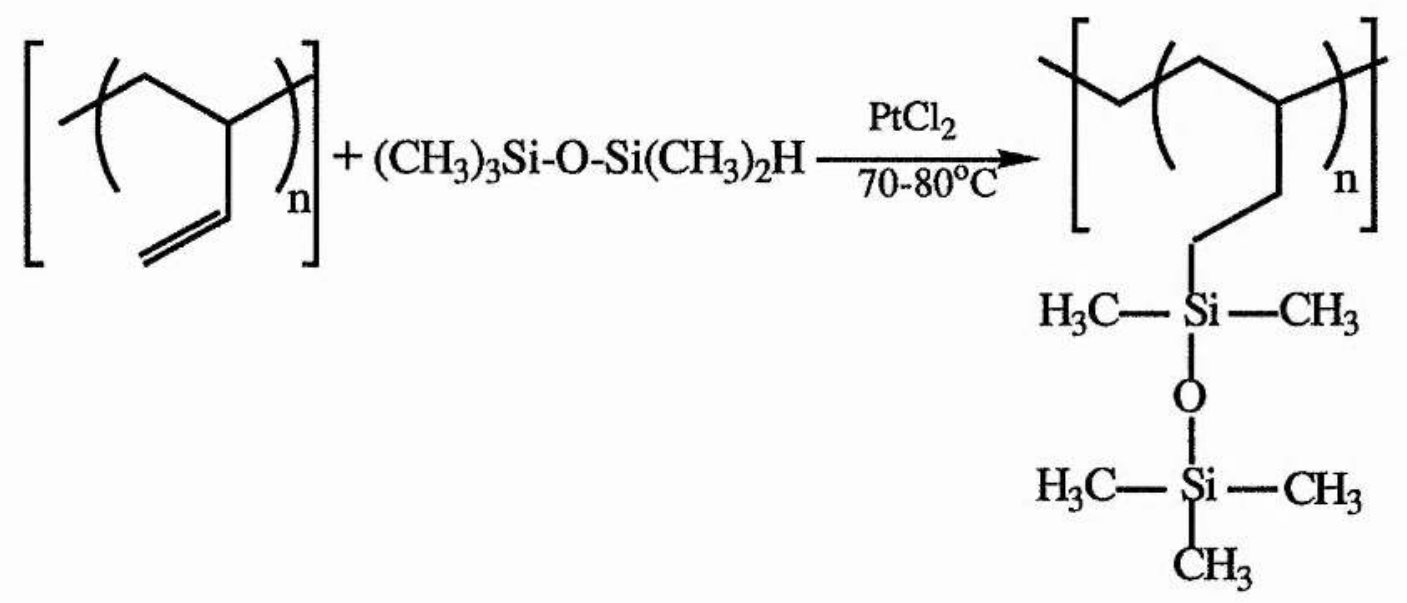

Equation 3.2

Cameron and Qureshi 83 have reported the exclusive hydrosilylation of polybutadiene containing both internal and pendant alkene bonds exclusively at the terminal position (Equation 3.3). These hydrosilylated polybutadienes were then coupled with salts of polystyrene and poly(a-methyl styrene).

Michel and coworkers 84 in a French patent report hydrosilylation of hydroxy terminated polybutadiene, in the presence of chloroplatinic acid, with the hydrosilylating agent, $\left[\left(\mathrm{CH}_{3}\right)_{2} \mathrm{SiH}\left(\mathrm{CH}_{2}\right)_{3} \mathrm{OCH}_{2} \mathrm{CH}_{2} \mathrm{OC}_{2} \mathrm{H}_{5}\right.$.] Information about the composition of the final hydrosilylated polybutadiene is not given. 
<smiles>C=CC(C=CCCC)CC(C)(C)CC=CCC(C)(C)C</smiles>

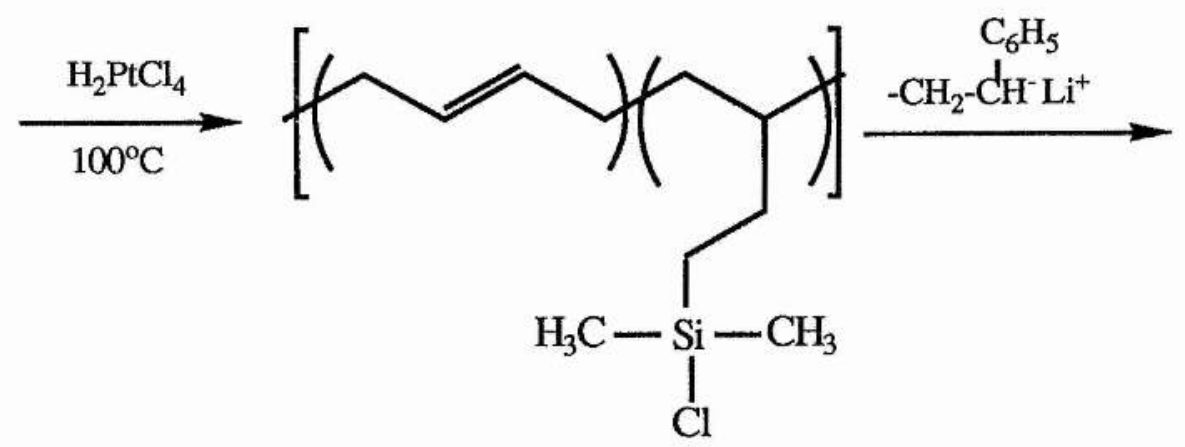<smiles>CC(C/C=C/CC(C)(C)C)CC[Si](C)(C)C(CI)c1ccccc1</smiles>

Equation 3.3

Michel and coworkers 85 in another European patent report hydrosilylation of the pendant alkene bonds of hydroxy terminated polybutadiene $(1,2$ units $\geq 90 \%)$ with $\left[\mathrm{Bi}\left(\mathrm{CH}_{2}\right)_{5} \mathrm{SiH}\left(\mathrm{CH}_{3}\right)_{2}\right]$, again in the presence of chloroplatinic acid. The amount of conversion of the pendant alkene bonds is not reported.

Guo, Farwarha and Rempel ${ }^{74}$ have reported hydrosilylating the pendant groups of polybutadienes (with 1,2 units ranging from 
$45-90 \%$ ), with a variety of hydrosilylating agents in the presence of [RhCl(PPh3)3] (Equation 3.4).
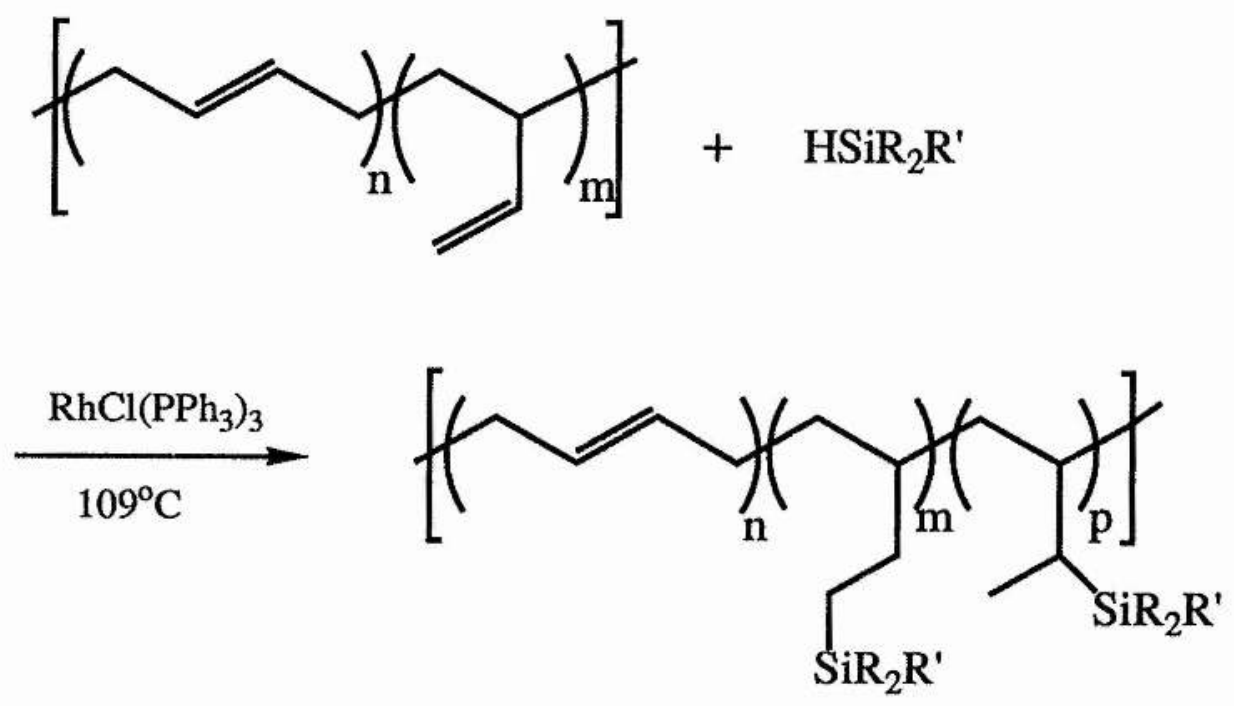

$$
\begin{aligned}
& \text { where } \mathrm{p}=0 \text { for } \mathrm{R}=\mathrm{R}^{\prime}=\mathrm{CH}_{3}, \mathrm{C}_{2} \mathrm{H}_{5}, \mathrm{C}_{4} \mathrm{H}_{9}, \mathrm{C}_{2} \mathrm{H}_{5} \mathrm{O} \\
& \text { and, } \mathrm{p}=0 \text { for } \mathrm{R}=\mathrm{CH}_{3}, \mathrm{R}^{\prime}=\mathrm{C}_{6} \mathrm{H}_{5}
\end{aligned}
$$

Equation 3.4

Hydrosilylation with triethylsilane, trimethylsilane, tri-n-butylsilane or tri-ethoxy silane results in the exclusive formation of the antiMarkownikov addition product, while dimethylphenylsilane addition produces both anti-Markownikov and Markownikov addition products. The results suggest that the nature of the substituents in the silanes play an important role in selectivity.

Cole-Hamilton and coworkers 86 have successfully hydrosilylated the $c i s$ and pendant carbon-carbon double bonds of polybutadiene (40$90 \% 1,2$ units) with a variety of hydrosilylating agents in the presence of chloroplatinic acid (Equation 3.5). 

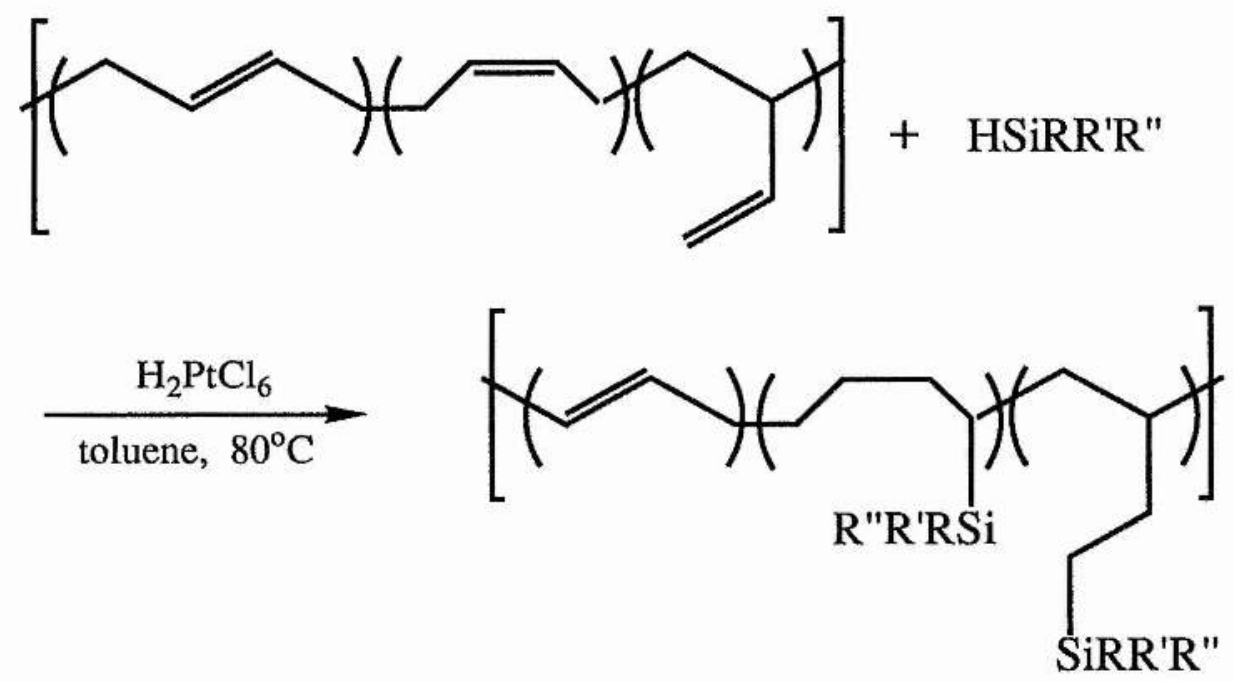

$$
\text { where, } \begin{aligned}
\mathrm{R} & =\mathrm{R}^{\prime}=\mathrm{CH}_{3}, \mathrm{R}^{\prime \prime}=\mathrm{Cl} \\
\mathrm{R} & =\mathrm{R}^{\prime}=\mathrm{Cl}, \quad \mathrm{R}^{\prime \prime}=\mathrm{CH}_{3} \\
\mathrm{R} & =\mathrm{R}^{\prime}=\mathrm{R}^{\prime \prime}=\mathrm{Cl}
\end{aligned}
$$

Equation 3.5

They made several observations. The terminal double bonds are the easiest to hydrosilylate, followed by the cis internal carbon-carbon double bonds. The trans internal carbon-carbon double bonds proved difficult if not impossible to hydrosilylate. For example, a polybutadiene containing $47 \%$ pendant carbon-carbon double bonds, $17 \%$ cis and $36 \%$ trans gave a modified polymer with complete conversion of the pendant carbon-carbon double bonds followed by cis (conversion $>95 \%$ ) and no conversion of the trans groups. Further studies are currently being carried out in order to fully understand the mechanism of selectivity of this reaction system. 


\subsubsection{Hydrogenation}

The first report on hydrogenation of polybutadiene relevant to this thesis using a heterogeneous catalyst was by Yakubehik and Gromova 87 . They hydrogenated polybutadiene at room temperature and pressure over $\mathrm{Pd} / \mathrm{CaCO}_{3}, \mathrm{Pd}$ on $\mathrm{Ni}, \mathrm{Pt}$ black, Pt-C activated with chloroplatinic acid, and Raney nickel. They observed that the external double bonds tend to be saturated more rapidly than do the internal ones in the main chain. The catalyst showed decline in activity as the process proceeded. Information about the composition of the starting material or the product is not reported.

Rachapudy and coworkers 88 reported partial hydrogenation of polybutadiene in the presence of homogeneous catalysts prepared by the reaction of metal alkyls (n-butyl lithium and triethyl aluminium) with metal salts (cobalt, nickel 2-ethyl hexanoate, platinum and palladium acetyl-acetonates) at $70^{\circ} \mathrm{C}$ and $\sim 1$ atmosphere for approximately 4 hours. Information about the starting material or the product is not reported.

Doi and co workers 89 reported complete hydrogenation of 1,4-,atactic 1,2-, and syndiotactic 1,2-polybutadienes under conditions of $100^{\circ} \mathrm{C}$ and 50 atmospheres of hydrogen in the presence of Wilkinson's catalyst [RhCl( $\mathrm{PPh} 3]_{3}$ (Equation 3.6).

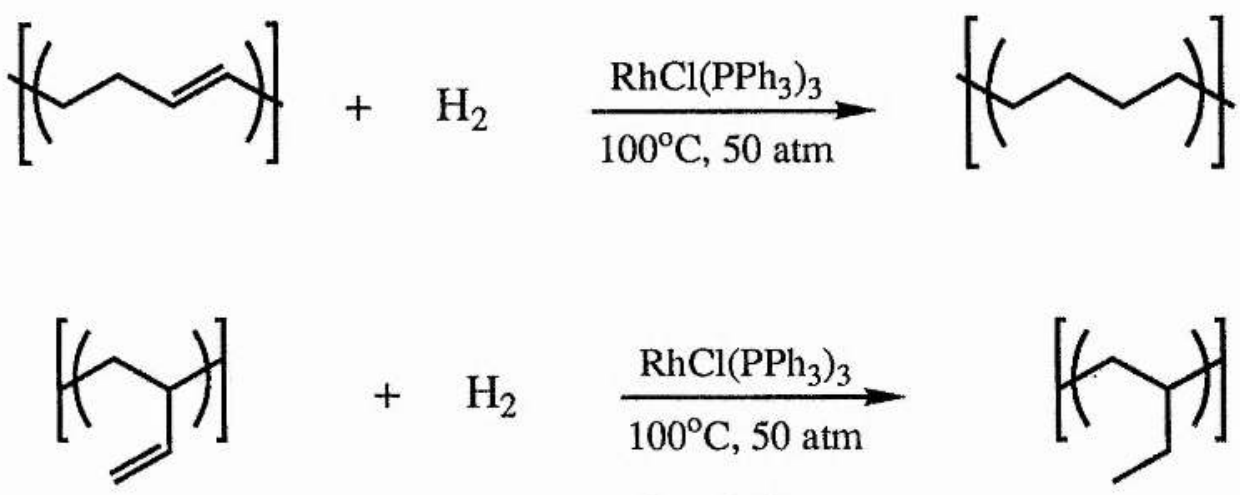


Using the same catalyst Rempel and Mohammadi 90 reported hydrogenation of a acrylonitrile-butadiene copolymer under mild reaction conditions. The carbon-carbon unsaturated bonds undergo quantitative hydrogenation without any hydrogenation of the nitrile functionality. The selectivity of the catalyst for pendant versus internal carbon-carbon double bonds present in the copolymer is markedly influenced by the nature of the solvent employed, athough the reasons for this are still under investigation. When the hydrogenation was carried out in 2-butanone, the catalyst showed no selectivity for hydrogenation of pendant over internal carbon-carbon double bonds. On the other hand, when chlorobenzene was employed as the solvent the temperature doubled, the catalyst showed greater selectivity for pendant versus internal carbon-carbon double bonds (Equation 3.7).

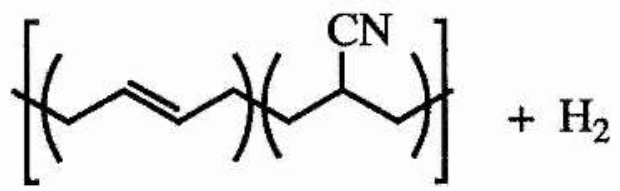

$\left[\begin{array}{lll}(1 & 1\end{array}\right]$

$+\mathrm{H}_{2}$

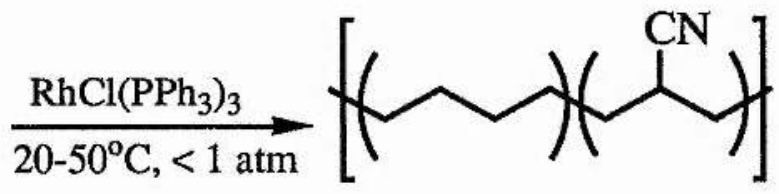

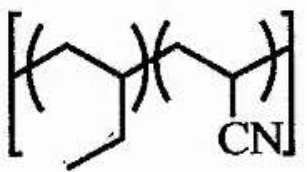

\section{Equation 3.7}

Fairly recently Gilliom ${ }^{91}$ reported the first bulk catalytic hydrogenation of 1,2 polybutadiene and a block copolymer of polystyrene and polybutadiene (PS-PB-PS) in the presence of $\left[\mathrm{RhCl}\left(\mathrm{PPh}_{3}\right)_{3}\right]$ and $\left.\left[\mathrm{Ir}(\mathrm{COD})\left(\mathrm{P}\left(\mathrm{CH}_{3}\right) \mathrm{Ph}_{2}\right)_{2}\right] \mathrm{PF}\right](\mathrm{COD}=1,5-$ cyclooctadiene). Samples were prepared by evaporating the solution containing the catalysts and the reducible hydrocarbon rubber and then 
subjecting them to hydrogenation at moderate temperature and pressure $\left(\sim 3 \mathrm{~atm}, 60^{\circ} \mathrm{C}\right)$. In the case of PS-PB-PS, $80 \%$ conversion was obtained within 72 hours using either of the catalysts. More detailed comparision of the catalytic system could not be made owing to the lack of more uniform systems i.e., uniformity of surface area, density, or thickness, local concentration of hydrogen and its variation in permeability through the sample materials.

\subsubsection{Hydroformylation}

The first hydroformylation reaction on diene-based polymers was reported by Ramp and coworkers 92 . They hydroformylated 1,4polybutadiene in the presence of a cobalt catalyst. 1,1-diethoxyethane was used as a condensing agent, preventing gel (cross linking) formation by interacting with the aldehyde groups to form acetals. Some alcohols were also obtained (Equation 3.8).

$$
\text { ] }
$$

Equation 3.8 
The same conditions were then applied to study other diene polymers like high-styrene-butadiene copolymers, ethyl acrylate-butadiene copolymer, methyl methacrylate-butadiene copolymer, isoprenebutadiene copolymer, natural rubber, balata. Glycol was added in these cases to prevent cross linking. All the above mentioned polymers, including polybutadiene gave polyaldehyde acetals with nearly quantitative double-bond conversion.

Hydroformylation and subsequent hydrogenation of polybutadiene at relatively high temperature and pressure in the presence of a mixed ligand cobalt catalyst is reported in a British patent ${ }^{93}$ (Equation 3.9). After hydroformylation the carbon monoxide pressure was decreased and hydrogenation was carried out under increased hydrogen pressure. No information is given on the composition of both the starting material and the final product.

$$
\begin{aligned}
& \mathrm{PBD}+\mathrm{CO}+\mathrm{H}_{2} \underset{200^{\circ} \mathrm{C}, 30-35 \mathrm{~atm}}{\stackrel{\left[\mathrm{Co}_{2}(\mathrm{CO})_{7}\left(\mathrm{PBu}_{3}\right)_{2}\right]}{\longrightarrow}} \text { PBD-Hyf } \\
& \text { PBD-Hyf }+\mathrm{H}_{2} \quad \stackrel{\left[\mathrm{Co}_{2}(\mathrm{CO})_{7}\left(\mathrm{PBu}_{3}\right)_{2}\right]}{120 \mathrm{~atm}} \text { PBD-Hyox } \\
& \text { where, PBD } \quad=\text { polybutadiene } \\
& \text { PBD-Hyf }=\text { hydroformylated polybutadiene } \\
& \text { PBD-Hyox }=\text { hydroxylated polybutadiene }
\end{aligned}
$$

Equation 3.9 
Soon after this, quite a number of patents came out on hydroformylation of polybutadiene in the presence of cobalt complexes. The hydroformylated polybutadiene was then mixed with other materials to give commercially viable products. For example, the hydroformylated polybutadiene was stirred in the presence of an anionic emulsifier, i.e. a salt of higher fatty acids, to prepare latex films 94 , blended with certain epoxidised polyolefin co-agents to produce baked coating materials 95 or mixed with high vinyl content $(1,2$ units) polybutadiene and cured with $\mathrm{SiO}_{2}$, vinyl triethoxy silane, dicumyl peroxide and calcium stearate to give polymers having improved resistance to thermoxidative degradation 96 .

The first report on the use of rhodium complexes for hydroformylation of polydienes was by Sanui and co-workers 97 (Equation 3.10). In the presence of $\left[\mathrm{RhH}(\mathrm{CO})\left(\mathrm{PPh}_{3}\right)_{3}\right]$ hydroformylation of polypentenamer was carried out under mild conditions to yield $20 \mathrm{~mol} \%$ of formyl side groups on the polypentenamer.

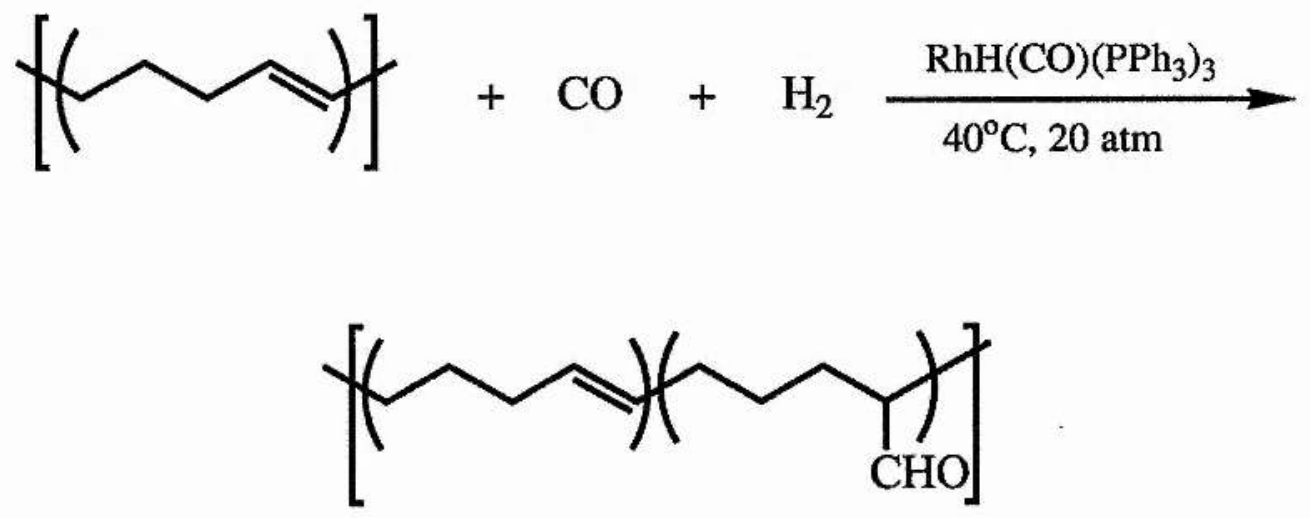

Equation 3.10 
Further reactions were carried out on the formyl group, but they are not relevant to our work. Azuma and coworkers 98 have reported a two step hydroxymethylation of polydienes via catalytic hydroformylation and subsequent hydrogenation in the presence of $\left[\mathrm{RhH}(\mathrm{CO})\left(\mathrm{PPh}_{3}\right)_{3}\right]$ catalyst and reducing agents such as sodium borohydride.

Fairly recently, working at relatively lower temperature and pressure conditions, Rempel and co-workers 99 have reported catalytic synthetic methods for the preparation of hydrogenated, hydroformylated and hydroxymethylated high vinyl content (90\% 1,2 units) polybutadiene in the presence of rhodium and ruthenium complexes. For example, they carried out hydrogenation of polybutadiene in the presence of Wilkinson's catalyst $\left[\mathrm{RhCl}\left(\mathrm{PPh}_{3}\right)_{3}\right]$ at $60^{\circ} \mathrm{C}$ and 2 atmospheres of hydrogen (Equation 3.11).
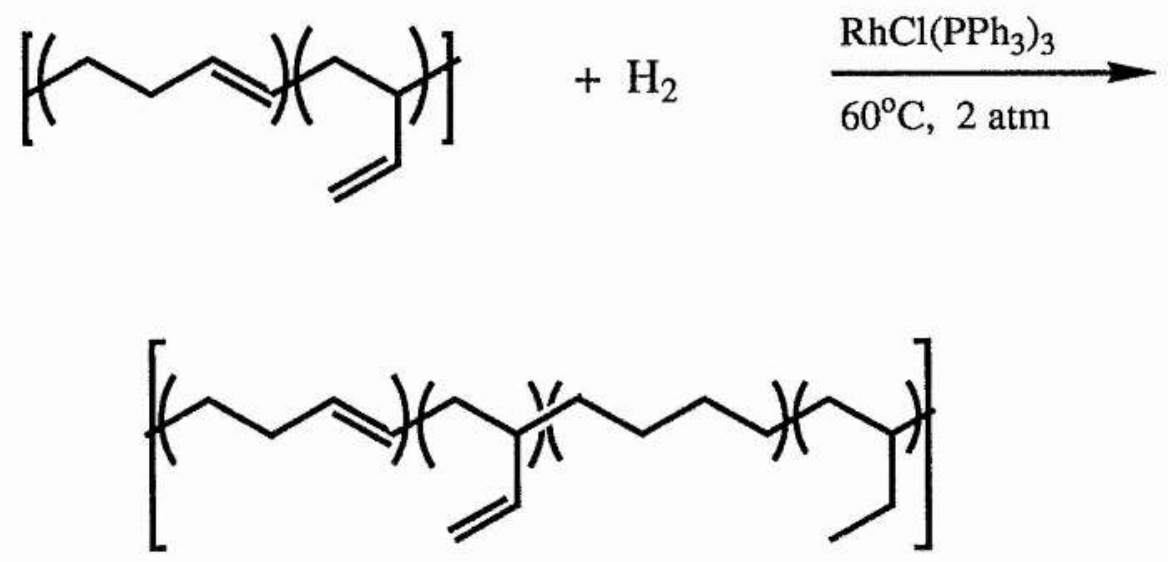

Equation 3.11

Hydroformylation of polybutadiene was carried out under similar conditions of temperature and pressure in the presence of [RhHCO(PPh) 3 ] (Equation 3.12). 


$$
\text { H }
$$

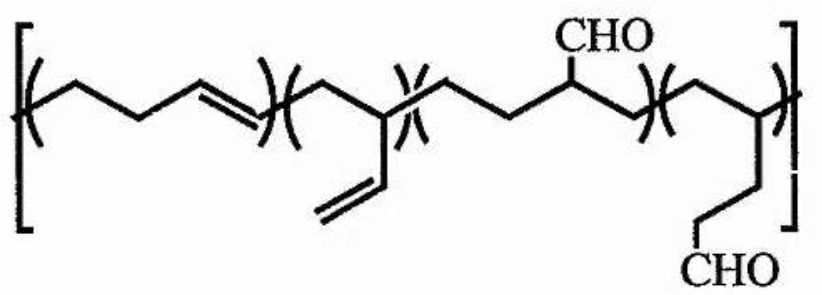

Equation 3.12

A ruthenium catalyst $\left[\mathrm{RuClH}(\mathrm{CO})\left(\mathrm{PPh}_{3}\right) 3\right]$, at 40 atmospheres hydrogen and $120^{\circ} \mathrm{C}$, was subsequently used to hydrogenate the above hydroformylated product. These reactions are also known as hydroxymethylation reactions (Equation 3.13).
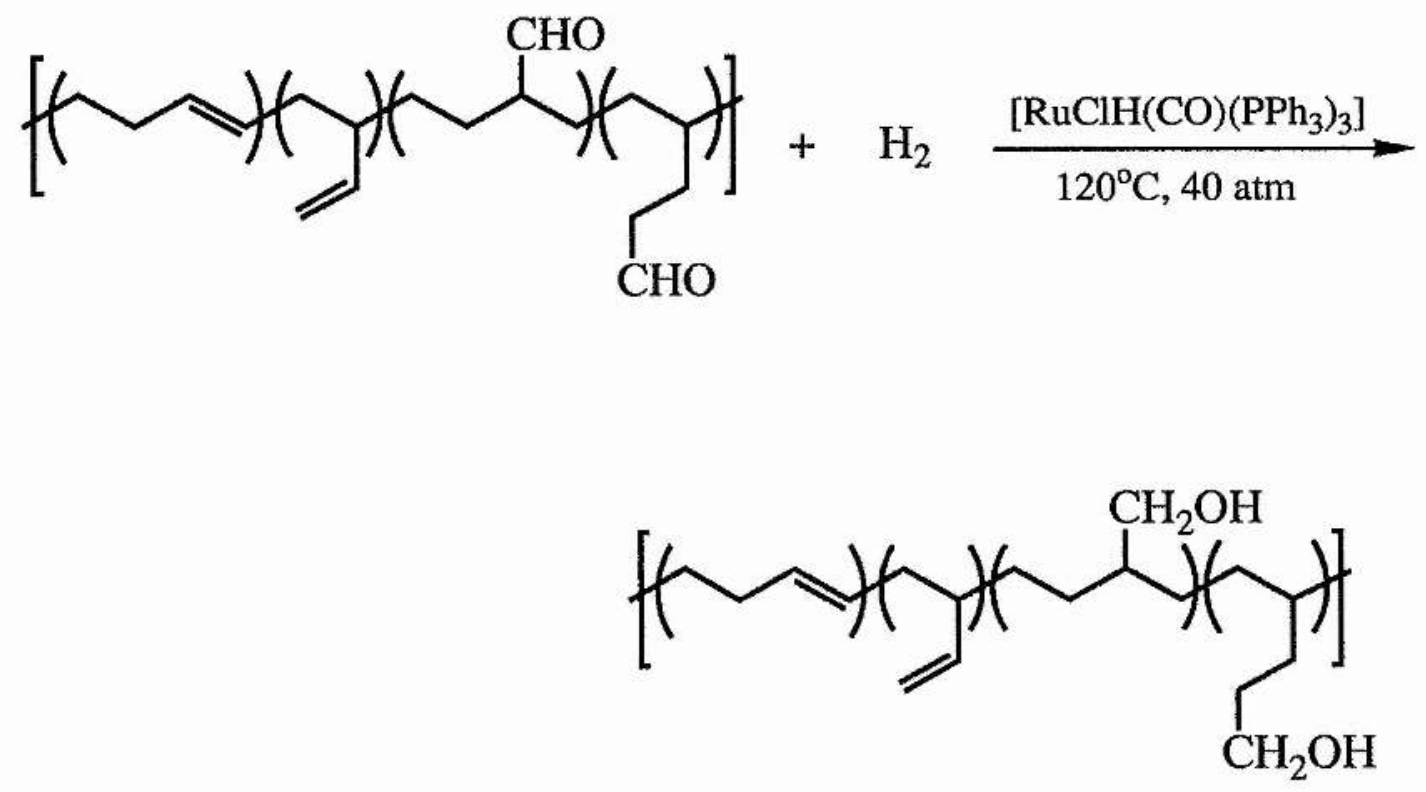

Equation 3.13 
However, quantitative results of the polybutadiene conversion and selectivities to the hydroformylated products are not reported. It is worth mentioning here that the above catalytic reactions were done without adding excess triphenylphosphine to the catalytic system.

Tremont, Remsen and Mills 100 have improved upon the results reported by Rempel and coworkers. Hydroformylation of polybutadiene of varying composition using a hydridocarbonyltris (triphenylphosphine) rhodium(I) $\left[\mathrm{RhH}(\mathrm{CO})\left(\mathrm{PPh}_{3}\right)_{3}\right]$ catalyst in the presence of excess triphenylphosphine under mild conditions yielded polyaldehyde product at nearly $100 \%$ selectivity. Thus hydroformylation of 1,4 cis polybutadiene yielded $53.9 \%$ internally branched aldehyde product (Equation 3.14).
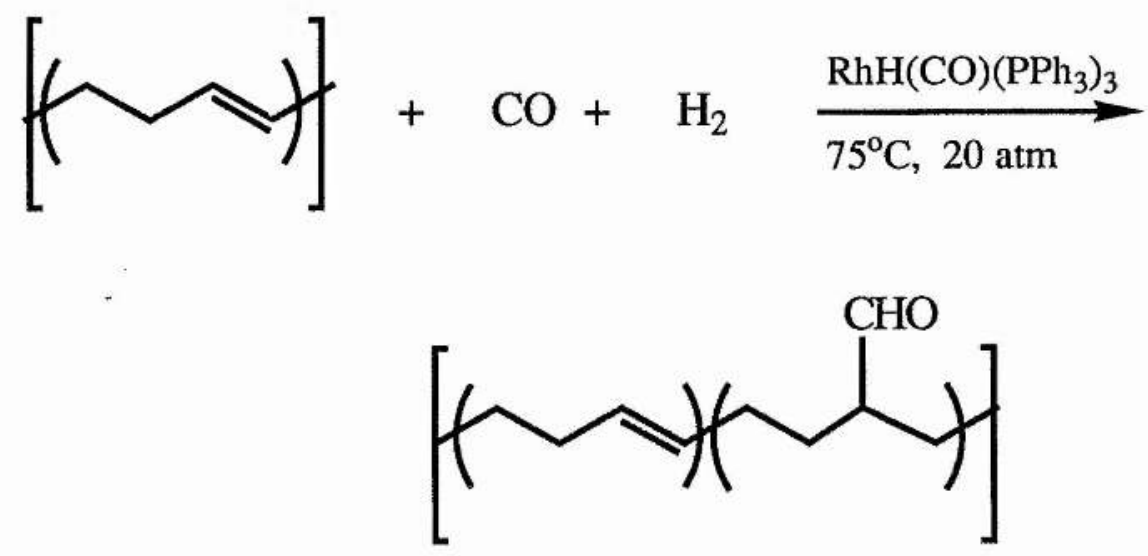

Equation 3.14

Hydroformylation of 1,2 syndiotactic polybutadiene under similar reaction conditions yields $22 \%$ of the terminal branched aldehyde. A trace of $i s o$-branched aldehyde is also observed (Equation 3.15). 


$$
\text { WyH }+\mathrm{CO}+\mathrm{H}_{2} \underset{75^{\circ} \mathrm{C}, 20 \mathrm{~atm}}{\stackrel{\mathrm{RhH}(\mathrm{CO})\left(\mathrm{PP}_{3}\right)_{3}}{\longrightarrow}}
$$

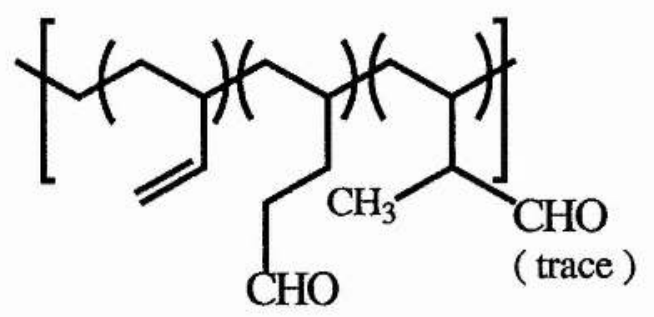

Equation 3.15

When a mixture of polybutadiene containing both 1,2-syndiotactic (12 wt\%) and 1,4 cis and trans isomer (88 wt\%) were hydroformylated under similar reaction conditions, the aldehyde products obtained correspond to those obtained for the pure constituents (Equation 3.16).
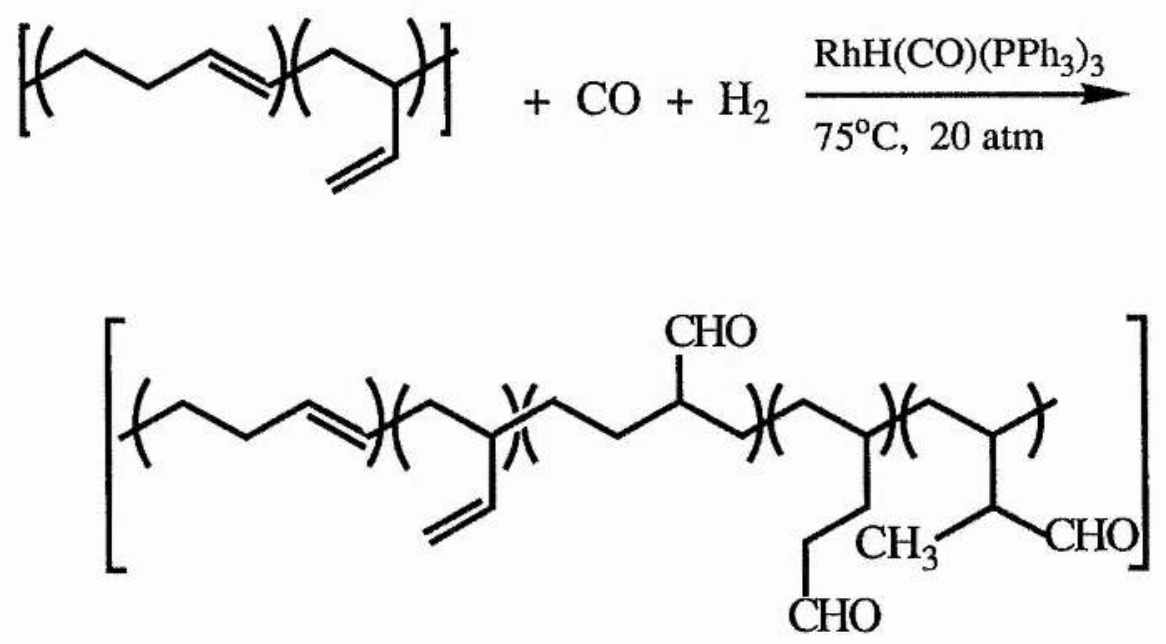

Equation 3.16

Comparison of kinetic data derived from gas uptake measurements showed that initial reaction rates for hydroformylation of 1,2 
syndiotactic polybutadiene to be about six times greater than that obtained for hydroformylation of $1,4 \mathrm{cis}$-polybutadiene. This difference in rate can be attributed to the accessibility of the carbon carbon double bond.

Similarly, Cole-Hamilton and coworkers 101 working at a slightly higher pressure and in the presence of the same catalyst report both selective and non-selective hydroformylation of polybutadiene, containing a mixture of both internal and pendant carbon-carbon double bonds. For example, in the presence of only $\left[\mathrm{RhH}(\mathrm{CO})\left(\mathrm{PPh}_{3}\right)_{3}\right]$ hydroformylation occurs at both the internal and pendant carbon-carbon double bond position. A trace of hydroformylation occuring at the penultimate carbon atom of the pendant carbon-carbon double bond is also observed. However in the presence of excess triphenylphosphine the reaction becomes highly selective (selectivity $>90 \%$ ) towards the terminal carbon position of the pendant carbon-carbon double bonds (Equation 3.17).
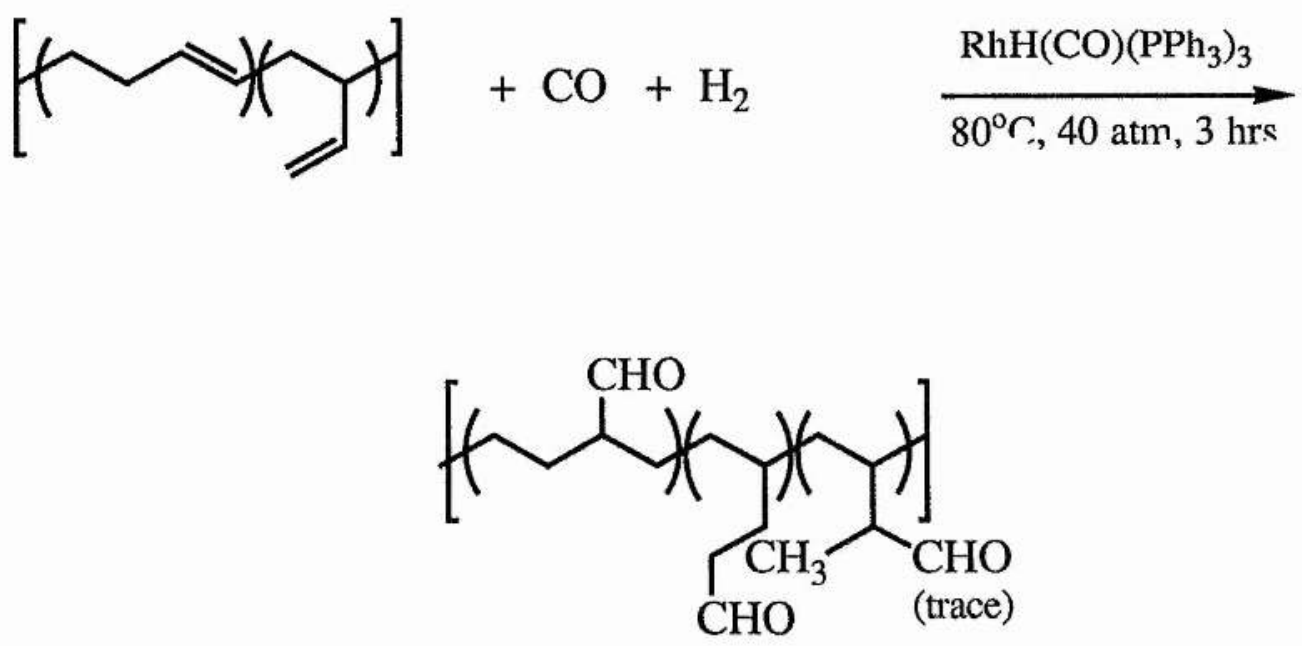

Equation 3.17 


\subsubsection{Epoxidation}

Epoxidation of butadiene by peracids to give the corresponding epoxide has been known for a long time. The commonly used epoxidising agent was peracetic acid and the product yield ranged from $45-100 \%$.

Epoxidation of polymeric alkene hydrocarbons with a peracid, such as peracetic acid, was first reported 102 in 1958 . The polymeric hydrocarbons studied had molecular weights in the range of 150250,000 . The product contained $1-3 \%$ oxirane oxygen and was used for film forming materials. No additional information about the starting materials and their composition is given.

Epoxidation of polybutadiene containing a mixture of $1,4 \mathrm{cis}, 1,4$ trans, and 1,2 units, using peracids - hydrogen peroxide103, monoperoxyphthalic acid 104 and with tert -butyl hydroperoxide 105 in the presence of a soluble molybdenum catalyst $\left[\mathrm{MoO}_{2}\right.$ (acac) 2$]$ have shown a preference for the back bone double bonds in the order Cis $-1,4>$ trans $-1,4>>1,2$ units. The greater reactivity of the cis $-1,4$ units than trans $-1,4$ units is almost certainly due primarily to sterric effects, although the energy difference between the cis and trans isomer may also be important. The pendant carbon-carbon double bonds start to epoxidise before all the back bone double bonds have reacted (i.e., some of the back bone double bonds are left unreacted). Therefore no high selectivity is observed.

The first highly regioselective epoxidation of polybutadiene using a soluble molybdenum complex was reported by Cole-Hamilton and co workers 106. Polybutadiene containing a mixture of $c$ is -1,4-, trans $-1,4$, and 1,2-units were subjected to epoxidation with tert buty1 hydroperoxide in the presence of a molybdenum catalyst $\left[\mathrm{MoO}_{2} \mathrm{Cl}_{2}[3-\right.$ 
(diethoxy phosphoryl camphor)complex] (Figure 3.1).

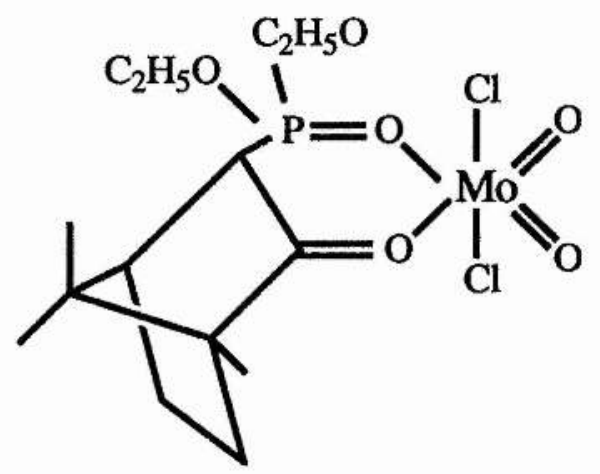

Figure 3.1

The reaction shows very high selectivity to epoxidation of back bone double bonds whilst the pendant carbon-carbon double bonds are hardly reacted (Equation 3.18).
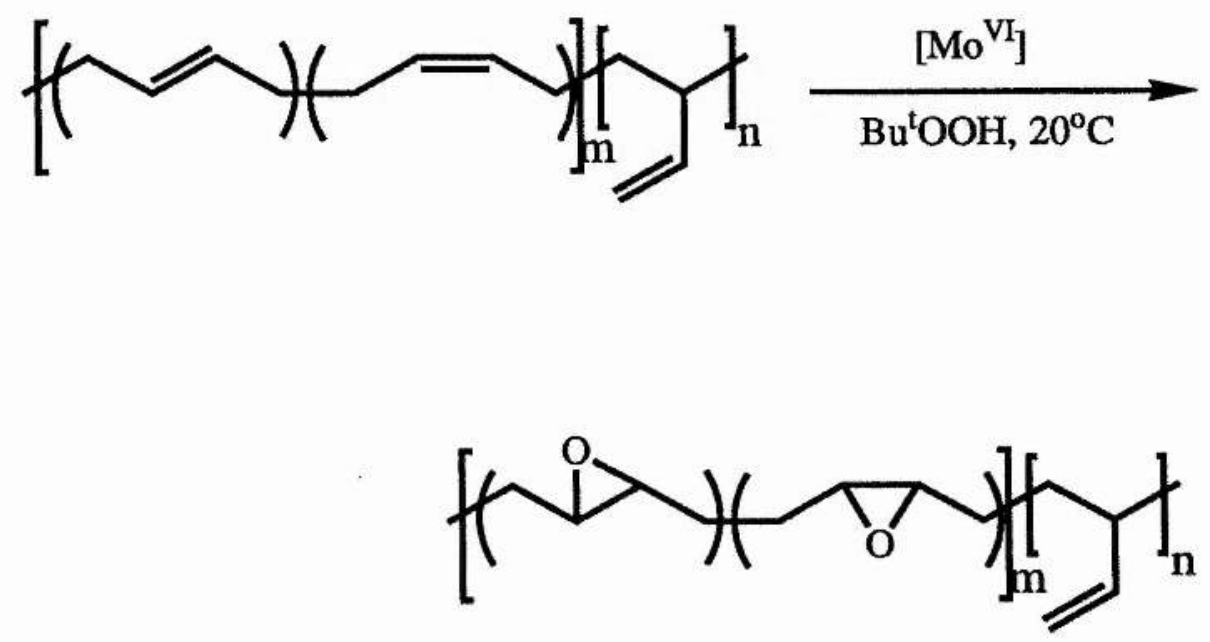

where, $\mathrm{m}=55 \%, \mathrm{n}=45 \%$

Equation 3.18 
Since the system reported by Knifton ${ }^{30}$ in Chapter 1(see page 19) afforded a very convenient method of regioselectively hydrocarboxylating alkenes with terminal carbon -carbon double bonds in the presence of palladium complexes, to give linear carboxylic esters, we were interested in applying the same methods for hydrocarboxylating polybutadienes (containing both a very high content of pendant carbon-carbon double bonds, and/or mixtures of internal and pendant carbon-carbon double bonds).

In theory, addition of carboxylic acid groups to polybutadiene can occur in three different ways (Equation 3.19). This would result in the formation of five types of hydrocarboxylated microstructures in the polymeric chain, as shown by species A-E.

$$
\left(\mathrm{CH}_{2} \mathrm{CH}=\mathrm{CHCH}_{2}\right)+\mathrm{CO}+\mathrm{H}_{2} \mathrm{O} \longrightarrow\left(\left.\right|_{\mathrm{COOH}} ^{\left.\mathrm{CH}_{2} \mathrm{CHCH}_{2} \mathrm{CH}_{2}\right)}\right.
$$

1,4 units

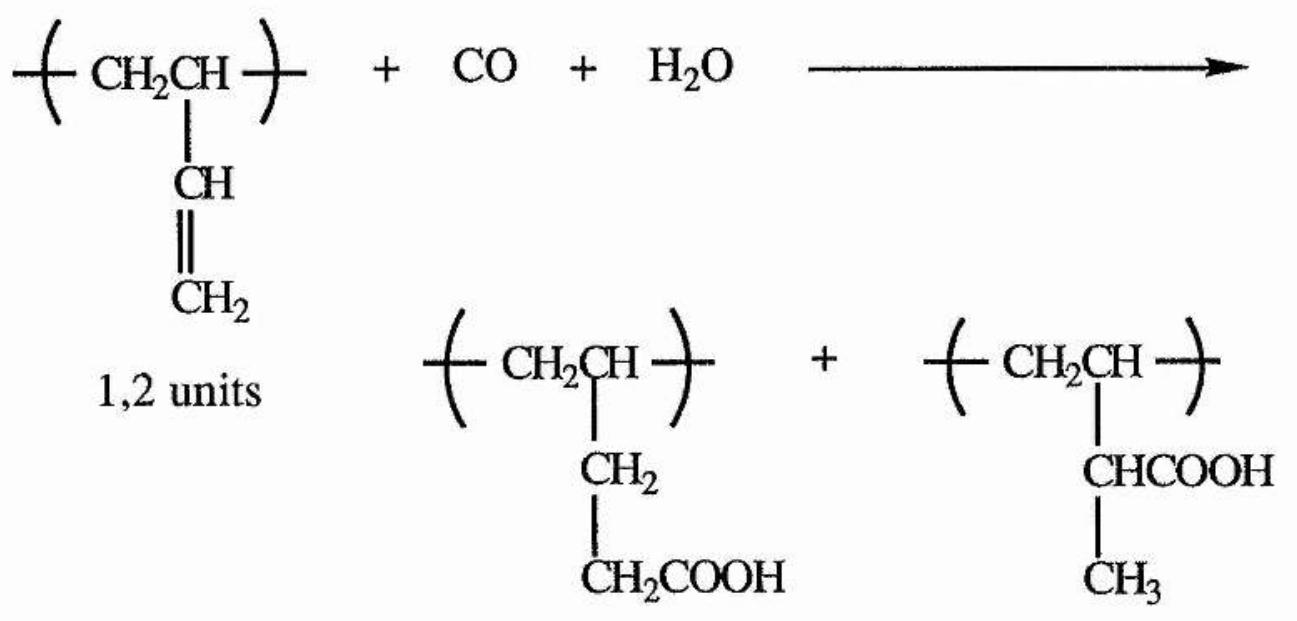

(B) 


$$
\begin{gathered}
\left.f \mathrm{CH}_{2} \mathrm{CH}=\mathrm{CHCH}_{2}\right)+\underset{\|_{\mathrm{CH}}}{-\mathrm{CH}_{2} \mathrm{CH}}+\mathrm{CO}+\mathrm{H}_{2} \mathrm{O} \longrightarrow \\
1,4 \text { units }+1,2 \text { units }
\end{gathered}
$$

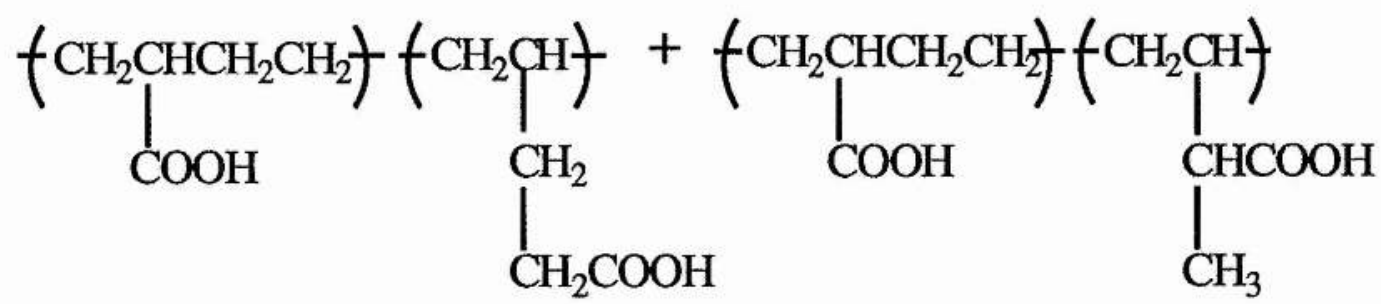

(D)

(E)

Equation 3.19

Species A is formed when hydrocarboxylation occurs only on the 1,4 addition units, i.e., cis or trans only or a combination of both cis and trans. structures. Products B and C are formed when the carboxylate group is introduced on the terminal or the internal carbon atom of the pendant carbon-carbon double bonds. Species B would thus be the result of an anti-Markownikov addition while species $\mathrm{C}$ would be a Markownikov addition product. Products D and E would be obtained when both the internal carbon-carbon double bonds and the pendant carbon-carbon double bonds are attacked by the - $\mathrm{COOH}$ acid groups.

One can expect that when using Knifton's method, species A and B should be formed on hydrocarboxylation of polybutadiene. 


\subsection{Results and Discussion}

There were three main purposes for this research. The first was to determine if Knifton's 30 method of hydroesterification of 1-alkenes could be effectively applied for hydrocarboxylation of unsaturated polymers in general, and in particular polybutadiene. Secondly to see if the same method could be made regioselective in hydrocarboxylating polybutadienes. Finally, whether complete hydrocarboxylation of polybutadiene could be obtained by slightly altering the catalytic system $\left[\mathrm{PdCl}_{2}\left(\mathrm{PPh}_{3}\right)_{2}\right]$ (either by adding other cocatalysts or excess ligand, etc.)

For this purpose we treated polybutadienes with different microstructures, from $100 \%$ cis polybutadiene to polybutadienes containing large amounts of pendant carbon-carbon double bonds (1,2 units $>80 \%$ ) with the catalytic mixture $\left[\mathrm{PdCl}_{2}\left(\mathrm{PPh}_{3}\right)_{2}\right]-\mathrm{SnCl}_{2} \cdot 2 \mathrm{H}_{2} \mathrm{O}$ under high temperature and pressure. These polybutadienes were chosen so as to represent a wide range of olefinic structures. They were terminated with a variety of functional groups such as phenyl, hydroxyl, acid, etc. The polymers had some degree of saturation (see Table 3.1).

Much of Knifton's work was carried out at very high pressures (240 atmospheres of carbon monoxide). Technical limitations meant that we were limited to $<120$ atmospheres carbon monoxide pressure so initial studies were carried out at 80 atmospheres and $90^{\circ} \mathrm{C}$. Initial studies were carried out on polymer no 7 (see Table 3.1). Hydrocarboxylation was observed and ${ }^{13} \mathrm{C}$ n.m.r. studies indicated that the reaction was highly selective towards introduction of the carboxylic acid group on the terminal carbon atom of the pendant double bonds. A systemmatic survey of the reaction variables was then carried out in 


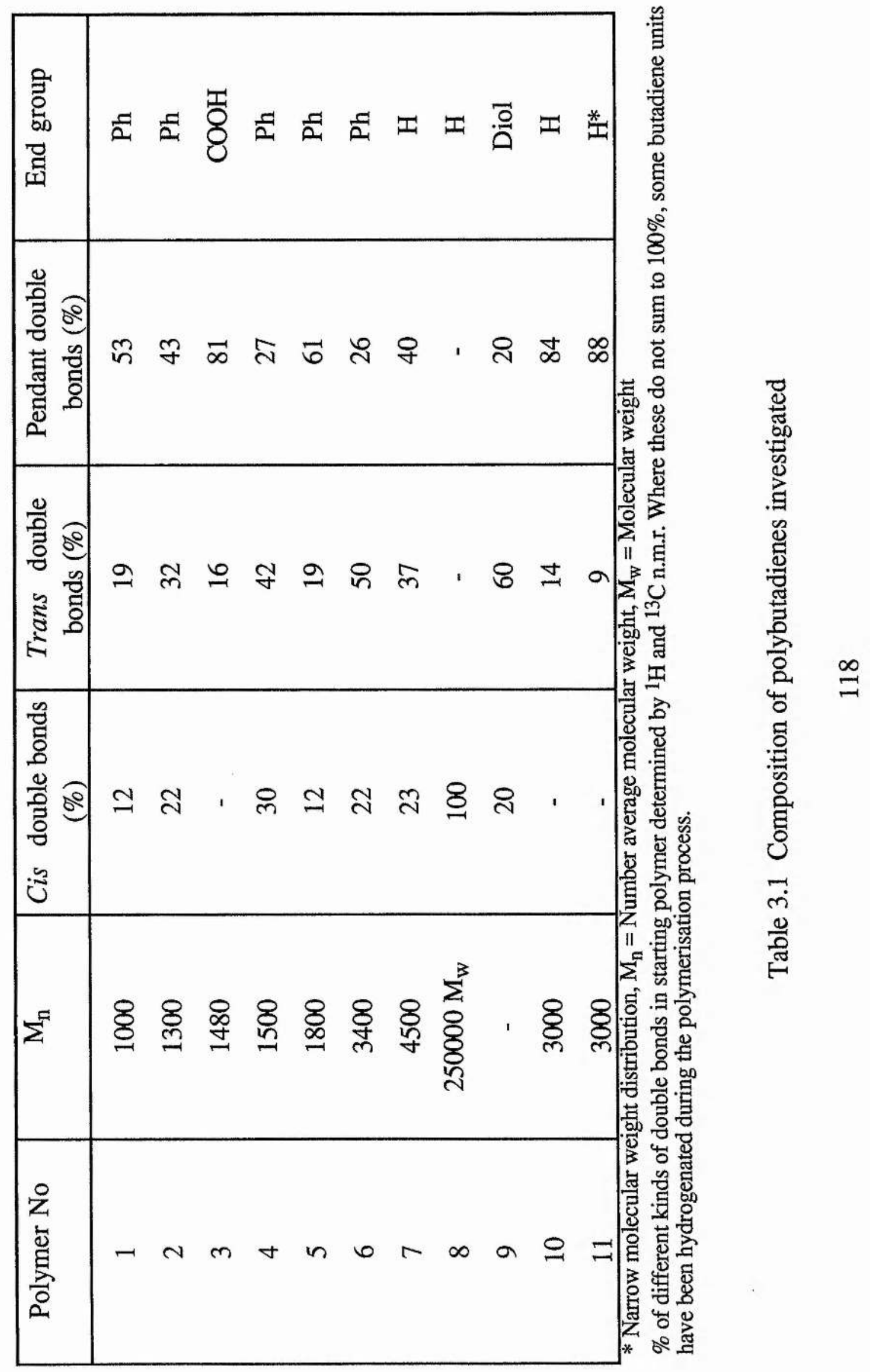


order to obtain the optimum reaction conditions.

\section{$\underline{3.2 .1 \text { Effect of pressure }}$}

Pressures ranging from $70-120$ atmospheres carbon monoxide at $90^{\circ} \mathrm{C}$ for 6 hours were studied. At 70 atmospheres carbon monoxide pressure very little or no conversion took place. At 80 atmospheres complete conversion took place. Further increase in pressures did not cause any noticeable change in selectivity. The pressure was thus fixed at 80 atmospheres.

\section{$\underline{3.2 .2 \text { Effect of temperature }}$}

Temperatures ranging from $70^{\circ} \mathrm{C}-100^{\circ} \mathrm{C}$ at 80 atmospheres carbon monoxide for 6 hours were studied. At $70^{\circ} \mathrm{C}$ very little conversion took place. At $90^{\circ} \mathrm{C}$ complete conversion took place.The temperature was thus fixed at $90^{\circ} \mathrm{C}$.

\section{$\underline{3.2 .3 \text { Reaction period }}$}

Since at $90^{\circ} \mathrm{C}$ and 80 atmospheres carbon monoxide pressure and 6 hours reaction period, complete conversion took place, reduced reaction periods were studied. It was observed that within 4 hours complete conversion took place. Further decrease in the reaction period decreased the yield. Further discussion of the progress of the reaction with time appears in the section '3.2.6. Catalyst stability'. 


\subsubsection{Amount of solvent}

Initially experiments were carried out with $40 \mathrm{~cm}^{3}$ of methyl isobutyl ketone. Experiments were then carried out using reduced amounts of solvent. It was found that the amount of solvent does not seem to affect the reaction greatly. The solvent was fixed at $10 \mathrm{~cm}^{3}$, enough to dissolve the polybutadiene. The $\mathrm{SnCl}_{2}$ dissolves in the aqueous phase.

3.2.4.1 Amount of polybutadiene

\begin{tabular}{|l|c|c|c|}
\hline $\begin{array}{c}\text { Moles of } \\
\text { polybutadiene }\end{array}$ & $\begin{array}{c}\text { Overall } \\
\text { conversion (\%) }\end{array}$ & $\begin{array}{c}\text { Conversion of } \\
\text { pendant C=C } \\
\text { bonds (\%) }\end{array}$ & $\begin{array}{c}\text { Catalyst turn } \\
\text { overs }\end{array}$ \\
\hline $3.697 \times 10^{-3}$ & 53.0 & 100 & 27.74 \\
$5.546 \times 10^{-3}$ & 41.2 & 77.39 & 32.35 \\
$7.395 \times 10^{-3}$ & 35.04 & 66.11 & 36.69 \\
0.011 & 24.39 & 46.01 & 37.98 \\
0.014 & 20.36 & 38.41 & 40.36 \\
0.018 & 18.34 & 34.60 & 46.75 \\
\hline
\end{tabular}

Table 3.2

From Table 3.2 it is evident that increasing the moles of polybutadiene for the same amount of the catalyst decreases the percentage of conversion, although selectivity towards the terminal carbon atom of the pendant carbon-carbon double bond remains the same. This is due to the fact that there is not enough catalyst present in the reaction system to 
react with the substrate. However, there is a small but probably significant increase in catalyst turnovers with increasing moles of substrate. This is in accord with the fact that at higher concentrations of the substrate the amount of unreacted substrate dispersed in the solvent is greater after 4 hours, thus increasing the chances for the interaction between the substrate and the catalyst (i.e., the rate will have fallen off more slowly for the more concentrated solutions).

Once the general conditions for specific hydrocarboxylation had been established, the method was applied to a variety of polybutadienes of varying composition under the optimum reaction conditions. The composition of the polybutadienes studied is shown in Table 3.1 and the analysis of the hydrocarboxylated polybutadiene is shown in Table 3.3.

\subsubsection{Analysis of polybutadienes}

Analysis of the hydrocarboxylated polybutadienes was carried out by various methods as follows. Polymer number 1 (see Table 3.3 ) is chosen as an example to show the various methods of analysis.

\section{$\underline{\text { 3.2.5.1 Infrared spectroscopy }}$}

The typical IR spectrum of polybutadiene and its corresponding hydrocarboxylated product is shown in parts (a) and (b) of Figure 3.2 respectively. The bands at $1640,992,969,912,740-732 \mathrm{~cm}^{-1}$ are due to carbon-carbon unsaturation. The IR spectra of the hydrocarboxylated polybutadiene lacks some of the characteristic peaks for unsaturation which indicates a degree of hydrocarboxylation. Besides the peaks for 


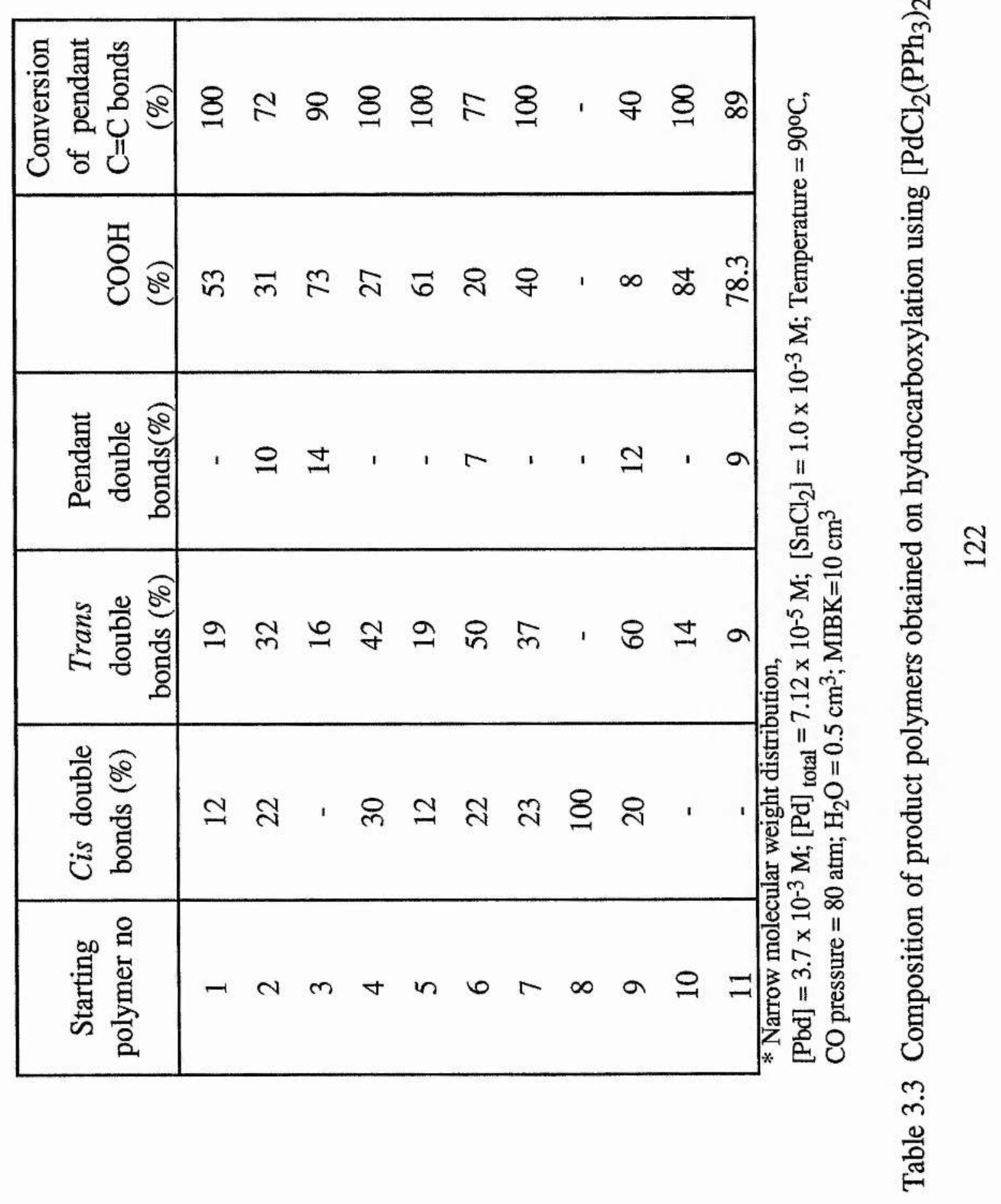


Figure 3.2 (a)

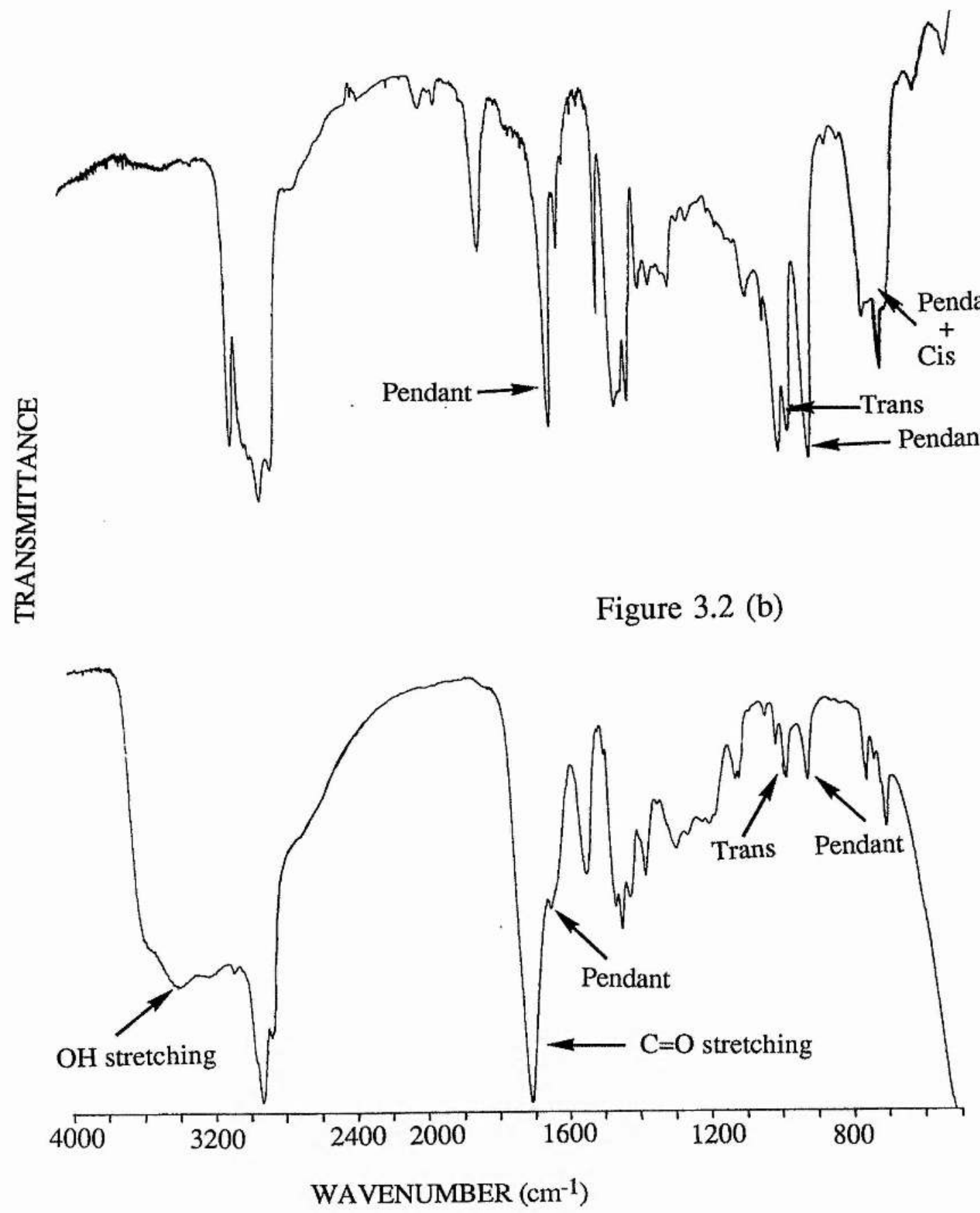

Figure 3.2 (a) Infrared spectrum of polybutadiene

(b) Infrared spectrum of corresponding hydrocarboxylated (selectively) polybutadiene at the pendant carbon position. 
unsaturation the characteristic band for the acid group $\mathrm{C}=\mathrm{O}$ stretching at $1727 \mathrm{~cm}^{-1}$ is seen. The broad peak at $3310 \mathrm{~cm}^{-1}$ is characteristic of $\mathrm{OH}$ stretching.

\subsubsection{2 ${ }^{1} \underline{\mathrm{H}}$ and ${ }^{13} \underline{\mathrm{C} \text { n.m.r. spectroscopy }}$}

\section{$\underline{\text { 3.2.5.2.1 }} 1 \underline{\underline{\mathrm{H}} \text { n.m.r. }}$}

The ${ }^{1} \mathrm{H}$ n.m.r. spectra of polybutadiene and its hydrocarboxylated product is shown in Figure 3.3 (a) and (b). The conspicous absence of a large peak at $5.0 \mathrm{ppm}$ and the absence of peaks at 5.6-5.8 ppm shows almost complete conversion of the pendant carbon-carbon double bonds to hydrocarboxylated product.

\subsubsection{2 ${ }^{13} \underline{\text { C n.m.r. }}$}

The ${ }^{13} \mathrm{C}$ n.m.r. spectra of both the starting material in $\mathrm{CDCl}_{3}$ and its hydrocarboxylated product in $\left(\mathrm{CD}_{3}\right)_{2} \mathrm{CO}$ is shown in Figure 3.4 (a) and (b) respectively. The absence of peaks at $115 \mathrm{ppm}$ and $145 \mathrm{ppm}$ (due to the carbon atoms of the pendant double bonds of polybutadiene) shows almost complete conversion of terminal carbon-carbon double bonds due to hydrocarboxylation. Consequently the presence of a new peak at $175 \mathrm{ppm}$ due to the carboxylic acid group directly attached to the terminal carbon position is seen.

${ }^{13} \mathrm{C}$ n.m.r. spectroscopy of the crude product (see Figure $3.4 \mathrm{~b}$ ) shows the presence of triphenyl phosphine oxide. This could be removed from the reaction mixture by precipitation of the polymer from the initial reaction solution with excess diethylether (see 3.3 Experimental section). ${ }^{13} \mathrm{C}$ n.m.r. spectra of the hydrocarboxylated 

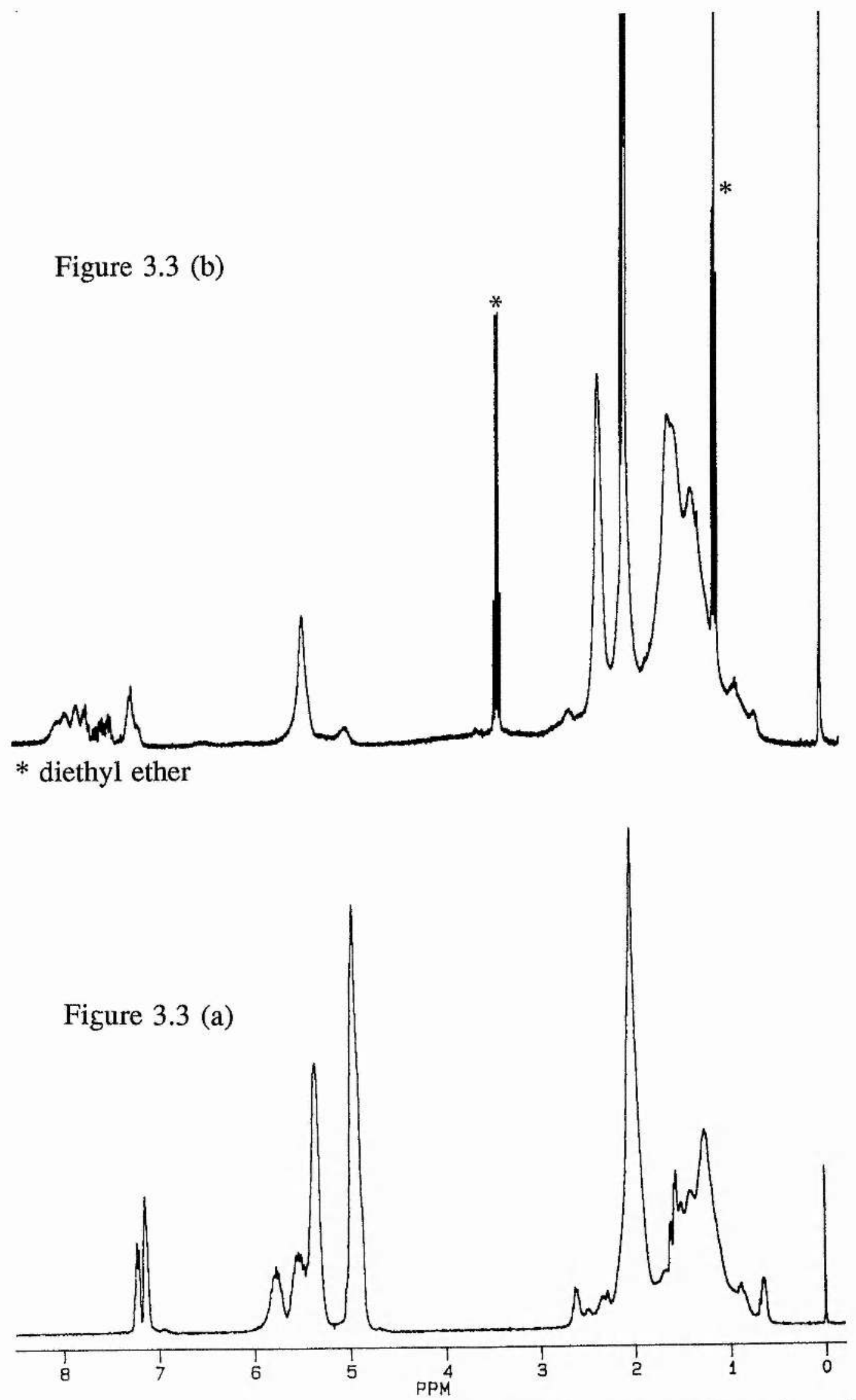

Figure 3.3 (a) 1 H n.m.r. spectrum of polybutadiene (phenyl terminated) (b) ${ }^{1} \mathrm{H}$ n.m.r. spectrum of corresponding hydrocarboxylated (selectively) polybutadiene at the terminal carbon position of the pendant group. 
Figure 3.4 (b)

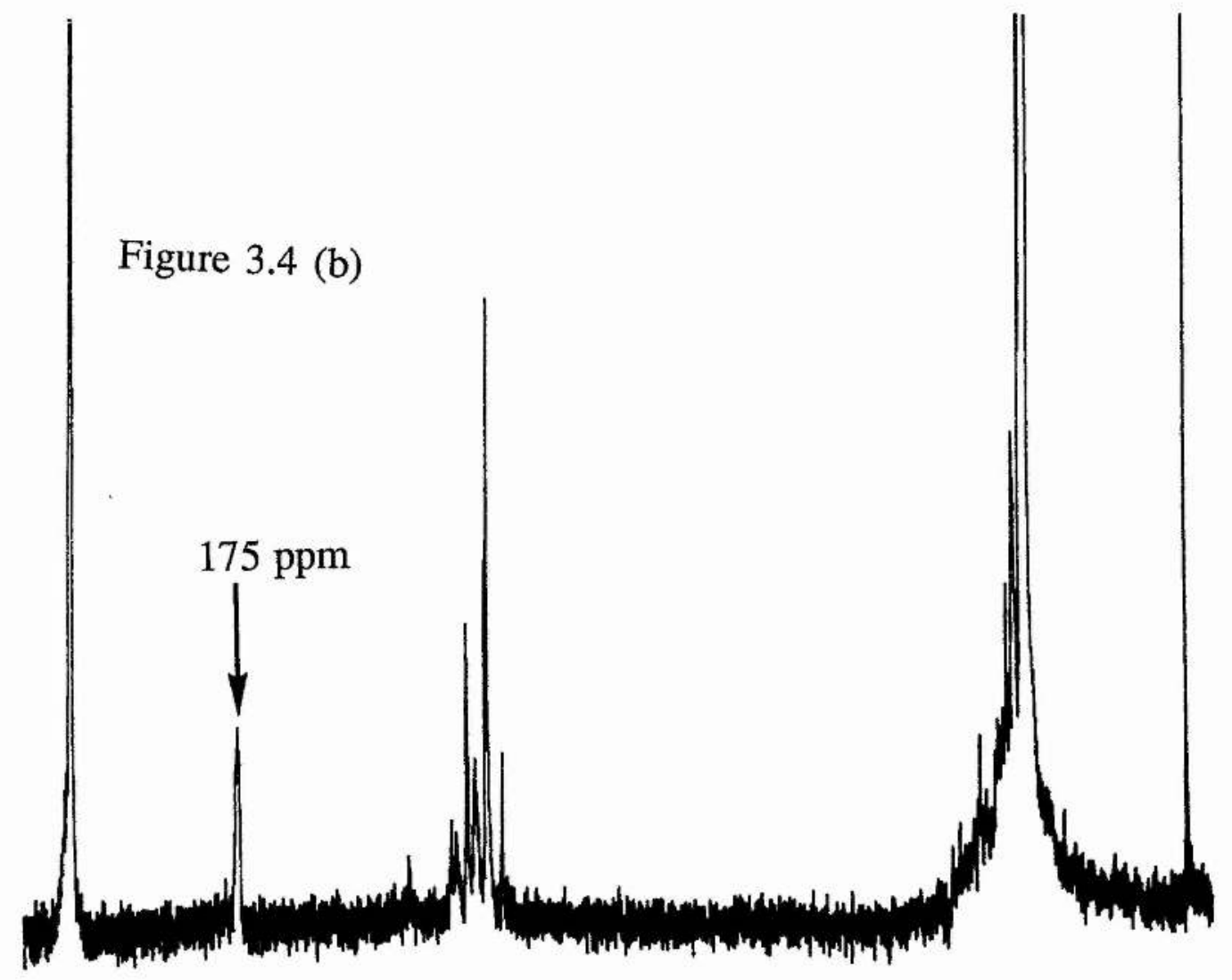

Figure 3.4 (a)

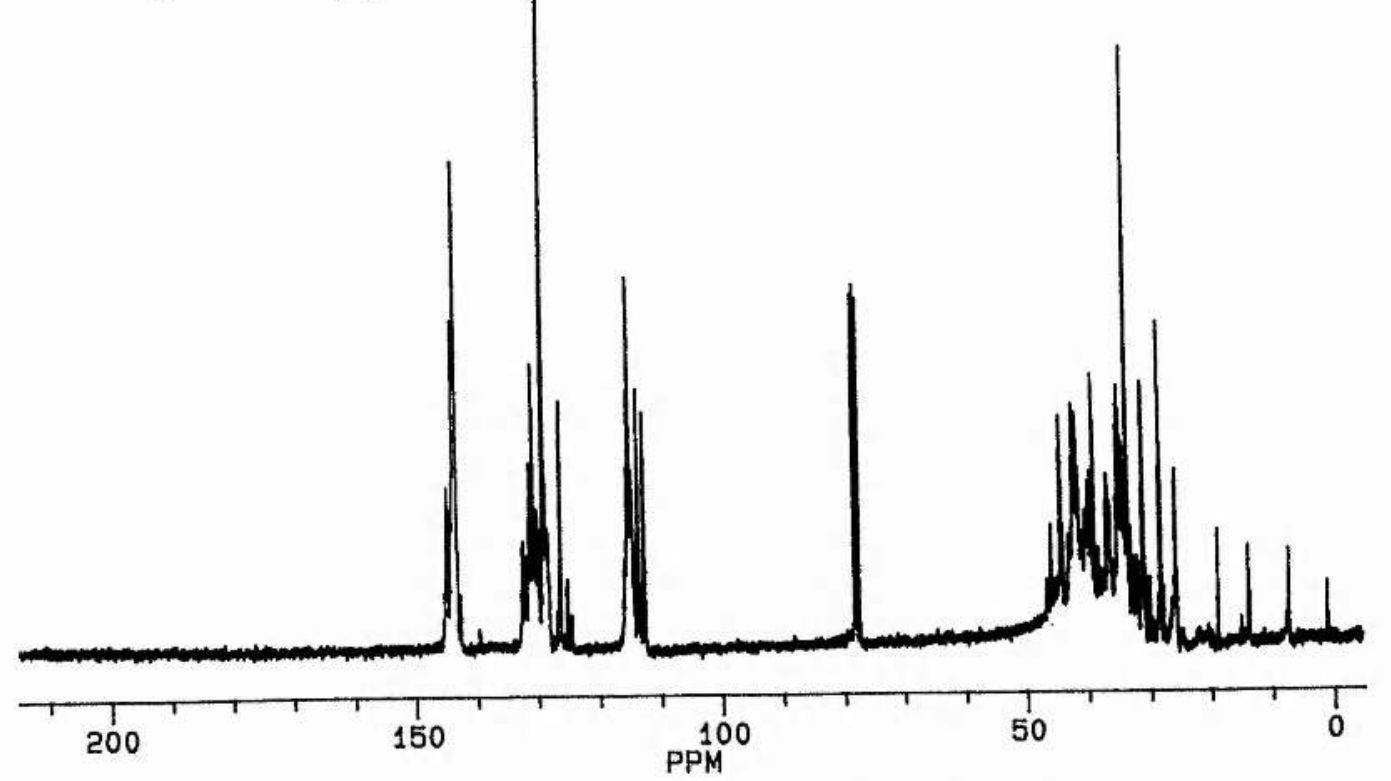

Figure 3.4 (a) ${ }^{13} \mathrm{C}$ n.m.r. spectrum of polybutadiene(phenyl terminated) (b) ${ }^{13} \mathrm{C}$ n.m.r. spectrum of corresponding hydrocarboxylated (selectively) polybutadiene at the terminal carbon position of the pendant group. 


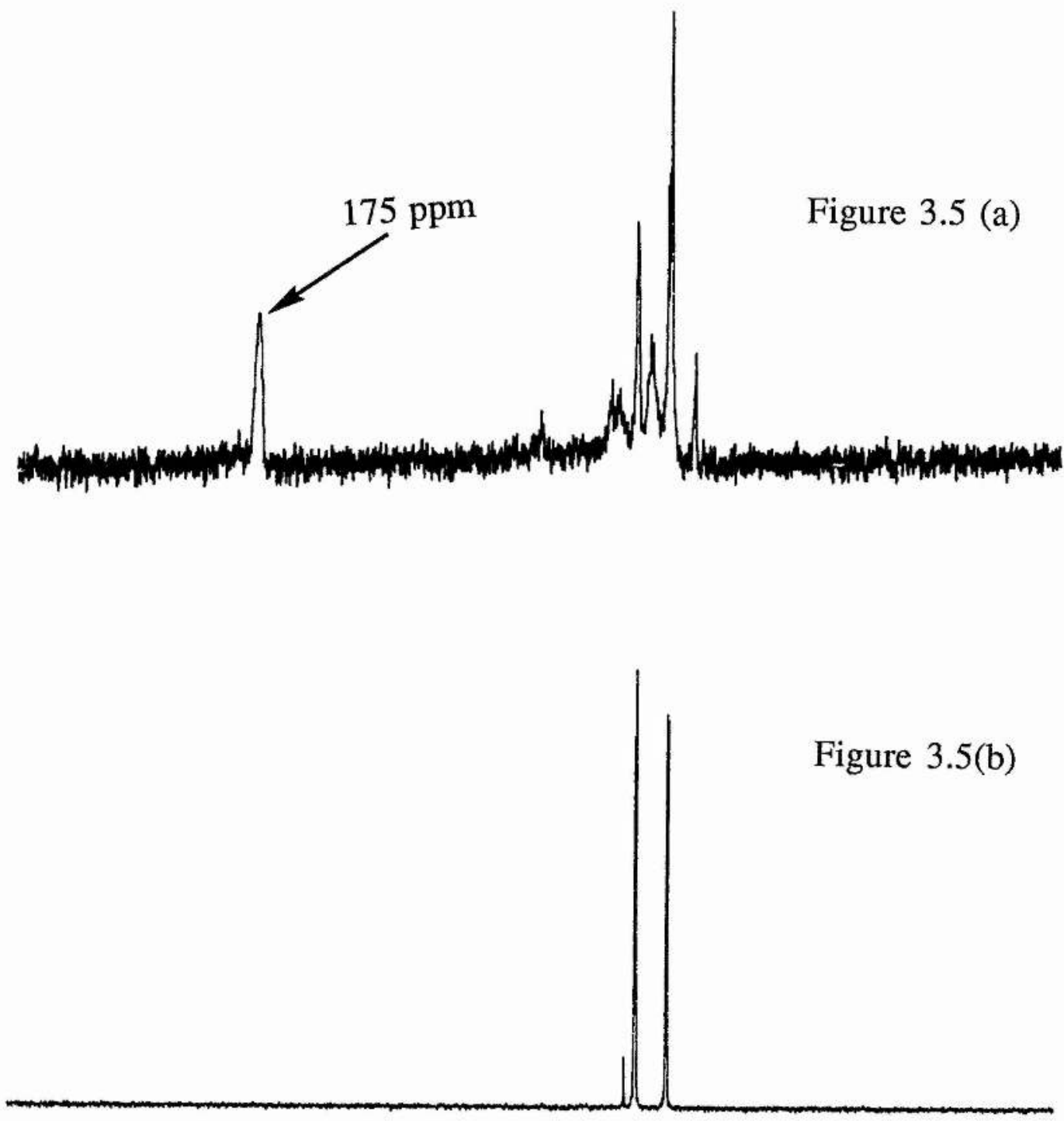

Figure 3.5 (c)

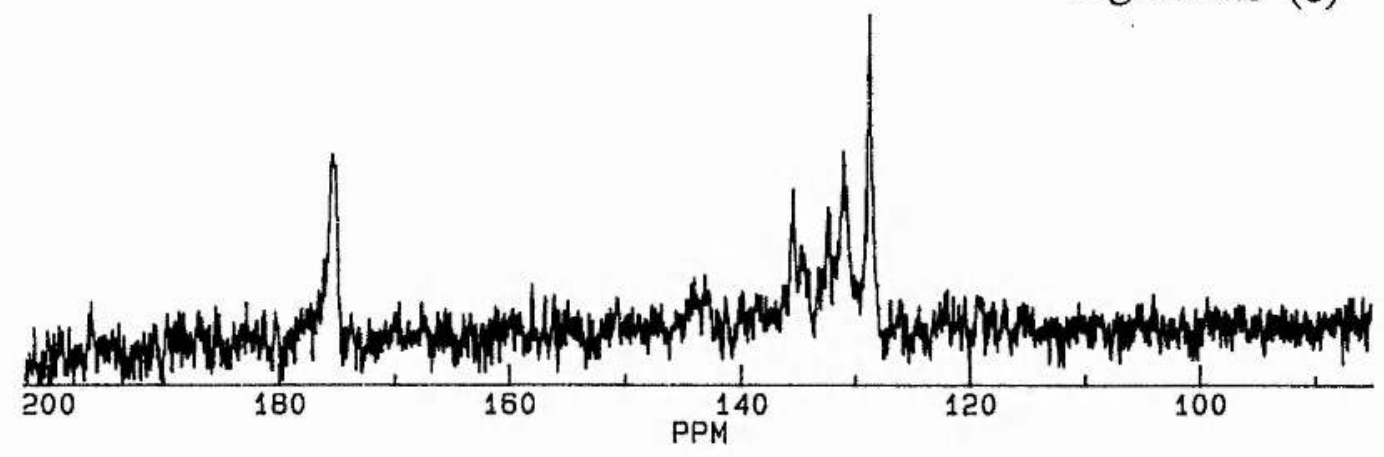

Figure 3.5 (a) ${ }^{13} \mathrm{C}$ n.m.r. spectrum of hydrocarboxylated product after reaction

(b) ${ }^{13} \mathrm{C}$ n.m.r spectrum of triphenylphosphine oxide

(c) ${ }^{13} \mathrm{C}$ n.m.r. spectrum of hydrocarboxylated polybutadiene after treatment for removal of triphenylphosphine oxide. 
product after reaction (Figure $3.5 \mathrm{a}$ ), triphenylphosphine oxide (Figure $3.5 \mathrm{~b}$ ) and the hydrocarboxylated product (Figure $3.5 \mathrm{c}$ ) after treatment for removal of triphenylphosphine oxide are shown for comparision.

As can be seen from Table 3.3 no reaction took place when only cis polybutadiene (see polymer no 8) was subjected to hydrocarboxylation. Further proof for selective hydrocarboxylation comes from the observation that when polybutadienes containing a mixture of both, back bone carbon-carbon double bonds (cis or trans) and pendant carbon-carbon double bonds were subjected to hydrocarboxylation, reaction took place only at the terminal carbon atom of the pendant carbon-carbon double bonds resulting in the appearance of only one carboxylic acid peak at $175 \mathrm{ppm}$. It is evident therefore, that the catalytic sytem $\left[\mathrm{PdCl}_{2}\left(\mathrm{PPh}_{3}\right)\right]-\mathrm{SnCl}_{2}$ is highly regioselective to the introduction of carboxylic acid group on the terminal carbon atom of the pendant carbon-carbon double bonds of the polybutadienes under study (Equation 3.20).
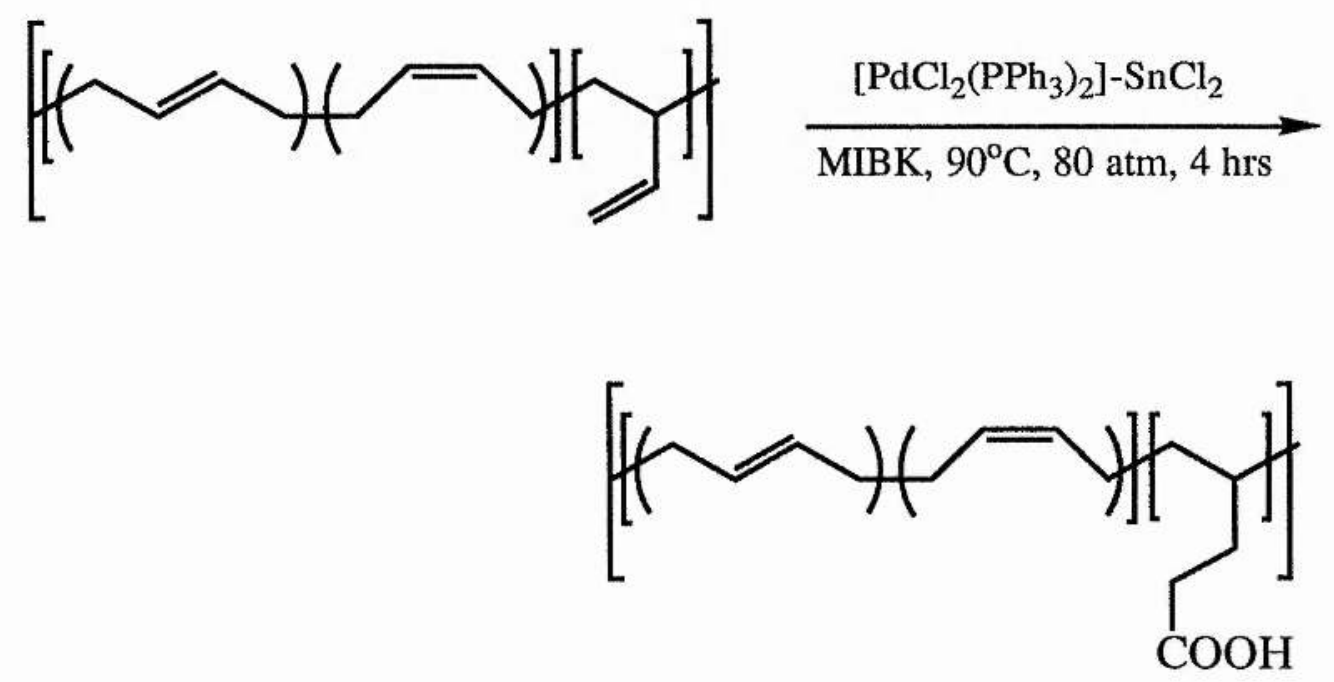

Equation 3.20 . 
3.2.5.3 Determination of weight average molecular weight $\left(\mathrm{M}_{\underline{\underline{w}}}\right)$ and number average molecular weight $\left(\mathrm{M}_{n}\right)$.

The hydrocarboxylated product of polymers number 1 and 5 (see Table 3.3) and their corresponding starting materials were chosen to study the change in weight average molecular weight $\left(\mathrm{M}_{\mathrm{w}}\right)$ and number average molecular weight $\left(M_{n}\right)$ upon hydrocarboxylation. Gel permeation chromotography (GPC) was carried out on our behalf at Ciba-Geigy. The samples were run in THF solvent using a polyethylene glycol standard. The results are shown in Table 3.4. and the GPC's of each polymer studied and their corresponding hydrocarboxylated products are shown in Figure 3.6 (a), (b) (polymer no. 1) and Figure 3.7 (a), (b) (polymer no.5)respectively.

\begin{tabular}{|r|c|c|c|c|c|c|}
\hline $\begin{array}{c}\text { Polymer } \\
\text { No }\end{array}$ & Cis $\mathrm{db}$ & $\begin{array}{c}\text { Trans } \\
\mathrm{db}\end{array}$ & $\begin{array}{c}\text { Pendant } \\
\mathrm{db}\end{array}$ & $\mathrm{COOH}$ & $\mathrm{M}_{\mathrm{w}}$ & $\mathrm{M}_{\mathrm{n}}$ \\
\hline 1 SM & 12 & 19 & 53 & - & 3750 & 1220 \\
$\mathrm{PR}$ & 12 & 19 & 12 & 41 & 6070 & 1430 \\
5. SM & 12 & 19 & 61 & - & 6840 & 2330 \\
PR & 12 & 19 & 12 & 49 & 8550 & 2170 \\
\hline
\end{tabular}

Where $\mathrm{SM}=$ starting material, $\mathrm{PR}=$ product, $\mathrm{db}=$ double bonds

Table 3.4

The shapes of the gel permeation chromotographs for both the starting material and the hydrocarboxylated product is very similar. The molecular weight distribution also remains similar. There is perhaps a slight shifting of the curves for the hydrocarboxylated product to shorter elution times (higher molecular weight) and is 

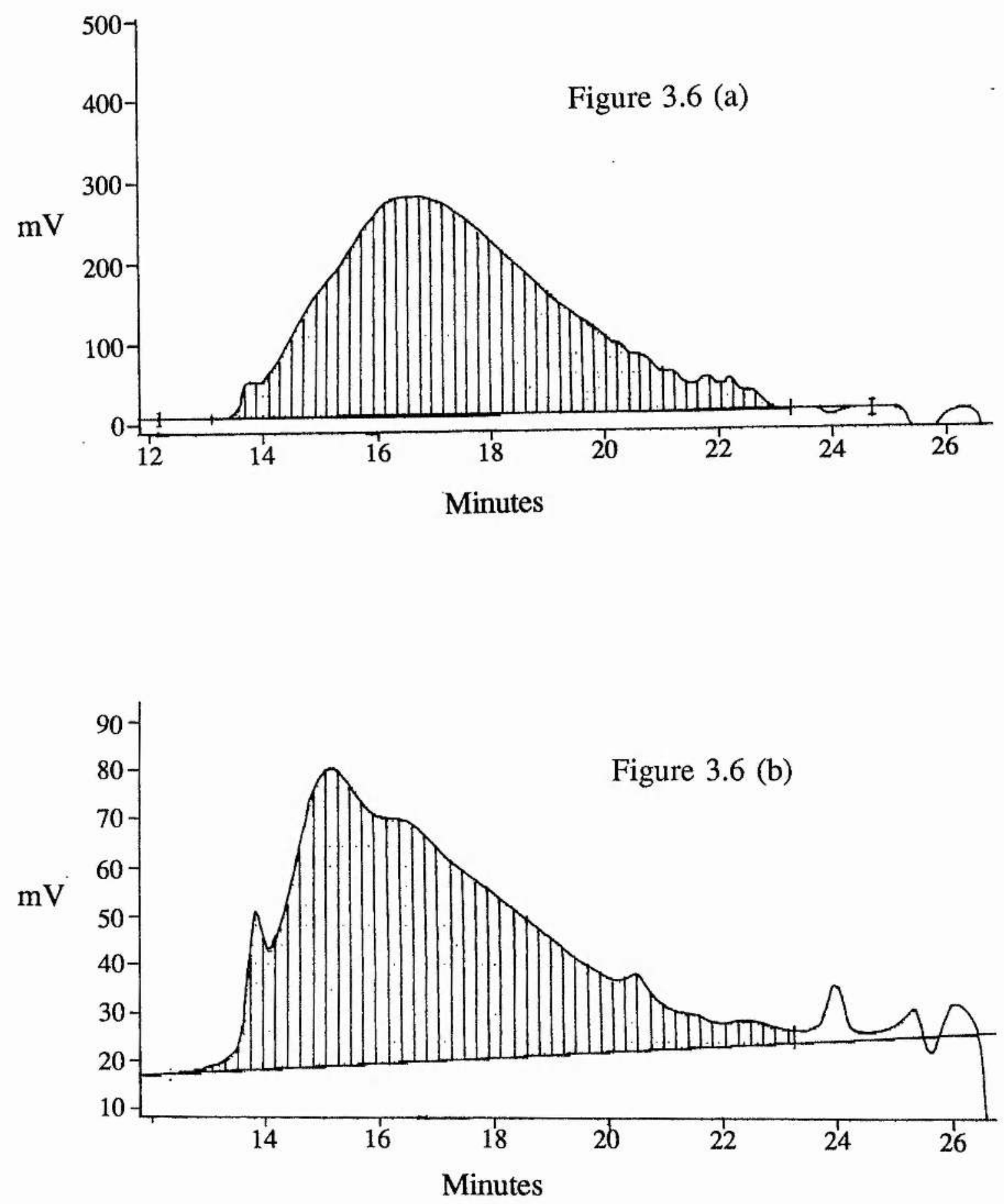

Figure 3.6 (a) GPC of polybutadiene (phenyl terminated, $M_{n}=1000$ )

(b) GPC of corresponding hydrocarboxylated polybutadiene 

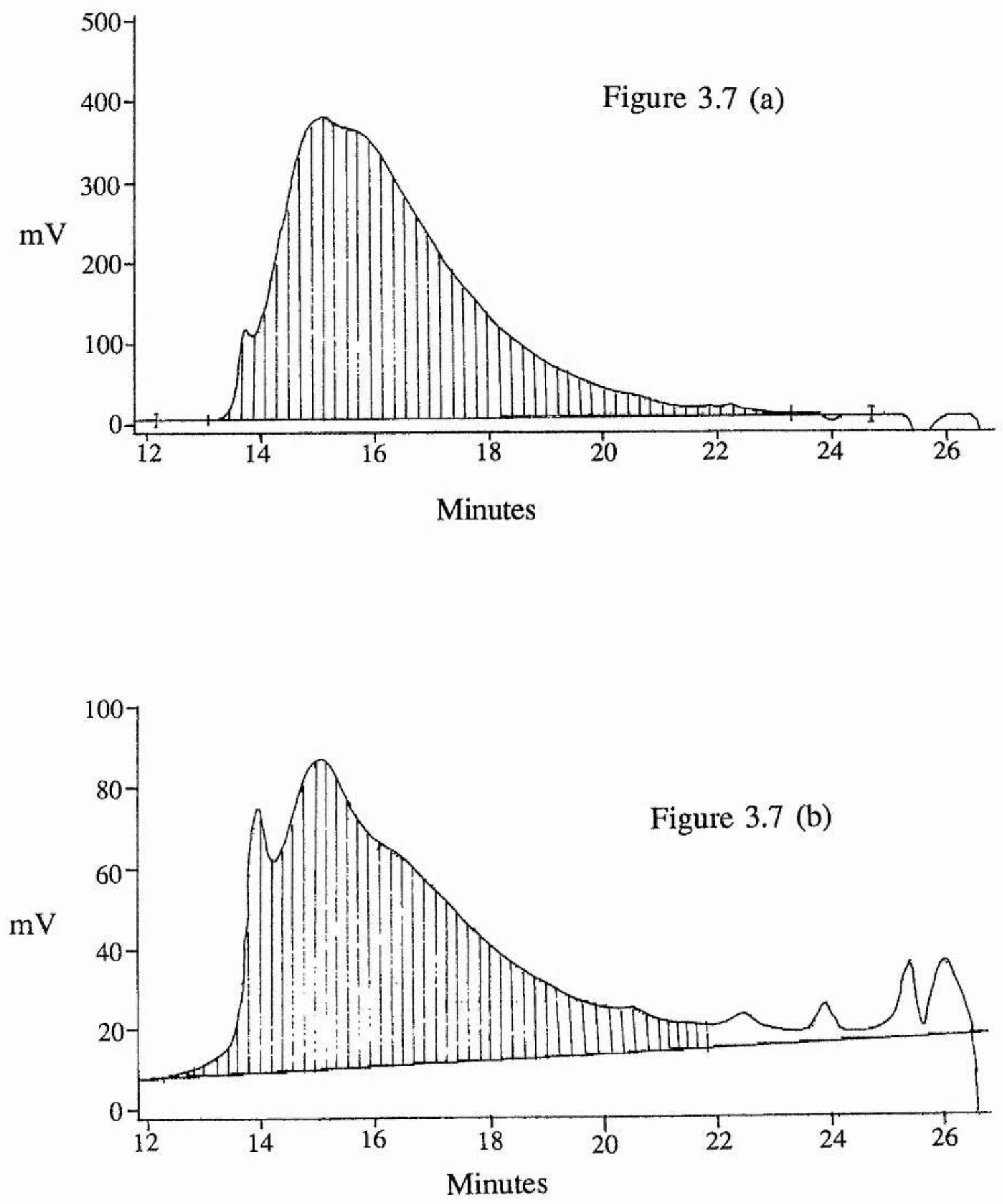

Figure 3.7 (a) GPC of polybutadiene (phenyl terminated, $M_{n}=1800$ ) (b) GPC of corresponding hydrocarboxylated polybutadiene 
consistent with increase in molecular weights caused by the addition of $\mathrm{HCOOH}$ units in the formation of the carboxylic acid. Any further increase in molecular weight may be due to inter polymer hydrogen bonding as shown in Figure 3.8.

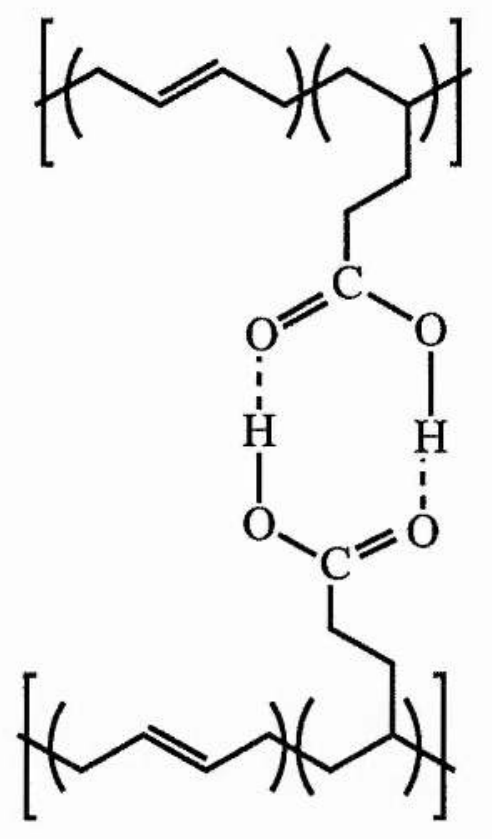

Figure 3.8

There is not any gross cross linking or chain scission. However the results obtained should not be taken too literally because of the fact that only polyethylene glycol was chosen as the standard and not polymers with closer structures to those of polycarboxylic acids.

\subsubsection{Differential Scanning Calorimetry (DSC).}

The effect of hydrocarboxylation of polybutadiene on the glass transition temperature $(\mathrm{Tg})$ was studied by differential calorimetric 
analysis. DSC studies on various polymers and their corresponding hydrocarboxylated products are shown in Table 3.5. The $\mathrm{Tg}$ of polymer number $10^{*}$ is shown in Figure 3.9.

\begin{tabular}{|c|c|c|c|c|c|c|}
\hline \multicolumn{2}{|c|}{$\begin{array}{l}\text { Polymer } \\
\text { number }\end{array}$} & $\begin{array}{c}\text { Cis } \\
\text { double } \\
\text { bonds (\%) }\end{array}$ & $\begin{array}{c}\text { Trans } \\
\text { double } \\
\text { bonds (\%) } \\
\end{array}$ & $\begin{array}{c}\text { Pendant } \\
\text { double } \\
\text { bonds (\%) }\end{array}$ & $\begin{array}{c}\text { Overall } \\
\text { conversio- } \\
\mathrm{n}(\%)\end{array}$ & $\mathrm{Tg}$ \\
\hline \multirow[t]{2}{*}{ (1) } & SM & 12 & 19 & 53 & - & - \\
\hline & PR & 12 & 19 & - & 53 & 66.4 \\
\hline \multirow[t]{2}{*}{ (11) } & SM & - & 9 & 88 & - & - \\
\hline & PR & - & 9 & 16 & 72 & 34.3 \\
\hline \multirow[t]{3}{*}{ (10) } & SM & - & 14 & 84 & - & - \\
\hline & PR & - & 14 & 39 & 45 & 40.3 \\
\hline & PR* & - & - & - & 98 & 45.7 \\
\hline \multirow[t]{3}{*}{ (3) } & SM & - & 16 & 81 & - & - \\
\hline & $\mathrm{PR}$ & - & 16 & 65 & 16 & 34.3 \\
\hline & PR & - & 16 & 48 & 33 & 41.7 \\
\hline
\end{tabular}

Where $\mathrm{SM}=$ starting polybutadiene, $\mathrm{PR}=$ Hydrocarboxylated polybutadiene, $*=$ This represents a recatalysis reaction where all the carbon-carbon double bonds in polybutadiene have been carboxylated (see section 3.2.13 - Recatalysis).

\section{Table 3.5}

From the table it can be seen that $\mathrm{Tg}$ increases as the percentage of conversion of the carbon-carbon double bonds increases. The high $\mathrm{Tg}$ for the hydrocarboxylated product of polymer number 1 is due to a high percentage of saturated double bonds $(16 \%)$ present in the starting 


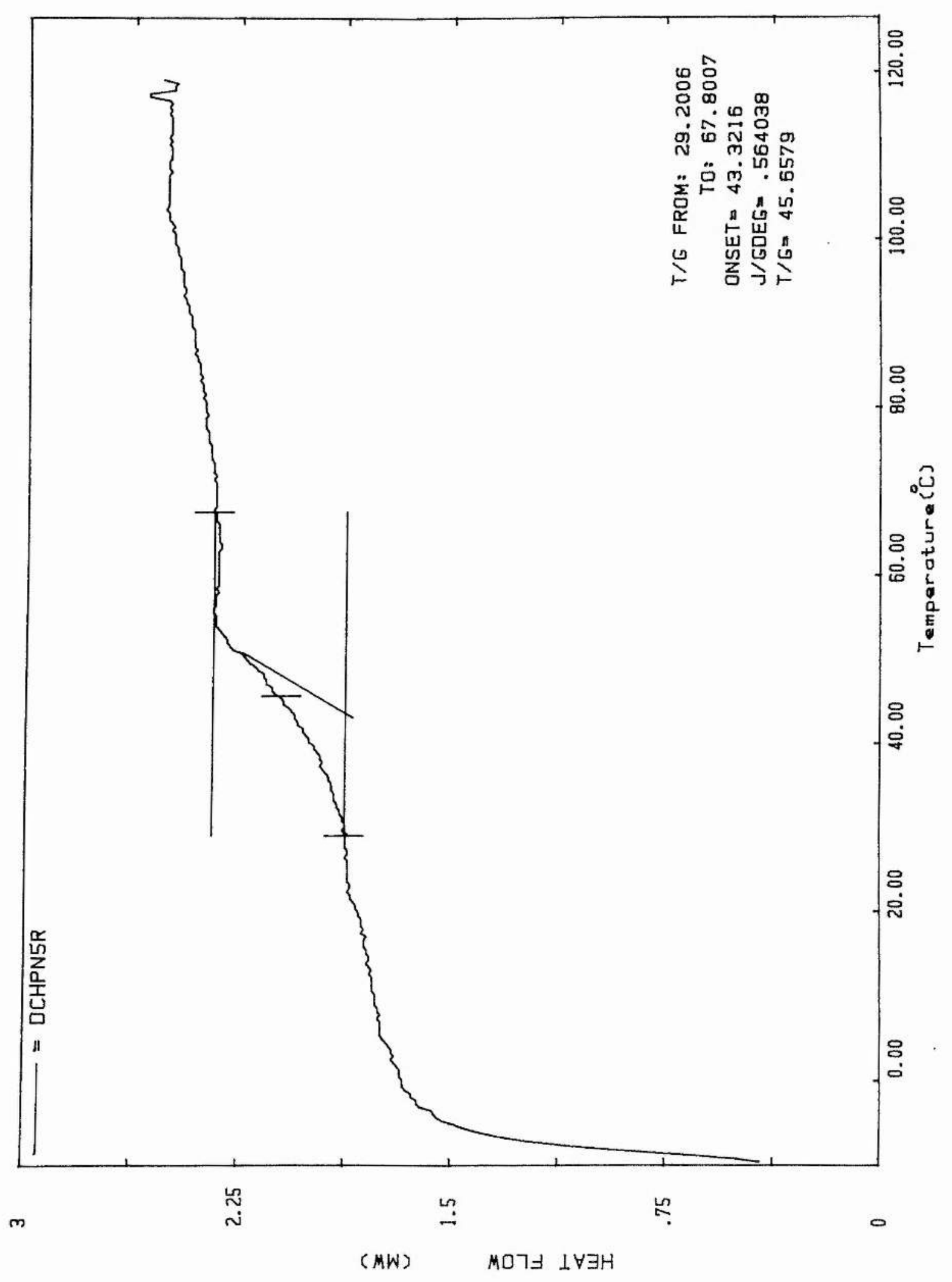

Figure 3.9 Tg of hydrocarboxylated polybutadiene (complete conversion of $\mathrm{C}=\mathrm{C}$, polymer no. 10 ) 
polymer.

Unlike the starting polymers, which are generally syrupy liquids with glass transition temperature ( $\mathrm{Tg}$ ) well below room temperature, the hydrocarboxylated product are solids which can be cast as films from solution. The products are soluble in polar solvents, e.g. acetone or methanol as well as in dilute $\mathrm{NaOH}$, provided that the $\mathrm{pH}$ is kept $\geq 7$.

\subsubsection{Catalyst stability}

The only problem with this catalytic system $\left\{\left[\mathrm{PdCl}_{2}\left(\mathrm{PPh}_{3}\right)_{2}\right]\right.$ $\left.\mathrm{SnCl}_{2}\right\}$ is that the catalyst decomposed at the end of the reaction under these conditions. Time variation studies were carried out to find the onset of the reaction. From the ${ }^{13} \mathrm{C}$ n.m.r. results obtained after various reaction periods it was evident that for the first 2 hours after introduction of the autoclave into the oven, there is very little conversion or no conversion at all. During this period there is no catalytic decomposition. After 2 hours reaction occurs rapidly and then levels off after 4 hours (see Figure 3.10), where by maximum conversion is obtained. After this time no further conversion was observed even after prolonged heating. As can be seen from Figure 3.10 it is during this short period when the reaction is occurring that the stability of the catalyst changes rapidly. The catalyst starts off with a slight decomposition and by the time the reaction is complete all the catalyst has decomposed. In other words there exists a small time window between the onset of the reaction and catalytic decomposition at which maximum conversion occurs.

Since recovery and reuse of catalyst to achieve maximum turn overs for a given amount of catalyst is of utmost importance in the 
process of catalysis, the various factors affecting the stability of the catalyst such as effects of cocatalysts and its concentration, ligands, ligand concentration, percentage of water, solvent etc., were throughly

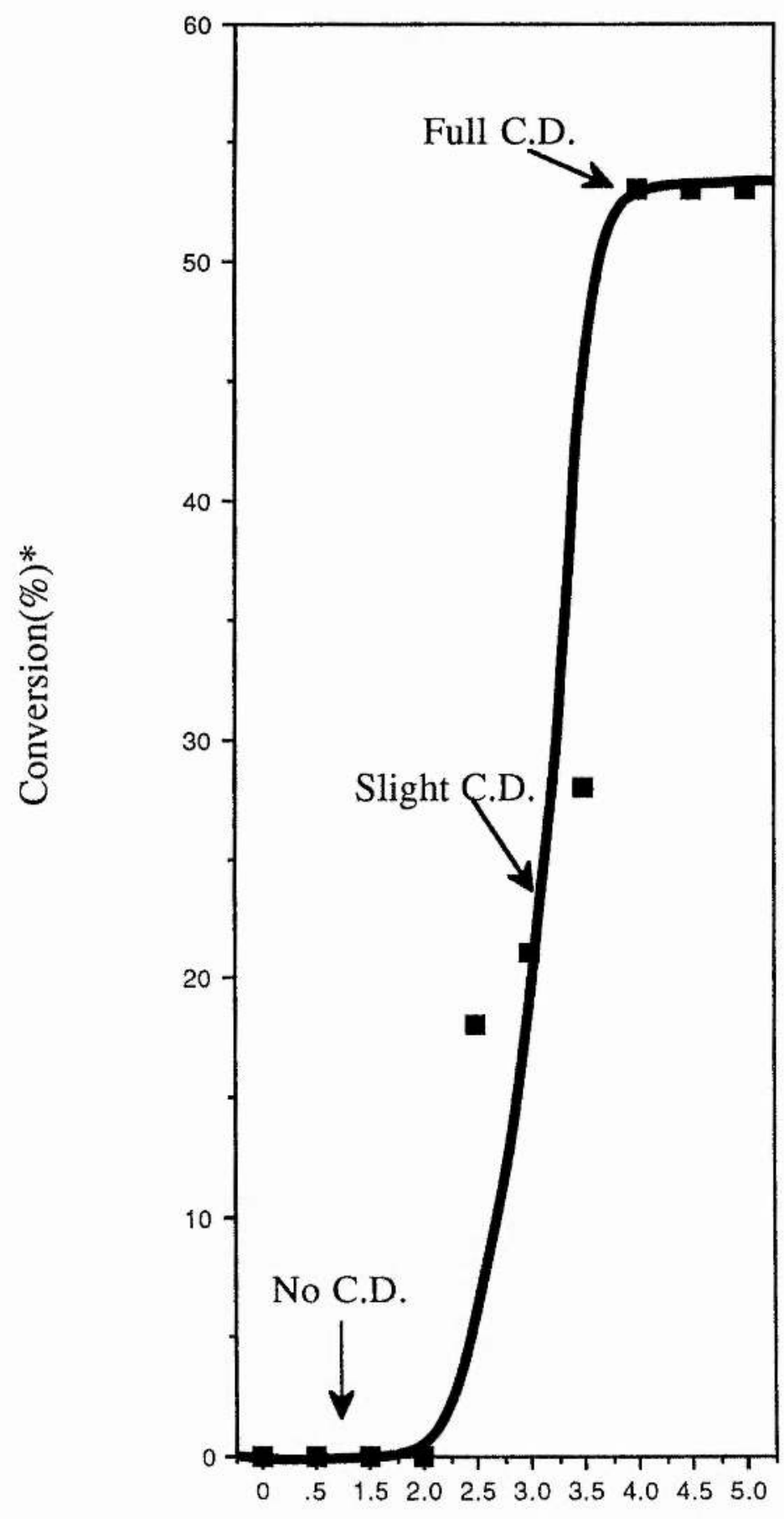

Time /Hours

Figure 3.10 Studies on stability/activity of the catalyst with time. 
investigated. The reaction conditions; 80 atmospheres carbon monoxide pressure, $90^{\circ} \mathrm{C}$ and 4 hours were used throughout the reactions studied unless otherwise stated.

\section{$\underline{3.2 .7 \text { Effect of co-catalysts. }}$.}

$\mathrm{SnCl}_{2} \cdot 2 \mathrm{H}_{2} \mathrm{O}$ was found to have unique properties that make it the most effective co-catalyst for hydrocarboxylation. In the absence of $\mathrm{SnCl}_{2} \cdot 2 \mathrm{H}_{2} \mathrm{O}$ no, or very little reaction takes place. That water in $\mathrm{SnCl}_{2} \cdot 2 \mathrm{H}_{2} \mathrm{O}$ has no effect on the stability of the catalyst was shown by comparing the hydrocarboxylation with the dihydrate and anhydrous $\mathrm{SnCl}_{2}$ as co-catalyst. The results were identical. For convenience, the dihydrate was therefore used throughout this work.

The results of varying the ratio of the cocatalyst to the catalyst was investigated (see Table 3.6).

\begin{tabular}{|c|c|c|}
\hline $\begin{array}{c}\text { Mole ratio } \\
\left(\mathrm{C}_{6} \mathrm{H}_{5}\right)_{3} \mathrm{P}: \mathrm{Pd}: \mathrm{SnCl}_{2}\end{array}$ & Stability of catalyst & $\begin{array}{c}\text { Coversion (\%) of } \\
\text { pend } n \text { t } \mathrm{C}=\mathrm{C} \text { bonds }\end{array}$ \\
\hline $2: 1: 1$ & C.D. observed & $<10 \%$ \\
$2: 1: 5$ & C.D. observed & $26 \%$ \\
$2: 1: 10$ & C.D. observed & $53 \%$ \\
$2: 1: 30$ & C.D. observed & $33 \%$ \\
\hline
\end{tabular}

Table 3.6

The results obtained revealed two things. Firstly, stability of the catalyst cannot be attained by changing the concentration of the cocatalyst and 
secondly, conversion increasing with inceasing tin-to-palladium ratio to a maximum ratio of 10 moles, then declining. Addition of excess $\mathrm{SnCl}_{2}$ i.e., $>10$ moles suppresses hydrocarboxylation reactions. This may be due to the fact that when a large excess of $\mathrm{SnCl}_{2}$ is present, it may not only drive the above reaction towards the formation of a tin-rich complex, but may also block some of the sites on the palladium atom, which would otherwise be available for coordination with the alkene (polybutadiene).

\subsubsection{Effect of adding excess triphenyl phosphine.}

Although selectivity and conversion remained the same upon addition of excess triphenyl phosphine, stability of the catalyst did not show any improvement. Decomposition of catalyst was observed.

\subsubsection{Effect of water}

Water has a profound effect on catalyst stability. Several experiments were carried out and observations made to study the effect of water on catalyst stability.

Bittler and coworkers 47 observed that during hydroesterification of 1,5,9-cyclododecatriene in the presence of $\left[\mathrm{PdCl}_{2}\left(\mathrm{PPh}_{3}\right)_{2}\right]$ at $75^{\circ} \mathrm{C}$ and 300 atmospheres carbon monoxide pressure, reduction of palladium (II) to metallic palladium became more pronounced when the "more water like" methanol is used instead of ethanol.

From our experiments we found that if water is replaced with an alcohol there was no decompositon of the catalyst but 
hydroesterification also did not occur. It was observed that catalytic decompositon increases with increasing amounts of water, but the amount of conversion was also increased (see Table 3.7).

\begin{tabular}{|c|c|c|}
\hline $\begin{array}{c}\text { Amount of water } \\
\left(\mathrm{cm}^{3}\right)\end{array}$ & Stability of catalyst & $\begin{array}{c}\text { Conversion (\%) of the } \\
\text { pendant C=C bonds. }\end{array}$ \\
\hline No water & No C.D. & 17.2 \\
0.1 & Slight C.D. & 26.5 \\
0.2 & C.D. observed & 30 \\
0.3 & C.D. observed & 39 \\
0.4 & C.D. observed & 42 \\
0.5 & C.D. observed & 53 \\
\hline
\end{tabular}

Table 3.7

We experimented on systems that would slowly release water into the reaction so that water can be used only as and when required. Several methods were tried to find an effective method of releasing water into the system. For example, molecular sieves (size 4A) were added along with water into the reaction vessel, with the aim that molecular sieves might absorb the water intially present in the reaction vessel and release it slowly as the reaction proceeded. In another experiment water was replaced with chloral hydrate to see if chloral hydrate would release the required amount of water during the reaction and hence avoid catalytic decomposition. Neither technique was successful.

To see if water kept in a separate compartment within the same reaction vessel might slowly distil into the reaction mixture and hence improve the catalyst stability, reactions were carried out with water 
$\left(0.5 \mathrm{~cm}^{3}\right)$ being kept in a test tube inside the reaction vessel as shown in Figure 3.11 .

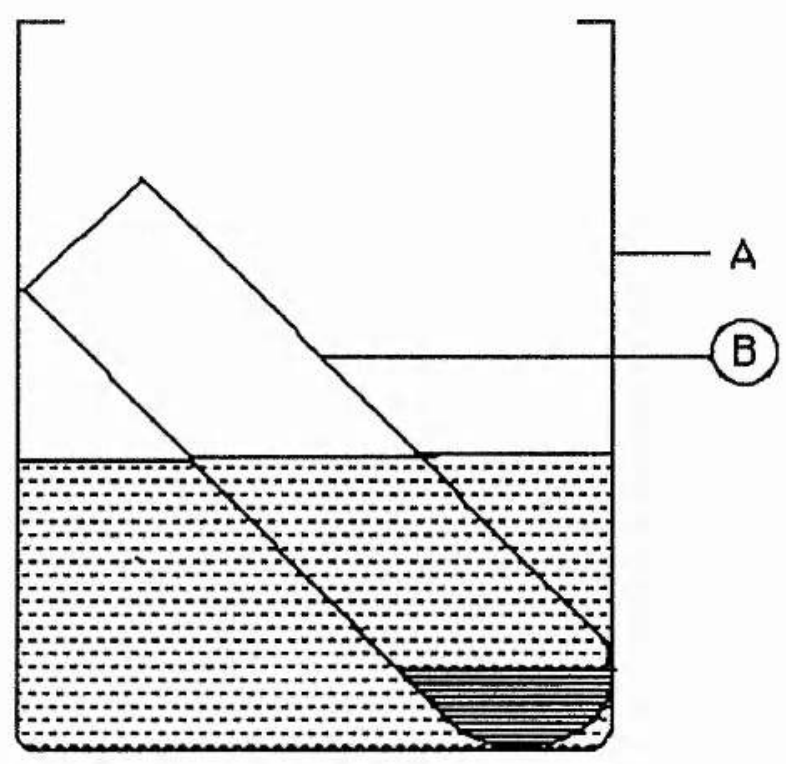

A- Glass liner, B - test tube

Figure 3.11

\begin{tabular}{|c|c|c|}
\hline Height of test-tube & Stability of catalyst & $\begin{array}{c}\text { Conversion (\%) of } \\
\text { pendant C=C bonds. }\end{array}$ \\
\hline 8.5 & No C.D. & 18 \\
7.5 & No C.D. & 22 \\
2.5 & No C.D* & 18 \\
\hline
\end{tabular}

*colour of the reaction solution changes from yellow to reddish brown

Table 3.8

After the reaction water was present in the test tubes in all cases. From Table 3.8 it is evident that the height of the test tube does not seem to matter. The conversion in all the cases resembles closely the results 
obtained from the absence of water in the reaction (see Table 3.7., item 1). However when the height of the test tube was $2.5 \mathrm{~cm}$ the colour of the reaction solution changes from yellow to reddish brown. The reason for this observed result might be due to the fact that a very little amount of water enough to cause catalytic decomposition, but not enough to cause high conversion distilled into the reaction chamber during the reaction.

\subsubsection{Effect of solvent}

The solvent is an important factor governing the activity of a soluble catalyst in homogeneous reactions. The solvent may improve (a) the selectivity on varying the concentration of the reactants, the intermediates and final products in the reaction medium and (b) the mass transfer between the gas and liquid phases. The solvent can also act as a coolant or as a selective medium for the feed stock or product. Furthermore, certain solvents are not inert since they can react selectively with reaction intermediates or products or they can exert electronic effects even in the inner coordination sphere of the catalysts. Often it is important that there should be a single phase reaction i.e., solvent must dissolve both the reactants and the catalyst although in certain situations it is desirable to work in two phases 107.

Methyl isobutyl ketone was choosen as the solvent for the hydrocarboxylation reactions because of its convenience for dissolving the catalyst, co-catalyst, and polybutadiene. Since it forms an immiscible layer with water it has been very convenient for also treating polybutadiene to remove any peroxide contamination (see 3.4 Experimental section). Other solvents, such as tetrahydrofuran, acetone, methanol, etc., were studied, but it was found that methyl isobutyl 
ketone gave the best results (see Table 3.9).

\begin{tabular}{|c|c|c|}
\hline Solvent & Catalyst stability & $\begin{array}{c}\text { Conversion (\%) of } \\
\text { pendant C=C bonds }\end{array}$ \\
\hline Methyl isobutyl ketone & C.D observed. & 53 \\
THF & C.D. observed & 0 \\
Acetone & C.D. observed & 36 \\
Toluene & C.D. observed & 0 \\
Carbon tetrachloride & C.D. observed & 0 \\
\hline
\end{tabular}

Table 3.9

\subsubsection{Studies on the relationship between stability and activity of the catalyst}

From the above results, it is clear that high conversions to polycarboxylic acids are only obtained in cases where there is substantial catalyst decomposition. Particularly striking is the time profile of the reaction. Thus, data from reactions carried out for different times are shown in Figure 3.10. There appears to be a long initiation period ( $c a 2.5$ hours). After the onset of reaction the conversion increases steadily for the next 1.5 hours until its completion. Examination of the recovered solutions indicates that no decomposition occurs for 2.5 hours but that essentially total decomposition has occurred after 4 hours. There are various possible explanations for these phenomenon; 
(i) The reaction may in fact be catalysed by palladium metal formed in the decomposition,

(ii) Since triphenylphosphine oxide is a major product of the decomposition, it may be that triphenylphosphine oxide in some way activates the catalyst towards reactivity, or

(iii) Some physical reaction parameters may be responsible for these unusual findings.

We have attempted to distinguish between these possiblities by a variety of experiments.

\subsubsection{Tests on the homogeneity of the reaction}

Attempts to use the black solid obtained at the end of a typical catalytic reaction as catalyst in the presence of added $\mathrm{SnCl}_{2}$, indicate that this is not itself active, but this does not rule out the possibility that colloidal palladium formed from the catalyst decomposition, is the active species and that it coagulates slowly enough to allow complete conversion of the pendant carbon-carbon double bonds on polybutadiene to carboxylic acids. Were this the case, the highly se'ective nature of the reaction would be surprising, but it stills needs to be definitively discounted.

Crabtree 108 has reported certain tests which allow the distinction between homogeneous and heterogeneous reactions. The simplest of these involves carrying out the reaction in the presence of metallic mercury which, in general, poisons heterogeneous (metal catalysed) reactions by amalgamating the metal.

We have, therefore, carried out a reaction in the presence of a stirred pool of mercury and found that, although catalyst decomposition still occurs, high conversion to polycarboxylic acid is observed. This 
would appear to indicate that the reaction is genuinely homogeneous, but may not be definitive in this case since palladium does not readily form an amalgam with mercury.

\subsubsection{Effect of triphenylphosphine oxide}

The $13 \mathrm{C}$ n.m.r. of hydrocarboxylated polybutadienes always showed the presence of triphenylphosphine oxide. It was therefore thought that possibly triphenylphosphine oxide, generated in situ during the reaction, in conjunction with the catalytic mixture $\left[\mathrm{PdCl}_{2}\left(\mathrm{PPh}_{3}\right)_{2}\right] / \mathrm{SnCl}_{2}$, generates the actual catalytic species for hydrocarboxylation, (analogous complexes, such as $\left[\mathrm{PtCl}_{2}\left(\mathrm{OPPh}_{3}\right)\right]_{2} 41$ are known). In order to test this hypothesis excess triphenyl phosphine oxide was added and the reaction carried out. It is evident from the

\begin{tabular}{|c|c|c|}
\hline Moles of $\mathrm{PPh}_{3} \mathrm{O}: \mathrm{Pd}$ & Catalyst stability & $\begin{array}{c}\text { Conversion (\%) of } \\
\text { pendant } \mathrm{C}=\mathrm{C} \text { bonds }\end{array}$ \\
\hline $0: 1$ & C.D.observed & 53 \\
$10: 1$ & C.D.observed & 19 \\
\hline
\end{tabular}

Table 3.10

Table 3.10 that addition of excess triphenyl phosphine did not improve the activity of the catalyst; the stability was not improved. 


\subsubsection{Possible physical effects on catalyst stability}

Commercially, where reactions can be carried out at high temperatures and pressures, the catalytic solution is usually heated, with stirring under pressure in the reaction vessel. In another compartment, the substrate is kept at the required temperature and pressure. Once the required conditions in the reaction vessel are stabilised, the substrate is pumped into the reaction chamber and the contents stirred throughout the reaction period. The temperature and the uptake of the reactant gas eg., carbon monoxide could be monitored throughout the reaction period.

However, with our technique we encountered several problems. Firstly, since we typically place a cold autoclave into a hot oven, it seemed possible that the reaction temperature might be rather lower than we had imagined and that the unusual reaction profile shown in Figure 3.10 might arise because the autoclave only reaches temperatures at which the reaction is rapid after $c a 2.5-3$ hours. Further increase in the temperature might then lead to catalyst decomposition, with only a rather narrow temperature window occurring between the onset of the reaction and the decomposition of the catalyst.

Accordingly, we modified an autoclave by introduction of a steel pocket dipping into the reaction solution (Figure 3.12) so that we could monitor the temperature of the solution. We found that the temperature of the autoclave reaches only $85^{\circ} \mathrm{C}$ in 4 hours although the oven was kept at $90^{\circ} \mathrm{C}$ (see Figure 3.13). Using a fan assisted oven, the temperature rose more quickly but still took an hour to reach the preset temperature. 


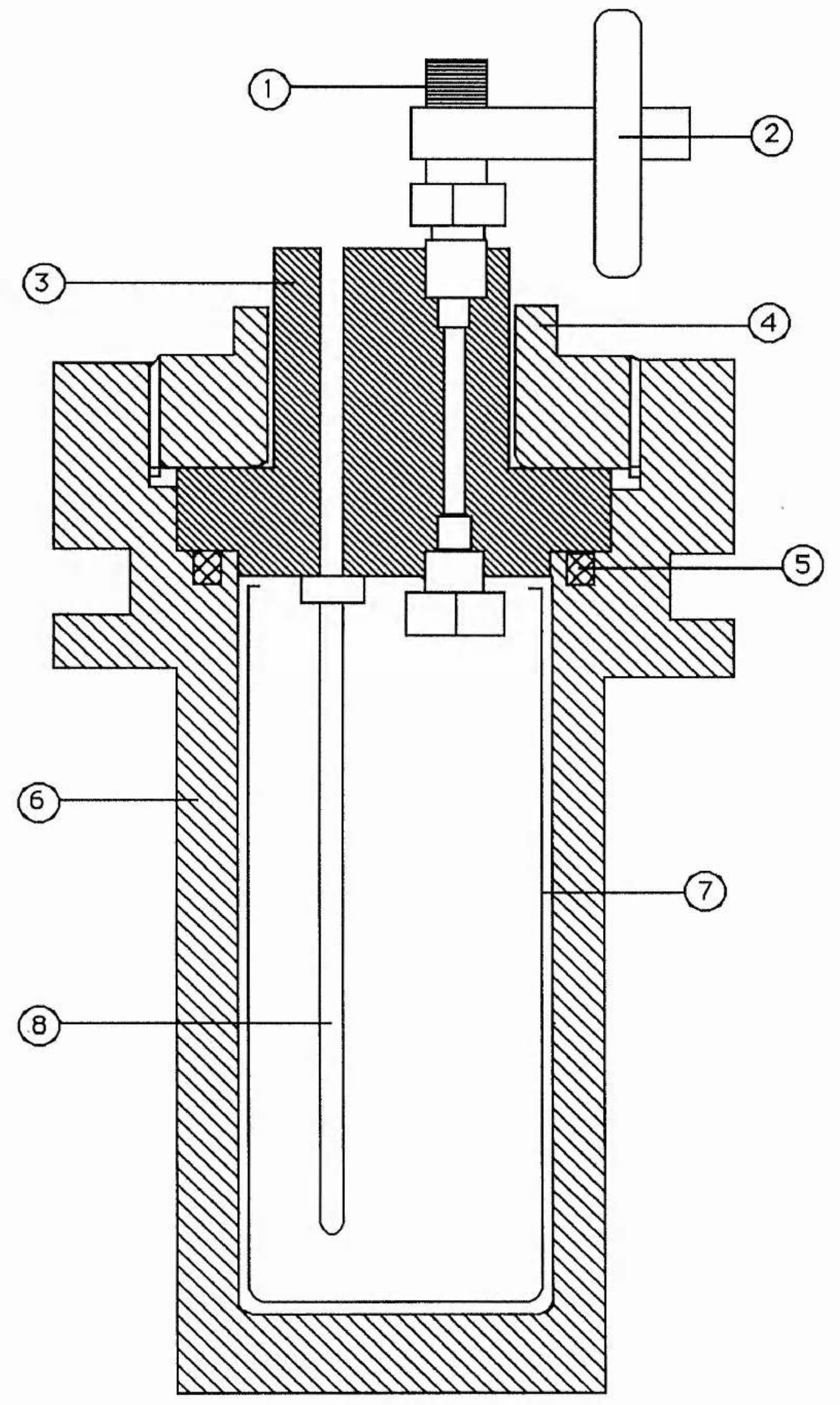

Figure 3.12 
Key to Figure 3.12

1. Screw cap for connecting the autoclave, through metal tubing, to the carbon monoxide cylinder

2. Valve for pressurising and depressurising the autoclave

3. Autoclave head/top

4. Autoclave screw top. This comes along with the autoclave head part 3 and fastens the autoclave screw top to the body / base of the autoclave.

5. Rubber gasket which goes between the head and the body of the autoclave

6. Steel autoclave body / base

7. Glass liner

8. A thin hollow steel tube (closed at the bottom) used for inserting the temperature probe to measure the temperature of the reaction solution. The temperature probe is connected to a digital thermometer.

The autoclave used for carrying out experiments was made of stainless steel.

Secondly in all the experiments mentioned above the contents of the reaction vessel were not stirred. It would also be desirable to stir the contents of the reaction mixture. Due to technical difficulties however, stirring of the contents could not be done in an oven so experiments were carried out in an oil bath with stirring. When the autoclave was placed in a preheated oil bath, and the temperature monitored through out the reaction it was observed that the autoclave acts initially, like a large heat sink. The temperature of the oil bath falls to almost half and then starts to rise. 


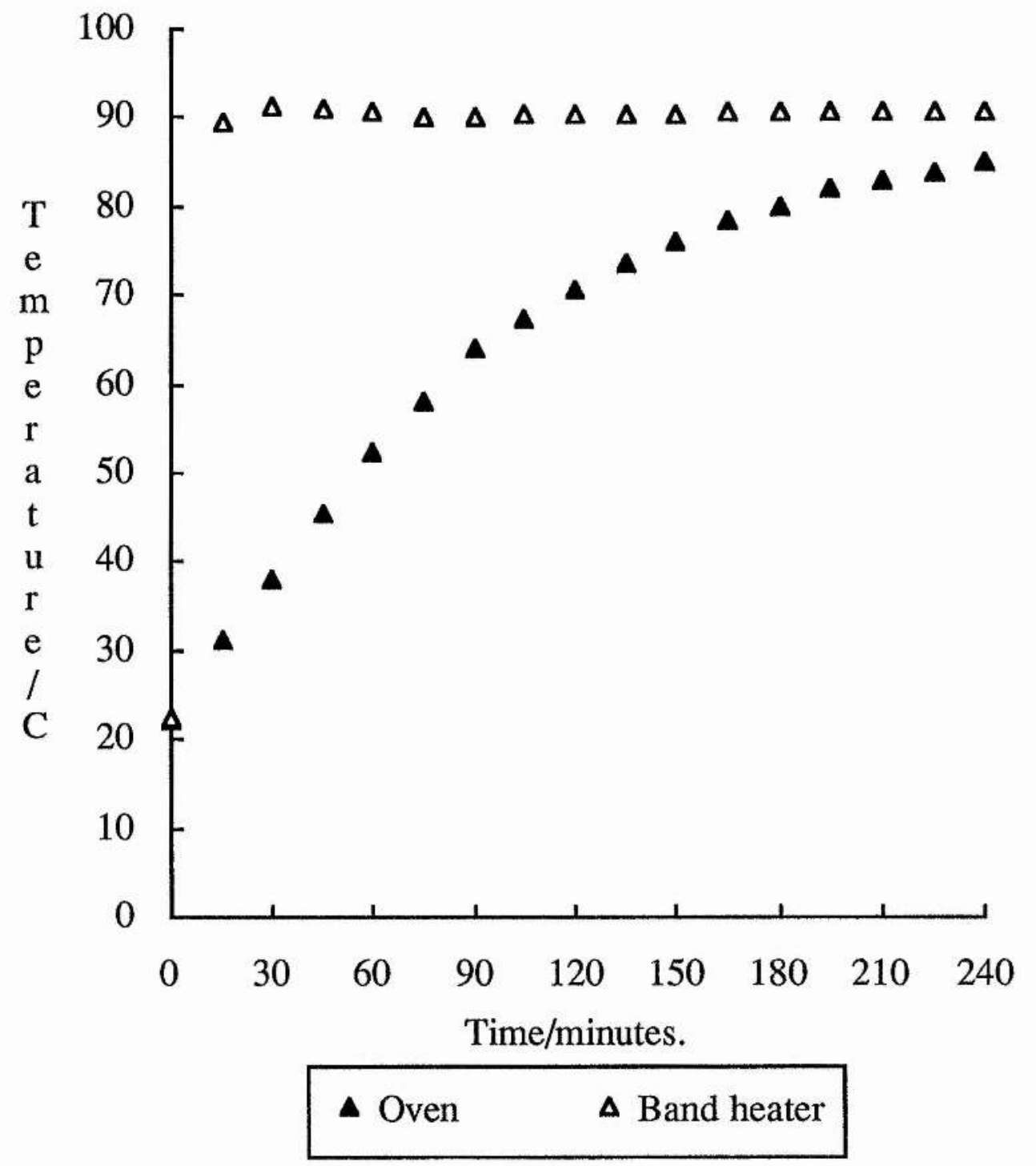

Figure 3.13

\section{$\underline{3.2 .12 \text { Effect of Heater design }}$}

The large heat capacity of the autoclave means that it is very difficult rapidly to achieve the desired reaction temperature. Examination of Figure 3.10 and 3.11 suggest that the onset of reaction 
occurs at $\mathrm{ca} 70^{\circ} \mathrm{C}$ or below. Experiments were performed by gradually lowering the temperature by $5^{\circ} \mathrm{C}$ each time. It was observed that between $50-55^{\circ} \mathrm{C}$ the catalyst did not decompose. However the yield was comparatively very small $<50 \%$. With the temperature between 50 $55^{\circ} \mathrm{C}$ and the pressure at 80 atmospheres carbon monoxide, various reaction time period were studied i.e., $4,24,48$, and 100 hours. It was observed that after a reaction period of 100 hours complete conversion of polybutadiene takes place with out any catalyst decomposition.

We conclude that the reaction is truly homogeneous but that there is only a small temperature window between the onset of catalysis and the onset of catalyst decomposition. Experiments were also run in which the autoclave was placed in a gas chromatograph oven. In one case the gas chromatograph oven was switched on after the autoclave had been placed in it, whilst in the other the gas chromatograph oven was kept at a preheated temperature and the autoclave introduced. In both cases catalyst decomposition was observed although complete conversion of polybutadiene was obtained. By heating the autoclave quickly, it is possible to obtain high conversions in a short time but catalyst decomposition also occurs. By using a band heater directly attached to the autoclave (see Figure $3.16 \mathrm{~b}$ ), we have now managed to obtain a heating method which allows the temperature of the solution to reach the required temperature within 10 minutes as can be seen in Figure 3.13.

3.2.13 Recatalysis : Complete hydrocarboxylation of all the carboncarbon double bonds in polybutadiene.

Lapidus and coworkers 36 reported that hydrocarboxylation of 
polybutadiene in the presence of $\left[\mathrm{PdCl}_{2}\left(\mathrm{PPh}_{3}\right)_{2}\right]$ and excess triphenylphosphine occured mainly at the pendant carbon-carbon double bonds, with a yield of $c a<60 \%$. No information is given about the catalyst stability. We carried out identical experiments and observed from ${ }^{13} \mathrm{C}$ n.m.r. that hydrocarboxylation takes place at three positions namely at the internal double bond position (177 ppm), and at the terminal $(175 \mathrm{ppm})$ and penultimate carbon atom position (173ppm) of the pendant carbon-carbon double bonds (Figure 3.14). As can be seen from ${ }^{13} \mathrm{C}$ n.m.r. the selectivity is greater towards the terminal carbon atoms of the pendant carbon-carbon double bonds, followed by the back bone carbon atoms. The final composition of the hydrocarboxylated product obtained (on using Lapidus and co-workers method) is shown in Table 3.11 .

\begin{tabular}{|c|c|c|c|c|c|c|c|}
\hline \multirow[t]{2}{*}{ Polymer } & \multirow[t]{2}{*}{ Number } & \multicolumn{3}{|c|}{ Double bonds } & \multicolumn{3}{|c|}{ Carboxylic acid (\%) } \\
\hline & & Cis & Trans & Pendant & $\mathrm{Bb}$ & $\mathrm{Tr}$ & Int \\
\hline \multirow[t]{2}{*}{1} & SM & 12 & 19 & 53 & - & - & - \\
\hline & PR & & 4 & 2 & 27 & 40 & 11 \\
\hline
\end{tabular}

Where $\mathrm{SM}=$ starting material, $\mathrm{PR}=$ product, $\mathrm{Bb}=$ back bone, $\mathrm{Tr}=$ terminal and Int $=$ internal

Table 3.11

In order to see if we could effectively hydrocarboxylate all the carbon-carbon double bonds in polybutadiene, the hydrocarboxylated product obtained by applying $\left[\mathrm{PdCl}_{2}\left(\mathrm{PPh}_{3}\right)\right]-\mathrm{SnCl}_{2}$ (Knifton's method) was subjected to further hydrocarboxylation using the same palladium catalyst $\left[\mathrm{PdCl}_{2}\left(\mathrm{PPh}_{3}\right)_{2}\right]$, but with excess $\mathrm{PPh}_{3}$ (Lapidus and coworkers 


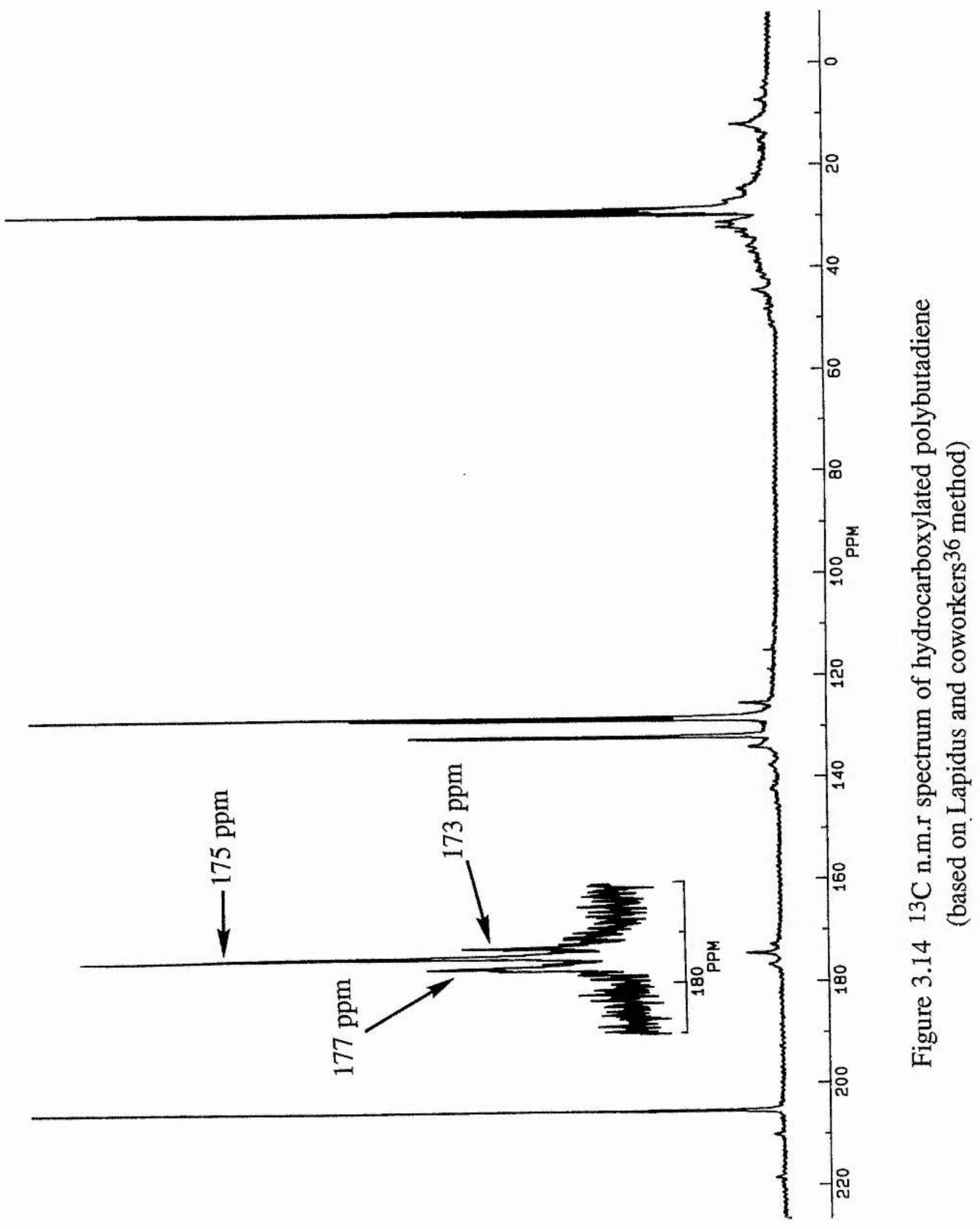



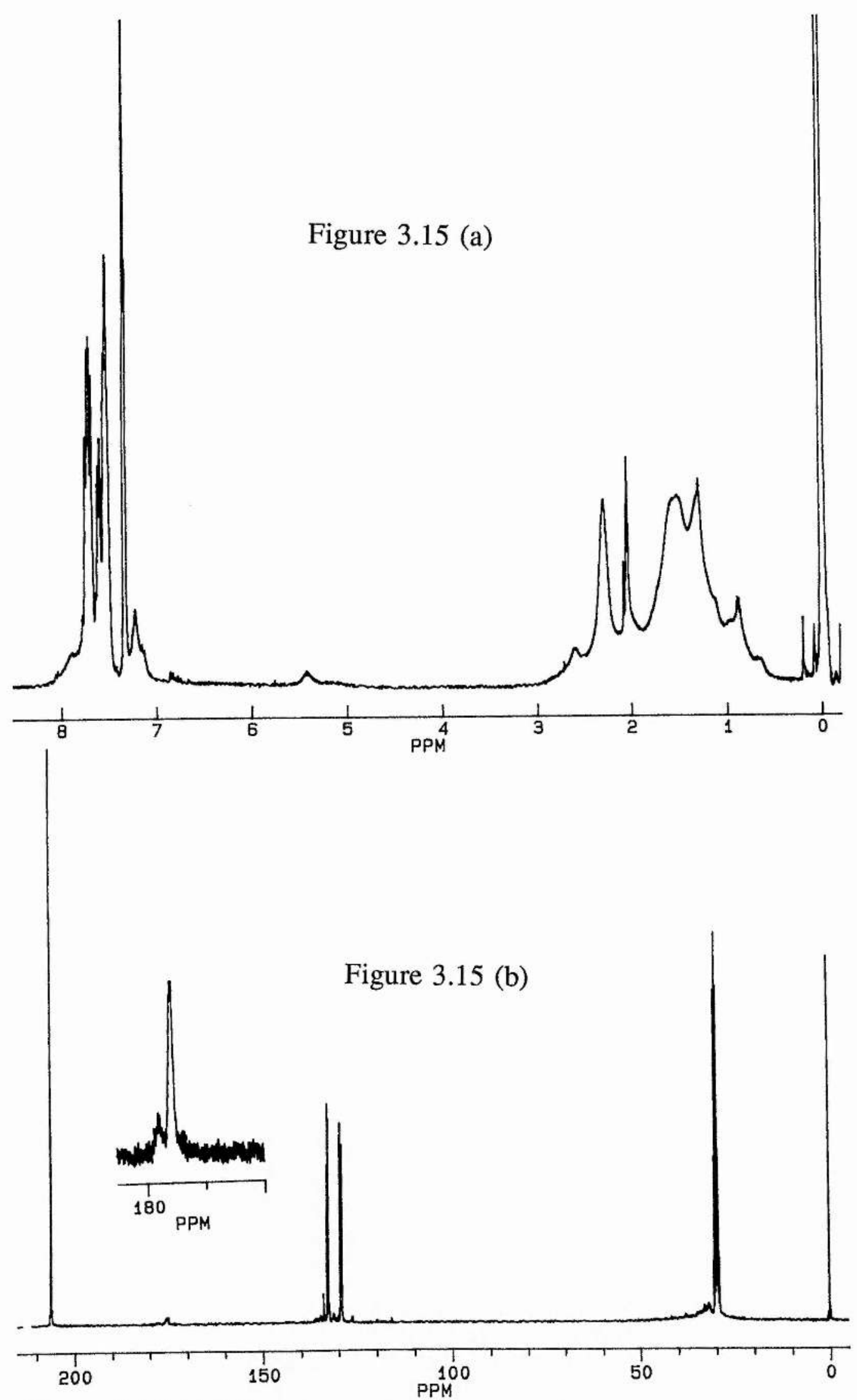

Figure 3.15 (a) ${ }^{1} \mathrm{H}$ n.m.r. spectrum of completely hydrocarboxylated polybutadiene (polymer no. 1)

(b) ${ }^{13} \mathrm{C}$ n.m.r. spectrum of the corresponding hydrocarboxylated polybutadiene 
method) rather than $\mathrm{SnCl}_{2}$. The analysis of the hydrocarboxylated product by ${ }^{1} \mathrm{H}$ n.m.r. and ${ }^{13} \mathrm{C}$ n.m.r. analysis shows (Figure 3.15 (a) and (b)) almost complete hydrocarboxylation of the remaining carboncarbon double bonds i.e., internal double bonds in polybutadiene. The pendant double bonds are selectively functionalised at the terminal carbon atom. These reactions are outlined in Scheme 3.1.
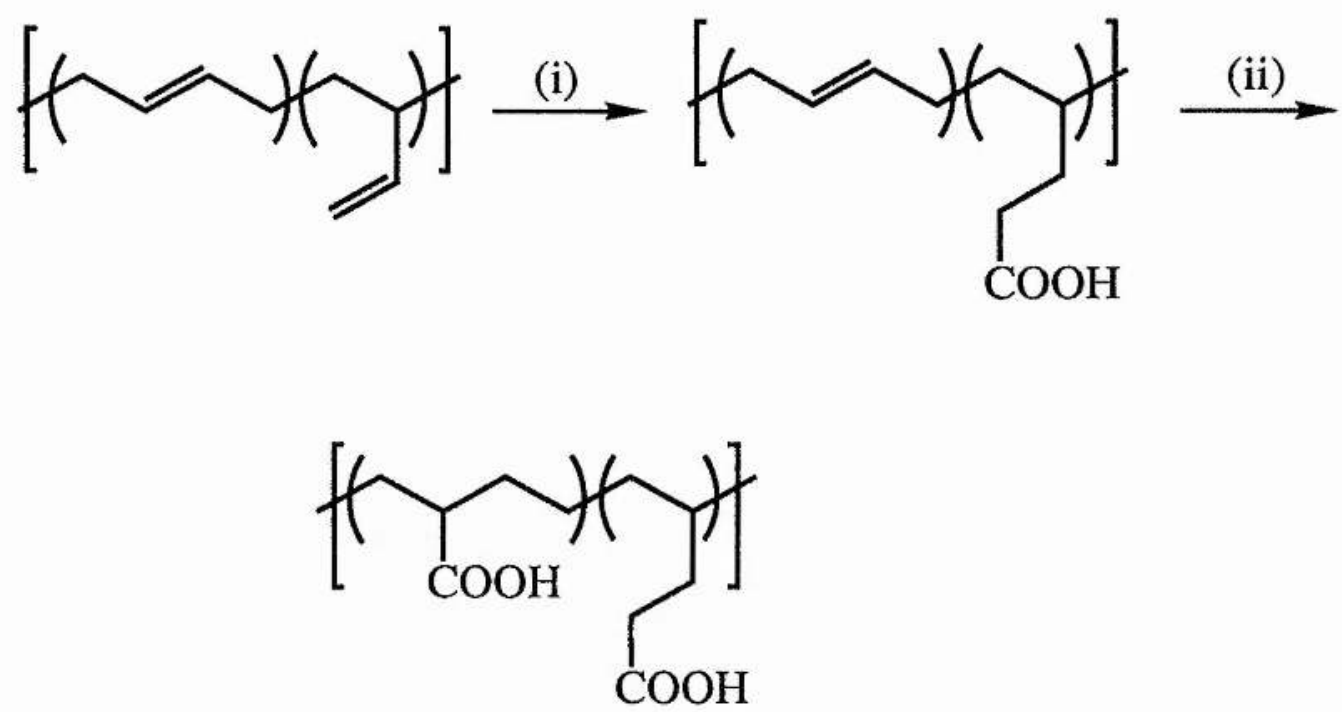

(i) $\left[\mathrm{PdCl}_{2}\left(\mathrm{PPh}_{3}\right)_{2}\right]-\mathrm{SnCl}_{2}, \mathrm{MIBK}, 90^{\circ} \mathrm{C}, 80 \mathrm{~atm}, 4 \mathrm{hrs}$

(ii) $\left[\mathrm{PdCl}_{2}\left(\mathrm{PPh}_{3}\right)_{2}\right]-\mathrm{PPh}_{3}$, benzene, $170^{\circ} \mathrm{C}, 80$ atm, $4 \mathrm{hrs}$

(Back bone double bonds can be cis or trans; only trans double bonds are shown for sake of clarity).

Scheme 3.1

\section{$\underline{3.2 .14 \text { Scale up }}$}

After having had initial success with selective hydrocarboxylation of polybutadienes at the terminal carbon position of the pendant carboncarbon double bonds, we were interested in investigating whether the 
same results could be reproduced on a larger scale.

Polymer number 1 (see Table 3.1) was initially choosen for our studies. The reactants were scaled up 50 times while the physical parameters such as temperature and pressure were unchanged. The reaction was carried out in a rocking autoclave (see Figure 3.16 a) of one litre capacity. Analysis of the product clearly demonstrated that the reaction is reproducible and the results were consistent with the results obtained on a small scale.

Reactions were then carried out with polybutadienes of different composition. We have obtained results for all these hydrocarboxylation reactions consistent with those obtained when the hydrocarboxylation are carried out on a small scale in a $100 \mathrm{~cm}^{3}$ capacity autoclave (Figure $3.16 b)$.

\section{$\underline{3.3 \text { Conclusion }}$}

From the experiments carried out on hydrocarboxylation of polybutadiene using $\left[\mathrm{PdCl}_{2}\left(\mathrm{PPh}_{3}\right)_{2}\right]-\mathrm{SnCl}_{2}$ the following conclusions can be made

1. Regioselective hydrocarboxylation of polybutadiene can be effectively carried out with complete conversion and selectivity to the introduction of the carboxylic acid group on the terminal carbon atom of the pendant carbon-carbon double bonds, at a comparatively low temperature and pressure.

2. The hydrocarboxylation reaction catalysed by $\left[\mathrm{PdCl}_{2}\left(\mathrm{PPh}_{3}\right)_{2}\right]-$ $\mathrm{SnCl}_{2}$ is truly homogeneous and there exists a small temperature window between the onset of catalysis and the onset of catalyst decomposition. 
Figure 3.16 (a) Rocking high pressure autoclave of 1 Litre capacity with inbuilt thermostat

Figure 3.16 (b) High pressure autoclave of $100 \mathrm{~cm}^{3}$ capacity along with band heater, glass liner and thermostat. 

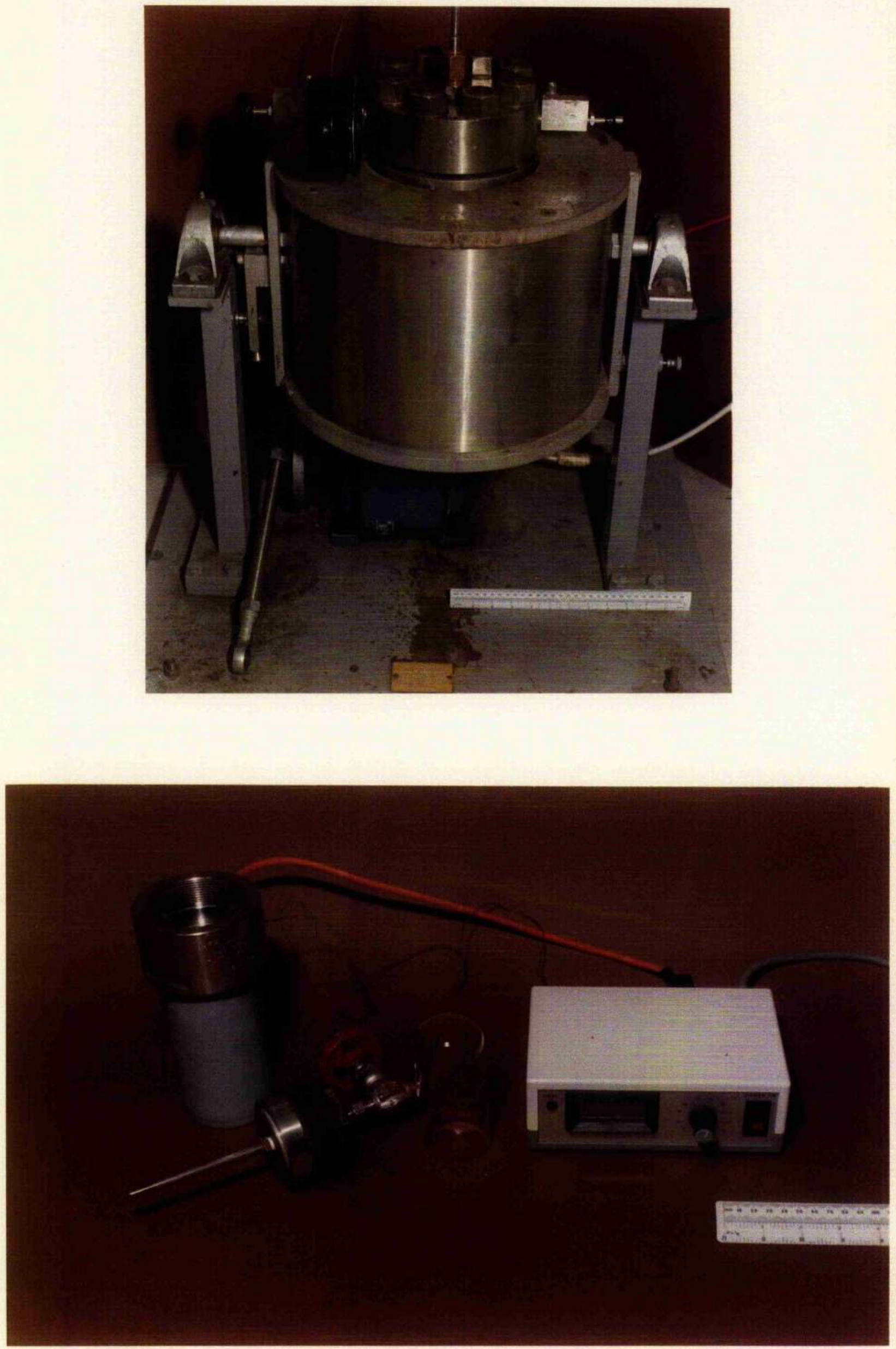
3. Complete hydrocarboxylation of all the carbon-carbon double bonds in polybutadiene can also be carried out by sequential catalytic reaction, but at a slightly higher temperature.

In principle, the selectively functionalised i.e., hydrocarboxylated polybutadiene could be prepared by copolymerisation of butadiene with pent-4-enoic acid but this does not appear to have been attempted. The relative scarcity of pent-4-enoic acid does not make this copolymerisation reaction attractive. So hydrocarboxylation is an attractive and simple route to a wide range of new polycarboxylic acids.

\subsection{Experimental Section}

\section{Treatment of polybutadiene}

Polybutadiene was freed of peroxide before reaction by treatment with a saturated solution of freshly prepared ferrous ammonium sulphate. In a typical reaction polybutadiene $(0.2 \mathrm{~g}, 3.7 \mathrm{x}$ $10^{-3}$ moles) was dissolved in $10 \mathrm{~cm}^{3}$ of methyl isobutyl ketone and to this was added an equal amount of freshly prepared saturated solution of ferrous ammonuim sulphate in sulphuric acid $(2 \mathrm{~mol} \mathrm{dm}-3)$. The contents were shaken and separated in a separating funnel. The organic phase was used directly, unless otherwise stated.

\section{$\underline{\text { Reaction procedure }}$}

a. Knifton's method

Dichlorobis(triphenylphosphine) palladium (II) $\left[\mathrm{PdCl}_{2}\left(\mathrm{PPh}_{3}\right)_{2}\right]$ 
(0.05 g, $7.12 \times 10^{-5}$ moles) and tin (II) chloride dihydrate $(0.19 \mathrm{~g}, 8.42$ $\mathrm{x} 10^{-3}$ moles) were added to a nitrogen saturated mixture of methyl isobutyl ketone $\left(10 \mathrm{~cm}^{3}\right)$ containing $\mathrm{H}_{2} \mathrm{O}\left(0.5 \mathrm{~cm}^{3}\right)$ and polybutadiene $\left(0.2 \mathrm{~g}, 3.7 \times 10^{-3}\right.$ moles $)$ in a $100 \mathrm{~cm}^{3}$ capacity specially designed glass liner. The glass liners / inserts were used to exclude any effects due to foreign ions from the walls of the autoclave. The glass liner was placed in a specially designed autoclave which was deoxygenated with nitrogen, flushed 3-4 times with carbon monoxide at 20-30 atmospheres and finally pressurised at room temperature to 80 atmospheres of carbon monoxide and sealed. It was then placed in an oven or oil bath, as required (see section - Results and Discussion) and maintained at $90^{\circ} \mathrm{C}$ for 4 hours.

\section{b. Lapidus and coworkers method}

Dichlorobis(triphenylphosphine) palladium (II) $\left[\mathrm{PdCl}_{2}\left(\mathrm{PPh}_{3}\right)_{2}\right]$ $\left(0.056 \mathrm{~g}, 7.97 \times 10^{-5}\right.$ moles $)$ and triphenylphosphine $\left(0.23 \mathrm{~g}, 8.76 \times 10^{-}\right.$ 4 moles) were added to a nitrogen saturated mixture of benzene (12 $\left.\mathrm{cm}^{3}\right)$ containing $\mathrm{H}_{2} \mathrm{O}\left(0.45 \mathrm{~cm}^{3}\right)$ and polybutadiene $(0.75 \mathrm{~g}, 0.0138$ moles) in a $100 \mathrm{~cm}^{3}$ capacity specially designed glass liner. The glass liners / inserts were used to exclude any effects due to foreign ions from the walls of the autoclave. The glass liner was placed in a specially designed autoclave which was deoxygenated with nitrogen, flushed 3-4 times with carbon monoxide at 20-30 atmospheres and finally pressurised at room temperature to 80 atmospheres of carbon monoxide and sealed. It was then placed in an oven and maintained at $170^{\circ} \mathrm{C}$ for 4 hours. 


\section{Product work up}

In both cases i.e., after reaction $\mathrm{a}$ or $\mathrm{b}$ as mentioned above, the autoclave was cooled to room temperature either by allowing it to stand at room temperature or by placing it in a water bath circulated with running water. The pressure was released gradually in a fume cupboard and the contents recovered. The solvent was evaporated using a rotary evaporator and the residue dissolved in $\mathrm{NaOH}\left(20 \mathrm{~cm}^{3} / 2 \mathrm{~mol}\right.$ $\mathrm{dm}^{-3}$ ). The polymer was then precipitated by adding an equal amount of $\mathrm{HCl}\left(7 \mathrm{~mol} \mathrm{dm}^{-3}\right)$ in portions. The polymer was separated, dissolved in acetone $\left(20 \mathrm{~cm}^{3}\right)$ and $\mathrm{MgSO}_{4}$ was added to remove any water present in the acetone solution. The solution was then filtered and evaporated to dryness under vacuum. The yield obtained in both cases was $>85 \%$.

\section{c. Recatalysis}

Dichlorobis(triphenylphosphine) palladium (II) [ $\left.\mathrm{PdCl}_{2}\left(\mathrm{PPh}_{3}\right)_{2}\right]$ (0.125 g, $1.78 \times 10^{-4}$ moles) and tin(II) chloride dihydrate $(0.475 \mathrm{~g}$, $2.10 \times 10^{-3}$ moles) were added to a nitrogen saturated mixture of methyl isobutyl ketone $\left(25 \mathrm{~cm}^{3}\right)$ containing $\mathrm{H}_{2} \mathrm{O}\left(1.25 \mathrm{~cm}^{3}\right)$ and polybutadiene $\left(0.5 \mathrm{~g}, 9.25 \times 10^{-3}\right.$ moles $)$ in a $100 \mathrm{~cm}^{3}$ capacity specially designed glass liner. The glass liners / inserts were used to exclude any effects due to foreign ions from the walls of the autoclave. The glass liner was placed in a specially designed autoclave which was deoxygenated with nitrogen, flushed 3-4 times with carbon monoxide at 20-30 atmospheres and finally pressurised at room temperature to 80 atmospheres of carbon monoxide and sealed. It was then placed in an oven and maintained at $90^{\circ} \mathrm{C}$ for 4 hours.

After the reaction the autoclave was cooled to room temperature 
either by allowing it to stand at room temperature or by placing it in a water bath circulated with running water. The pressure was released gradually in a fume cupboard and the contents recovered. The solvent was evaporated using a rotary evaporator and the residue dissolved in $\mathrm{NaOH}\left(50 \mathrm{~cm}^{3} / 2 \mathrm{~mol} \mathrm{dm}^{-3}\right)$. The polymer was then precipitated by adding an equal amount of $\mathrm{HCl}\left(7 \mathrm{~mol} \mathrm{dm}^{-3}\right)$ in portions. The polymer was separated, dissolved in acetone $\left(30 \mathrm{~cm}^{3}\right)$ and $\mathrm{MgSO}_{4}$ was added to remove any water present in the acetone solution. The solution was then filtered and evaporated to dryness under vacuum. The yield obtained was $>85 \%$.

Dichlorobis(triphenylphosphine) palladium (II) $\left[\mathrm{PdCl}_{2}\left(\mathrm{PPh}_{3}\right)_{2}\right]$ $\left(0.028 \mathrm{~g}, 3.98 \times 10^{-5}\right.$ moles) and triphenylphosphine $(0.115 \mathrm{~g}, 4.38 \mathrm{x}$ $10^{-4}$ moles) were added to a nitrogen saturated mixture of benzene ( 6.0 $\left.\mathrm{cm}^{3}\right)$ containing $\mathrm{H}_{2} \mathrm{O}\left(0.225 \mathrm{~cm}^{3}\right)$ and hydrocarboxylated polybutadiene $\left(0.375 \mathrm{~g}, 4.76 \times 10^{-3}\right.$ moles $)$ in a $100 \mathrm{~cm}^{3}$ capacity specially designed glass liner. The glass liners / inserts were used to exclude any effects due to foreign ions from the walls of the autoclave. The glass liner was placed in a specially designed autoclave which was deoxygenated with nitrogen, flushed 3-4 times with carbon monoxide at 20-30 atmospheres and finally pressurised at room temperature to 80 atmospheres of carbon monoxide and sealed. It was then placed in an oven and maintained at $170^{\circ} \mathrm{C}$ for 4 hours.

After the reaction the autoclave was cooled to room temperature either by allowing it to stand at room temperature or by placing it in a water bath circulated with running water. The pressure was released gradually in a fume cupboard and the contents recovered. The solvent was evaporated using a rotary evaporator and the residue dissolved in $\mathrm{NaOH}\left(20 \mathrm{~cm}^{3} / 2 \mathrm{~mol} \mathrm{dm}^{-3}\right)$. The polymer was then precipitated by adding an equal amount of $\mathrm{HCl}\left(7 \mathrm{~mol} \mathrm{dm}^{-3}\right)$ in portions. The polymer 
was separated, dissolved in acetone $\left(20 \mathrm{~cm}^{3}\right)$ and $\mathrm{MgSO}_{4}$ was added to remove any water present in the acetone solution. The solution was then filtered and evaporated to dryness under vacuum. The yield obtained was $>75 \%$.

Procedure for removing excess triphenyl phosphine oxide.

Immediately after the reaction, the solvent methyl isobutyl ketone was reduced to less than half the initial volume by evaporation in vacuo. The solution was then poured slowly and gently into a flask containing excess diethylether $\left(100 \mathrm{~cm}^{3}\right)$ with constant stirring. The hydrocarboxylated polymer precipitated instantly. After a few minutes of continued stirring, the whole solution was left aside to settle. The product was finally separated by decantation and dried under vacuum. After this, the product was dissolved in $\mathrm{NaOH}$ and precipitated with hydrochloric acid, as detailed earlier. 


\section{Chapter 4}

Hydrocarboxylation of polybutadiene catalysed by $\mathrm{PdCl}_{2}$, in the presence of air and $\mathrm{CuCl}_{2}$.

\subsection{Introduction}

This chapter discusses the results obtained on hydrocarboxylation of polybutadiene catalysed by $\mathrm{PdCl}_{2}$, in the presence of air and $\mathrm{CuCl}_{2}$.

\section{The Wacker process}

It has been known for a long time that an aqueous solution of palladium chloride can oxidise ethene to acetaldehyde with concomitant deposition of palladium 109 . The hydrolysis of Zeise's salt $\left\{\mathrm{K}\left[\left(\mathrm{C}_{2} \mathrm{H}_{4}\right) \mathrm{PtCl}_{3}\right]\right\}$, produces ethene, acetaldehyde, and ethanol accompanied by deposition of platinum. The accidental rediscovery of these reactions by Smidt and co-workers in 1959 in the laboratories of the Consortium für Electrochemische Industrie and development by the parent company, Wacker Chemie, has resulted in the Wacker process for the oxidation of ethene to acetaldehyde 24 . This discovery became an important land mark in the development of organo-transition metal chemistry. The commercial success of this process provided an enormous stimulus for further studies on homogeneous catalysis.

The so called ' Wacker process' involves the stoichiometric oxidation of ethene to acetaldehyde, by $\mathrm{Pd}(\mathrm{II})$ in aqueous solution. In the presence of $\mathrm{CuCl}_{2}$, palladium(0) is reoxidised to palladium(II) and 
the $\mathrm{CuCl}_{2}$ is in turn regenerated by dissolved oxygen. The sequence of reactions proposed is shown in Scheme 4.1.

$$
\begin{array}{ll}
\mathrm{C}_{2} \mathrm{H}_{4}+\mathrm{PdCl}_{2}+\mathrm{H}_{2} \mathrm{O} & \rightarrow \mathrm{CH}_{3} \mathrm{CHO}+\mathrm{Pd}+2 \mathrm{HCl} \\
\mathrm{Pd}+2 \mathrm{CuCl}_{2} & \rightarrow \mathrm{PdCl}_{2}+2 \mathrm{CuCl} \\
2 \mathrm{CuCl}+2 \mathrm{HCl}+1 / 2 \mathrm{O}_{2} \rightarrow-2 \mathrm{CuCl}_{2}+\mathrm{H}_{2} \mathrm{O} \\
\mathrm{C}_{2} \mathrm{H}_{4}+1 / 2 \mathrm{O}_{2} \longrightarrow \mathrm{CH}_{3} \mathrm{CHO}
\end{array}
$$

Scheme 4.1

Aqueous solutions of other group VIII metal salts, such as salts of $\mathrm{Pt}(\mathrm{II}), \mathrm{Ir}(\mathrm{III}), \mathrm{Ru}(\mathrm{III})$ and $\mathrm{Rh}(\mathrm{III})$ were also found to oxidise alkenes, but Pd salts were found to be the most effective catalysts for alkene oxidation 110,111,112,113. Alkenes other than ethene were oxidised to ketones. For example propene was oxidised under similar conditions to acetone in $90 \%$ yield and 1-butene afforded methyl ethyl ketone in approximately $85 \%$ yield $114,115,116$.

Alkenes branched at the double bond did not form ketone and underwent allylic oxidation. Terminal alkenes of higher molecular weight generally afforded low yields of ketones under the standard Wacker conditions, since mixtures of isomeric ketones are often formed as a result of the palladium-catalysed isomerisation of the alkenes. The extent of isomerisation was markedly dependent on the reaction temperature. For example, 1-octene which generally produced a mixture of 2-,3- and 4- octanones, gave a 97\% yield of 2-octanone at $30^{\circ} \mathrm{C}, 85 \%$ at $60^{\circ} \mathrm{C}$, but only $82 \%$ at $90{ }^{\circ} \mathrm{C}$. 
Effective oxidation of higher terminal alkenes has been realised using alcohols 117,118 , dimethylformamide 119 or sulfolane 120 as cosolvents. Thus, Lloyd and Luberoff 118 found that most monosubstituted and 1,2-disubstituted alkenes readily oxidised to the corresponding ketones in aqueous methanol or ethanol solutions. Clement and Selwitz ${ }^{119}$ reported that in aqueous dimethylformamide 1-dodecene was oxidised to 2 -dodecanone in greater than $80 \%$ yield, and 10 -undecanoic acid afforded 10-ketoundecanoic acid in $83 \%$ yield (Equation 4.1 ).

$$
\mathrm{CH}_{2}=\mathrm{CH}\left(\mathrm{CH}_{2}\right)_{8} \mathrm{COOH}+\mathrm{O}_{2} \stackrel{\mathrm{PdCl}_{2} / \mathrm{CuCl}_{2}}{\mathrm{DMF}-\mathrm{H}_{2} \mathrm{O}}-\mathrm{CH}_{3} \stackrel{\mathrm{O}}{\stackrel{\mathrm{C}}{\|}\left(\mathrm{CH}_{2}\right)_{8} \mathrm{COOH}}
$$

Equation 4.1

Oxidation of cyclohexene with $\mathrm{PdCl}_{2}$ and $\mathrm{CuCl}_{2}$ in aqueous ethanol afforded cyclohexanone in $95 \%$ yield ${ }^{117}$ (Equation 4.2 ).

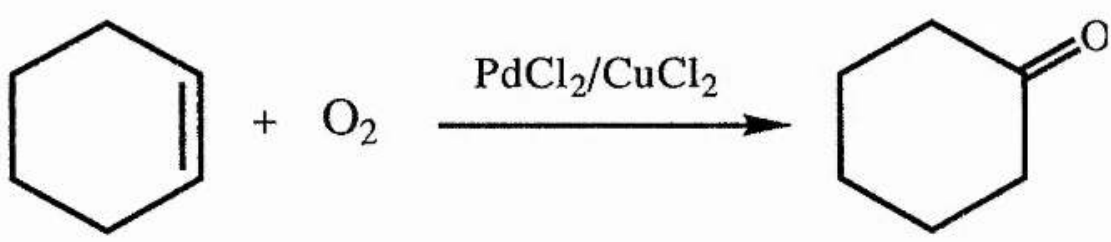

Equation 4.2

A wide range of oxidants has been employed including benzoquinones, ferric salts, potassium dichromate, potassium persulphate, potassium bromide and lead dioxide. Electrolytic oxidation 
has also been used 121,122 . However the most common oxidant employed is a cupric salt, either using a quantitative amount, or a lesser amount together with a supply of oxygen to reoxidise the cuprous ion. Direct aerial oxidation of palladium( 0 ) to palladium(II), required to regenerate the catalyst is too slow. An additional advantage of using copper salts is that copper(I) forms alkene complexes thereby increasing the amount of alkene available in solution. As these complexes are less stable than the palladium ones, they do not compete with the reaction intermediate (see Scheme 4.2).

Anions can also influence the reaction. It has been found that 123 the rate of the reaction is inversely proportional to the square of the chloride ion concentration. The chloride ion suppresses complex formation between the alkene and palladium(II). Anions such as sulphate, nitrate, phosphate, perchlorate and fluoride which have very limited coordinating ability have little effect on the reaction rate.

The mechanism of the $\mathrm{Pd}(\mathrm{II})$-catalysed oxidation of alkenes as proposed by Bäckvall, Akermark and Ljunggren124 is shown in Scheme 4.2.

$\begin{array}{ll}\mathrm{PdCl}_{4}{ }^{2-}+\mathrm{C}_{2} \mathrm{H}_{4} & \rightleftharpoons\left[\mathrm{PdCl}_{3} \mathrm{C}_{2} \mathrm{H}_{4}\right]^{-}+\mathrm{Cl}^{-} \\ {\left[\mathrm{PdCl}_{3} \mathrm{C}_{2} \mathrm{H}_{4}\right]^{-}+\mathrm{H}_{2} \mathrm{O}} & \rightleftharpoons\left[\mathrm{PdCl}_{2}\left(\mathrm{H}_{2} \mathrm{O}\right) \mathrm{C}_{2} \mathrm{H}_{4}\right]+\mathrm{Cl}^{-}\end{array}$

$\left[\mathrm{PdCl}_{2}\left(\mathrm{H}_{2} \mathrm{O}\right) \mathrm{C}_{2} \mathrm{H}_{4}\right]+\mathrm{H}_{2} \mathrm{O} \rightleftharpoons\left[\mathrm{HOCH}_{2} \mathrm{CH}_{2} \mathrm{PdCl}_{2}\left(\mathrm{H}_{2} \mathrm{O}\right)\right]^{-}+\mathrm{H}^{+}(3)$

$\left[\mathrm{HOCH}_{2} \mathrm{CH}_{2} \mathrm{PdCl}_{2}\left(\mathrm{H}_{2} \mathrm{O}\right)\right]^{-} \longrightarrow \mathrm{HOCH}_{2} \mathrm{CH}_{2} \mathrm{PdCl}\left(\mathrm{H}_{2} \mathrm{O}\right)+\mathrm{Cl}^{-}$

$\mathrm{HOCH}_{2} \mathrm{CH}_{2} \mathrm{PdCl}\left(\mathrm{H}_{2} \mathrm{O}\right) \longrightarrow \mathrm{CH}_{3} \mathrm{CHO}+\mathrm{Pd}+\mathrm{HCl}+\mathrm{H}_{2} \mathrm{O}$ 
The first step involves the formation of a $\pi$ complex (eq 1), which reduces the electron density at the double bond rendering it susceptible to nucleophilic attack. In the second step (eq 2) aquation of the complex takes place in a reversible reaction by external attack of water, together with loss of chloride. Formation of the new C-O bond occurs via nucleophilic attack of external water on the coordinated alkene to give the anionic hydroxyethyl complex (eq 3). The dissociation of the chloride ligand in equation 4 would give a 14 electron complex which would be prone to undergo rapid $\beta$-elimination (eq 5) to give first vinyl alcohol which would rapidly tautomerise to acetaldehyde. The palladium hydride so formed is unstable and rapidly deposits palladium metal. The key features of this mechanism are the nucleophilic attack on the coordinated alkene in equation 3 and the $\beta$-hydride elimination of the hydroxyethylpalladium (II) intermediate in equation 5 .

Alper, Woell, Despeyroux and Smith 25 successfully modified the Wacker process by bubbling carbon monoxide (1 atm) through the reaction solution along with oxygen (Equation 4.3). This resulted in hydrocarboxylating straight chain alkenes, both terminal and internal, under exceedingly mild conditions. For terminal alkenes, the product are mainly $\alpha$-methyl acids indicating stereospecific addition of the carboxyl group to the internal carbon atom of the double bond.

$$
\mathrm{RCH}=\mathrm{CH}_{2}+\mathrm{CO}+\mathrm{H}_{2} \mathrm{O} \underset{\mathrm{O}_{2}, \mathrm{rtm}, 1 \mathrm{~atm}}{\stackrel{\mathrm{PdCl}_{2}, \mathrm{CuCl}_{2}, \mathrm{HCl}}{\longrightarrow}} \mathrm{RCH}(\mathrm{COOH}) \mathrm{CH}_{3}
$$

Equation 4.3

Di-alkenes such as octa-1,7-diene and deca-1,9-diene exclusively formed the branched product. Cis ortrans- dec-2-ene gave only 2-methyl- 
decanoic acid. Similarly, only 2,4-dimethylpentanoic acid was isolated using cis -4-methylpent-2-ene as the substrate. No isomeric acids were obtained in these reactions.

Concurrently in their patent, Alper and Smith ${ }^{26}$ had extended the above reaction to hydrocarboxylation of polymeric compounds containing residual carbon-carbon double bonds as starting materials. However there appears to be an anomaly in the patent as the authors have quoted polyisobutene as an example for the starting material. It may be noted that polymers of isobutene have two methyl groups on alternate carbon atoms along the chain and two hydrogen atoms on the other chain carbon atoms (Equation 4.4).
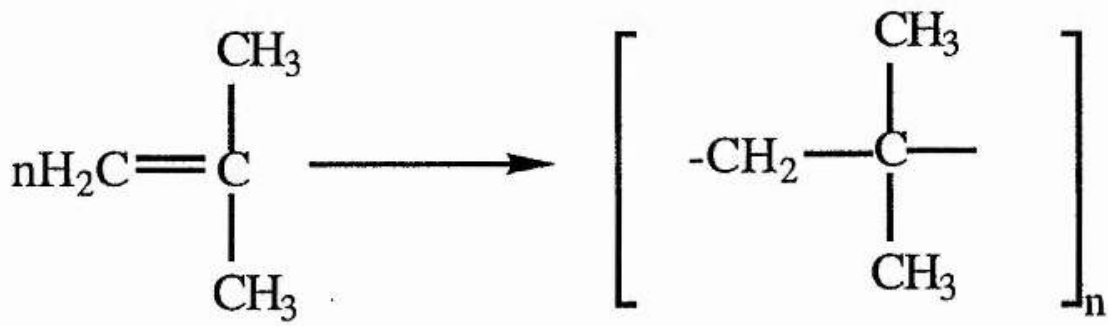

Equation 4.4

In other words polyisobutene is a saturated polymer with no double bonds available for hydrocarboxylation apart, perhaps from end groups of the chain. No information was given for the product yield or conversion.

Since the method by Alper and coworkers afforded a convenient method of hydrocarboxylating alkenes with internal double bonds, to give exclusively branched chain carboxylic acids, we were interested in using the same method for hydrocarboxylating polybutadiene (containing both internal double bonds only and/or mixtures of internal 
and pendant carbon-carbon double bonds.

In theory application of Alper's method of hydrocarboxylation would result in the formation of products $\mathrm{A}, \mathrm{C}$, and $\mathrm{E}$, as shown in Equation 3.19, Chapter 3, page 115.

\subsection{Results and Discussion}

The composition of the polymers employed in this study are shown in Table 4.1. The analysis of the product polymer is shown in Table 4.2. Polymer number 1 (see Table 4.2 ) was chosen to shown the various methods of analysis.

\subsubsection{Methods of analysis}

\subsubsection{I.R analysis}

The typical IR spectra of polybutadiene (polymer no. 1, as shown in Table 4.1) and its corresponding hydrocarboxylated product is shown in parts (a) and (b) of Figure 4.1 respectively. The bands at 1640, $992,969,912$ and $740-732 \mathrm{~cm}^{-1}$ are due to carbon-carbon double bond unsaturation. IR spectra of the hydrocarboxylated polybutadiene lack some of the characteristic peaks for unsaturation which indicates a degree of hydrocarboxylation. Beside the peaks for unsaturation the characteristic peak for the acid group i.e., $\mathrm{C}=\mathrm{O}$ stretching at $1727 \mathrm{~cm}^{-1}$ is seen. The broad peak at $3310 \mathrm{~cm}^{-1}$ is characteristic of the $\mathrm{OH}$ stretching vibration. 


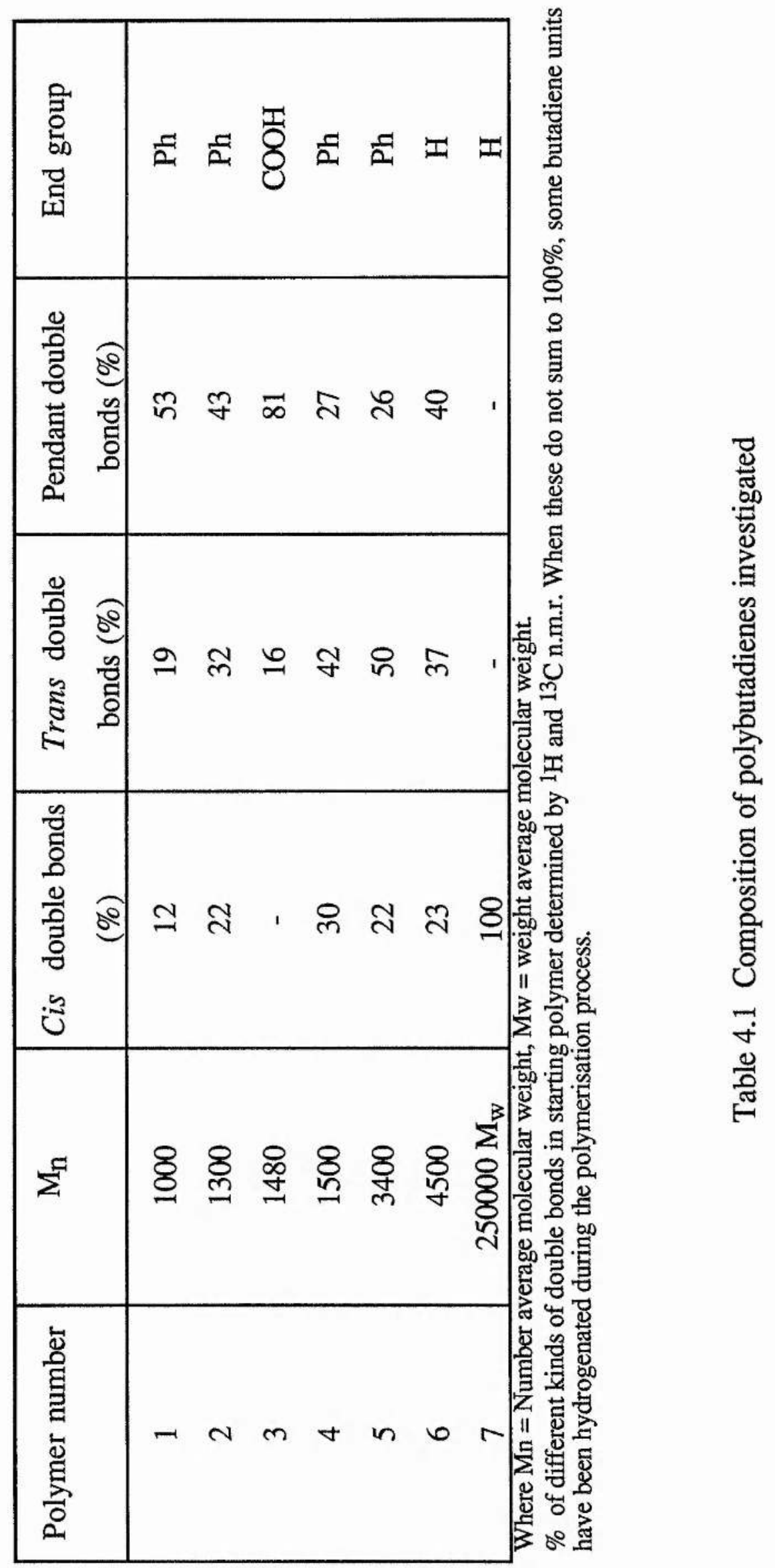

$\stackrel{\infty}{\circ}$ 


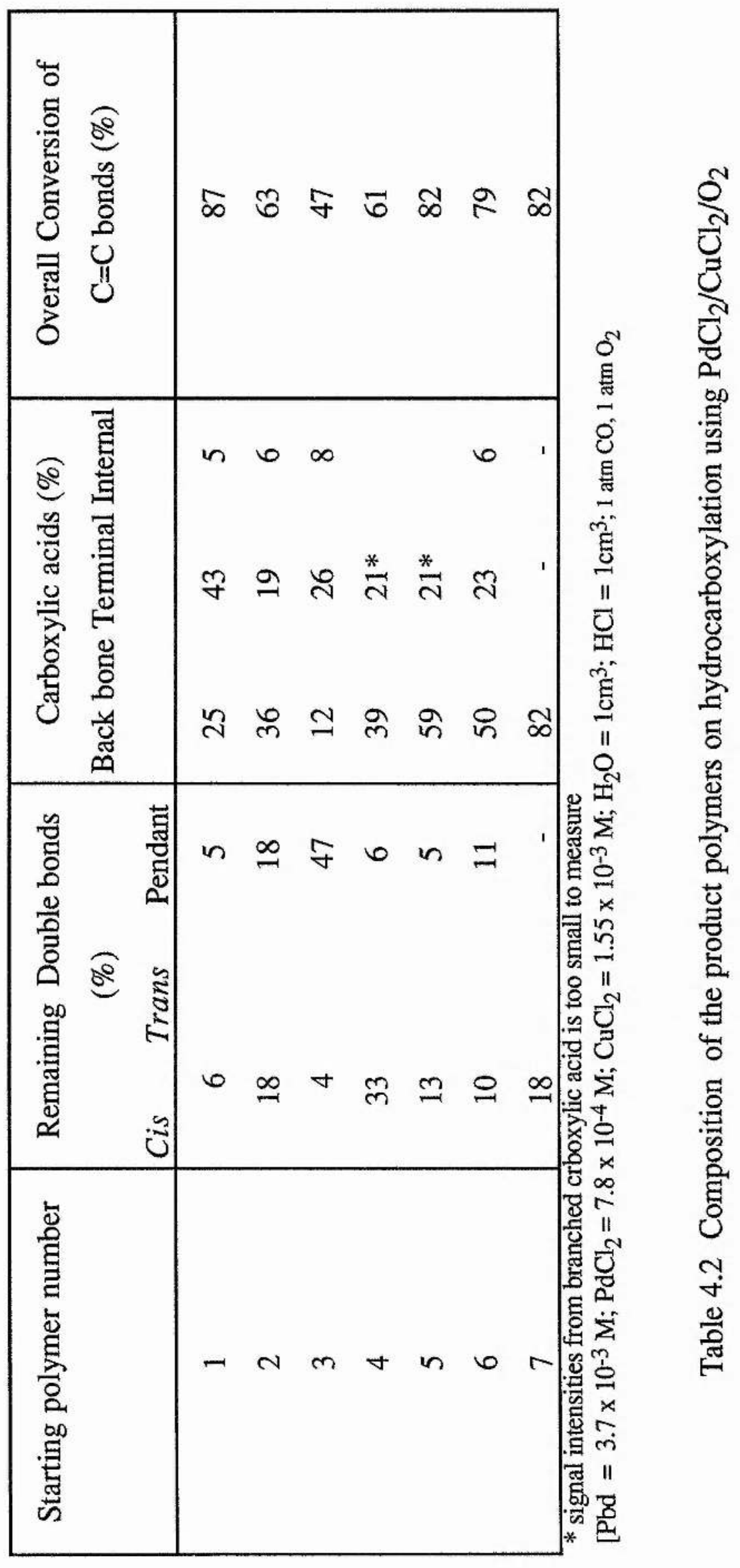

$\stackrel{8}{9}$ 
Figure 4.1 (a)

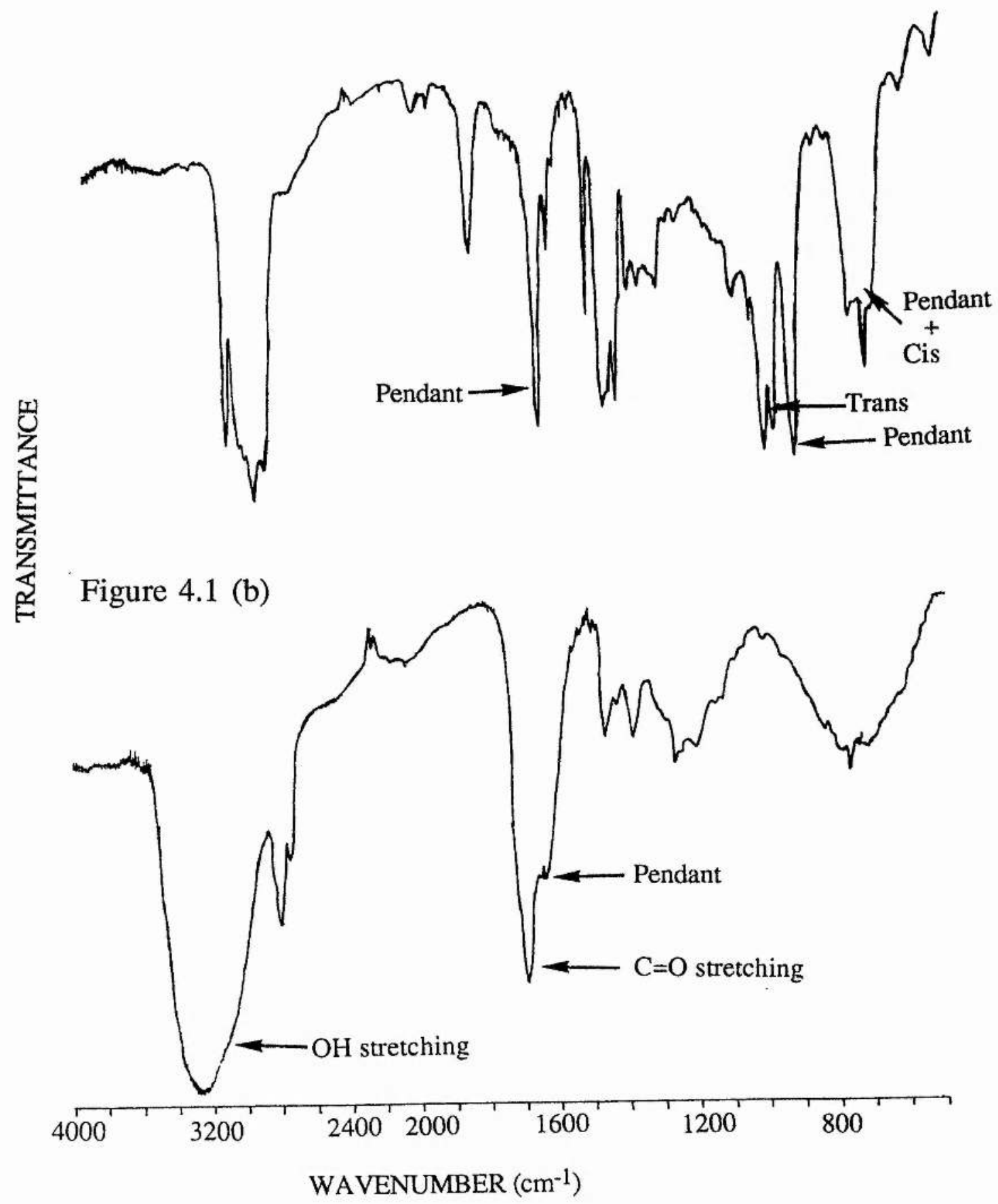

Figure 4.1 (a) I.R. spectrum of polybutadiene

(b) I.R. spectrum of corresponding hydrocarboxylated polybutadiene 


\subsubsection{2 ${ }^{1} \underline{\mathrm{H} \text { and }}{ }^{13} \underline{\mathrm{C} \text { n.m.r analysis }}$}

\subsubsection{1 ${ }^{1} \underline{\mathrm{H} \text { n.m.r. }}$}

The ${ }^{1} \mathbf{H}$ n.m.r. spectrum of the hydrocarboxylated polybutadiene is shown in Figure 4.2. (for ${ }^{1} \mathrm{H}$ n.m.r of the starting polybutadiene see chapter 3, page 125 ). The absence of peak at $5.7 \mathrm{ppm}$ and the decrease in the height of the peak at $5.0 \mathrm{ppm}$ indicates degree of hydrocarboxylation. Further evidence for this conversion comes from ${ }^{13}$ C n.m.r. spectrum.

\section{$\underline{4.2 .1 .2 .2}{ }^{13} \underline{\mathrm{C} \text { n.m.r. }}$}

The ${ }^{13} \mathrm{C}$ n.m.r. spectrum of the hydrocarboxylated product is shown in Figure 4.3 (for ${ }^{13} \mathrm{C}$ n.m.r of the starting polybutadiene see chapter 3 , page 126). It can be seen that the peak intensity at $115 \mathrm{ppm}$ and at $145 \mathrm{ppm}$ are considerably reduced relative to the intensity of peaks at $130 \mathrm{ppm}$ (arising due to back bone carbon-carbon double bonds). The presence of three new peaks at ( $\delta 173 \mathrm{ppm}, \delta 175 \mathrm{ppm}, \delta 177$ ppm), characteristic of carboxylic acid is seen. From our studies using only cis polybutadiene (see Table 4.2, polymer number 7) assignment of the three peaks have been made as follows.

The peak at $177 \mathrm{ppm}$ is due to hydrocarboxylation taking place at the internal double bond position i.e., either cis or trans. Hydrocarboxylation of pendant double bonds on the terminal carbon position gives rise to an acid peak at $175 \mathrm{ppm}$. The peak at $173 \mathrm{ppm}$ thus results from hydrocarboxylation at the penultimate carbon atom of the pendant position. 


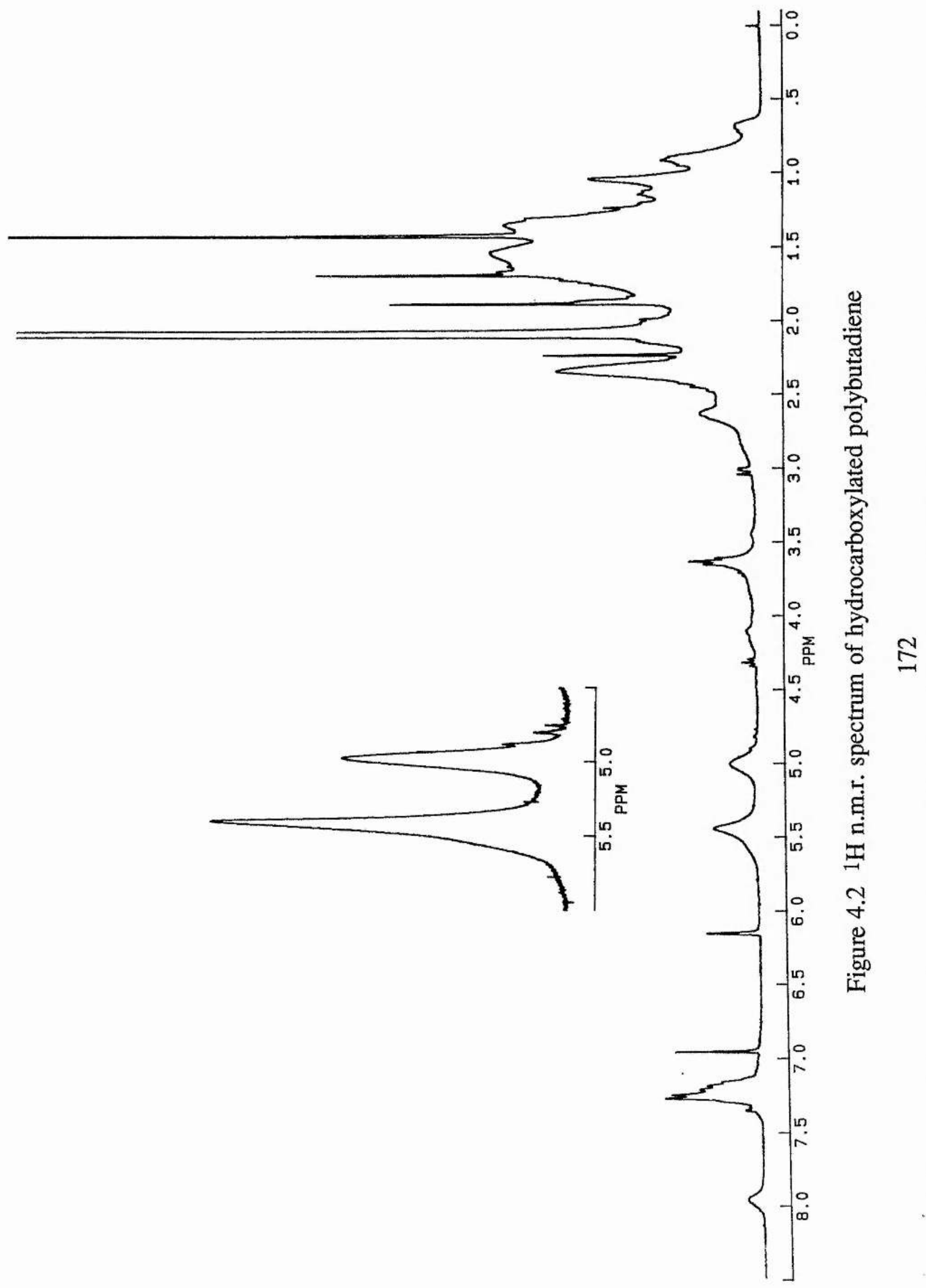




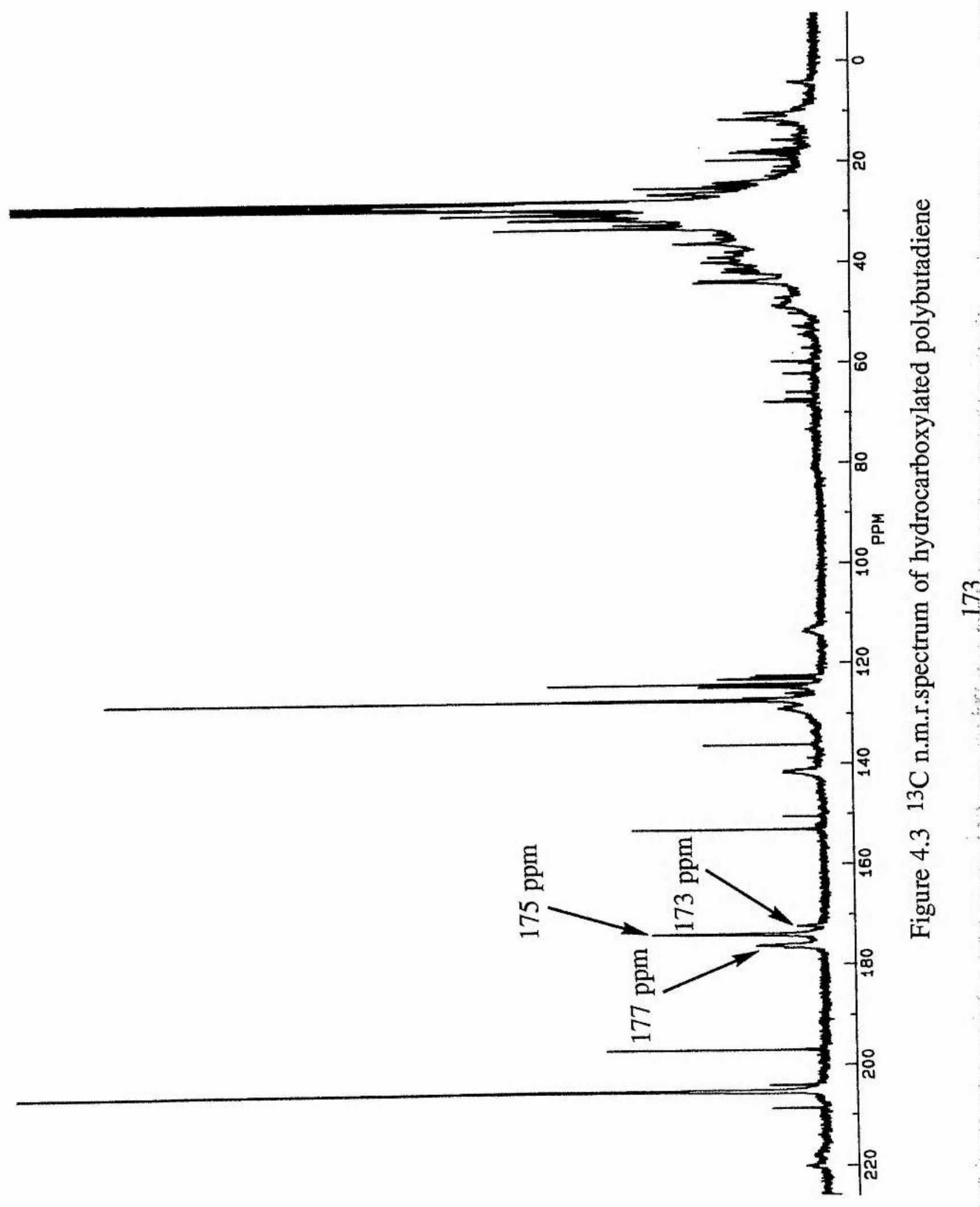




\subsubsection{Discussion}

The results obtained i.e., $\mathrm{COOH}$ insertion at the cis or trans terminal and penultimate carbon-carbon double bond (pendant) position show that the catalytic system $\mathrm{PdCl}_{2} / \mathrm{CuCl}_{2} / \mathrm{O}_{2}$ is more reactive towards the pendant carbon-carbon double bonds (Equation 4.5. Back bone double bonds can be cis or trans; only trans are shown for reasons of clarity).

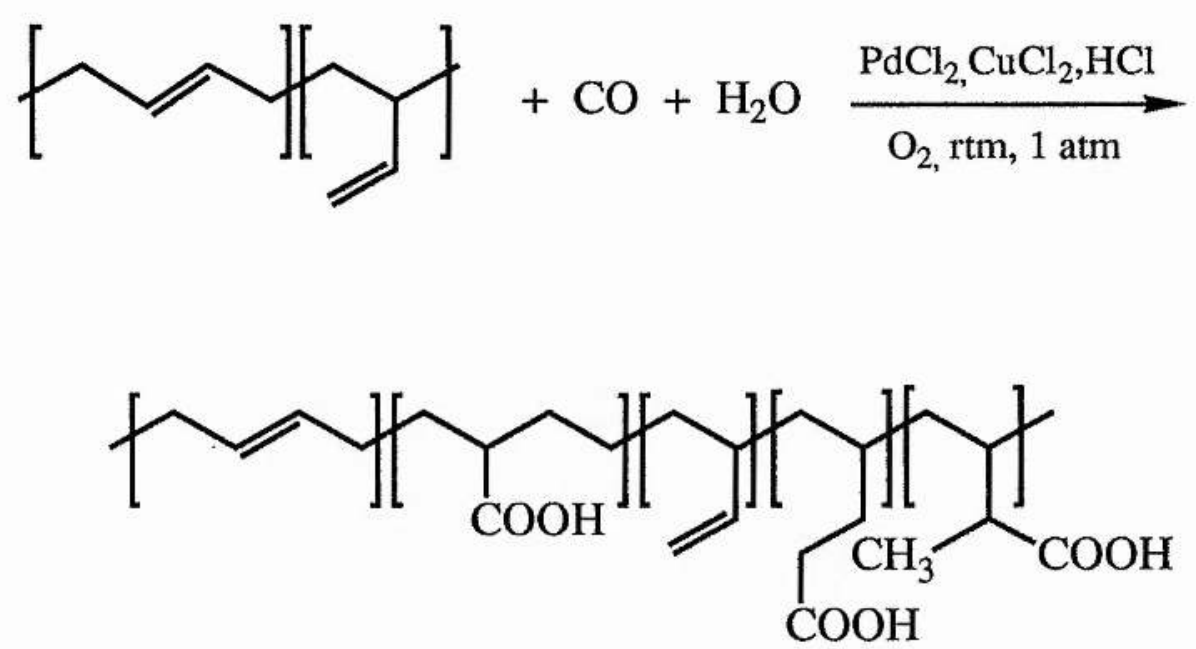

Equation 4.5

In Alpers work on simple alkenes, terminal alkenes have been shown to produce predominantly branched carboxylic acids. For polybutadienes, this is not the case and the reaction of the pendant double bonds show substantial, although not total, selectivity towards terminal carboxylic acid formation. This difference in selectivity presumably arises from steric problems associated with the presence of the main chain on the carbon atom $\alpha$ - to the pendant double bonds. A related effect can be noted 25 in the exclusive formation of 2,4dimethylpentanoic acid on hydrocarboxylation of 4-methylpent-2-ene using the same system (Equation 4.6). 


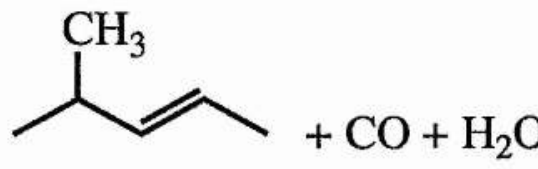

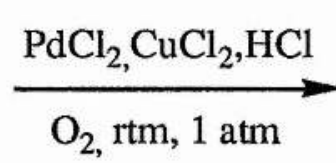<smiles>CC(C)CC(C)C(=O)O</smiles>

Equation 4.6

Here branching of the chain at the carbon $\alpha$ - to the double bond apparently directs the incoming carboxylate group to the end of the double bond remote from the branching point.

For the polybutadiene and reaction conditions considered in this study, the $\mathrm{PdCl}_{2}$ catalyst adds the carboxylic acid functionality over the entire range of number average molecular weight. To find out if the reaction can be carried out regioselectively i.e., if the reaction can be regiospecific in hydrocarboxylating polybutadiene, other chloride complexes like $\mathrm{SnCl}_{2}, \mathrm{GeCl}_{2}$ were added to the existing $\mathrm{PdCl}_{2} / \mathrm{CuCl}_{2}$ system, but no reaction took place.

Increasing the temperature of the reaction caused loss of solvent tetrahydrofuran. This problem was overcome by attaching a water condenser to the reaction vessel and by passing $\mathrm{CO}$ and $\mathrm{O}_{2}$ saturated with tetrahydrofuran before bubbling them through the reaction solution. On increasing the temperature to $\sim 50^{\circ} \mathrm{C}$, hydrocarboxylation takes place at the 3 carbon-carbon double bond position in polybutadiene i.e., at the back bone carbon-carbon double bond position, at the penultimate carbon-carbon double bond and at the terminal carbon-carbon double bond of the pendant carbon-carbon double bond position Here selectivity appears to be greater towards the pendant carbon atoms relative to the back bone carbon atoms. The overall conversion is very high compared to a normal 24 hour reaction (see Table 4.4). ${ }^{13} \mathrm{C}$ n.m.r. spectra (see Figure 4.4) of the hydrocarboxylated product shows a relatively higher conversion taking 
place at the penultimate carbon position of the carbon-carbon double bonds in comparision with the ${ }^{13} \mathrm{C}$ n.m.r. of a normal 24 hour reaction (Figure 4.3). However, a black coating of palladium metal coating occured at the tip of the bubbling tubes with an hour after starting the reaction.

Varying the reaction time resulted in selectivity and varying degrees of hydrocarboxylation. For example, from ${ }^{13} \mathrm{C}$ n.m.r. spectrum (see Figure 4.5) of a 12 hour reaction only one carboxylic acid peak corresponding to the terminal carbon position of the pendant carboncarbon double bond can be seen, whilst for a 100 hour reaction time, reaction took place at two positions i.e., at the terminal carbon position (175 ppm) of the pendant carbon-carbon double bond and at the internal carbon position (177 ppm) of the back bone carbon-carbon double bond (see Figure 4.6).The corresponding conversions are shown in Table 4.4.

\begin{tabular}{|c|l|c|c|c|c|c|}
\hline $\begin{array}{c}\text { Polymer } \\
\text { number }\end{array}$ & $\begin{array}{l}\text { Conditi- } \\
\text { ons }\end{array}$ & $\begin{array}{c}\text { bb dbs } \\
(\%)\end{array}$ & $\begin{array}{c}\text { bb } \\
\text { COOH } \\
(\%)\end{array}$ & $\begin{array}{c}\text { pendant } \\
\text { dbs (\%) }\end{array}$ & $\begin{array}{c}\text { pendant } \\
\text { COOH } \\
(\%)\end{array}$ & $\begin{array}{c}\text { Overall } \\
\text { conver- } \\
\text { sion (\%) }\end{array}$ \\
\hline 1 & $\begin{array}{l}12 \text { hrs } \\
\text { reaction } \\
\text { time } \\
24 \text { hrs } \\
\text { reaction } \\
\text { time } \\
100 \text { hrs } \\
\text { reaction } \\
\text { time } \\
\text { Increase } \\
\text { tempera- } \\
\text { ture (24 } \\
\text { hours })\end{array}$ & 3 & 21 & 14 & 39 & 71 \\
\hline
\end{tabular}

Table 4.4 


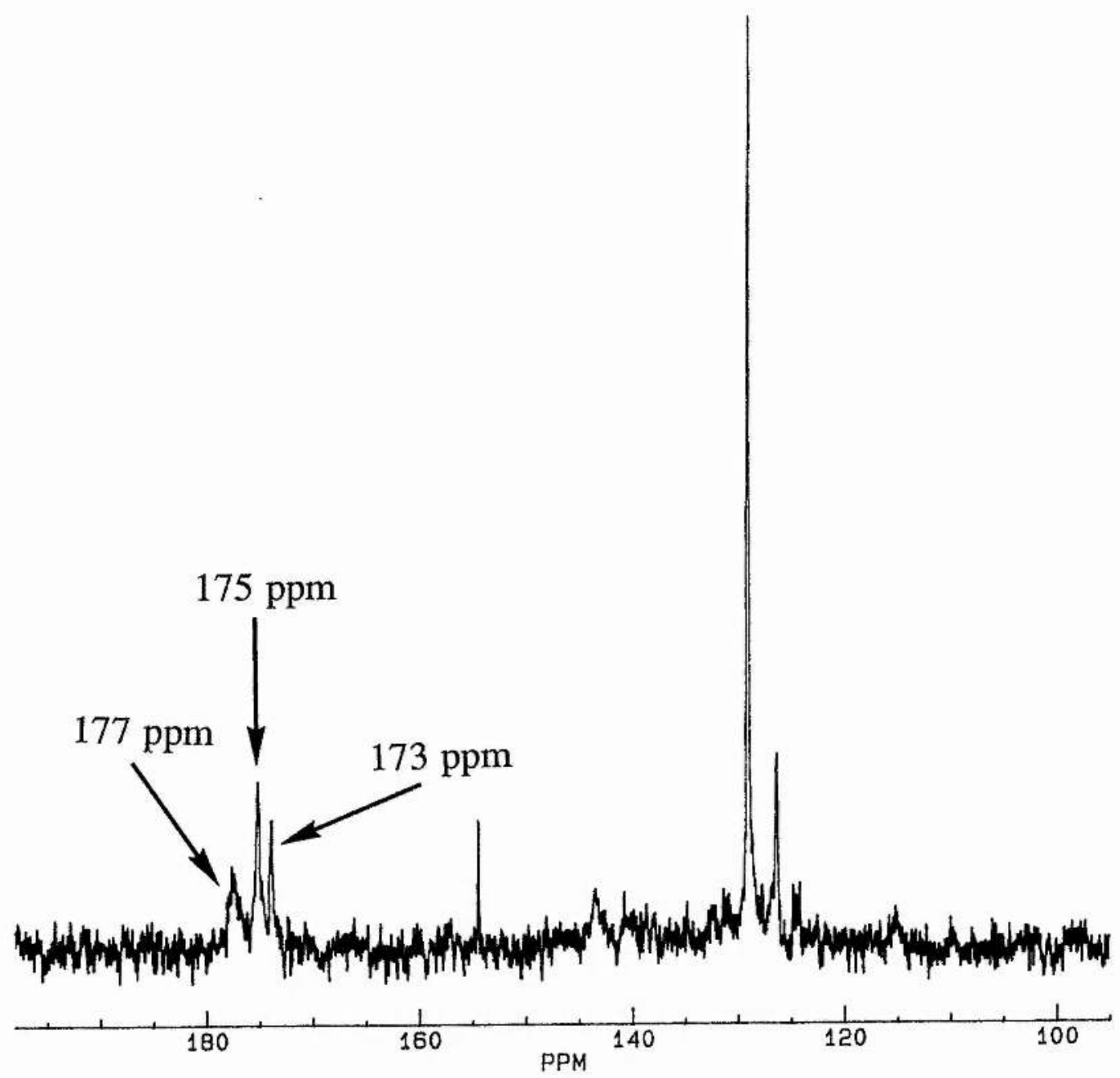

Figure $4.4{ }^{13} \mathrm{C}$ n.m.r.spectrum of hydrocarboxylated polybutadiene (obtained by increasing reaction temperature) 
Figure 4.5

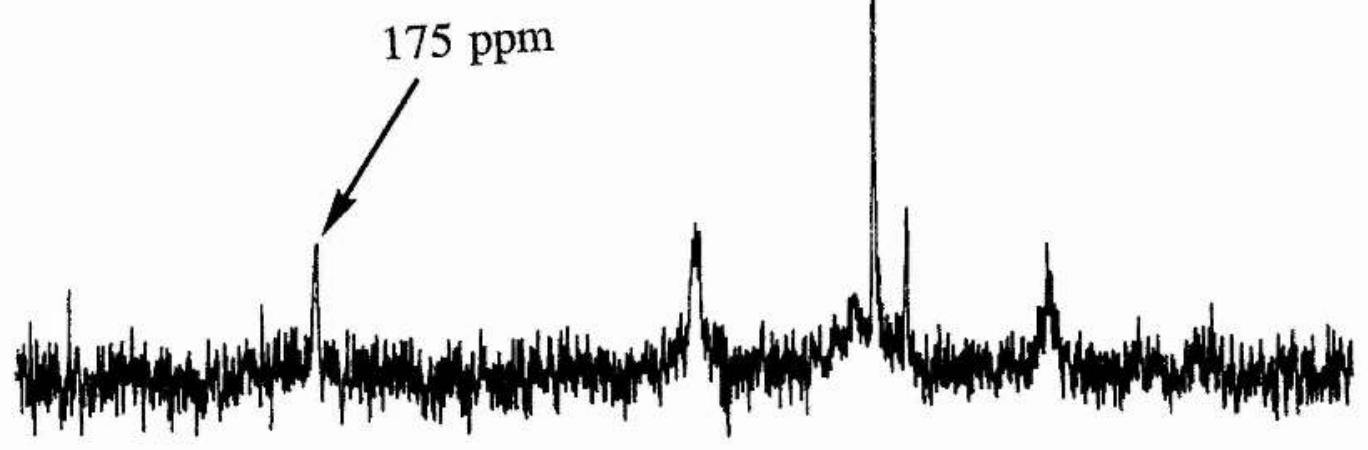

Figure 4.6

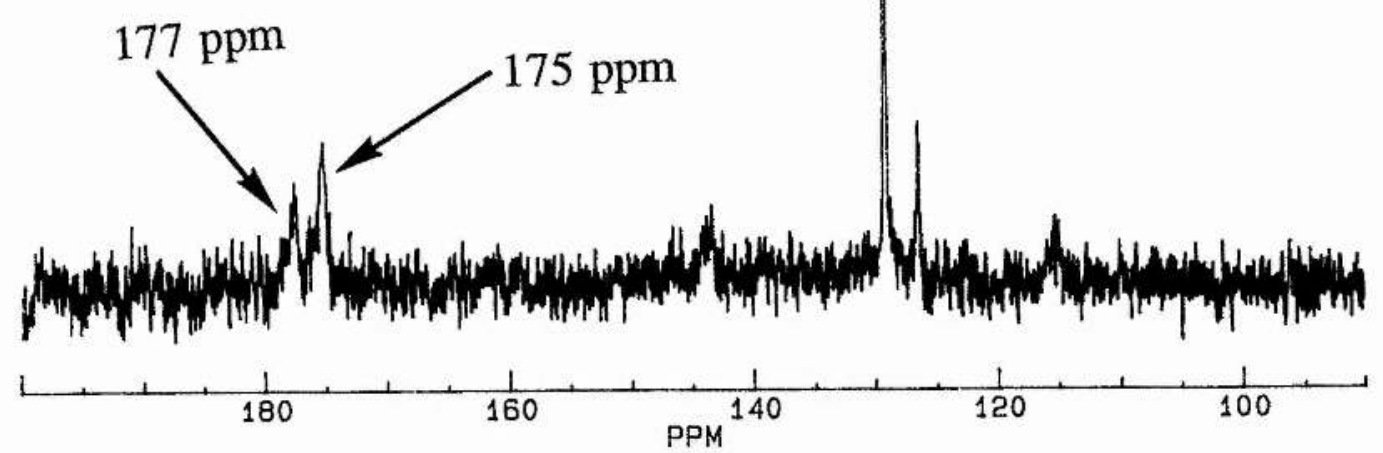

Figure $4.5{ }^{13} \mathrm{C}$ n.m.r. spectrum of hydrocarboxylated polybutadiene (12 hours reaction time)

Figure 4.6 ${ }^{13} \mathrm{C}$ n.m.r. spectrum of hydrocarboxylated polybutadiene (100 hours reaction time) 
As one would expect increasing the reaction time increases conversion. From the table it is evident that greater conversion can be achieved in a relatively shorter time by increasing the temperature i.e., increasing reaction rate.

The proportion of water used had a significant influence on the reaction. No reaction took place when water was used as the only solvent, as polybutadiene does not dissolve in water. Also when the amount of water was greater than 5 moles equivalent of the solvent tetrahydrofuran, the reaction failed to take place. No reaction took place in the absence of either oxygen or carbon monoxide. Also variation in the rate of bubbling carbon monoxide and/or oxygen through the solution had no observable effect on hydrocarboxylation.

One main drawback of this method is that the catalyst $\mathrm{PdCl}_{2}$ could not be recovered for further catalysis. It was observed that if the reaction was left for a few days without bubbling oxygen or carbon monoxide, precipitation of palladium metal occured as a thin coating on the sides of the reaction vessel. The recovered metal showed very little or no catalytic activity.

Application of Alper's method of hydrocarboxylation of alkenes to polymers gave reduced conversion. For example, according to Alper and coworkers hydrocarboxylation of alkenes such as deca-1,9-diene gave $100 \%$ conversion, but in the case of polybutadiene complete conversion could not be obtained $(<70 \%)$ on using normal reaction temperature and pressure conditions..This could account for the low reactivity of polybutadiene; due to the size and thus the sterric effect of the bulky polymer chain. 


\subsection{Conclusion}

From our experimental work we have made two main observations.

1. With cis polybutadiene, the hydrocarboxylation reaction does takes place and the conversion is $>60 \%$ i.e., species $\mathrm{A}$ is obtained according to Equation 3.19, Chapter 3, page 115.

2. When the polymer contains mixture of both internal and terminal double bonds, hydrocarboxylation takes place at three positions namely at the internal double bond position, terminal and at the penultimate carbon position of the pendant group. i.e., species $\mathrm{D}$ and $\mathrm{E}$ are obtained.

\section{4. Experimental Section}

Polybutadiene, obtained from Aldrich was used as received. Carbon monoxide was bubbled through a solution containing tetrahydrofuran $\left(30 \mathrm{~cm}^{3}\right)$ and water $\left(1 \mathrm{~cm}^{3}\right) . \mathrm{PdCl}_{2}\left(0.14 \mathrm{~g}, 7.8 \times 10^{-4}\right.$ moles) was added, followed by concentrated hydrochloric acid (1.0 $\mathrm{cm}^{3}$ ) and the mixture was then stirred until $\mathrm{PdCl}_{2}$ dissolved. $\mathrm{CuCl}_{2} .2 \mathrm{H}_{2} \mathrm{O}\left(0.26 \mathrm{~g}, 1.55 \times 10^{-3}\right.$ moles $)$ was then added and $\mathrm{O}_{2}$ bubbled through the solution. Polybutadiene $\left(0.2 \mathrm{~g}, 3.7 \times 10^{-3}\right.$ moles $)$ dissolved in tetrahydrofuran $\left(10 \mathrm{~cm}^{3}\right)$ was added and the reaction was stirred at room temperature for 16 hours or left to stir overnight. The gases were bubbled through the reaction mixture via gas inlet adaptors below the surface of the solvent as shown in Figure 4.1. The flow of 


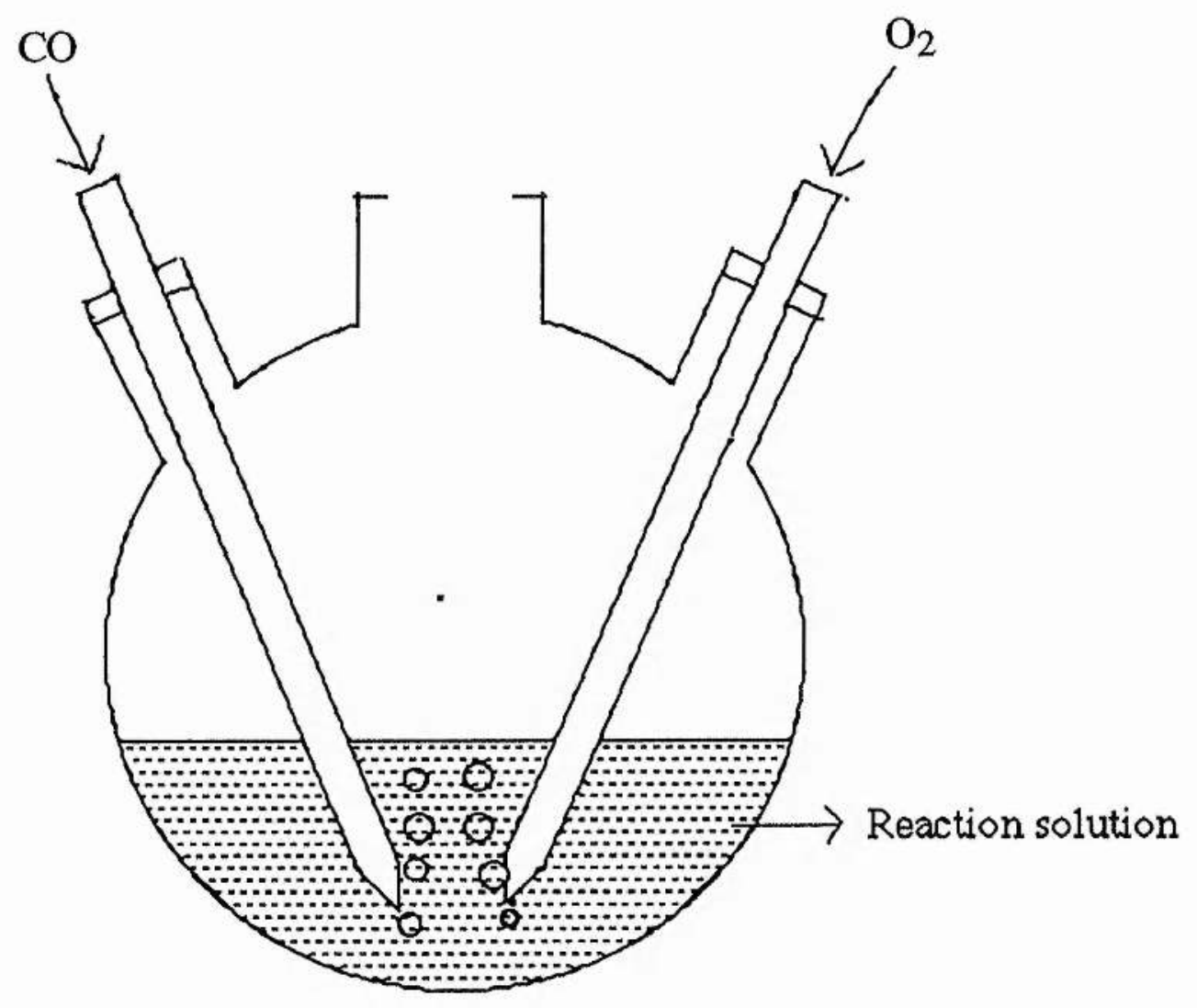

Figure 4.1

carbon monoxide and oxygen was maintained through out the reaction period.

The solvent was evaporated in a rotary evaporator and the residue dissolved in $\mathrm{NaOH}\left(20 \mathrm{~cm}^{3} / 2 \mathrm{~mol} \mathrm{dm}^{-3}\right)$. The polymer was then precipitated by adding an equal amount of $\mathrm{HCl}\left(7 \mathrm{~mol} \mathrm{dm}^{-3}\right)$ in portions, separated and dissolved in acetone $\left(20 \mathrm{~cm}^{3}\right) . \mathrm{MgSO}_{4}$ was added, to remove any water present in the acetone solution. The acetone solution was filtered and finally evaporated to dryness. The yield was $<60 \%$. 


\section{Chapter 5}

\section{Future Work}

\section{$\underline{5.1 . ~ I n t r o d u c t i o n}$}

This chapter briefly discusses the current work being carried out using hydrocarboxylated polybutadienes. Based on the success of selectively hydrocarboxylating polybutadienes two patents have been filed, and currently, studies are being carried out to see if these hydrocarboxylated polymers could be used for

1. treatment of wood and,

2. corrosion inhibition.

The results obtained so far have been very encouraging. It is not intended to include a detailed discussion as studies are currently in progress and hence the description of the methods are only intended to be thumbnail sketches.

\subsubsection{Wood treatment by polycarboxylic acids}

The ready availability and unique physical properties of wood have made it the material of choice for mankind for thousands of years. Although wood is amongst the most resistant of all organic materials, as time passes, various chemical, morphological and physical changes take place resulting in its degradation. Wood exposed to natural weathering processes undergoes discolouration, and degradation by light and moisture, etc. Consequently wood has to be protected by paints, stains, and similar materials. Since the late 1960's and early 1970's 
considerable research effort has gone into finding polymeric materials that would not only protect the surface of wood but would also penetrate the wood and strengthen it from inside by undergoing changes like cross linking, etc. Materials that penetrate deep inside the wood surface in a relatively short time and are also cheap are required and to this end polymers, particularly water soluble polymers are currently being investigated.

Our aim was to see if hydrocarboxylated polybutadiene which shows water solublity would fulfil the above requirements. Studies are being carried out at our laboratory. The initial studies and the results obtained are as follows.

As hydrocarboxylated polybutadiene in its acid form is sparingly soluble in water, it must be converted into the sodium salt to increase its solubility by the following method. Polybutadiene $84 \%$ unsaturation (53\% pendant, $12 \%$ cis $-1,4,19 \%$ trans-1,4) was hydrocarboxylated so that all of the pendant carbon-carbon double bonds were converted into terminal carboxylic acid groups. A sample of this product polymer $(0.5$ g) was suspended in water $\left(10 \mathrm{~cm}^{3}\right)$ and $\mathrm{NaOH}(2 \mathrm{~mol} \mathrm{dm}-3)$ was added dropwise until all the polymer dissolved, with the $\mathrm{pH}$ kept at 7.0.

Three pieces of dry balsa wood $(30 \mathrm{~cm} \times 0.3 \mathrm{~cm} \times 0.3 \mathrm{~cm})$ were soaked in water for 43 hours, during which time the water was shown by ${ }^{1} \mathrm{H}$ n.m.r. imaging 125 to have penetrated (see Figure 5.1) $\mathrm{ca} 0.2 \mathrm{~mm}$ all round. In Figure 5.1 the white areas indicate the mobile protons (from water). The three pieces of wood were further allowed to stand in water for 14 days. After 14 days the wood pieces became water logged and sank. ${ }^{1} \mathrm{H}$ n.m.r. imaging of such a piece of wood showed (see Figure 5.2) that water had penetrated uniformly into the wood. 
Figure $5.1^{1} \mathrm{H}$ n.m.r transverse image of dry balsa wood after floating in water for 43 hours

Figure $5.2{ }^{1} \mathrm{H}$ n.m.r transverse image of dry balsa wood after floating in water for 16 days

Figure 5.3 ${ }^{1 \mathrm{H}}$ n.m.r transverse image of dry balsa wood after floating in water for 52 hours followed by polymer solution for 14 days 

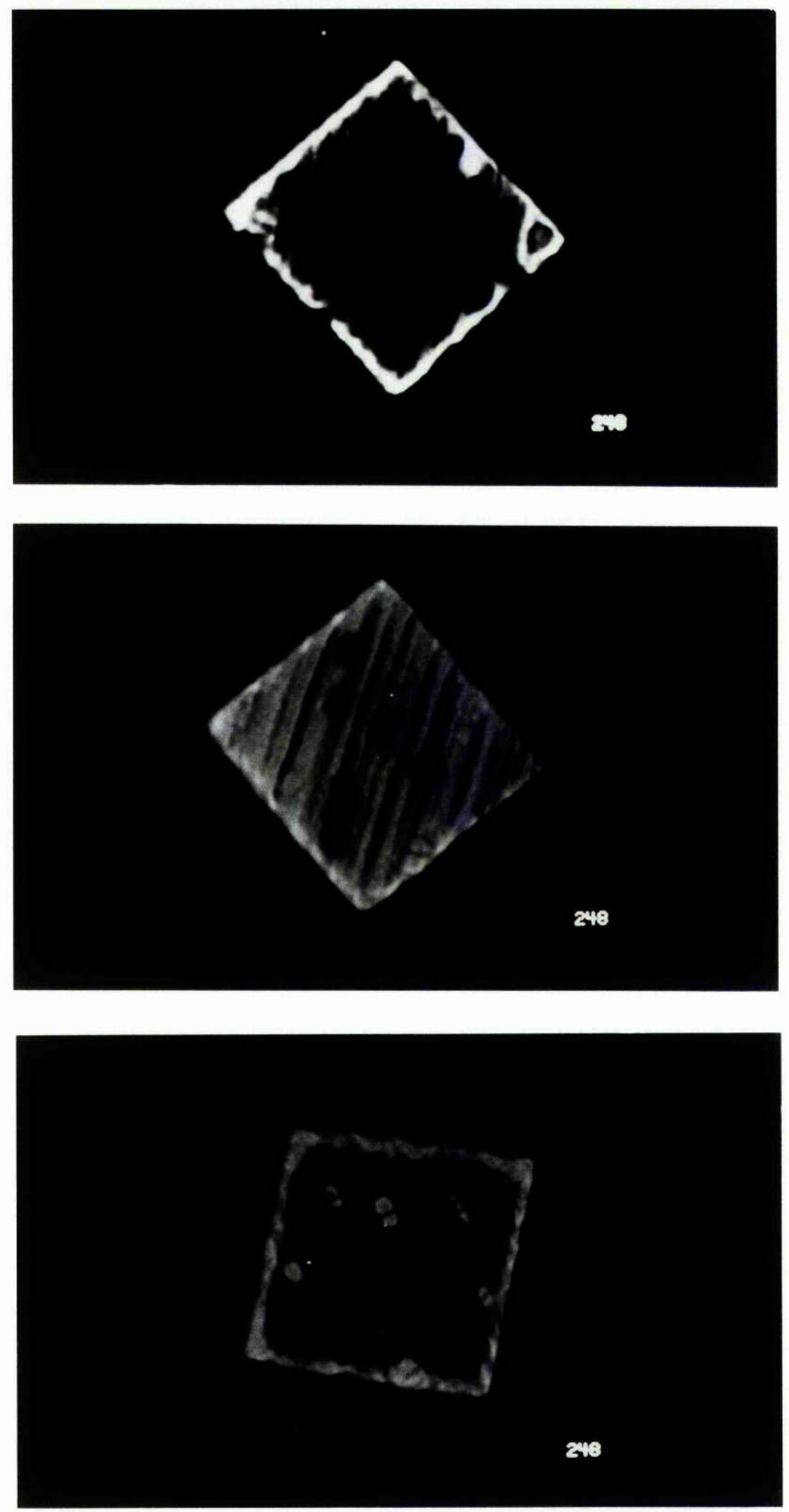
Three pieces of balsa wood, which had been standing in water for 52 hours were transferred to the polymeric solution described above. After 14 days, the wood was still afloat. ${ }^{1} \mathrm{H}$ n.m.r. imaging (see Figure 5.3) indicated that the polymer has prevented any further ingress of water into the wood. After 5 weeks, n.m.r. imaging again showed no further water had penetrated the wood. The pieces of wood are still floating at this point and were still floating after 18 months, suggesting that water had still not penetrated.

\subsubsection{Corrosion inhibition}

When pipes made from metals, such as iron or steel, are in contact with water for a prolonged period, chemical reactions take place between the ions present in water and the metallic surface resulting in corrosion. In industrial plants such as desalination plants, water cooling systems, steam-generating plants, bottle washing plants, closed circuit heating systems, waste treatment plants etc., the problem of corrosion is acute resulting in increased maintenance and/or replacement of the corroded pipes with costs running to billions of pounds. One way to circumvent this problem is to prevent the deposition of inorganic salts on metal surfaces and to reduce metallic corrosion. Water soluble polymers can offer an easy solution to this problem as they can be mixed with the water entering the system.

Our aim was to see if hydrocarboxylated polybutadiene would meet the above requirement. Tests are currently being carried out at Ciba-Geigy, and one of the tests, known as a rotating coupon test is described below. It is conducted using corrosive water of composition: 


$\begin{array}{lc}\mathrm{pH} & 8.4 \\ \text { Total alkalinity (ppm) } & 350 \\ \text { Total acidity (ppm) } & 225 \\ \mathrm{Ca}^{2+}(\mathrm{ppm}) & 150 \\ \mathrm{Mg}^{2+}(\mathrm{ppm}) & 75 \\ \mathrm{Cl}^{-}(\mathrm{ppm}) & 200 \\ \mathrm{SO}_{4}^{2-}(\mathrm{ppm}) & 200\end{array}$

The test is conducted as follows:

In a 1 litre reservoir of the test water, two precleaned and preweighed mild steel coupons are rotated. The test is conducted over 48 hours in oxygenated water at $40^{\circ} \mathrm{C}$ using $20 \mathrm{ppm}$ of the appropriate concentration of corrosion inhibitor.

The coupons are removed, scrubbed, immersed for one minute in hydrochloric acid inhibited by $1 \%$ by weight of hexamine and then rinsed, dried and weighed. A certain loss in weight will have occured. A blank test i.e. immersion of mild steel specimen in the test water in the absence of any any potential corrosion inhibitor, is carried out with each series of tests. The corrosion rate is calculated in milligrams of weight loss/square decimeter/day (m.d.d.). The results obtained in a series of tests are set out in the following Table 5.1.

\begin{tabular}{|c|c|c|}
\hline Example & Corrosion inhibitor & $\begin{array}{c}\text { Corrosion rate } \\
\text { (m.d.d.) }\end{array}$ \\
\hline 1 & Blank & 197 \\
2 & polymer 5* & 9.6 \\
3 & polymer 7* & 32.9 \\
\hline
\end{tabular}

* For composition of the hydrocarboxylated polymers see Table 3.3, Chapter 3, page 122

Table 5.1 
Traditionally zinc chromates have been used as corrosion inhibitors. As they are extremely toxic and harmful if released into the environment they have been replaced by less toxic corrosion inhibitors such as, polyphosphates and phosphoric acids. But these compounds do contain phosphorous in them which are harmful to aquatic life as they are the main cause of eutrophication in rivers, lakes, etc. Currently attention is being foccused on corrosion inhibitors, scale control reagents etc., that are not only environmentally friendly but also readily biodegradable.

The hydrocarboxylated polybutadiene synthesised by us and currently being tested for corrosion inhibition is amongst the most effective of compounds containing only $\mathrm{C}, \mathrm{H}$, and $\mathrm{O}$, in them and also has the advantage of being readily biodegradable.

\subsubsection{Hydrocarboxylated polybutadienes with other functional groups}

Introduction of other functional group on to the hydrocarboxylated product might lead to unusual and interesting physical and chemical properties. For example, polybutadiene which has been selectively hydrocarboxylated at the pendant carbon-carbon double bond position can be epoxidised at the back bone carbon-carbon double bonds.. The epoxidised product thus obtained might offer firstly, the advantage of being water soluble and secondly offer better cross linking than those of hydrocarboxylatef product. The epoxidised hydrocarboxylated product might also/interesting properties upon ring opening for example, form diols, which/linkages between polymer chains giving a highly cross linked net work. 
Hydrogenation of the hydrocarboxylated product might offer different physical properties which would be interesting to study. The resulting product would be less susceptible to cross linking than the hydrocarboxylated product and hence might find useful application as ion exchange resins.

\subsection{Conclusion}

Products of selective and non selective hydrocarboxylation of polybutadienes are being tested for possible commercial applications, particulary as corrosion inhibitors and in wood preservation. The principle of selectively hydrocarboxylating polybutadienes can be extended to other diene polymers. Introduction of more than one fucntional group on to a polymer will open scope for further research. The products thus obtained may have wide commercial application. 


\section{Chapter 6}

\section{Experimental techniques and Starting Materials}

\section{N.M.R. spectroscopy}

1H n.m.r. spectra were recorded on a Brucker AM300 spectrometer $(300 \mathrm{MHz})$ or on a Brucker WP80 $(80 \mathrm{MHz}) .{ }^{13} \mathrm{C}$ n.m.r. spectra were recorded on a Brucker AM300 instrument operating in the pulse Fourier Transform mode. The chemical shifts quoted in this thesis are relative to internal tetramethyl silane (TMS) for ${ }^{1} \mathrm{H}$ and ${ }^{13} \mathrm{C}$ spectra.

\section{Infrared Spectroscopy}

Infrared spectra of organic compounds were recorded on Perkin Elmer 1710 (Fourier Transform) spectrometer as Nujol mulls for solids and thin films for liquid between $\mathrm{KBr}$ plates.

\section{Micro Analysis}

Micro analysis were performed by the University of St.Andrews microanalytical service.

\section{Differential Scanning Calorimetry (DSC)}

All DSC scans were performed on a Perkin-Elmer DSC7 equipped with glove box and nitrogen purge. Samples were prepared using standard crimped sample pans. The heating rate was $10^{\circ} \mathrm{C} / \mathrm{min}$. Transition 
temperatures have been corrected using Indium and Zinc standards. Tg's were taken as the midpoint in the transition curve.

\section{Solvents}

Methylisobutylketone (MIBK), tetrahydrofuran, diethylether, acetonitrile, acetone, benzene were obtained from Aldrich Chemical Company and, unless otherwise specified, were used as obtained.

\section{$\underline{\text { Vacuum Lines }}$}

The experimental work previously described were carried out under nitrogen standard Schlenk line and catheter techniques. The nitrogen was further purified by passing through a $\mathrm{Cr}^{+}$on silica column. The vacuum line used was a standard poly(tetrafluoroethylene) greaseless tap line with ball and socket compression joints.

\section{Starting materials}

1. Polybutadiene, Cis Average $\mathrm{M}_{\mathrm{w}}=200,000$

2. Polybutadiene containing $45 \%$ vinyl, $55 \%$ cis and trans Average $M_{n}=4,500$

3. Polybutadiene diol containing $20 \%$ vinyl, $20 \%$ cis-1,4 and $60 \%$ trans-1,4

4. Polybutadiene, phenyl terminated containing $60 \%$ unsaturation (45\% vinyl, $10 \%$ trans $-1,4$ and 5\% cis-1,4) Average $M_{n}=1,000$ 
5. Polybutadiene, phenyl terminated containing $99 \%$ unsaturation (40\% vinyl, $30 \%$ trans $-1,4)$

Average $M_{n}=1,300$

6. Polybutadiene, phenyl terminated containing $99 \%$ unsaturation (25\% vinyl, $40 \%$ trans $-1,4)$

Average $M_{n}=1,500$

7. Polybutadiene, phenyl terminated containing $60 \%$ unsaturation (45\% vinyl, $10 \%$ trans $-1,4$ and $5 \%$ cis $-1,4)$

Average $M_{n}=1,800$

8. Polybutadiene, phenyl terminated containing $99 \%$ unsaturation (25\% vinyl, $40 \%$ trans $-1,4)$

Average $M_{n}=3,400$

9. Polybutadiene, hydrogen terminated containing $98 \%$ unsaturation ( $84 \%$ vinyl, $14 \%$ trans)

Average $M_{n}=3,000$

10. Polybutadiene, acid terminated containing $97 \%$ unsaturation ( $81 \%$ vinyl and $16 \%$ trans)

11. Polybutadiene, hydrogen terminated with narrow molecular weight distribution containing $97 \%$ unsaturation ( $88 \%$ vinyl, $9 \%$ trans) 
$M_{n}$ mentioned above means number average molecular wieght and $\mathrm{M}_{\mathrm{W}}$ means weight average molecular weight. Polybutadienes 1-8 were purchased from Aldrich Chemical Company. Polybutadienes 9-11 were obtained from Japanese Soda Company.

Tin(II)chloride dihydrate, Copper(II)chloride dihydrate, Triphenylphosphine, Triphenylphosphine Oxide, were purchased from Aldrich Chemical Company. $\mathrm{PdCl}_{2}$ was purchased from Johnson Matthey and Company.

Preparation of Catalyst $\left[\mathrm{PdCl}_{2}\left(\mathrm{P}\left(\mathrm{C}_{6} \underline{\mathrm{H}}_{5}\right)_{2}\right)_{2} \underline{2}_{2}\right]$

$\left[\mathrm{PdCl}_{2}\left(\mathrm{P}\left(\mathrm{C}_{6} \mathrm{H}_{5}\right)_{3}\right)_{2}\right]$ was prepared according to standard procedures 126 . 


\section{$\underline{\text { References }}$}

1. R.M. Ottenbrite, Amer. Chem. Soc., Symp. Ser., 1982, 186, 205.

2. 'Archeological Wood' eds R.M. Rowell and R.J. Barbour, Advan. in Chem. Ser., 225, Amer. Chem. Soc., Washington, DC.,1990, pg 226.

3. N.A. Mohammadi and G.L. Rempel, Amer. Chem. Soc., Symp. Ser., 1988, 364, 392.

4. W. Reppe, Annalen, 1953, 582, 1; Chem. Abstr.,1954, 48, 11308.

5. D.V.N. Hardy, J. Chem. Soc., 1936, 358.

6. F. Morandini, G. Consiglio and F. Wenzinger, Helv. Chim. Acta., 1979, $62,59$.

7. B. Fell and J.M.J. Tetteroo, Angew. Chem.,Int. Ed. Engl., 1965, 4, 790 .

8. W. Reppe and H. Kroper, Annalen , 1953, 582, 38; Chem. Abstr.,1954, 48, 11308.

9. F. Piancenti, P.D. Neggiani and F. Calderazzo, Atti. Soc. Toscani Sci. Nat. Piasa, Proc. Verbali Mem., Ser. B, 1962, 69, 42; Chem. Abstr.,1965, 63, 11347.

10. A. Matsuda and H.Uchida, Bull. Chem. Soc. Jpn., 1965, 38, 710.

11. N.S.Imyanitov, N.M. Bogoradovskaya and T.A. Semenora, Kinet. Katal., 1978, 19, 573; Chem. Abstr.,1978, 89, 118395.

12. J. Tsuji, M. Morikawa and J. Kiji, Tetrahedron Lett. ,1963, 1437.

13. D.M. Fenton, J. Org. Chem., 1973, 38, 3192.

14. A.V. Protchenko, R.R. Shifrina and E.S. Petrov, Neftekhimiya, 1988, 28, 200; Chem. Abstr.,1988, 109, 128360.

15. Yu.G. Noskov, M.I. Terekhova and E.S. Petrov, Zh. Obshch. Khim., 1990, 60, 1336; Chem. Abstr.,1990, 112, 157576. 
16. J.H. Craddock, A. Hershman, F.E. Paulik and J.F. Roth, GP 1,941,501 (1969); Chem. Abstr.,1970, 72, 110811.

17. D. Foster, A. Hershman and D.E. Morris (i) GP 2,533,679; Chem. Abstr., 1976, 85, 32431 (ii)Catal. Rev., 1981, 23, 89.

18. H.J. Hagemeyer, USP 2,739,169; Chem. Abstr.,1956, 50, 16835.

19. D.R. Levering and A.L. Glasebrook, J. Org. Chem., 1958, 23, 1836.

20. P. Pino, F. Piacenti and M. Bianchi, in 'Organic Synthesis via Metal Carbonyls', eds., I.Wender and P.Pino, Wiley, NewYork, 1977, Vol.2, p 233.

21. I. Tkatchenko, in 'Synthesis with Carbon Monoxide and a Petroleum Product', ed., G.Wilkinson, Pergamon Press, Oxford, 1982, Vol 8, p 101.

22. W.F. Gershman, R.E. Brooks, USP 2,448,368; Chem. Abstr., 1949, 43, 669.

23. R.F. Heck and D.S. Breslow, J. Am. Chem. Soc., 1963, 85, 2779.

24. J. Smidt, W. Hafner, R. Jira, J. Sedlmeier, R. Sieber, R. Ruttinger and H. Kojer, Angew. Chem. , 1959, 71, 176; Chem. Abstr., 1959, 53, 16940.

25. H. Alper, J.B. Woell, B. Despeyroux and D.J.H. Smith, J.Chem. Soc., Chem. Commun. , 1983, 1270.

26. H. Alper and D.J.H. Smith, EP 0148,592 (1984).

27. R. Pautrat and R. Cheritat, USP 3,539,654 (1970).

28. G. Consiglio and M. Marchetti, Chimia , 1976, 30, 26; Chem. Abstr., 1976, 85, 32577.

29. T. Fuchikami, K. Ohishi and I. Ojima, J. Org. Chem., 1983, 48, 3803.

30. J.F. Knifton, J. Org. Chem., 1976, 41, 2885. 
31. J.V. Kingston and G.R. Scollary, J. Chem. Soc. A, 1971, 3765.

32. M.I. Terekhora, L.F. Starosel'skaya, V.V. Yurov, A.A. Potatuer and E.S. Petrov, Khim. Promst.(Moscow) 1989,165; Chem. Abstr.,1989, 111, 59930.

33. A.D. Karpyuk, E.S. Petrov, and I.P. Beletskaya, Izv. Akad. Nauk SSSR, Ser. Khim ,1986, 1134; Chem. Abstr.,1986, 105, 171804.

34. A.D. Karpyuk, A.V. Protchenko, E.S. Petrov and I.P. Beletskaya, Izv. Akad. Nauk SSSR, Ser. Khim., 1984, 2155; Chem. Abstr., 1988, 102, 61765.

35. A.D. Karpyuk, L.F. Starosel'skaya, E.S. Petrov, I.P. Beletskaya, Izv. Akad. Nauk SSSR, Ser. Khim., 1986, 218; Chem. Abstr., 1986, 105, 152636.

36. A.L. Lapidus, S.Ya. Grobovenko, A.V. Goryachevskaya, E.L. Berman, A.D. Kagarlitskii, Izv. Akad. Nauk SSSR, Ser. Khim., $1989,1390$.

37. P.M. Burke, EP 2,74076; Chem. Abstr., 1988,109, 151946.

38. S.C. Thomas, USP 4,132,734; Chem. Abstr., 1979, 90, 86758.

39. F.E. Paulik, A. Hershman, W.R. Knox and J.F. Roth, BP 4,792,620, 1988.

40. L.J. Kehoe and R.A. Schell, J. Org. Chem., 1970, 35, 2846.

41. J.F. Knifton, J. Org. Chem., 1976, 41, 793.

42. I. Tkatchenko, in 'Synthesis with Carbon Monoxide and a Petroleum Product', ed., G.Wilkinson, Pergamon Press, Oxford, 1982, Vol 8, p 190.

43. Y. Souma and H. Sano, Bull. Chem. Soc. Jpn., 1976, 49, 3296.

44. N.S. Imayanitov and D.M. Rudkovskii, Zh. Prikl. Khim., 1967, 40, 2885; Chem. Abstr.,1968, 68, 86805.

45. D. Foster, and D.E. Morris, GP 2,263,442 (1971); Chem. Abstr.,1974, 79, 78121. 
46. S. Brewis, P.R. Huges, J. Chem. Soc., Chem. Commun., 1965, 489.

47. K. Bittler, N.v. Kutepov, D. Neubauer and H. Reis, Angew. Chem. Internat. Ed. Engl., 1968, 7, 329.

48. J.B. Zachry and C.L. Aldridge, USP 3,161,672; Chem. Abstr., 1965, 62, 9018.

49. B.E. Kuvaev, N.S. Imayanitov and D.M. Rudkovskii, Zh. Prikl. Khim., 1967, 40, 1359; Chem. Abstr.,1967, 67, 99587.

50. N.S. Imayanitov and D.M. Rudkovskii, Zh. Org. Khim., 1966, 2, 231; Chem. Abstr.,1966, 65, 2119.

51. A. Matsuda and K. Bando, JP 7,420,172; Chem. Abstr.,1975, 82, 58475 .

52. N.v. Kutepov, D. Neubauer and K. Bittler, GP 1,229,089; Chem. Abstr.,1967, 66, 37510.

53. S. Brewis and P.R. Hughes, J. Chem. Soc., Chem. Commun., $1965,157$.

54. J. Tsuji, S. Hosaka, J. Kiji and T. Susuki, Bull. Chem. Soc. Jpn., 1966, 39, 141.

55. W. Reppe and H. Kroper, GP 863,195; Chem. Abstr.,1954, 48, 1425.

56. L. Garlaschelli, M. Marchionna, M.C. Iapalucci, and G. Longoni, J. Organomet. Chem., 1989, 378, 457.

57. O. Norio and T. Osamu, JP 01,168,639; Chem. Abstr.,1990,112, 55006.

58. F. Bernhard and J. Zilin, Chem.-Ztg. 1987, 111, 317; Chem. Abstr.,1988, 108, 133785.

59. A. Matsuda, Bull. Chem. Soc., Jpn., 1967, 40, 135.

60. A. Matsuda, Bull. Chem. Soc., Jpn., 1969, 42, 571.

61. E.N. Frankel and F.L. Thomas, J. Am. Oil Chem. Soc., 1973, 50, 
39.

62. J.J. Brunet and E. Passedargue, Organometallics , 1990, 9, 1711.

63. I. Ojima and K. Hirai, in ' Asymmetric Hydrosilylation and Hydrocarboxylation', ed., J.D. Morrison, Academic Press, Inc. London, 1985, Vol.5, p 103.

64. C. Botteghi, G. Consiglio and P.Pino, Chimia , 1973, 27, 477; Chem. Abstr., 1973, 79, 115269.

65. H. Alper and N. Hamel, J. Chem. Soc., Chem. Commun., 1990, 135.

66. T. Ohita, H. Takaya, M. Kitamura, K. Nagai and R. Noyori, J. Org. Chem., 1987, 52, 3174.

67. G. Parrinello and J.K. Stille, J. Am. Chem. Soc., 1987, 109, 7122.

68. H. Alper and N. Hamel, J. Am. Chem. Soc., 1990, 112, 2803.

69. M.W. Duch and D.M. Grant, Macromolecules, 1970, 3, 165.

70. V.D. Mochel, J. Polym. Sci., Part A- I , 1972, 10, 1009.

71. D. Kumar, M.R. Rao and K.V.C. Rao, J. Polym. Sci., Chem., Edi., 1983, 21, 365.

72. A.D.H. Clague, J.A.M. van Broekhoven and L.P. Blaauw, Macromolecules , 1974, 7, 348.

73. J.Zymonas, E.R. Santee and H.J. Harwood, Macromolecules, 1973, 6, 129

74. X. Guo, R.Farwaha and G.L.Rempel, Macromolecules, 1990, 23, 5407.

75. R.R. Hampton, Anal. Chem., 1949, 21, 923.

76. J.L. Binder, Anal. Chem., 1954, 26, 1877.

77. W.S. Richardson, J. Polym. Sci., 1954, 13, 229.

78. R.S. Silas, J. Yates and V. Thornton, Anal. Chem., 1959, 31, 529. 
79. D. Morero, A. Santambrogio, L.Porri and F. Ciampelli, Chimica Industria , 1959, 8, 758.

80. Nippon Soda Company, Ltd., Tokyo, Japan, Private communication.

81. A.J. Barry, L. Depree, J.W.Gilkey and D.E.Hook, J. Am.Chem.Soc., 1947, 69, 2916.

82. I. Kunio and K. Kimittaka, JP 78,144,996; Chem. Abstr., 1979, 90, 138863.

83. G.G. Cameron and M.Y. Quershi, Makromol.Chem. Rapid Commun., 1989, 2 ,287.

84. F. Michel, K. Nicholas, G. Claude and R. Serge, FP 2,579,982; Chem. Abstr., 1987, 107, 7857.

85. F. Michel, G. Jean Marc, R. Patrice, S.Pierre and V.Jean Jacques, EP 291,427; Chem. Abstr., 1989, 110, 155079.

86. A. Iraq and D.J. Cole-Hamilton, Private Communication.

87. A.I. Yakubehik and G.N. Gromova, Zhur.Obshchei Khim, 1956, 26, 1381; Chem. Abstr., 1956, 50, 15115.

88. H. Rachapudy, G.G. Smith, V.R. Raju, and W.W. Graessley, J. Polym. Sci., Polym. Physics. Edi., 1979, 17, 1211.

89. Y. Doi, A.Yano, K. Soga and D.R. Burfield, Macromolecules 1986, 19, 2409.

90. N.A. Mohammadi and G.L. Rempel, Macromolecules, 1987, 20, 2362.

91. R.Gilliom, Macromolecules, 1989, 22, 662.

92. F.L. Ramp, E.J. Dewitt and L.E.Trapasso, J. Polym. Sci., Part A-I, 1966, 4, 2267.

93. Esso Research and Engineering Company, BP 1,072,796; Chem. Abstr., 1967, 67, 12249.

94. N.L. Cull, USP 3,314,911; Chem.Abstr., 2967, 67, 12249. 
95. K.J. Mertzweiller and N.L.Cull, USP 3,318,972; Chem.Abstr., 1967, 67, 22984.

96. D.F. Lohr and J.W.Kang, USP 3,928,282; Chem.Abstr., 1976,84 75176.

97. K. Sanui, W.J. Macknight, and R.W.Lenz, Macromolecules, 1974, 7, 952.

98 G. Azuma, T. Mitsuboshi, K. Sanui and N.Ogata, J. Polym. Sci., Polym.Chem.Edi., 1980, 18, 781.

99 N.A. Mohammadi, S.S.M. Ling and G.L. Rempel, Polym. Prep (Am.Chem. Soc., Div. Polym.Chem) 1986, 27, 95; Chem.Abstr., 1986, 105, 98083.

100. S.J.Tremont, E.E. Remsen and P.L. Mills,Ind. Eng. Chem. Res., 1990, 29, 1443.

101. I.Utuk and D.J. Cole-Hamilton, Private Communication.

102. F.P. Greenspan and R.E. Light, USP 2,833,747 (1958); Chem.Abstr.,1958, 52, 17800.

103. V.N.Gorbunov, S.S.Rydvanora and G.I. Zalkind,Plasticheskie Massy, 1964, 8, 7; Chem.Abstr.,1964, 61, 14847.

104. C. Pinnazi, J.C. Soutif and J.C. Brosse, Bull.Soc.Chim.Fr., 1973, $5,1652$.

105. V.V. Popova, V.V. Volynets, N.A. Koshel, B.S.Turnov and O.P. Yablonskii, Vysokomol.Soedin., Ser.B., 1988, 30, 95;

Chem. Abstr., 1988, 109, 56292.

106. D.J. Cole-Hamilton, R.K. Mackie, D.C. Cupertino, A. Iraqi and M. Gahagan, J. Chem.Soc., Chem.Commun., 1989, 1688.

107. T.G. Southern, Polyhedron , 1989, 8, 407.

108 D.R. Anton, and H. Crabtree, Organometallics, 1983, 2, 855

109. F.C. Philips, Amer. Chem.J ., 1894, 16, 255.

110. W. Berndt, L. Hoerning, O. Probst, W. Schmidt, U. Schwenk, 
and E. Weber, USP 3,122,586; Chem. Abstr.,1964,61,1758.

111. C.B. Cotterill and F.Dean; BP 941,951; Chem. Abstr.,1964, 60, 4011.

112. H.A.G. Farbwerke, BP 898,790; Chem Abstr.,1964, 61, 8189.

113. W. Reimenschneider, W. Schmidt and L. Hoering, GP $1,136,685$; Chem Abstr.,1963, 58, 12423.

114. B.C.Gates, J.R. Katzer, and G.A. Schuit, 'Chemistry of Catalytic Processes,' 1979, McGraw-Hill, New York, p129.

115. R. Jira, R.and W. Freiesleben, Organomet. React., 1972, 3, 1.

116. J. Smidt, Chem. Ind. (London), 1962, 54.

117. A.A. Grigorev, M.Y.Klimenko, and I.I. Moiseev, USSR P 189,415; Chem Abstr.,1967, 67, 63,795.

118. W.G. Lloyd and B.J.Luberoff, J. Org. Chem., 1969, 34, 3949.

119. W.H. Clement, and C.M. Selwitz, J. Org. Chem., 1964, 29, 241.

120. D.R.Fahey, and A.E. Zuech, J. Org. Chem., 1974, 39, 3276.

121. H.A.G.Farbweke, Neth P 6,504,302; Chem Abstr.,1966, 64, 12554.

122. D.L. Klass, USP 3,147,203; Chem Abstr.,1964, 61, 13195.

123. W. Riemenshneidev, U. Schwenk, and E. Weber, GP 1,132,553; Chem Abstr.,1962, 57, 16407.

124. J.E. Backvall, B. Akermark and S.O. Ljunggren, J. Am. Chem. Soc., 1979, 101, 2411.

125. D.J. Cole-Hamilton, J.A. Chudek, G. Hunter and C.J.M. Martin, J. Inst. Wood Sci., 1990, 12, 111.

126. J. Chatt and F.G. Mann, J. Chem. Soc., 1939, 1631. 